\title{
Thymus dependent autoimmunity : thymic selection versus peripheral tolerance in the model of experimental Cyclosporin-A induced autoimmunity
}

Citation for published version (APA):

Beijleveld, L. J. J. (1996). Thymus dependent autoimmunity : thymic selection versus peripheral tolerance in the model of experimental Cyclosporin-A induced autoimmunity. [Doctoral Thesis, Maastricht University]. Rijksuniversiteit Limburg. https://doi.org/10.26481/dis.19960920lb

Document status and date:

Published: 01/01/1996

DOI:

10.26481/dis.19960920lb

Document Version:

Publisher's PDF, also known as Version of record

Please check the document version of this publication:

- A submitted manuscript is the version of the article upon submission and before peer-review. There can be important differences between the submitted version and the official published version of record.

People interested in the research are advised to contact the author for the final version of the publication, or visit the DOI to the publisher's website.

- The final author version and the galley proof are versions of the publication after peer review.

- The final published version features the final layout of the paper including the volume, issue and page numbers.

Link to publication

\footnotetext{
General rights rights.

- You may freely distribute the URL identifying the publication in the public portal. please follow below link for the End User Agreement:

www.umlib.nl/taverne-license

Take down policy

If you believe that this document breaches copyright please contact us at:

repository@maastrichtuniversity.nl

providing details and we will investigate your claim.
}

Copyright and moral rights for the publications made accessible in the public portal are retained by the authors and/or other copyright owners and it is a condition of accessing publications that users recognise and abide by the legal requirements associated with these

- Users may download and print one copy of any publication from the public portal for the purpose of private study or research.

- You may not further distribute the material or use it for any profit-making activity or commercial gain

If the publication is distributed under the terms of Article $25 \mathrm{fa}$ of the Dutch Copyright Act, indicated by the "Taverne" license above, 
Thymus dependent Autoimmunity

Thymic selection versus peripheral tolerance

in the model of experimental

Cyclosporin- $\mathrm{A}$ induced autoimmunity 
The studies described in this thesis were supervised by

Prof. Dr. P.J.C. van Breda Vriesman

Department of Immunology

University of Limburg, Maastricht

Financed by

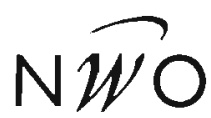

Netherlands Organization for Scientific Research

(grant 900-506-160)

Printed by

Grafisch Bedrijf Ponsen \& Looijen BV, Wageningen, 1996

Illustration cover by

Peter Brouwers 


\section{Thymus dependent Autoimmunity}

Thymic selection versus peripheral tolerance

in the model of experimental

Cyclosporin-A induced autoimmunity

\section{PROEFSCHRIFT}

ter verkrijging van de graad van doctor

aan de Rijksuniversiteit Limburg te Maastricht, op gezag van de Rector Magnificus, Prof. Mr. M.J. Cohen, volgens het besluit van het College van Dekanen, in het openbaar te verdedigen

op vrijdag 20 september 1996 om 14.00 uur

door

Leonardus Johannes Josephus Beijleveld

geboren 5 augustus 1963 te Maastricht 
Promotor:

Co-promotor:

Beoordelingscommissie: Prof. dr. J.W. Arends (voorzitter)

Prof. dr. J.M.J.P. van der Linden

Prof. dr. P. Nieuwenhuis (Rijksuniversiteit Groningen)

Prof. dr. F.C.S. Ramaekers

Prof. dr. J.J. Weening (Universiteit van Amsterdam) 
One can only see what one observes, and one observes only things which are already in the mind.

Alphonse Bertillon

Opgedragen aan Suzan en Flater

Voor mijn ouders

Voor Eef 

List of Abbreviations 6

Introduction $\quad 7$

Chapter 1 Origin and characterization of effector $\mathrm{T}$ cells in relation to tolerance in Cyclosporin-A induced Autoimmune Disease; An overview of the literature

Chapter $2 \quad \mathrm{X}$-irradiation of the Thymus is not required for the Induction of Cyclosporin-A induced Autoimmunity

Chapter 3 The differential effects of $\mathrm{X}$-irradiation and Cyclosporin-A administration on the thymus with respect to the generation of Cyclosporin-A induced Autoimmunity

Chapter 4 The Effects of in vivo Cyclosporin A Administration on Rat Thymic Dendritic Cells

Chapter 5 Susceptibility for clinically manifest Cyclosporine A induced autoimmune disease is associated with Interferony producing CD45RC+RT6- Thelper cells

Chapter 6 Effector Cells in Cyclosporin-A-Induced Autoimmunity: Both CD4 and CD8 T cells Generate Autoimmune Disease Upon Adoptive Transfer

Summary

Samenvatting

Publications

Dankwoord

137

Curriculum Vitae 
List of Abbreviations

$\begin{array}{ll}\text { APC } & \text { antigen presenting cell } \\ \text { BM } & \text { bone marrow } \\ \text { BMT } & \text { bone marrow transplantation } \\ \text { BN } & \text { Brown Norway rat } \\ \text { BSA } & \text { bovine serum albumin } \\ \text { CR3 } & \text { complement receptor 3 (recognized in the rat by the mAb ED8) } \\ \text { CSA } & \text { Cyclosporin A/Cyclosporin A-treated } \\ \text { CSA-AI } & \text { Cyclosporin A-induced autoimmunity } \\ \text { DBSS } & \text { Dulbecco's balanced salt solution } \\ \text { DC } & \text { dendritic cells } \\ \text { DN } & \text { double negative } \\ \text { DP } & \text { double positive } \\ \text { GvH } & \text { graft-versus-host disease } \\ \text { LCA } & \text { leukncyte common antigen } \\ \text { mAb } & \text { monoclonal antibody } \\ \text { MLR } & \text { mixed leukocyte reaction } \\ \text { Mtv } & \text { mouse mammary tumor virus } \\ \text { CO } & \text { olive oil-treated } \\ \text { PBL } & \text { peripheral blood leukocyte } \\ \text { PBS } & \text { phosphate buffered saline } \\ \text { PBSA } & \text { PBS with 0.5\% (w/v) bovine serum albumin } \\ \text { PBSAA } & \text { PBS with } 0.5 \% \text { (w/v) bovine serum albumin, 10mM NaN3 } \\ \text { PHA } & \text { phytohaemagglutinin } \\ \text { RTE } & \text { recent thymic emigrant } \\ \text { SP } & \text { single positive } \\ \text { TCR } & \text { T cell receptor } \\ \text { TCRBC } & \text { T cell receptor- } \beta \text {-chain constant region } \\ \text { TCRBV } & \text { T cell receptor- } \beta \text {-chain variable region } \\ \text { X-BM } & \text { X-irradiated and bone marow reconstituted } \\ \end{array}$




\section{Introduction}

This thesis originated from an attempt to develop an experimental model of human scleroderma in terms of microvascular changes and dermal histology. The model of Cyclosporin A induced autoimmunity, originally called syngeneic graft-versus-host disease, yielded in its chronic phase histological changes, indistinguishable from cutaneous scleroderma in man. The present study addresses the question how these changes are brought about in terms of immunological mechanisms involved. It was at the beginning of this study apparent that in the generation of these lesions both the thymus and the peripheral $T$ cells were involved. For induction of disease Lewis rats are lethally $\mathrm{X}$-irradiated, rescued with syngeneic bone marrow, and next given Cyclosporin A, an immunosuppressive drug, for 6 weeks; disease develops a few weeks after cessation of Cyclosporin A therapy. Since thymectomies prior to irradiation prevent disease, the source of the autoreactive $T$ cells had to be the thymus. It was also clear however, from adoptive transfer studies with autoreactive $T$ cells from Lewis rats suffering from Cyclosporin $\mathrm{A}$ induced autoimmune disease, that discase could not be transferred unless the peripheral autoregulatory $T$ cell circuit of the normal Lewis recipient rats was first eliminated with X-irradiation or Cyclophosphamide. Thus the model required the presence of autoreactive thymus derived $\mathrm{T}$ cells on the one hand and a deficient or aberrant peripheral autoregulatory $\mathrm{T}$ cell circuit on the other hand. This topic is covered in Chapter $\mathbf{1}$ which presents a review of the literature.

The role of the thymus in this model was examined in Chapters 2,3 and 4. In Chapter 2 we determined at which point in time the autoreactive $T$ cells leave the thymus; the question being whether or not these autoreactive cells leave the thymus during CsA therapy: throughout medication or at a defined time span. We wanted to know in addition, whether or not Xirradiation of the thymus itself was necessary for disease to develop.

In Chapter 3 we addressed the question how Cyclosporin A manages to increase the output of the thymus of autoreactive T cells, and asked specifically the question whether or not this was brought about by elimination of the medullary dendritic cells of the thymus. For if this was the case, interference with negative selection would have an immunohistological basis. In addition, dendritic cells, from normal and Cyclosporin A treated Lewis rats, were isolated from the thymus and tested for biological function in vitro. 
Chapters 5 and 6 deal with the peripheral T cells. In Chapter 5 we examined the peripheral autoregulatory $\mathrm{T}$ cell circuit of Lewis rats which are susceptible to disease, and Brown Norway rats which are resistant to it; the reasoning being that given the observation that the effect of Cyclosporin A on the thymus of Brown Norway and Lewis rats was indistinguishable, resistance to or susceptibility to the disease had to be determined by the peripheral autoregulatory $T$ cell circuit.

In Chapter 6 finally, we addressed the question which autoreactive $T$ cells cause the disease in a model of adoptive transfer studies, which allows the undisturbed expansion of the adoptively transferred $\mathrm{T}$ cell subset. 


\section{ITHATER 1 Origin and characterization of effector $\mathrm{T}$ cells in relation to tolerance in Cyclosporin-A induced Autoimmune Disease; an overview of the literature}

Leo J.J. Beijleveld, Jan G.M.C. Damoiseaux and Peter J.C. van Breda Vriesman

Department of Immunology, Faculty of Medicine, University of Limburg, P.O.B. 616, 6200 MD Maastricht, the Netherlands

Submitted

\section{Introduction}

The major aim of the immune system is to protect the individual against infections and to avoid at the same time autoimmunity. The accurate discrimination between pathogens and self-antigens, i.e. the difference between an immune response and tolerance, is based on specific recognition by receptors on lymphocytes; surface-bound immunoglobulins in the case of B cells and T Cell-antigen Receptors (TCR) in case of $T$ cells. An enormous diversity in immunoglobulins and TCR, achieved by random rearrangement of DNA segments coding for the receptor, results in foreign- and self-antigen recognizing receptors. Hence, selective mechanisms are required to eliminate the potentially self-reactive receptor bearing cells and to retain potentially useful but harmless lymphocytes, in the context of self-recognition. Autoimmunity is the consequence of an inappropriate, yet conventional, immune response against self-antigens for which tolerance was not established, or if established, breaks down.

Human autoimmune diseases can be divided roughly into two categories: organ specific autoimmune diseases and systemic autoimmune diseases, depending on whether or not the response is directed against antigens localized in particular organs. Studies of human autoimmune diseases are hampered by the fact that most patients are seen when disease is already clinically manifest. However, the mechanisms underlying autoimmunity can be 
studied in animal models of disease resembling human autoimmunity. There are a few spontaneous animal models for autoimmune diseases such as diabetes (the non-obese diabetic (NOD) mouse and the diabetic-prone Bio-Breeding (DP-BB) rat), thyroiditis (the obese chicken), systemic lupus erythematosus (the MRL-lpr and the New Zealand Black mice) and scleroderma (the tight skin (TSK) mouse and Line 200 chicken). These models offer the opportunity to study pathogenesis of disease and effector mechanisms. For some other autoimmune diseases there are no spontaneous models and models equivalent to human autoimmune diseases have to be induced. There are two types of experimentally induced $T$ cell mediated autoimmune diseases; antigen induced and more or less "physiological" models. Antigen induced models, such as collagen-induced arthritis (CIA), adjuvant arthritis (AA) and experimental allergic encephalomyelitis (EAE), are induced by introducing an antigen equal to or mimicking the autoantigen. In addition, these models require an adjuvant that elicits a strong immune response. The antigen-specific autoreactive $\mathrm{T}$ cells are offered an ideal environment with abundant presence of the autoantigen and "professional" antigen presenting cells (APC). The immunization will allow expansion of the autoreactive cells and disease will develop.

On the other hand there are the more or less "physiological" autoimmune models, induced by irradiation or neonatal thymectomy (neo-Tx). These models are not induced by immunization but are based on the activation of already present autoreactive $T$ cells. These cells are not directly activated by the antigen but become active by eliminating a large part of the normal regulatory and suppressive $\mathrm{T}$ cell population. The Cyclosporin- $\mathrm{A}$ induced Autoimmunity model, described by Glazier et al. (1) and referred to as CsA-AI, has in common with these "physiological" models that it is not caused by immunization. This model is induced by high dose $\mathrm{X}$-irradiation and syngeneic bone marrow transplantation (BMT), in combination with Cyclosporin-A (CsA) therapy.

The peripheral $T$ cell circuit is built up according to an apparently simple principle; during $T$ cell ontogeny in the thymus useful cells are retained, useless cells are discarded by neglect and harmful cells are destroyed or inactivated. As valid and simple as this principle seems, every individual harbours autoreactive $T$ cells in the periphery, albeit in a low frequency. $T$ cells, reactive to a scala of autoantigens can be found and yet, autoimmune disease is not a common phenomenon. However, some individuals are prone to develop autoimmune diseases due to $\mathrm{T}$ cells reacting against self-antigens. Special circumstances have to be created for the autoreactive $T$ cells to exert their autoaggressive activity. In this overview, possible mechanisms, involved in development and activation of autoreactive $\mathrm{T}$ cells, will be discussed using the CsA-AI model. The purpose of this review is to compile diverse concepts on the mechanisms acting in the thymus and the periphery in CsA-AI. Aberrant thymic selection, a prerequisite for CsA-AI, will be discussed related to normal 
self-tolerance induction in the thymus. Next peripheral mechanisms will be discussed in terms of regulatory versus effector cells.

\section{Cyclosporin-A induced Autoimmunity}

CsA induced Autoimmunity (CsA-AI) may provide additional insight in peripheral $\mathrm{T}$ cell development and some of the requirements for development of autoimmune disease. CsA-AI is a remarkable experimental model because it is induced with the immunosuppressive drug CsA that is normally used to prevent allograft rejection, to suppress ongoing autoimmune diseases and to suppress Graft-versus-Host disease $(\mathrm{GvH})$ after allogeneic BMT.

Experimental CsA-AI is readily induced in Lewis rats, 5 to 6 weeks of age, subjected to lethal 8.5 Gy $\mathrm{X}$-irradiation. The haemopoetic stem cell damage is corrected by syngeneic BMT or autologous BM engraftment, by shielding one of the hindlegs during $\mathrm{X}$-irradiation. Starting on the day of syngeneic BMT, within 24 hours after X-irradiation, the rats are treated daily with low dose C.A (7.5 to $15 \mathrm{mg} / \mathrm{kg}$ ) for several weeks. About 2 weeks after cessation of the CsA treatment the rats will develop macroscopic signs of disease indistinguishable from GvH. Severe weight loss is an early parameter of development of disease and is accompanied in chronologic order by erythroderma (an intense red discolouration of the skin observed on the ears, nose and footpads), dermatitis (inflammation of the skin, noticed as a brown discoloured and ruffled fur) and alopecia (severe hairloss), which are observed during the first 6 weeks in the acute phase of disease. The late chronic phase of disease, after about 12 weeks and thereafter, is microscopically characterized by deposition of collagen in the dermis. Proper recovery of the hair follicles is absent; the rats remain almost hairless (2).

The CsA-AI model is of interest for 3 reasons. First, induction of CsA-AI is therapeutically used in leukemia patients. Second, the chronic phase of CsA-AI in the Lewis rat resembles Scleroderma, an autoimmune disorder in man. And third, CsA-AI provides a model to study the development of more or less "physiological" autoimmunity.

Leukemia patients are often subjected to high dose $\mathrm{X}$-irradiation or treatment with cytostatic drugs. After the anti-cancer therapy has destroyed the majority of the leukemic cells and also the patient's hacmopoetic stem cells, reconstitution with allugencic BM is required. The hest suited, i.e. hest MHC matched, donor available will be used. Still, development of allogeneic GvH may occur and immuno-suppressive therapy becomes necessary. However. CsA therapy after BMT can have conflicting results. Like in the Lewis rats, CsA therapy may lead to development of a CsA-AI like (i.e. GvH like-) syndrome. Omitting immuno-suppressive therapy may result in the development of $\mathrm{T}$ cell mediated GvH caused by $\mathrm{T}$ cells derived from the donor BM; CsA treatment is given to suppress this disease but may paradoxically, see above, also bring it about (3). Human CsA-AI as well as $\mathrm{GvH}$ both have deleterious and beneficial effects. The deleterious effect is the destruction of 
tissues by infiltrating $\mathrm{T}$ cells. The beneficial effect resides in the fact that GvH has antileukemic potential, so-called graft versus leukemia effect, possibly because of the MHC class $\Pi$ molecule being the target antigen. Analogous to $\mathrm{GvH}$, it has been suggested that a nonpolymorphic determinant of the MHC class II molecule is also the autoantigen in rat CsA-AI $(4,5)$. Human CsA-AI after BMT (induced after allogeneic, syngeneic or autologous BMT) is already tested for it's usefulness as an anti-cancer therapy and has shown regression of leukemia in some of the patients $(3,6-9)$. Knowledge of CsA-AI may provide a handle to control post BMT GvH and still retain $\mathrm{T}$ cell reactivity with anti-leukemic properties.

CsA-AI resembles Scleroderma, an autoimmune disorder in man (10). The etiology of Scleroderma is unknown and there is little knowledge of the autoaggressive effector cells. Three animal models resembling Scleroderma exist; allogeneic BMT induced GvH showing the typical vascular changes (11), the TSK-mouse (12) and the Line 200 chicken (13). Lewis rat CsA-AI also shares similarities with this autoimmune disease. The late chronic phase of CsA-AI is characterized by extensive collagen depositions in the skin lesions (2), and T cell infiltrates in the epidermis, mostly CD8 T cells (14), phenomena that are observed in Scleroderma as well.

Finally, CsA-AI is not induced by immunization with a known antigen, but is based upon aberrant $T$ cell development. The disease is caused by $T$ cells and the requirement of the thymus has unequivocally been established. The $T$ cells causing this syndrome are formed during CsA-therapy. When disease is clinically manifest, CsA-AI can be adoptively transferred to secondary syngeneic recipients provided regulatory cells are eliminated by $\mathrm{X}$ irradiation or cyclophosphamide. While CsA-AI is readily induced in Lewis rats, Brown Norway (BN) rats are resistant (15). Taking these observations together, CsA-AI provides a tool to study $\mathrm{T}$ cell development (maturation and tolerance induction) and to determine some of the prerequisites for autoimmune diseases.

\section{The thymus in CsA-AI}

The role of the thymus The thymus plays unequivocally a key role in CsA-AI. Thymectomy prior to X-irradiation completely prevents development of CsA-AI and the presence of an intact thymus is obligatory during at least the first 2 weeks of CsA treatment $(16,17)$. Xirradiation of the thymus itself is, however, not required (17). The radiation dose required to induce CsA-AI eliminates almost all peripheral lymphocytes and thymocytes. Hence, the effector $T$ cells must be generated in the thymus after $X$-irradiation and leave the thymus during CsA therapy (17). The development of TCR $\alpha \beta^{+} T$ cells, the effector cells in CsA-AI, will be discussed. For the sake of brevity, extra-thymic $T$ cell development as well as development of the $\gamma \delta \mathrm{T}$ cell lineage, are not discussed. 
Thymic selection Inside the thymus thymocytes develop into functional $\mathbf{T}$ cells. During maturation the thymocytes travel through the thymus and the intrathymic journey of developing thymocytes can be viewed as a series of educational experiences. The normal thymus can be divided in a cortical and a medullary area, each with specific stromal cells and thymocytes. The cortex is filled with the CD4CD8 double positive (DP) thymocytes, whereas the medulla contains predominantly CD4 or CD8 single positive (SP) thymocytes. The expression of the TCR is upregulated during maturation: CD4CD8 DP have an intermediate expression of TCR $\alpha \beta$ whereas the CD4 and CD8 SP thymocytes have a high expression of TCR $\alpha \beta$. Normal thymocyte populations contain approximately 80 to $90 \%$ CD4CD8 DP thymocytes and less than $20 \%$ CD4 or CD8 SP thymocytes (Fig. 1, 2a \& c).

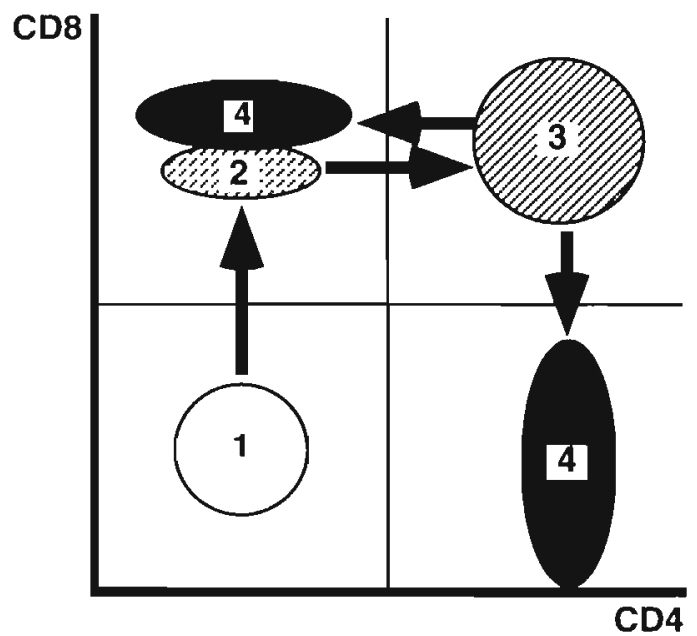

Figure 1. Rat thymocyte maturation (1) Bone rnarrow-derived cells enter the thymus as CD4CD8 TCR triple negative cells. (2) Via the $\mathrm{CD}^{-} \mathrm{CD}^{+}{ }^{+} \mathrm{TCR}^{-}$stage they become (3) CD4CD8 DP and begin to express TCR $\alpha \beta$. (4) The final stage is formed by the CD4 or CD8 SP TCR $\alpha \beta^{+}$thymocytes.

The major function of the thymus is to test thymocytes for their usefulness, i.e. self-MHC restriction together with non-self antigen recognition. Hereto thymocytes need surface expression of a functional TCR and expression of MHC class I and II on surrounding stromal cells $(18,19)$. Once the thymocytes express functional TCR $\alpha \beta$ on their surface, they become subject to selection. In principle, thymocytes have to pass two selection filters; positive selection favouring the cells able to recognize antigen in the context of self-MHC molecules, and negative selection to eliminate or inactivate thymocytes bearing TCR recognizing selfantigen in the context of self-MHC molecules (20). Elimination of self-reactive thymocytes would require the presentation of many self-antigens and multiple testing of thymocytes that encounter antigen-MHC complexes presented by the thymic stromal cells. Introduction of non-thymic antigens into the thymus indeed results in tolerance induction, albeit in principle only via the MHC class II molecule. Allograft rejection is prevented by intrathymic injection of allogeneic splenocytes or even allogeneic MHC class I and II peptides (21) and 
A

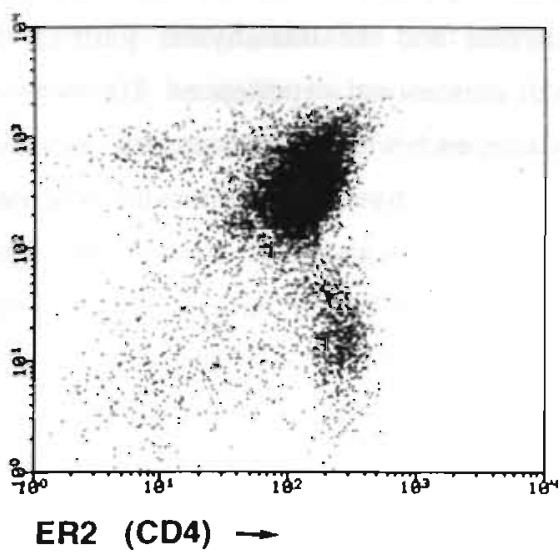

C

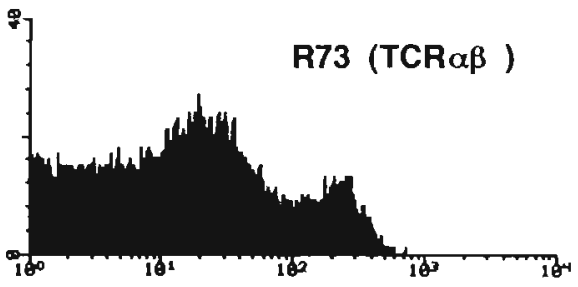

B

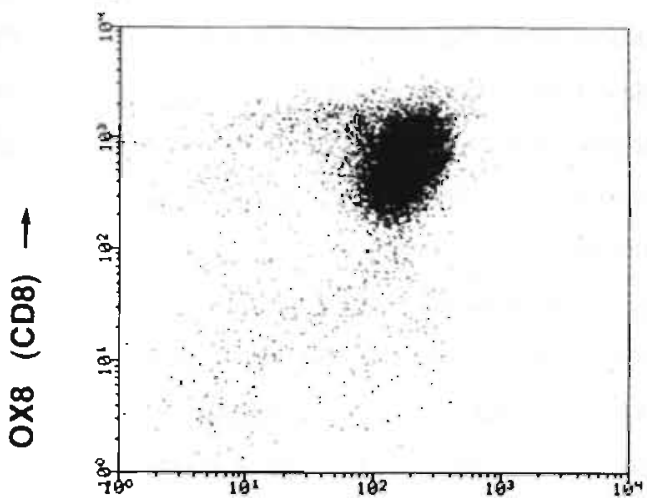

ER2 (CD4) $\rightarrow$

Figure 2. Tri-colour flowcytometry analysis of thymocytes stained for expression of CD4 (mAb ER2), CD8 (mAb OX8) and TCR $\alpha \beta$ (mAb R73). Based on expression of CD4, CD8 and TCR $\alpha \beta$, thymocytes can be subdivided in 4 populations as described in figure 1 . In control thymuses about 10 to $20 \%$ of the thymocytes are CD4 or CD8 SP TCR $\alpha$ hhigh as depicted in the upper-left dotplot for CD4 and CD8 expression and lower-left histogram for TCR $\alpha \beta$-expression. Upon CsA therapy $(7.5 \mathrm{mg} / \mathrm{kg}$ administered daily for 4 weeks) the number of these mature thymocytes is severely decreased as can be noted in the upper-right CD4, CD8 dotplot and lowerright TCR $\alpha \beta$-histogram. The experimental design is described in chapter 3 .

development of diabetes in DP-BB rats is prevented by intrathymic transplantation of syngeneic Langerhans islets (22). Selective mechanisms to prevent autoimmunity can use self-antigens presented in the thymus even if they are presented only in minute amounts (23). However, although the blood thymus barrier is not absolute $(18,19,24,25)$, it is not plausible that the thymus is able to present all self-antigens to all thymocytes. However, not only the TCR specificity determines the fate of the thymocyte but affinity/avidity of the TCR for the MHC/peptide complex plays a major role as well. This would allow testing in few events, by combined or separate positive and negative selection (Fig. 3). Selection, positive or negative, is dependent upon the signal rendered by the TCR's affinity/avidity for the selfMHC antigen complex. An intermediate or higher signal, on an arbitrary scale, will result in 
positive selection and continuation of development (area B \& C). Absent or only minor interaction with self-MHC results in an inadequate signal and the thymocytes will not continue maturation; cell death occurs by neglect (area A). At the other side of the scale, a high signal, is indicative for high affinity/avidity of the TCR for self-MHC/self-antigen equal to self-reactivity. The high signal leads to apoptosis or programmed cell death and selfreactive thymocytes are hereby clonally deleted (area $\mathrm{C}$ ).

There is ample evidence for the affinity/avidity model based on TCR transgenic mice and clonal deletion of "forbidden" $\beta$-chain variable region (BV) families due to endogenous mouse mammary tumor virus (Mtv) superantigens. Selection by affinity is not only driven by the TCR itself, but is also dependent on the accessory molecules CD4 and CD8. Mice, transgenic for a single antigen-specific TCR, demonstrate that given a single TCRspecificity, the density of CD8 molecules on the cell surface determines whether the thymocytes will be positively selected or deleted (27). This indicates that the fate of the cel] is dependent upon the total signal of the interaction between TCR and CD4 or CD8 with the MHC molecule. The X-axis of figure 3 can therefore be replaced by the intracellular signal, achieved by cross-linking of TCR and accessory molecules to the MHC molecules. On the other hand, Mtv superantigens cause clonal deletion by linking the TCR BV to the MHC class II molecule, thereby mimicking TCR-antigen recognition, irrespective of the antigen

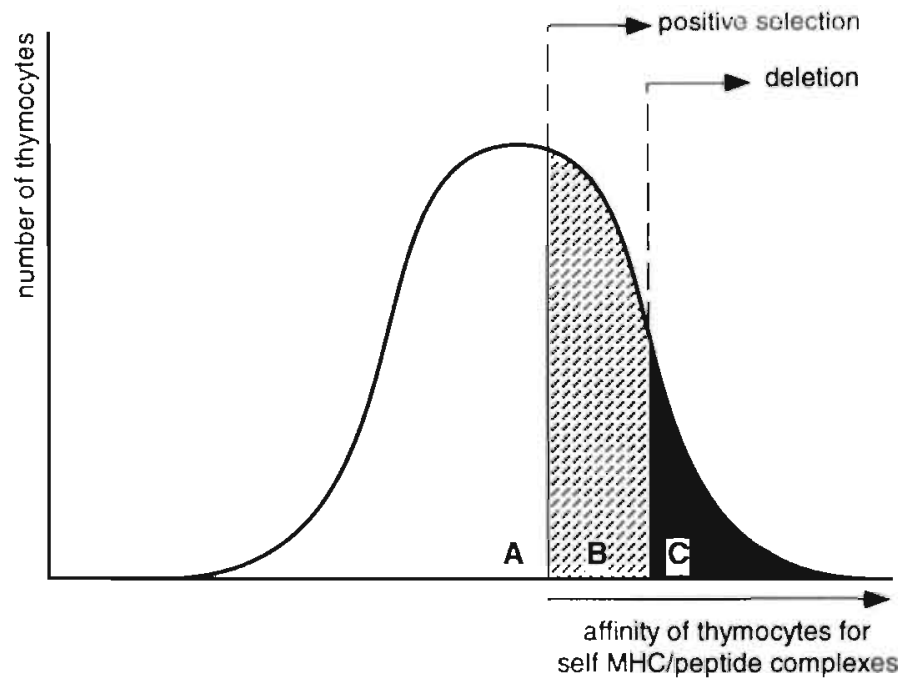

Figure 3. Affinity/avidity model for thymic selection. Interaction of the thymocyte TCR with MHC-peptide results in an intracellular signal, responsible for the fate of the thymocyte. Only thymocytes with moderate affinity/avidity for the MHC-peptide complex will become fully mature thymocytes (area B). Thymocytes with low affinity/avidity (area A) will die by neglect. Thymocytes with a high affinity/avidity will be clonally deleted via apoptosis (Area C). Adapted from J.I. Eliot, Imm. Rev. 135, 1993 (26) 
that is presented by the MHC class II molecule. Every Mtv strain has different affinities for the different BV families. Inbred mouse strains with their specific Mtv superantigens therefore show different TCR BV deletion patterns. This provides a unique tool to determine whether clonal deletion is active inside the thymus or in the periphery.

Although there is no consensus as to whether positive and negative selection occur at the same time and the same location in the thymus, it is generally held that positive selection occurs in the cortex when CD4CD8 DP TCR $\alpha \beta^{\text {intermediate }}$ expressing thymocytes react with the cortical epithelium, whereas negative selection is caused by interaction of the CD4 or CD8 SP TCR $\alpha \beta^{\text {high }}$ thymocytes with medullary dendritic cells. This was elegantly demonstrated in situ in mice; direct evidence for apoptosis due to negative selection was obtained by crossing TCR BV5 transgenic mice to I-E ${ }^{+}$and I-E- micc. I-E ${ }^{+}$mice are known to eliminate TCR BV5+ T cells whereas I-E mice do not. Only in the medulla of I-E ${ }^{+} \times$TCR BV5 transgenic mice many apoptotic thymocytes were observed, whereas the cortex of I-E ${ }^{+}$ $x$ TCR BV5 was similar to the cortex of I-E- x TCR BV5 (28). The absence of certain BVfamilies (due to endogenous Mtv superantigens) in both the CD4 and CD8 SP medullary thymocyte population, but not in the CD4CD8 DP cortical thymocyte population, however, is indicative for negative selection in the CD4CD8 DP stage (29). Still, this does not define the localization where negative selection, based on BV-family expression, occurs. Dendritic cells, thought to be involved in negative selection are mainly present in the cortico-medullary region, the extensive border between cortex and medulla, i.e. in the area of transition of DP to $\mathrm{SP}$ thymocytes. The role of medullary epithelial cells has been addressed in double transgenic mice. DBA ( $\mathrm{H}-2^{k}$ haplotype) mice expressed the transgenic MHC class $\mathrm{I} \mathrm{H}-2 \mathrm{~K}^{\mathrm{b}}$ molecule under control of the bovine keratin type IV promotor, and a second transgene encoding for a TCR specilic for the $\mathrm{H}-2 \mathrm{~K}^{\mathrm{b}}$ antigen. The keratin type IV promotor induced expression of the $\mathrm{H}-2 \mathrm{~K}^{\mathrm{b}}$-antigen on peripheral keratinocytes and also on thymic medullary epithelial cells. This resulted in the induction of anergy, not deletion, in the CD8 SP TCRtransgenic thymocyte population (30). Thymocytes that enter the medulla, which are probably already positively selected, can undergo negative selection either by clonal deletion or induction of anergy.

Cyclosporin-A and the thymus CsA has a clearcut effect on the thymic stroma and its cells. First there is the effect of CsA therapy on thymic size and thymocyte numbers. CsA therapy decreases the total number of thymocytes, although the most profound effect is observed on the medullary thymocytes; the relative numbers of CD4 and CD 8 SP TCR $\alpha \beta^{\text {high }}$ thymocytes are strongly decreased (Fig. $2 b$ \& d). Second, there is the effect on thymic morphology. The medulla disappears almost completely and medullary MHC class II expressing cells are reduced $(31,32)$. Relatively large area's void of epithelium are found in the center of the 
thymic Jobuli, where normally the medulla is located (33). These area's now contain small cortex-like thymocytes. Suggestions have been offered to explain the reduced numbers of medullary thymocytes and the defective intrathymic tolerance induction. Upon CsA therapy cortical thymocytes emigrate to the periphery where the thymocytes mature in the absence of intrathymic selection mechanisms (34-36), or absence of MHC class II expression by medullary stromal cells prevents proper negative selection, and thymocytes leave the thymus unselected. However, we were not able to detect increased emigration of thymocytes upon CsA administration. On the contrary, we observed a decrease in thymic output using a CsAdosage that is sufficient to cause autoimmune disease in the syngeneic BM chimacras (Chapter 5). Furthermore, the reduced medulla of CsA treated rats still contains dendritic cells and medullary epithelial cells (33). Immunohistology revealed that the stromal cells are phenotypically not altered. In addition, dendritic cells, isolated from CsA treated rats, are phenotypically and functionally not different from dendritic cells isolated from control rats (37). Therefore, the few remaining medullary thymocytes can still be subjected to negative selection.

CsA has a direct effect on thymocyte maturation; the immunosuppressive drug not only effectively blocks the proliferation of mature peripheral $\mathrm{T}$ cells, but also blocks thymocyte maturation from cortical CD4CD8 DP thymocytes into medullary CD4 and CD8 SP thymocytes (38-40). CsA inhibits $T$ cell activation by interacting with the intracellular route of signalling following ligation of the TCR. Upon binding of CsA to cyclophylin the newly formed immunophylin-drug complex binds next to calcineurin. This tri-molecular complex is able to block the translocation of the cytoplasmic component of the transcription factor NFAT to the nucleus and eventually results in inhibition of cytokine synthesis (reviewed by Schreiber and Crabtree, (41)). Since TCR-ligation is not restricted to mature $T$ cells in the periphery, but is also required for maturation and selection of thymocytes, it is plausible that CsA has profound effects on thymocyte maturation. The intracellular signal that results from interaction of the TCR with the MHC/peptide complex is down-regulated by CsA. However, the intracellular signal is an important event in thymocyte maturation. Now, only the thymocytes that react with high affinity for the MHC-peptide complex, and consequently will respond with a higher intracellular signal, will be positively selected (Fig. 4); the positive selection window shifts towards a higher affinity. Consequently, less cells will be positively selected and migrate to the medulla. In the medulla some thymocytes that would normally receive a lethal clonally deleting signal will now survive due to their higher affinity. The result is (1) less positive selection and (2) survival of cells with a higher affinity for the presented MHC-peptide complexes. The net result is impaired clonal deletion and thymocytes bearing high affinity TCR are able to enter the periphery. Indeed normal clonally deleted T cells, detected by the expression of "forbidden" TCR BV families, are reappearing 


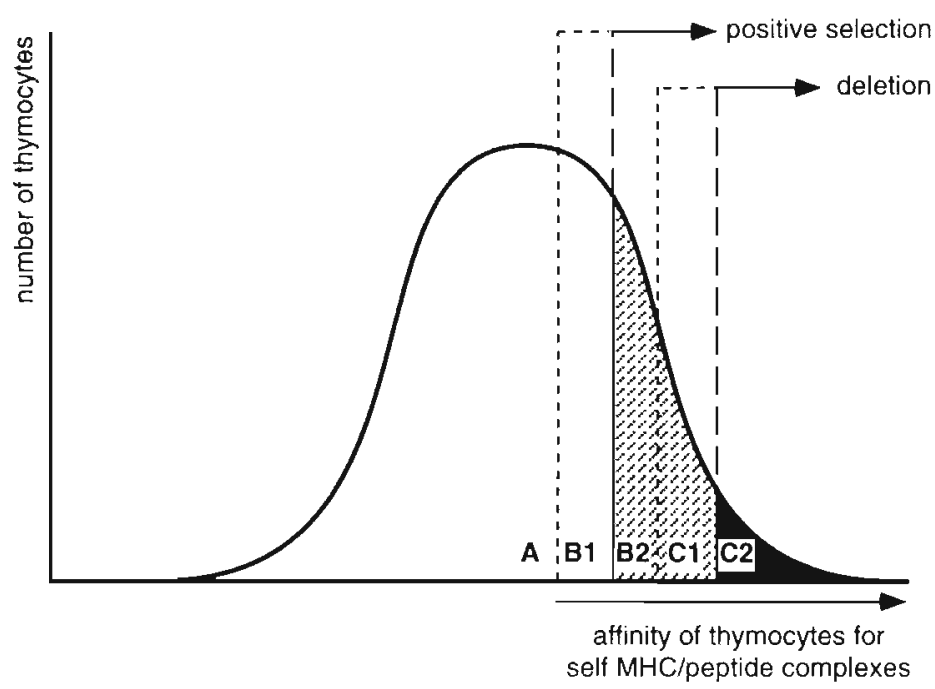

Figure 4. Affinity/avidity model for thymic selection. CsA-administration decreases the intracellular signal upon thymocyte TCR/MHC-peptide interaction. Positive selection (area B in Fig. 2) is now shifted towards a higher affinity to compensate for the decreased intracellular signal. Thymocytes in area $\mathrm{A}$ and $\mathrm{B} 1$ are not positively selected, whereas thymocytes in $\mathrm{B}_{2}$ and $\mathrm{C}_{1}$ (under normal conditions the negative selection area) are positively selected. Only thymocytes in $\mathrm{C}_{2}$ are negatively selected. Altogether less thymocytes are selected with an average higher affinity. Adapted from J.I. Eliot, Imm. Rev. 135, 1993 (26)

in the medullary thymocyte population and periphery after CsA therapy $(38,39)$.

CsA causes a decrease in mature medullary thymocytes because of the decreased survival of cortical thymocytes by positive selection. The constitution of the entire medulla is highly dependent on the presence of mature SP TCR $\alpha \beta^{\text {high }}$ thymocytes. Degeneration of the medulla is observed in naturally immune deficient animals such as severe combined immune deficiency (SCID-) mice (42) as well in experimentally induced immune deficient RAG-1, $\operatorname{TCR} \alpha, \delta, \beta$ or $\beta / \delta$ knock out mice, reviewed by Ritter and Boyd (43). Reconstituting the inınune deficient animals with TCR $\alpha \beta^{\text {high }}$ thymocytes results in the generation of a normal medulla, both in terms of size and stromal cells (44). The two stromal components of the thymic medulla, i.e. epithelium and dendritic cells, show striking similarities to each other in a way that, at least in the mouse, $\operatorname{relB}$, a gene otherwise specific for mature peripheral dendritic cells, is critical in the coordinated activation of genes necessary for the differentiation of both cell types (45). It is therefore possible that CsA, by directly inhibiting thymocyte maturation, indirectly causes degeneration of the entire thymic medullary microenvironment. 
In summary, the thymus offers the thymocyte an environment to test the usefulness of the TCR. The TCR presented inside the thymus has to answer to MHC recognition with an "intermediate" signal. It is doubted whether the entire self-antigen repertoire is represented in the thymus, but the thymus is probably capable to present many self-antigens that are related to normal cellular functions. Organ- or site-specific antigens may be absent in the thymus. Thymic selection is therefore not complete, however, intrathymal selection decreases the frequency of autoreactive $\mathrm{T}$ cells. Inhibition of thymic negative selection, as caused by $\mathrm{CsA}$, results in a increased frequency of normally clonally deleted T cells. Additional peripheral tolerizing mechanisms will be required.

\section{The periphery in CsA-AI}

Peripheral Tolerance versus Autoimmunity Under normal circumstances potentially autoreactive $T$ cells escape from the thymus, but these cells will not bring about an autoimmune response. Peripheral mechanisms such as extrathymic deletion, anergy induction and active suppression by regulatory $\mathrm{T}$ cells prevent autoimmunity. Even when increased numbers of autoreactive $T$ cells escape into the periphery, autoimmunity docs not develup since autoreactive $\mathrm{T}$ cells have to encounter their antigen in the context of the right $\mathrm{MHC}$ molecule together with costimulatory signals. Absence of this sccondary signal prevents proper $\mathrm{T}$ cell activation and causes either clonal deletion or anergy; both mechanisms cause functional tolerance. These peripheral regulatory mechanisms have been demonstrated in double transgenic mice. TCR transgenic mice, with a TCR recognizing the MHC class I H-2 $\mathrm{K}^{\mathrm{b}}$ molecule, were crossed with mice transgenic for the expression of this MHC class I H-2 $\mathrm{K}^{\mathrm{b}}$. Different promoters were used to regulate the expression of this $\mathrm{H}-2 \mathrm{~K}^{\mathrm{b}}$ molecule. These promotors are site/organ related (the GFAP promotor results in $\mathrm{H}-2 \mathrm{~K}^{\mathrm{b}}$ expression on neuroectodermal cells, the keratin promotor in expression on epithelial cells, the albumin promotor in a constant expression in the liver and the promotor for C-reactive protein induces $\mathrm{H}-2 \mathrm{~K}^{\mathrm{b}}$ expression in the liver only after systemic LPS infusion) and therefore cause expression in different locations and in different amounts (46). All these different models yielded tolerance by deletion or anergy, albeit there were different levels (reversible or irreversible) of anergy. In addition it was shown that anergic $T$ cells themselves can make other $T$ cells anergic as well by competing for APC surface and locally produced IL2 (47).

$\mathrm{T}$ cell-mediated suppression as such is a known phenomenon, but its underlying mechanisms are still matter of debate. Regulatory $T$ cells are not clearly defined, although in ieveral experimental autoimmune models regulatory $T$ cells have been demonstrated that prevent development of autoimmunity. These regulatory cells constitute a normal part of the total peripheral $\mathrm{T}$ cell population. In adoptively transferred gold-salt induced autoimmunity 
CD8 T cells have regulatory properties (48). In autoimmune models such as diabetes, EAE and inflammatory bowel disease a regulatory role is attributed to the balance between Th1 and $\mathrm{Th} 2$ cells.

In order to develop autoimmune disease, a triggering event is necessary. In man e.g. intraveneus administration of IL2 may cause hypothyroidism, probably by a breakdown of tolerance to thyroglobulin, thus causing autoimmune thyroiditis (49). Induction of experimental autoimmune diseases in animals require a major change in the immune status of the animal. Antigen-induced autoimmune models require adjuvants that elicit a strong local immune response. The more "physiological" autoimmune models require drastic changes such as neonatal thymectomy or high dose $\mathrm{X}$-irradiation. Both kinds of models appear to depend on increasing the frequency of autoaggressive $\mathrm{T}$ cells relative to the regulatory $\mathrm{T}$ cells.

Events that may be important in order to develop autoimmune disease are discussed on the basis of CsA-AI in relation to other autoimmune diseases. Three aspects are observed in CsA-AI; (1) disease is $\Upsilon$ cell mediated and the thymus is only required during CsA-therapy, (2) CsA-AI can be adoptively transferred to syngeneic recipients by $\mathrm{T}$ cells provided the recipients are depleted for peripheral $\mathrm{T}$ cells and (3) not all strains are susceptible.

Regulatory $T$ cells and CSA-AI CsA-AI is induced by a combination of increased output of autoreactive $T$ cells and an incomplete recovery of the total peripheral $T$ cell population. CsA-AI is easily transferred to secondary syngeneic animals. Two major requirements for adoptive transfer of disease are (1) full-blown development of disease in the donor and (2) Xirradiation of the recipient. Since disease is manifest in the donor, effector $T$ cells are already generated and activated. Sufficient effector $\mathrm{T}$ cells are present in the lymph nodes (chapter 6) or spleen to adoptively transfer disease to syngeneic recipients. If, however, $T$ cells isolated from a healthy normal rat are added to the effector $T$ cells in a ratio of 2:1 (normal cells:effector cells) no disease will develop. Further studies on the "protective" property of normal $\mathrm{T}$ cells have yielded two important findings. First, protection is abrogated if the normal $T$ cells are depleted of CD45RC negative Th cells (50). CD45RC is a high molecular weight isoform of the leukocyte common antigen (LCA) CD45, recognized by the monoclonal antibody OX22 (51), and expressed by part of the CD4 and CD8 T cells. Second, the ability to protect against CsA-AI can be increased by immunizing rats with 2,000 rad Xirradiated syngeneic CsA-AI effector cells (52). Protection is now achieved by adding $T$ cells from "immunized" donors in a ratio of $0.67: 1$ of normal cells:effector cells, which is a threefold enhancement of protection. The latter study attributes a regulatory role to the CD4 $\tau$ cell population, without further defining expression of CD45RC. 
CD4 Th cells can be divided into Th1 and Th2 cells, functionally characterized by the production of specific cytokines and the type of immune response the subsets are involved in. Th1 cells produce mainly IL2, ILI2, IFN $\gamma$ and TNF $\alpha$ and are involved in cellular immune responses such as delayed type hypersensitivity, whereas Th2 cells produce IL4, IL.5 ind IL10 and provide help to B cells (53). In rats, CD4 Th cells can be divided into CD4.5RC positive and negative populations. Expression of CD45RC correlates well with the cytnkine pattern described for Thl cells (54) and CD45RC+ Th cells have autoimmune properties with respect to $\mathrm{CsA}-\mathrm{AI}$, wasting disease and diabetes $(50,55,56)$. CD45RC- Th cells are protective in a way that these cells, when adoptively transferred, prevent development of CsA-AI, wasting disease or autoimmune diabetes. Expression of RT6, an alloantigen surface molecule in the rat, also discriminates two Th cell subsets. Like CD45RC, RT6 distinguishes between Th cells with a regulatory and Th cells with an autoimmune character. RT6 ${ }^{+}$Th cells are the regulatory cells and are producers of $\mathrm{L} 2$ and L4 but not IFN $\gamma$. RT6- Th cells are on the other hand producers of IL2 and IFN $\gamma$ and have no protective properties in T cell mediated autoimmunity such as diabetes (57-59). Development of autoimmunity appears to be dependent upon a disturbed balance between $\mathrm{CD} 45 \mathrm{RC}^{+}$and $\mathrm{CD} 45 \mathrm{RC}^{-}$or RT6* and RT6 ${ }^{+}$ Th cells. The combination of RT6 and CD45RC to describe regulatory Th cells was used for the first time in radiation-induced diabetes in the non-diabetogenic PVG RTI ${ }^{\mathrm{U}}$ rat strain. Regulatory Th cells could be characterized by expression of RT 6 and absence of CD45RC expression (56).

We used a similar approach to study Lewis rats subjected to induction of CsA-AI. According to a model proposed by Kampinga et al. (60), Thl-like cells are phenotypically characterized by expression of CD45RC and no expression of RT6. Activation of this Th cell subset (by cross-linking of the TCR in the presence of syngeneic dendritic cells) induces the production of $\Pi 22$ and IFN $\gamma$ mRNA, a trait which is unique for this Th cell subset (chapter 5). On the other hand, Th2-like cells express RT6 but not CD45RC. This Th2-like CD45RC , $\mathrm{RT}^{+}$Th subset is phenotypically equal to the regulatory Th cell described by Fowell et al. (56). In Lewis rats the ratio between the phenotypically defined Thl like and Th2 like cells is about 1:3, and upon development of CsA-AI this ratio is reversed in favour of the Thl like cells, resulting in a ratio of $2: 1$ (chapter 5), indicating that the reversal of the Th1:Th2 ratio, in favour of the Th1-like cell population, is a critical determinant for development of CsAAI.

Lewis rats are highly susceptible for induction of CsA-AI; the Brown Norway (BN) rat strain on the other hand is resistant. In BN rats, which do not develop CsA-AI, the expansion of CD45RC+, RT6- Th cells does not occur. The susceptibility for CsA-AI is not related to the MHC haplotype of the strain used. The Lewis IN (a Lewis-congenic with the same MHC haplotype as the BN, RT1 ${ }^{n}$ ) is susceptible, whereas the BNIL (a BN congenic with the Lewis 
MHC haplotype RTIl) is resistant. Susceptibility is therefore related to non-MHC antigens. The resistance, as determined by the $\mathrm{BN}$ non-MHC antigens is a dominant trait since LewisxBN F1 hybrids are completely resistant to CsA-AI like the BN (unpublished results). With respect to the Th1:Th2 ratio's Lewis and Lewis $1 \mathrm{~N}$ rats are similar and so are BN and $\mathrm{BN} 1 \mathrm{~L}$ rats. The regulatory role that has been attributed to the $\mathrm{CD} 45 \mathrm{RC}^{-}, \mathrm{RT}^{+}$Th2 like population correlates well with the resistance to CsA-AI in BN and BN1L rats. In mice, CD45RB, the high molecular weight form of LCA, analogous to rat CD45RC, also discriminates between regulatory and autoreactive $T$ cells, as described in relation to inflammatory bowel disease $(61,62)$.

While $\mathrm{BN}$ rats are resistant to induction of T cell mediated diseases such as EAE, AA and CsA-AI, they are very susceptible for the antibody mediated Mercury-Chloride induced autoimmunity (63). Here an inversed situation exists: the effector cells are found within the CD45RC - T cells, whereas protection is obtained with normal CD45RC+ T cells (64). It has phenotypically been shown that the large differences in the CD45RC+RT6- CD45RC-RT6+ ratio is different between rat strains, but not between age and sex matched individuals within a given inbred rat strain (65). The observed $\mathrm{CD} 45 \mathrm{RC}+\mathrm{RT} 6-\mathrm{CD} 45 \mathrm{RC}-\mathrm{RT} 6^{+}$ratio correlates well with susceptibility for cell or antibody mediated experimental autoimmune models in the respective rat strains $(65)$.

Effector T cells in CsA-AI The skin lesions in CsA-AI are characterized by infiltrating T cells in the epidermis and hair follicles, and the expression of MHC class II by the keratinocytes. Expression of MHC class II is only observed if infiltrating $\mathrm{T}$ cells are locally present. The $\mathrm{T}$ cell infiltrates consist of both CD4 and CD8 T cells.

The phenotype of the effector $\mathrm{T}$ cell is matter of debate. Several studies have tried to define the culprit $T$ cell. Lewis rat skin biopsies, taken during the acute phase of disease, revealed the presence of predominantly $\mathrm{CD} 4^{+}$lymphocytes $(66)$, or equal numbers of $\mathrm{CD}^{+}$ and $\mathrm{CD} 8^{+}$lymphocytes co-localizing with TCR $\alpha \beta^{+}$lymphocytes in the epidermis (14). Experimental settings that allowed manipulation of the putative effector $\mathrm{T}$ cells also revealed contradicting results. Adoptive transfer studies showed effector $\mathrm{T}$ cells to be present in the CD4 population (67), or in the CD8 population (68), whereas another study claimed the requirement of both $\mathrm{CD} 4$ and $\mathrm{CD} 8 \mathrm{~T}$ cells (50). In vivo depletion with mAb against CD4 or CD8 after adoptive transfer showed that CD8 depletion completely abrogated disease whereas CD4 depletion strongly delayed onset of disease (5). In all these experiments, development of CsA-AI after adoptive transfer was used as a read-out system for effector $T$ cell potential. The recipient rats, however, were not thymectomized and the role of $T$ cells developing after irradiation was not studied. We tried to determine effector $\mathrm{T}$ cells by adoptive transfer of lymph node cell-suspensions, isolated from rats suffering from acute 
CsA-AI, in vitro depleted for either CD4 or CD8. Cell-suspensions were next infused into Xirradiated thymectomized recipients. Since in vitro depletion never yields $100 \%$ depletion, the recipients were in vivo depleted by repeated mAb injections after adoptive transfer. Development of disease was monitored macroscopically, microscopically and by tri-colour flowcytometry (chapter 6). This study revealed development of CsA-AI after adoptive transfer in the almost complete absence of either CD4 or CD8 T cells. Even in this experimental setting complete depletion of CD4 or CD8 $\mathrm{T}$ cells was not achieved. But it is not plausible to attribute development of disease to the contaminating $T$ cell subset. This would mean that the minute contamination of CD4 T cells could give specific "help" to the CD8 $\mathrm{T}$ cells similar to a few contaminating CD8 T cells that give specific "help" to C.D4 T cells. A more comprehensible way to explain development of CsA-AI, after adoptive transfer in the absence of CD4 or CD8 T cells, is to attribute equal characteristics to CD4 and CD8 effector T cells. More and more evidence is emerging that CD4 and CD8 T cells can fulfil similar functions in the immune response such as cytokine production and cytotoxic activity (69).

Other autoimmune models have been described to be dependent on both CD4 and CD8 T cells. Radiation-induced diabetes and thyroiditis in thymectomized and X-irradiated PVG rats is completely blocked by CD8 depletion. Infusing CD8 T cells from normal healthy donors, however, allows development of disease (56). This indicates that the CD8 T cell population, required for induction of disease, is not necessarily a population subjected to autoreactive $T$ cell-promoting manipulations. In the spontaneous diabetes developing NOD mouse and DP/BB rat the requirement of both T cell subsets has also been described $(59,70)$. However, a recent report on the use of autoreactive $T$ cell clones, adoptively transferred to both $\mathrm{X}$ irradiated syngeneic NOD and NOD-SCID mice, shows that diabetes develops in the absence of CD4 T cells (71).

Mechanisms in CSA-AI Increased thymic output of self-reactive $T$ cells does not cause autoimmunity as was demonstrated in rats and mice treated with CsA only $(33,38)$. After CsA-therapy in mice so-called "forbidden" TCR BV-families reappear in the periphery but no disease develops (38). In another experiment, shielding of the MHC class II molecules, by in vivo treatment with saturating doses of $\mathrm{MHC}$ class II reactive $\mathrm{mAb}$, inhibits clonal deletion. Prolonged antibody administration into DBA/2 or (DBA/2 x C57BL/6) F1 results in the presence of BV6 T cells in the periphery which are normally absent. As long as the MHC class II is blocked the BV6 T cells are present. When tested in a syngeneic "mixed leukocyte reaction' there is a marked proliferative response and an expansion of the BV6 T cell population, i.e. these $\mathrm{T}$ cells are not tolerant. Abrogation of the mAb administration does not yield any signs of autoimmune disease but eliminates the BV6 T cells in the periphery within 
3 weeks. However, two models are described where the presence of self-reactive BV families coincides with development of autoimmunity. One model is the neonatal thymectomized $\mathrm{BALB} / \mathrm{c}$ mouse, where BV5 T cells are observed in peripheral blood and lymph nodes (72). The other model is the $\mathrm{X}$-irradiated, syngeneic BM reconstituted and CsA-treated mouse model, induced like the Lewis rat $\mathrm{CsA}-\mathrm{AI}$, using BALB/c, C57Bl6, DBA/2 and $\mathrm{C} 3 \mathrm{H} / \mathrm{He}$ strains (73). Whether the "forbidden" BV-bearing T cells, that appear in mouse CsA-AI, play a role themselves in development of autoimmunity is questionable, but the presence of these cells is indicative for impaired thymic selection (74). Repeated total lymphoid irradiation of mice, with shielding of the long bones, lung and skull, elicits organ specific autoimmune diseases such as thyroiditis and gastritis (reviewed by Sakaguchi and Sakaguchi (75)). In PVG rats thyroiditis and diabetes are the result of repeated X-irradiation after thymectomy (76). The similarity between the 2 latter models and the models of impaired clonal deletion is that the peripheral $T$ cell pool is diminished. However, there is no direct relation between impaired thymic selection and autoimmunity in the latter models. It can be argued whether a decreased $\mathrm{T}$ cell number is a key to development of autoimmune disease as observed in the lymphopenic diabetic-prone $\mathrm{BB}$ rat $(77,78)$.

It has been demonstrated that peripheral autoreactive $T$ cells by themselves are no cause of autoimmunity. If however, potentially autoreactive $T$ cells enter a periphery that is depleted of normal $\mathrm{T}$ cells, and therefore encounter no suppressor $\mathrm{T}$ cells, only peripheral clonal anergy or clonal deletion remain as tolerizing mechanisms. But the few $\mathrm{T}$ cells that exist after neonatal thymectomy or $\mathrm{X}$-irradiation may escape these tolerizing mechanism because these cells may have different migratory patterns or are prone to meet APC with a higher incidence because there are fewer $\mathrm{T}$ cells to compete with (reviewed by Bonomo et al, (79)). The fact that $\mathrm{CD}^{2} 5 \mathrm{RC}^{+}$, $\mathrm{RT}^{-}$- Th cells are also transiently expanded in X-irradiated Lewis rats may be related to an empty environment and a temporary lack of regulatory cells. We were able to demonstrate the production of IL2 and IFN $\gamma$ mRNA by CD45RC+ ${ }^{+}$RT6 $^{-}$Th cells. This is a unique trait and defines this cell as Th1-like cells. As soon as the periphery becomes inhabited by new $\mathrm{T}$ cells, the ratio between CD45RC ${ }^{+} \mathrm{RT}^{-}$and CD45RC $\mathrm{RT}^{+}{ }^{+}$is normalized, and no autoimmunity develops. This is in line with the model proposed by Perez et al (80), who describe the irreversible switch from Th1 to Th2 and not vice versa. This process allows a rapid Th1 cell-mediated immune response, later on controlled by Th2 cells that downregulate the Thl response, and promote a humoral response. This model explains autoimmunity in terms of a Th1 response that is not followed by a Th2 response. Neo-natal thymectomy and repeated $\mathrm{X}$-irradiation promote increased frequency of autoreactive $\mathrm{T}$ cells and in the mean time prevent proper recovery. In CsA-AI, after irradiation, peripheral T cell recovery is impaired by CsA in two ways: 1) CsA inhibits thymocyte maturation, resulting in slow peripheral recovery, and 2) CsA inhibits negative thymic selection, resulting in an 
increased frequency of potentially autoreactive $\mathrm{T}$ cells $(38-40)$. The disturbed peripheral $\mathrm{T}$ cell repertoire transiently exhibits increases in $T$ cells of the Thl type, which persist upon CsA treatment (chapter 5). A lack of regulatory cells combined with an increased frequency of autoreactive $\mathrm{T}$ cells in the CD4 and CD8 subsets enhances CsA-AI development as soon as the inhibitory effect of CsA is taken away.

A dichotomy of CD4 $\mathrm{T}$ cells, known as Th1 and Th2 cells, has also been described for CD8 cells (69). The consequence of this duality is that both CD4 and CD8 T cells can be driven in their response to exhibit typical Th1 or Th2 characteristics. The role of cells producing IL2, IFN $\gamma$, as described in CsA-AI and other autoimmune models $(56,81,82)$, may, therefore, reside in skewing both $\mathrm{CD} 4$ and $\mathrm{CD} 8 \mathrm{~T}$ cells towards a cell-mediated immune response. Once effector cells are generated in sufficient quantity within these subsets, they can persist in their autoaggressive behaviour and generate new lesions upon adoptive transfer, provided regulatory mechanisms of the normal recipients are eliminated prior to transfer $(16,50,52,67)$.

\section{Conclusions}

CsA-AI is only induced by the combination of X-irradiation and CsA therapy. The immunosuppressive effect of CsA seems to be most important in the thymus. It appears that CsA therapy has no direct effect on the stromal cells. Although decreased in number, the stromal cells are still able to provide the micro-environment that is important for negative selection. CsA acts directly on the thymocytes by interfering with the intracellular signal upon activation via the TCR, and thereby alters the fate of the thymocytes during maturation. The net effect of CsA is a decrease in the number of mature thymocytes with an ovcrall higher affinity for the MHC/peptide complexes. Hence, autoreactive thymocytes will survive and migrate into the periphery.

The periphery plays a dominant role in development of CsA-AI. X-irradiation is critical to condition the periphery. Only if the periphery is void of regulatory cells, CsA-AI can develop. Already during CsA therapy, thymus derived autoreactive thymocytes enter the periphery. As long as CsA is present, the autoreactive $T$ cells accumulate and remain quiescent. After CsA therapy is stopped, CsA-AI will develop and autoreactive T cells are demonstrable in lymph nodes, spleen and in the lesions. The expansion of Th1-like $\mathrm{CD}^{2}$ RRC ${ }^{+}$, RT6- cells is critical for CsA-AI to develop. Whether or not this will occur is genetically controlled, but is not related to the MHC haplotype. Activation of these ThI-like cells results in production of IL2 and IFN $\gamma$, which in addition may lead to further skewing of other $\mathrm{T}$ cells, including CD8 $\mathrm{T}$ cells, to respond in a similar fashion. As soon as disease is clinically manifest, effector $\mathrm{T}$ cells are demonstrable within the CD4 and CD8 T cell 
population by adoptive transfer. CsA-AI develops after adoptive transfer without prior activation of the putative effector $\mathrm{T}$ cells. There is no evidence for restricted usage of any TCR BV family. The autoantigens in CsA-AI are unknown, but both CD4 and CD8 T cell populations contain effector $\mathrm{T}$ cells. Since virtually all Lewis rats, subjected to $\mathrm{X}$-irradiation and CsA therapy develop similar disease it is suggested that the autoantigen(s) are related to epithelial cells antigen(s) expressed in the thymus and in the skin.

\section{References}

I Glazier, A., Tutschka, P. J., Farmer, E. R. and Santos, G. W. (1983) Graft-versus-host disease in cyclosporin A-treated rats after syngeneic and autologous bone marrow reconstitution. J. Exp. Med. 158: $1-8$

2 Bos, G. M. J., Majoor, G. D., Willighagen, R. G. J. and van Breda Vriesman, P. J. C. (1989) Chronic cyclosporine-induced autoimmune disease in the rat: a new experimental model for scleroderma. $J$. lnvest. Dernutol. 93:610-615

3 Jones, R. S., Hess, A. D., Mann, R. B., Piantadosi, S., Vogelsang, G. B., Farmer, E. R., Geller, R. B. and Santos, G. W. (1989) Induction of graft-versus-host disease after autologous bone marrow transplantation. Lancet. 1:754-747

4 Hess, A. D., Horwitz, L., Beschorner, W. E. and Santos, G. W. (1985) Development of graft-vs-host disease-like syndrome in cyclosporine-treated rats after syngeneic bone marrow transplantation. $J$. Exp. Med. 161:718-730

5 Hess, A. D., Horwitz, L. R., Laulis, M. K. and Fuchs, E. (1993) Cyclosporine-induced syngeneic graft-vshost disease: prevention of autoaggression by treatment with monoclonal antibodies to $T$ lymphocyte cell surface determinants and to MHC class II antigens. Clin. Immunol. Immunopathol. 69:341-350

6 Dale, B. M., Atkinson, K., Kotasek, D., Biggs, J. C. and Sage, R. E. (1989) Cyclosporine-induced graft vs host disease in two patients receiving syngeneic bone marrow transplants. Transpl. Proc. 21:38163817

7 Vogelsang, G. B., Jones, R. J., Hess, A. D., Geller, R., Schucter, L. and Santos, G. W. (1989) Induction of autologous graft-versus-host disease. Transpl. Proc. 21:2997-2998

8 Talbot, D. C., Powles, R. L., Sloane, J. P., Rose, J., Treleaven, J., Aboud, H., Helenglass, G., Parikh, P., Smith, C., Rowley, M., Cavanagh, J., Milliken, S., Hewetson, M. and Norton, J. (1990) Cyclospurineinduced graft-versus-host disease following autologous bone marrow transplantation in acute myeluid leukaemia. Bone Marrow Transplant. 6:17-20

9 Yeager, A. M., Vogelsang. G. B., Jones, R. J., Farmer, E. R., Altomonte, V., Hess, A. D. and Santos, G. W. (1992) Induction of cutaneous graft-versus-host disease by administration of cyclusporine to patients undergoing autologous bone marrow transplantation for acute myeloid leukemia. Blood. 79:3031-3035

10 Batuman, O. A. and Jimenez, S. A. (1993) Systemic Sclerosis. In The molecular pathology of autoimmune diseases. C.A. Bona, K.A. Siminovitch, M. Zanetti and A.N. Theofilopoulos, Editors. Harwood Academic Publishers, Chur, Switzerland. 377-399

11 Bos, G. M. J., Majoor, G. D., Slaaf, D. W., Reneman, R. S. and van Breda Vriesman, P. J. C. (1988) In vivo demonstration of microvascular pathology by intravital microscopy in experimental chronic graftversus-host disease. Analogy with scleroderma. J. Rheumarol. 15:1339-1345 
12 Bona, C. A. (1993) Experimental models for scleroderma. In The molecular pathology of autoimmune disenses. C.A. Bona, K.A. Siminovitch, M. Zanetti and A.N. Theofilopoulos, Eds. Harwood Acad. Publ., Chur, Switzerland. 401-413

13 van de Water, J., Haapanen, L., Boyd, R., Abplanalp, H. and Gershwin, M. E. (1989) Identification of T cells in early dermal lymphocytic infiltrates in avian scleroderma. Arthritis and Rheumatism. 32:10311040

14 Damuiseaux, J. G. M. C., Beijleveld, L. J. J. and van Breda Vriesman, P. J. C. (1995) Cutaneous immunopathology of Cyclosporin-A induced autoimmunity in the rat. Clin. Immunol. Immunopathol. 77:315-323

15 Wodzig, K. W. H., Majoor, G. D. and van Breda Vriesman, P. J. C. (1993) Susceptibility and resistance to Cyclusporin A-induced autoimmunity in rats. Autoimmunity. 16:29-37

16 Fischer, A. C., Beschorner, W. E. and Hess, A. D. (1989) Requirements for the induction and adoptive transfer of cyclosporine-induced syngeneic graft-verus-host-disease. J. Exp. Med. 169: 1031-1041

17 Beijleveld, L. J. J., Damoiseaux, J. G. M. C., Wudzig, K. W. H. and van Breda Vriesman, P. J. C. (1995) $\mathrm{X}$-irradiation of the thymus is not required for the induction of Cyclosporin- $\mathrm{A}$ induced autoimmunity. Trunsplantation. 59:1601-I605

18 Kruisbeek, A. M., Mond, J. J., Fowlkes, B. J., Carmen, J. A., Bridges, S. and Longo, D. L. (1985) Absence of the Lyl-2- $23 \mathrm{~T}^{+}$lineage of T cells in mice treated neonatally with anti-I-A correlates with absence of intrathymic I-A-bearing antigen-presenting cell function. J. Exp. Med. 161:1029-1047

19 Marusic, G. S., Stephany, D. A., Longo, D. L. and Kruisbeek, A. M. (1988) Development of CD4-CD8+ cytotoxic T cells requires interactions with class I MHC determinants. Nature. 333:180-183

20 von Bochmer, H. (1992) Thymic selection: a matter of life and death. Immunol. Today: 13:454-458

21 Sayegh, M. H., Perico, N., Gallon, L., Imberti, O., Hancock, W. H., Remuzzi, G. and Carperter, C. B. (1994) Mechanisms of acquired thymic unresponsiveness to renal allografts. Thymic recognition of immunodominant allo-MHC peptides induces peripheral T eell anergy. Transplantation. 58:125-132

22 Posselt, A. M., Barker, C. F., Friedman, A. L. and Naji, A. (1992) Prevention of autoimmune diabetes in the $\mathrm{BB}$ rat by intrathymic islet transplantation at birth. Science. 256:1321-1324

23 Husbands, D. S., Schönrich, G., Arnold, B., Chandler, P. R., Simpson, E., Philpott, K. L., Tomlinson, P.. O'Reilly. L., Cooke, A. and Mellor, A. L. (1992) Expression of major histocompatibility complex class I antigens at low levels in the thymus induces $T$ cell tolerance via a non-deletional mechanism. Eur. $J$. Imminol. 22:2655-2661

24 Kyewski, B. A., Fathman, C. G. and Kaplan, H. S. (1984) Intrathymic piesentation of circulating nonmajor histocompatibility complex antigens. Nafure. 308:196-199

25 Nieuwenhuis, P., Stet, R. J., Wagenaar, J. P., Wubbena, A. S., Kampinga J. and Karrenbeld, A. (1988) The transcapsular route: a new way for (self-) antigens to by-pass the blood-thymus barrier? Immunol Toduy. 9:372-5

26 Elliot, J. I. (1993) Thymic selection reinterpreted. Immunol. Rer. 227-242

27 Lec. N. A., Loh, D. Y. and Lacy, E. (1992) CD8 surface levels alter the fate of $\alpha / \beta$ T cell receptorexpressing thymocytes in transgenic mice. J. Exp. Med. 175: 1013-1025

28 Surh, C. D. and Sprent, J. (1994) T-cell apoptosis detected in situ during positive and negative selection in the thymus. Nature. 372:100-103

29 Jones, L. A., Chin, L. T. and Kruisbeek, A. M. (1990) Acquisition of self-tolerance in T cells is achieved by different mechanisms, operating both inside and outside the thymus. Thymus. 16:195-206 
30 Schünrich, G., Momburg, F., Hümmerling, G. J. and Arnold, B. (1992) Anergy induced by thymic medullary epithelium. Eur. J. Immunol. 22:1687-1691

31 Schuurman, H.-J., Loveren, v. H., Rozing, J., van Dijk, A., Locber, J. G. and Vos, J. G. (1990) Cyclosporin and the rat thymus. An immunohistochemical study. Thymus. 16:235-254

32 de Waal, E. J., Rademakers, L. H. P. M., Schuurman, H. J. and van Loveren, H. (1992) Interdigitating cells in the rat thymus during Cyclosporin A treatment: ultrastructural observations. Thymus. 20:163-170

33 Beijleveld, L. J. J., Damoiseaux, J. G. M. C. and van Breda Vriesman, P. J. C. (1995) The differential effects of $\mathrm{X}$-imadiation and Cyclosporin-A administration on the thymus with respect to the generation of Cyclosporin-A induced Autoimmunity. Dev. lmmunol. 4:127-138

34 Chen-Woan, M., Delaney, C. P., Fournier, V., Wakizaka, Y., Murase, N., Fung, J., Starzl, T. E. and Demetris, A. J. (1995) A new protocol for the propagation of dendritic cells from rat bone marrow using recombinant GM-CSF, and their quantification using the mAb OX-62. J Immunol Meth. 178: $157-171$

35 Hosseinzadeh, H. and Goldschneider, I. (1993) Recent thymic emigrants in the rat express a unique antigenic phenotype and undergo post-thymic maturation in peripheral lymphoid tissues. J. Immunol. 150:1670-1679

36 Hosseinzadeh, H. and Goldschneider, I. (1993) Demonstration of large-scale migration of cortical thymocytes to peripheral lymphoid tissues in cyclosporin A-treated rats. J. Exp. Med. 178:285-293

37 Damoiseaux, J. G. M. C., Beijleveld, L. J. J. and van Breda Vriesman, P. J. C. (1994) The effects of in vivo cyclosporin A administration on rat thymic dendritic cells. Clin. Exp. Immunol. 96:513-520

38 Gao, E. K., Lo, D., Cheney, R., Kanagawa, O. and Sprent, J. (1988) Abnormal differentiation of thymocytes in mice treated with Cyclosporin A. Nature. 336:176-179

39 Jenkins, M. K., Schwartz, R. H. and Pardoll, D. M. (1988) Effects of Cyclosporin A on T cell development and clonal deletion. Science. 241:1655-1658

40 Kanariou, M., Huby, R., Ladyman, H., Colic. M., Sivolapenko, G. and Lampert, I. (1989) Immunosuppression with cyclosporin A alters the thymic microenvironment. Clin. Exp. Immunol. 78:263-270

41 Schreiber, S. L. and Crabtree, G. R. (1992) The mechanism of action of cyclosporin A and FK506. Immunol. Today. 13:136-141

42 Shores, E. W. Ewijk, W. v. and Singer, A. (1991) Disorganization and restoration of thymic medullary epithelial cells in T-cell receptor-negative SCID mice: evidence that receptor-bearing lymphocytes influence maturation of the thymic microenvironment. Eur. J. Immunol. 21:1657-1661

43 Ritter, M. A. and Boyd, R. L. (1993) Development in the thymus: it takes two to tango. Immunol. Today. 14:462-469

44 Surh, C. D., Ernst, B. and Sprent, J. (1992) Growth of epithelial cells in the thymic medulla is under the control of mature T cells. J. Exp. Med. 176:611-616

45 Burkly, L., Hession, C., Ogata, L., Reilly, C., Marconi, L. A., Olson, D., Tizard, R, Cate, R. and Lo, D. (1995) Expression of relB is required for the development of thymic medulla and dendritic cells. Nature. 373:531-536

46 Schönrich, G., Momburg, F., Malissen, M., Schmitt-Verhulst, A.-M., Malissen, B., Hämmerling, G. J. and Arnold, B. (1992) Distinct mechanisms of extrathymic T cell tolerance due to differential expression of self antigen. Imt. Immunol. 4:581-590 
47 Lombard, G., Sidhu, S., Batchelor, R. and Lechler, R. (1994) Anergic T cells as suppressor cells in vitro. Science 264:1587-1589

48 Saoudi, A., Castedo, M., Nochy, D., Mandet, C., Pasquier, R., Druet, P. and Pelletier, L. (1995) Selfreactive anti-class II $\mathrm{T}$ helper type 2 cell lines derived from gold salt-injected rats trigger $\mathrm{B}$ cell polyclonal activation and transfer autoimmunity in CD8-depleted normal syngeneic recipients. Eur. J. Inmunel. 25:1972-1979

49 Atkins, M. B., Mier, J. W., Parkinson, D. R., Gould, J. A., Berkman, E. M. and Kaplan, M. M. (1988) Hypothyroidism after treatment with interleukin-2 and lymphokine-activated killer cells. N. Eng. J. Med. 318:1557-1563

50 Fischer, A. C., Laulis, M. K., Horwitz, L., Beschorner, W. E. and Hess, A. D. (1989) Host resistance to cyclosporine induced syngeneic graft-versus-host disease: Requirements for two distinct lymphocyte subsets. J. Immunol. 143:827-832

51 Spickett, G. P., Brandon, M. R., Mason, D. W., Williams, A. F. and Wooliet, G. R. (1983) MRC OX-22, a monoclonal antibody that labels a new subset of $\mathrm{T}$ lymphocytes and reacts with the high molecular weight form of the leukncyte-common antigen. J. Exp. Med. 158:795-810

52 Hess, A. D., Fischer, A. C., Horwitz, L., Bright, E. C. and Laulis, M. K. (1994) Characterization of peripheral autoregulatory mechanisms that prevent development of Cyclosporin-induced syngeneic graft-versus-host disease. J. Immunol. 153:400-411

53 Mosmann, T. R. and Sad, S. (1996) The expanding universe of T-cel subsets: Th1, Th2 and more. Immunol. Today, 17:138-146

54 Fowell, D., McKnight, A. J., Powrie, F., Dyke, R. and Mason, D. (1991) Subsets of CD4+ T cells and their roles in the induction and prevention of autoimmunity. Inmunol. Rev. 123:37-64

55 Powrie, F. and Mason, D. (1990) OX-22 high CD4+ T Cells induce wasting disease with multiple organ pathology: Prevention by the OX-22 low subset. J. Exp. Med. 172:1701-1708

56 Fowell, D. and Mason, D. (1993) Evidence that the T cell repertoire of normal rats contains cells with the potential to cause diabetes. Characterization of the CD4+ T cell subset that inhibits this autoimmune potential. J. Exp. Med. 177:627-636

57 Greiner, D. L., Handler, E. S., Nakano, K., Mordes, J. P. and Rossini, A. A. (1986) Absence of the RT-6 T cell subset in diabetes-prone BB/W rats. J. Immunol. 136:148-151

58 Greiner, D. L., Mordes, J. P., Handler, E. S., Angelillo, M., Nakamura, N. and Rossini, A. A. (1987) Depletion of RT6.1+ T lymphocytes induces diabetes in resistant biobreeding/worcester (BB/W) rats. J. Exp. Med. 166:46]-475

59 Whalen, B. J., Greiner, D. L., Mordes, J. P. and Rossini, A. A. (1994) Adoptive transfer of autoimmune diabetes mellitus to athymic rats: syngergy of $\mathrm{CD} 4+$ and $\mathrm{CD} 8+\mathrm{T}$ cells and prevention by $\mathrm{RT} 6+\mathrm{T}$ cells. J Autoimmunity. 7:819-831

60 Kampinga, J., Groen, H., Klatter, F., Meedendorp, B., Aspinall, R., Roser, R. and Nieuwenhuis, P. (1992) Post-thymic T cell development in rats: an update. Biochem. Soc. Trans. 20:191-197

61 Powrie, F., Correa-Oliveira, R., Mauze, S. and Coffman, R. L. (1994) Regulatory interactions between CD45RBhigh and CD4SRBlow CD4+ $T$ cells are important for the balance between protective and pathogenic cell-mediated immunity. J. Exp. Med. 179:589-600

62 Powrie, F. (1995) T cells in inflammatory bowel disease: protective and pathogenic roles. Immunity. 3:171174

63 Mathieson, P. W. (1992) Mercuric chloride-induced autoimmunity. Autoimmunity. 13:243-247 
64 Mathieson, P. W., Thiru, S. and Oliveira, D. B. G. (1993) Regulatory role of OX22high T-cells in mercuryinduced autoimmunity in the Brown Norway rat. J. Exp. Med. 177:1309-1316

65 Groen. H., Klatter, F. A., van Petersen, A. S., Pater, J. M., Nieuwenhuis, P. and Kampinga, J. (1993) Composition of rat CD4+ resting memory $\mathrm{T}$-cell pool is influenced by major histocompatibility complex. Trunsplant. Proc: 25:2782-2783

66 Beschorner, W. E., Hess, A. D., Shinn, C. A. and Santos, G. W. (1988) Transfer of Cyclosporineassociated syngeneic gruft-versus-host disease by thymocytes. Transplantation. 45:209-215

67 Sorokin, R., Kimura, H., Schroder, K., Wilson, D. H. and Wilson, D. B. (1986) Cyclosporin-induced autoimmunity: Conditions for expressing discase, requirement for intact thymus, and potency estimates of autoimmune lymphocytes in drug-treated rats. J. Exp. Med. 164:1615-1625

68 Hess, A. D., Fischer, A. C. and Beschorner, W. E. (1990) Effector mechanisms in cyclosporine A-induced syngeneic graft-versus-host disease. Role of CD4+ and CD8+ T lymphocyte subsets. J. Immunol. 145:526-533

69 Kemeny, D. M., Noble, A., Holmes, B. J. and Diaz-Sanchez, D. (1994) Imune regulation: a new role for the $\mathrm{CD}^{+}{ }^{\mathrm{T}}$ cell. Immunol. Today. 15:107-110

70 Thivolet, C., Bendelac, A., Bedossa, P., Bach, J.-F. and Carnaud, C. (1991) CD8+ T cell homing to the pancreas in the nonobese diabetic mouse is CD4+ T cell-dependent. J. Immunol. 146:85-88

71 Wong, F. S., Visintin, I., Wen, L., Flavell, R. A. and Janeway, C. A. (1996) CD8 T cell clones from young nonobese diabetic (NOD) islets can transfer rapid onset of diabetes in NOD mice in the absence of CD4 cells. J. Exp. Med. 183:67-76

72 Jones, L. A., Chin, L. T., Merriam, G. R., Nelson, L. M. and Kruisbeek, A. M. (1990) Failure of clonal deletion in neonatally thymectomized mice: Tolerance is preserved through clonal anergy. J. Exp. Med. 172: $1277-1285$

73 Bucy, R. P., Xu, X. Y., Li, J. and Huang, G. Q. (1993) Cyclosporin A-induced autoimmune disease in mice. J. Immunol 151:1039-1050

Bryson, J. S., Caywood, B. E. and Kaplan, A. M. (1991) Relationship of cyclosporin A-mediated inhibition of clonal deletion and development of syngeneic graft-versus-host disease. J. Immunol. 147:391-397

75 Sakaguchi, N., Miyai, K. and Sakaguchi, S. (1994) Ionizing radiation and autoimmunity. Induction of autoimune disease in mice by high dose fractionated total lymphoid irradiation and its prevention by inoculating normal T cells. J. Immunol. 152:2586-2595

76 Penhale, W. J., Farmer, A., McKenna, R. P. and Irvine, W. J. (1973) Spontaneous thyroiditis in thymectomized and irradiated Wistar rats. Clin. Exp. Immunol. 15:226-236

77 Sarkar, P., Crisa, L., McKecver, U., Bortell, R., Handler, E., Mordes, J. P., Waite, D., Schoenbaum, A., Haag, F., Koch-Nolte, F., Thiele, H.-G., Greiner, D. and Rossini. A. (1994) Loss of RT6 message and most circulating $T$ cells after thymeciomy of diabetes prone BB rats. Autoimmunity. 18:15-22

78 Groen, H., Klatter, F. A., Brons, N. H. C., Mesander, G., Nieuwenhuis, P. and Kampinga, J. (1996) Abnormal thymocyte subset distribution and differential reduction of $\mathrm{CD} 4^{+}$and $\mathrm{CD} 8^{+} \mathrm{T}$ cell subsets during peripheral maturation in Diabetes-prone BioBreeding rats. J. Immunol. 156:1269-1275

79 Bonomo, A., Kehn, P. J. and Shevach, E. M. (1995) Post-thymectomy autoimmunity: abnormal T-cell homeostasis. Immunol Today. 16:61-67

80 Perez, V. L., Lederer, J. A., Lichtman, A. H. and Abbas, A. K. (1995) Stability of Th1 and Th2 populations. International Immunol. 7:869-875 
SI Stuudi. A., Simmond. S., Huitinga, I. and Mason, D. (1995) Prevention of experimental allergic encephalomyelitis in rats by targeting autoantigen to B cells: evidence that the protective mechanism depends on changes in the cytokine response and migratory properties of the autoantigen-specific $T$ cells. J Exp Med. 182:335-344

X2 Katz, J. D., Benvist, C and Mathis, D. (1995) T helper cell subsets in insulin-dependent diabetes. Science. 268:1185-118K 


autoimmunity

Leo J.J. Beijleveld, Jan G.M.C. Damoiseaux, K. Willem H. Wodzig and Peter J.C. van Breda Vriesman

Department of Immunology, Faculty of Medicine, University of Limburg, P.O.B. 616, 6200 MD Maastricht, the Netherlands

Published in: Transplantation, Volume 59, pages 1601-1605, No. 11, 1995

\section{Summary}

The thymus-dependent model of Cyclosporin A-induced autoimmunity (CsA-AI) in the Lewis rat requires a lethal total body $\mathrm{X}$-irradiation and rescue with syngeneic or autologous bone marrow and Cyclosporin $\mathrm{A}$ (CsA) administration for at least 4 weeks; two to 3 weeks after cessation of CsA, the animals develop a graft-versus-host like disease. The obligatory role of the thymus in the etiology of CsA-AI has been established unequivocally, but the way in which disease is thymus dependent is topic of debate.

In the present study we demonstrate that the model of CsA-Al requires the presence of a thymus for at least 2 weeks alter total body irradiation and CsA administration but that Xirradiation of the thymus itself is not necessary to bring about disease. Transplantation of neonatal thymus shows, in addition, that in the absence of X-irradiation of the thymus, CsAtherapy is required to generate autoreactive cells, but that disease occurs only if peripheral autoregulatory cells are eliminated by $\mathrm{X}$-irradiation. 


\section{Introduction}

In Lewis rats the combination of lethal $\mathrm{X}$-irradiation, syngeneic hune marrow transplantation (BMT), and a 4-week course of CsA administration causes, upon withdrawal of CsA, the development of an autoimmune disease (Cyclosporin A induced autoimmunity [CsA-AI]) resembling allogeneic graft-versus-host disease $(\mathrm{GVH})(1,2)$. The presence of an initially intact thymus and the irradiation of that thymus are required for CsA-AI to occur $(3,4)$. The disease can be adoptively transferred with TCR $\alpha \beta^{+} \mathrm{T}$ cells, provided that, prior to adoptive transfer, the peripheral autoregulatory $T$ cel] circuit of the recipient is eliminated by total body irradiation or cyclophosphamide (5). It is widely held that following $\mathrm{X}$-irradiation and bone marrow grafting, the ensuing recapitulation of ontogeny in the thymus, including negative selection, is interfered with by $\mathrm{CsA}$, thus resulting in leakage of autoreactive $T$ cells into the periphery $(6,7)$. In the mouse, the peripheral occcurence of $T$ cells bearing selfreactive $T$ cell receptors as determined by the use of monoclonal antibodies recognizing specific "forbidden T cell Receptor $\beta$-chain variable region (TCR BV)" has been demonstrated after CsA treatment $(6,8,9)$. The down-regulation of MHC class II antigens in the thymic medulla, such as observed after CsA administration, particularly has been thought responsible for the lack of tolerance induction (10). Upon use of high dosages of CsA. medullary dendritic cells (DC) have been claimed to disappear immunohistochemically ( 11 13); using lower dosages of CsA, sufficient to cause CsA-AI, substantial numbers of medullary dendritic cells are demonstrable immunohistochemically (14). Also, after isolation of these DC from thymus suspensions, they showed no altered phenotype or function (15), An alternative hypothesis holds that CsA may generate autoreactive $T$ cells in the thymus by interfering with selection because CsA prevents apoptosis $(16,17)$. However, CsA treatment by itself does not elicit CsA-AI in the Lewis rat. Total body irradiation is thought to eliminate a peripheral autoregulatory circuit; additionally, it may damage the thymic stroma or prolong the CsA-induced alterations and thereby interfere with thymic selection (18). Finally, after cessation of CsA medication, the thymic output of potentially autoreactive versus autoregulatory cells may be differentially influenced by X-irradiation and CsA treatment (19).

We therefore examined the necessity of irradiation (both on the thymus and the periphery) and CsA treatment for the induction of CsA-AI separately. First, we determined the time span in which the presence of the thymus was required in order to generate sufficient autoreactive cells to induce CsA-AI. Second, we investigated the extent to which irradiation and/or CsA treatment could induce prolonged or permanent changes in the thymic stroma that could be held responsible for the induction of CsA-AI. We determined next whether irradiation of the thymus was essential or alternatively that only peripheral irradiation 
damage was required. Finally, the suggested delay in thymic output of autoregulatory $\mathrm{T}$ cells versus the presence of autoreactive $\mathrm{T}$ cells upon CsA administration without irradiation was examined.

\section{Materials \& Methods}

Animals Female inbred Lewis rats (RT11) were obtained from the Central Animal Facility of the University of Limburg, the Netherlands. The animals were maintained under specific pathogen free conditions until use and had free access to food and water. Rats were 6 weeks of age at the start of the experiment.

Protocol for the Induction of CsA-AI Rats were given $8.5 \mathrm{~Gy} X$-irradiation at $0.5 \mathrm{~Gy} / \mathrm{min}$., using a Röntgen irradiation machine (Philips MU15GF/225 kV, Hamburg, Germany) one day prior to syngeneic BMT. Recipient rats were given $6 \times 10^{7}$ viable nucleated syngeneic bone marrow cells intravenously into a tail vein as previously described (20). Starting from the day of BMT the rats received subcutaneously $7.5 \mathrm{mg} \mathrm{CsA} / \mathrm{kg}$ per day for 28 days. CsA, a kind gift from Sandoz Pharma Ltd., Basel, Switzerland, was dissolved in olive oil at a concentration of $7.5 \mathrm{mg} / \mathrm{ml}$. In the experiments, where indicated, the $X$-irradiated syngeneic $\mathrm{BM}$ reconstituted, CsA-treated (X-BM CsA-) rats, were compared to X-BM OO-rats (Xirradiated, syngeneic BM reconstituted and olive oil treated), CsA-rats (only CsA-treated rats) and OO-rats (olive oil only-treated rats).

Thymectomies Rats were thymectomized on different time points as indicated. Rats were intubated and maintained on artificial respiration while under ketamine (Nimatek $50 \mathrm{mg} / \mathrm{kg}$, i.m.) and xylazine (Sedamun $6 \mathrm{mg} / \mathrm{kg}$, s.c.) anesthesia. The thorax was opened and all prepericardial soft tissue inclusive of the thymus was removed; the thorax and skin were closed with 4-0 suture. Sham thymectomized rats were operated in a similar fashion, except that the thymus was not removed.

Thymus Transplantation Thymic lobes were obtained aseptically from neonatal syngeneic donors less than $24 \mathrm{hr}$ old. These were used without further treatment. One lobe of thymus tissue was grafted beneath the capsule of each kidney of recipients thymectomized earlier. Thymic lobes of adult syngeneic donors were obtained aseptically within 48 -hr after total body irradiation $(8.5 \mathrm{~Gy}$ ) of the donor. One lobe of the remaining thymic stroma was grafted under the kidney capsule of both kidneys of thymectomized recipients.

Scoring for CsA-AI During the course of CsA treatment, all animals appeared healthy. After withdrawal of CsA, development of CsA-AI was assessed daily by examination of the rats for signs and symptoms of disease, including erythroderma, dermatitis, alopecia and weight loss (table I) (21). 
Table I: Symptoms of CsA-AI

\begin{tabular}{l|l}
\hline \hline \multicolumn{2}{l}{ Symptoms of Cyclosporin A induced Autoimmunity } \\
\hline E & Erythroderma of the acra (hyperemia of the skin of the ears, feet and tail) \\
D & $\begin{array}{l}\text { Dermatitis, usually starting with brown/red discoloring of the fur of the neck and inside of the front } \\
\text { and/or hind legs. Expansion is restricted to the ventral part of the body. }\end{array}$ \\
A & Alopecia \\
$\mathrm{T}$ & $\begin{array}{l}\text { Thin fur, usually dorsal as a consequence of slowly progressive disease or partial recovery from } \\
\text { alopecia }\end{array}$ \\
\hline \hline
\end{tabular}

\section{Results}

Thymectomy prevents Disease To determine the requirement of the thymus in time, irradiated and bone marrow reconstituted rats were given CsA and and were next subjected to thymectomy or sham-thymectomy on days $-1,4,8,12,14,16,21,28,35$, and 42 after BMT. On each given day, groups of 10 rats were thymectomized; CsA was continued up to day 42 after BMT in 5 rats and discontinued on the day of thymectomy in the remaining 5 rats. The latter protocol was also applied to sham-thymectomized rats. Rats thymectomized on day -1, 4 , or 8 after BMT did not develop symptoms of CsA-AI for over 100 days, regardless of continuation for up to 42 days or cessation of the CsA therapy on the day of thymectomy (Table II). Only some rats thymectomized on day 12, 14, or 16 after BMT developed CsAAI; other rats in these cohorts remained free of symptoms. In contrast, CsA-AI developed in almost all rats that were subjected to thymectomy or sham-thymectomy on days $21-42$ after BMT, regardless of the duration of CsA treatment after TX. These data show that induction of CsA-AI required the presence of the thymus for at least 12 days after BMT. Abrogation of CsA administration on the day of thymectomy or continuation up to 42 days after BMT does not influence the development of CsA-AI.

The Disease can not be transplanted by X-Irradiated and CsA-treated Thymic Stroma To detect a prolonged effect of irradiation and CSA administration on the thymic stroma, rats were irradiated and given CsA or OO for 21 days after BMT. On day 21 , the rats were again irradiated with $8.5 \mathrm{~Gy}$, thus eliminating all thymocytes. The remaining thymic stroma was used for transplantation under the kidney capsule into rats, thymectomized earlier. These recipient rats were irradiated one day before transplantation of thymic stroma and received syngeneic bone marrow on the day of transplantation. These recipients were next given either CsA or OO for 21 days (table III) and were assessed daily for development of disease. Disease did not develop in rats transplanted with CsA-treated thymic stroma and given OO after transplantation. In rats transplanted with either CSA or OO-treated thymic stroma, and 
Table II: Thymectomy prevents disease

\begin{tabular}{|c|c|c|c|c|c|}
\hline \multirow{2}{*}{$\begin{array}{l}\text { Treatment } \\
\text { Thymectomy }\end{array}$} & \multirow{2}{*}{$\begin{array}{l}\text { Time of surgery after } \\
\text { BMT (days) } \\
-1\end{array}$} & \multirow{2}{*}{$\begin{array}{l}n \\
5\end{array}$} & \multirow{2}{*}{$\begin{array}{c}\begin{array}{c}\text { Course of CsA } \\
\text { after BMT (days) }\end{array} \\
42\end{array}$} & \multicolumn{2}{|c|}{$\begin{array}{l}\text { Incidence and symptoms } \\
\text { of CsA-AI (see table I) }\end{array}$} \\
\hline & & & & $0 / 5$ & \\
\hline Sham thymectomy & & 5 & 42 & $5 / 5$ & $D(5), A(5)$ \\
\hline None & & 5 & 42 & $5 / 5$ & $D(5), A(5)$ \\
\hline Thymectomy & 4 & 5 & 42 & $0 / 5$ & \\
\hline Thymectomy & & 5 & 4 & $0 / 5$ & \\
\hline Thymectomy & 8 & 5 & 42 & $0 / 5$ & \\
\hline Thymectomy & & 5 & 8 & $0 / 5$ & \\
\hline Thymectomy & 12 & 5 & 42 & $2 / 5$ & $E(2), D(2)$ \\
\hline Thymectomy & & 5 & 12 & $2 / 5$ & $E(2), D(2)$ \\
\hline Sham thymectomy & & 5 & 12 & $3 / 5$ & $\mathrm{~T}(3)$ \\
\hline Thymectomy & $14-16$ & 9 & 42 & $7 / 9$ & $D(7), A(7)$ \\
\hline Thymectomy & & 9 & $14-16$ & $6 / 9$ & $E(1), D(5), A(5)$ \\
\hline Sham thymectomy & & 9 & $14-16$ & $3 / 9$ & $E(2), D(1), A(1)$ \\
\hline Thymectomy & $21-42$ & 17 & 42 & $17 / 17$ & $D(17), A(17)$ \\
\hline Thymectomy & & 19 & $21-42$ & $17 / 19$ & $\mathrm{D}(17), \mathrm{A}(17)$ \\
\hline
\end{tabular}

Table III: Disease can not be transplanted by X-irradiated and CsA-treated thymic stroma

\begin{tabular}{|c|c|c|c|c|}
\hline \multicolumn{3}{|c|}{ Treatment of thymic stroma donors } & Treatment of thymic stroma recipients & \multirow{2}{*}{$\frac{\text { Incidence of } \operatorname{CsA} \cdot \mathrm{AI}}{0 / 3}$} \\
\hline $\mathrm{X}-\mathrm{BM}+$ & 2I days $\operatorname{Cs} A$ & Irradiation & Thymectomy $+X-B M+21$ dilys $O O$ & \\
\hline $\mathrm{X}-\mathrm{BM}+$ & 21 days $\operatorname{CsA}$ & Irradiation & Thymectomy $+\mathrm{X}-\mathrm{BM}+21$ days CsA & $2 / 4$ \\
\hline$X-B M+$ & 21 days $\mathrm{OO}$ & Jrradiation & Thymectomy $+X-B M+21$ days CsA & $3 / 3$ \\
\hline
\end{tabular}

given CsA after transplantation, CsA-AI did develop. The highest incidence and most severe signs of disease were found in rats that received the OO-treated thymic stroma and were next given CsA. These data show that the disease-inducing effects of irradiation and CsA treatment on the thymus are not transferred with pretreated thymic stroma.

Thymic Irradiation is not required for Induction of Disease The role of thymic irradiation in eliciting CsA-AI was examined in two different experiments. First we explored whether radiation damage in the thymus could result in the output of autoreactive $T$ cells prior to restoration of the peripheral autoregulatory $T$ cell circuit. Hence, thymectomies were performed 7, 10, and 14 days after total body irradiation and syngeneic BMT without CsA 
administration. Disease did not develop in any of theseanimals, which indicates that thymic radiation damage does not disturb the recapitulation of thymic ontogeny including negative selection. In the second experiment, we determined whether $\mathrm{X}$-irradiation of the thymus is essential for the generation of autoreactive $\mathrm{T}$ cells. Recipient rats were thymectomized, subjected to total body $\mathrm{X}$-irradiation and BMT, and then received unmanipulated neonatal thymus transplants beneath the kidney capsule; the recipients were then treated with CsA for 28 or 42 days (table IV). Neonatal thymus transplantation after irradiation resulted in high incidence of disease with a severity comparable to control rats. in which CsA-AI was induced according to the standard protocol. Rats transplanted with neonatal thymus lobes before Xirradiation developed a very low incidence of very mild disease. These results show that irradiation of thymic tissue is not required for the induction of CsA-AI. In fact, thymuses that were not manipulated gave a more severe disease. As a control experiment, we determined whether neonatal thymuses leak autoreactive $T$ cells into the periphery. Neonatal thymus lobes were transplanted into previously thymectomized and irradiated rats and treated with $\mathrm{OO}$ only. None of these rats developed signs of $\mathrm{CsA}$-AI within a period of 8 weeks after BMT.

Table IV: Thymic Irradiation is not required for induction of CsA-AI

\begin{tabular}{|c|c|c|c|c|c|c|}
\hline \multirow[t]{2}{*}{ Treatment } & \multicolumn{2}{|c|}{$\begin{array}{c}\text { Time of surgery after BMT } \\
\text { (days) }\end{array}$} & \multirow[t]{2}{*}{ n } & \multirow[t]{2}{*}{$\begin{array}{l}\text { Course of CsA } \\
\text { after BMT }\end{array}$} & \multicolumn{2}{|c|}{$\begin{array}{c}\text { Incidence and } \\
\text { symptoms of CsA-AI } \\
\text { (see table I) }\end{array}$} \\
\hline & Thymectomy & $\begin{array}{l}\text { Thymus } \\
\text { nsplantation }\end{array}$ & & & & \\
\hline None & - & - & 6 & 28 days & $6 / 6$ & $E(5), D(5)$ \\
\hline None & - & - & 6 & 42 days & $5 / 6$ & $E(5), D(5)$ \\
\hline Thymectomy + thymus transplantation & -1 & -1 & 6 & 28 days & $3 / 6$ & $E(3)$ \\
\hline Thymectomy + thymus transplantation & -1 & -1 & 5 & 42 days & $1 / 5$ & $E(1)$ \\
\hline Thymectomy + thymus transplantation & -1 & +1 & 5 & 28 days & $5 / 5$ & $E(5), D(3)$ \\
\hline Thymectomy + thymus transplantation & -1 & +1 & 7 & 42 days & $6 / 7$ & $E(6), D(5)$ \\
\hline Thymectomy + thymus transplantation & -1 & +1 & 5 & 42 days $O O$ & $0 / 5$ & \\
\hline
\end{tabular}

Total Body Irradiation is required for the Induction of Disease Although CsA administration by itself appears to be sufficient to interfere with thymic selection resulting in the output of autoreactive T cells, Beschorner et al. (19) have suggested that CsA could also cause a delay in the thymic output of autoregulatory $T$ cells. To determine whether total body irradiation was required, rats were also treated with CsA for 5 weeks without prior irradiation and BMT. 
When CsA administration was stopped, animals were thymectomized to prevent the restoration of the peripheral autoregulatory circuit. In two separate experiments, no CsA-AI symptoms developed in any of the animals, which indicates that peripheral irradiation is required for the elimination of the autoregulatory celis.

\section{Discussion}

Thymectomies performed at different time points after irradiation and CsA treatment revealed the obligatory presence of the thymus for at least 12 days. It has been established previously that the presence of the thymus is required for 14 days only (4); shorter periods have not been tested. Although disease occurred after CsA administration for only 12-14 days after BMT, disease manifested itself more frequently and also more severely after prolongation of C.A administration for another week. Previous analysis of thymic architecture and thymocyte population by immunohistochemistry has revealed that the damage of irradiation is repaired between day 7 and 14 after syngeneic BMT (14). Extending the period of CsA administration (even up to 12 weeks after BMT), however, has no clear effect on the incidence or severity of CSA-AI (2). Recovery of negative thymic selection or generation of counteractive cellular circuits from about 3 weeks after BMT onward are possible explanations for this observation. In adoptive transfer studies, thymocytes harvested from thymectomized animals at different time points during CsA treatment were not able to transfer disease (22), which indicates that only low numbers of autoreactive effector cells are present in the thymus or that, alternatively, expansion in the periphery is required. These results demonstrate that sufficient autoreactive T cells are generated in the thymus within 12 days after BMT and that they are able to leave the thymus under CsA administration soon after generation.

$\mathrm{X}$-irradiation and CsA treatment are considered mainly to effect the thymic struna (10, 18). Both medullary epithelial cells and medullary dendritic cells have been reported to be altered or even to have disappeared upon CsA administration $(12,13)$, thus interfering with thymic selection. Transplantation of irradiated and/or CsA-pretreated thymic stroma into thymectomized recipients resulted only in CsA-AI, provided the recipients were irradiated and treated in addition with CsA. Recent studies have shown that CsA interferes directly with thymocyte maturation and that the effect on stromal cells is secondary to the strong reduction in mature $\mathrm{T}$ cells in the thymic medulla (23). A more appropriate explanation of our results is the hypothesis that regardless of pretreatment of the thymic transplants, the autoreactive thymocytes escape apoptosis because of the CsA treatment $(16,24)$ and next enter the 
periphery $(6,8,9)$. Hence, the presence of CsA is obligatory during thymocyte maturation in order to generate autoreactive $T$ cells.

Irradiation by itself seems not to affect thymocyte selection, since thymectomies performed up to 2 weeks after irradiation without prior CsA treatment did not lead to CsAAI. On the other hand, irradiation is required for the development of disease. Repeated low dose total body irradiation without $\mathrm{CsA}$ administration results in development of autoimmune diseases, both in rat (25) and in mice (26). Fowell and coworkers demonstrated that repeated low dose X-irradiation induced diabetes; this could be prevented by injection of $\mathrm{CD4} 4^{+} \mathrm{OX} 22^{-}$ $\mathrm{RT}^{+} \mathrm{T}$ cells (the mAb OX22 recognizes CD45RC (27), a high m.w. isoform of CD45, the Leukocyte Common Antigen, whereas RT6 is an allotypic marker present on rat CD4 and CD8 $\mathrm{T}$ cell subsets $(28,29)$ ). In $\mathrm{T}$ cell-mediated experimental autoimmune models, special attention has been paid to OX22+ or RT6- CD4 T cells as effector cells and OX22- or RT6 $6^{+}$ CD4 T cells as regulatory cells $(25,30)$. Functional studies on $\mathrm{OX}^{2} 2^{+}$or RT6- cells revealed that these cells have Th1-like properties, whereas the OX22- or RT6 $6^{+}$cells are more like Th2 cells (30-32); this has resulted in a phenotypical characterization of Th1 and Th2 cells in the rat (33). Whether or not autoimmunity will develop appears to be determined by the balance between Th1 as effector cell and Th2 as regulatory cell type. Also in CsA-AI, it has been shown that in normal rats a radiosensitive autoregulatory $\mathrm{Th}$ cell population resides in the periphery which can prevent development of disease (34); this population has been identified as a OX22- CD4 $\mathrm{T}$ cell population (35). The fact that OX22- $\mathrm{T}$ helper cells are more radiosensitive compared with the Thl population (25) supports the hypothesis that these are the regulatory cells in radiation-induced autoimmunity. In the CsA-AI model, the expression of markers discriminating between Th1 and Th2 is described in Chapter 5. Indeed there is a skewing in the Th1/Th2 ratio in favour of the Th1-like CD4 $T$ cells in comparison to control rats.

Results show that the thymus itsclf does not require irradiation in order to induce CsAAI. Transplantation of newborn thymus lobes into thymectomized recipients after irradiation, but before CsA administration, consistently induced CsA-AI. Control experiments using normal newborn thymuses without CsA administration failed to induce autoimmunity; this suggests that, in the rat, in contrast to some strains of mice, clonal deletion by the thymus of possible autoreactive $\mathrm{T}$ cells involved in development of CsA-AI is efficient $(36,37)$. This result may appear to be in contrast to results reported by Glazier et al (3). Their study established that shielding of the thymus during irradiation prevents the development of CsAAI. However, shielding of the thymus also prevents irradiation of the thymus associated lymph nodes as well as parts of the lungs. Since the lungs are known to contain large amounts of $\mathrm{T}$ cells (38), it may well be that shielding the thymus from irradiation protects a 
substantial part of the peripheral autoregulatory T cells. Also Sakaguchi and Sakaguchi (39) showed that transplantation of unirradiated, but CsA-pretreated thymuses into nude mice results in various organ-specific autoimmune phenomena. These CsA-pretreated thymic lobes still contain the thymocytes that have matured in the presence of $\mathrm{CsA}$ and which enter the periphery of the recipient after transplantation; a periphery void of peripheral $T$ cells. Taken together, X-irradiation seems to be essential only in the sense that is has to destroy the peripheral autoregulatory circuit. In conclusion, our results show that only the combination of total body irradiation and CsA administration is capable of inducing CsA-AI. The role of the thymus in CsA-AI seems to be the production of $\mathrm{T}$ cells which have undergone aberrant selection under influence of CsA; X-irradiation of the thymus is not required. Provided the peripheral autoregulatory circuits are eliminated these autoreactive, thymus-derived $\mathrm{T}$ cells are able to cause autoimmune phenomena.

\section{Acknowledgements}

The authors wish to thank Marie-José van de Gaar and Harry van der Heijden for their excellent technical assistance.

\section{References}

1 Glazier, A., Tutschka, P. J., Farmer, E. R. and Santos, G. W. (1983) Graft-versus-host disease in cyclosporin A-treated rats after syngeneic and autologous bone marrow reconstitution. J. Exp. Med. $158: 1-8$

2 Bos, G. M. J., Majoor, G. D. and van Breda Vriesinan, P. J. C. (1988) Cyelosporin-A induces a selective, reversible suppression of $T$-helper lymphocyte regeneration after syngeneic bone marrow transplantation: association with syngeneic graft-versus-host disease. Clin. Exp. Immunol. 74:443-448

3 Glazier, A., Tutschka, P. J. and Farmer. E. R. (1983) Studies on the immunobiology of syngencic and autologous graft-yersus-host disease in cyclosporine-treated rats. Transpl. Proc. 15:3035-3041

4 Sorokin, R. Kimura, H., Schroder, K., Wilson, D. H. and Wilson, D. B. (1986) Cyclosporin-induced autoimmunity: Conditions for expressing disease, requirement for intact thymus, and potency estimates of autoimmune lymphocytes in drug-treated rats. J. Exp. Med. 164:1615-1625

5 Fischer, A. C., Beschorner, W. E. and Hess, A. D. (1989) Requirements for the induction and adoptive transfer of cyclosporine-induced syngeneic graft-verus-host-disease. J. Exp. Med. 169:1031-1041

6 Bryson, J. S., Caywood, B. E. and Kaplan, A. M. (1991) Relationship of cyclosporin A-mediated inhibition of clonal deletion and development of syngeneic graft-versus-host discase. J. Immunol. 147:391-397

7 Bucy. R. P., Xu, X. Y., Li, J. and Huang, G. Q. (1993) Cyclosporin A-induced autoimmune disease in mice. J. Immunol. 151:1039-1050

8 Gao, E. K., Lo, D., Cheney, R.. Kanagawa, O. and Sprent, J. (1988) Abnormal differentiation of thymocytes in mice treated with Cyclosporin A. Nature. 336:176-179

9 Jenkins, M. K., Schwartz, R. H. and Pardoll, D. M. (1988) Effects of Cyclosporin A on T cell development and clonal deletion. Science. 241:1655-1658

10 Beschorner, W. E., Namnoum, J., D., Hess, A. D., Shinn, C. A. and Santos, G. W. (1987) Cyclosporin A and the thymus. Am. J. Pathol. 126:487-496 
11 Beschorner, W. E. and Armas, O. A. (1991) Loss of medullary dendritic cells in the thymus after cyclosporine and irradiation. Cell. Immunol. 132:505-514

12 de Waal, E. J., Rademakers, L. H. P. M., Schuurman, H. J. and van Loveren, H. (1992) Interdigitating cells in the rat thymus during Cyclosporin A treatment: ultrastructural observations. Thymus. 20:163-170

13 Schuurman, H.-J., Loveren, v. H., Rozing, J., van Dijk, A., Loeber, J. G. and Vos, J. G. (1990) Cyclosporin and the rat thymus. An immunohistochemical study. Thymus. 16:235-254

Beijleveld, L. J. J., Damoiseaux, J. G. M. C. and van Breda Vriesman, P. J. C. (1995) The differential effects of $\mathrm{X}$-irradiation and Cyclosporin-A administration on the thymus with respect to the generation of Cyclosporin-A induced Autoimmunity. Dev. Immunol. 4: 127-138

15 Damoiseaux, J. G. M. C., Beijleveld, L. J. J. and van Breda Vriesman, P. J. C. (1994) The effects of in vivo cyclosporin A administration on rat thymic dendritic cells. Clin. Exp. Immunol. 96:513-520

16 Yasutomi, D., Odaka, C., Saito, S., Niizeki, H., Kizaki, H. and Tadakuma, T. (1992) Inhibition of programmed cell death by Cyclosporin A; preferential blocking of cell death induced by signals via TCR/CD 3 complex and its mode of action. Immunology. 77:68-74

17 Urdahl, K. B., Pardoll, D. M. and Jenkins, M. K. (1994) Cyclosporin A inhibits positive selectiun and delays negative selection in $\alpha \beta$ TCR transgenic mice. J. Immunol. 152:2853-2859

18 Beschorner, W. E., Namnoum, J. D. and Hess, A. D. (1987) Immunopathology of rat thymus after Cyclosporine A. Transpl. Proc. 19:1230-1235

19 Beschorner, W. E., Ren, H., Phillips, J., Pulido, H. B. J., Hruban, R. H. and Hess, A. D. (1991) Prevention of syngeneic graft-versus-host disease by recovery of thymic microenvironment after cyclosporine. Transplantation. 52:668-674

20 Bos, G. M. J., Majoor, G. D., Willighagen, R. G. J. and van Breda Vriesman, P. J. C. (1989) Chronic cyclosporine-induced autoimmune disease in the rat: a new experimental model for scleroderma. $J$. Invest. Dermatol 93:610-615

21 Wodzig, K. W. H., Majoor, (3. D. and van Breda Vriesman, P. J. C. (1991) On the localozation of effector cells in cyclosporin-induced autoimmunity. Autoimmunity. 10:275-283

22 Wodzig, K. W. H., Majoor, G. D. and van Breda Vriesman, P. J. C. (1993) Kinetics of inducer/effector cell generation in the thymus in cyclosporine-induced autoimmunity. Transplant. Proc. 25:2819-2821

23 Surh, C. D., Ernst, B. and Sprent, J. (1992) Growth of epithelial cells in the thymic medulla is under the control of mature T cells. J. Exp. Med. 176:611-616

24 MeCarthy, S. A., Cacchione, R. N., Mainwaring, M. S. and Cairns. J. C. (1992) The effects of immunusuppressive drugs on the regulation of activation-induced apoptotic cell death in thymocytes. Tramsplantation. 54:54,3-547

25 Fowell, D. and Mason, D. (1993) Evidence that the $T$ cell repertoire of normal rats contains cells with the potential to cause diabetes. Characterization of the $\mathrm{CD}^{+} \mathrm{T}$ cell subset that inhibits this autoimmune potential. J. Exp. Med. 177:627-636

26 Sakaguchi, N., Miyai, K. and Sakaguchi, S. (1994) Ionizing radiation and autoimmunity. Induction of autoimune disease in mice by high dose fractionated total lymphoid irradiation and its prevention by inoculating normal $T$ cells. J. Immunol. 152:2586-2595

27 Spickett, G. P.. Brandon, M. R., Mason, D. W., Williams, A. F. and Woollett, G. R. (1983) MRC OX-22, a monoclonal antibody that labels a new subset of T lymphocytes and reacts with the high molecular weight form of the leukocyte-common antigen. J. Exp. Med. 158:795-810

28 Greiner, D. L., Barton, R. W., Goldschneider, I. and Lubaroff, D. M. (1982) Genetic linkitge and cell distribution analysis of $\mathrm{T}$ cell alloantigens in the rat. $J$. Immunogenetics. 9:43-50 
29 Lubaroff, D. M., Butcher, G., DeWit, C., Gill III, T., Günther, E., Howard, J. and Wonigeit, K. (committee members) (1983) Standardized nomenclature for rat $T$ cell alloantigens: Report of the committee. Transpl. Proc. 15:1683

30 Fowell, D., McKnight, A. J., Powrie, F., Dyke, R. and Mason, D. (1991) Subsets of CD4 ${ }^{+} \mathrm{T}$ cells and their roles in the induction and prevention of autoimmunity. Immunol. Rev. 123:37-64

31 Greiner, D. L., Mordes, J. P., Handler, E. S., Angelillo, M., Nakamura, N. and Rossini, A. A. (1987) Depletion of RT6.1 ${ }^{+}$T lymphocytes induces diabetes in resistant biobreeding/worcester (BB/W) rats. J. Exp. Med. 166:461-475

32 Powrie, F. and Mason, D. (1988) Phenotypic and functional heterogeneity of CD4+ T cells. Immunol. Today. 9:274-277

33 Kampinga, J., Groen, H., Klatter, F., Meedendorp, B., Aspinall, R., Roser, R. and Nieuwenhuis, P. (1992) Post-thymic T cell development in rats: an update. Biochem. Soc. Trans. 20: 191-197

34 Hess, A. D., Fischer, A. C., Horwitz, L., Bright, E. C. and Laulis, M. K. (1994) Characterization of peripheral autoregulatory mechanisms that prevent development of Cyclosporin-induced syngeneic graft-versus-host disease. J. Immunol. 153:400-411

35 Fischer, A. C., Laulis, M. K., Horwitz, L., Beschorner, W. E. and Hess, A. D. (1989) Host resistance to cyclosporine induced syngeneic graft-versus-host disease: Requirements for two distinct lymphocyte subscts. J. Immunol. 143:827-832

36 Jones, L. A., Chin, L. T., Merriam, G. R., Nelson, L. M. and Kruisbeek, A. M. (1990) Failure of clonal deletion in neonatally thymectomized mice: Tolerance is preserved through clonal anergy. J. Exp. Med. 172: $1277-1285$

37 Signorelli, K., Benoist, C. and Mathis, D. (1992) Why is clonal deletion of neonatal thymocytes defective? Eur. J. Immunol. 22:2487-2493

38 Holt, P. G., Degebrodt, A., Venaille, T., O'Leary, C., Krska, K., Flexman, J., Farrell, H., Shellam, G., Young. P., Penhale, J., Robertson, T. and Papadimitriou, J. M. (1985) Preparation of interstitial lung cells by enzymatic digestion of tissue slices: preliminary characterization by morphology and performance in functional assays. Immunology. 54:139

39 Sakaguchi, S. and Sakaguchi, N. (1988) Thymus and autoimmunity: Transplantation of the thymus from cyclosporin A-treated mice causes organ-specific autoimmune disease in athymic nude mice. J. Exp. Med. 167:1479-1485 


thymus with respect to the generation of Cyclosporin-A induced Autoimmunity

Leo J.J. Beijleveld, Jan G.M.C. Damoiseaux and Peter J.C. van Breda Vriesman

The Department of Immunology, Faculty of Medicine, University of Limburg, Maastricht, the Netherlands

Published in: Developmental Immunology, Volume 4, pages 127-138, 1995

\section{Summary}

Cyclosporin A (CsA), a potent inhibitor of $T$ cell activation, has been shown to have several effects on thymocyte maturation, thymic stromal cells, and the generation of autoreactive $T$ cells. In Lewis rats, combination of lethal irradiation, syngeneic bone marrow transplantation, and a 4-week course of CsA administration causes the development of an autoimmune disease (CsA-AI) resembling allogeneic graft-versus-host disease. This occurs upon withdrawal of CsA, provided the thymus receives irradiation and is present during CsA treatment. In this study, the separate effects of irradiation or CsA treatment on thymic stromal cells and thymocytes, compared to the combinatory effects, were examined using immunohistochemistry and tri-colour flowcytometric analysis.

CsA treatment causes an involution of the thymic medulla and a strong reduction of the cell number of thymocytes and stromal cells residing in the medulla. However, within the remaining medullary area, changes in cell distribution and antigen density on these cells were not observed. Irradiation on the other hand causes a strong depletion of thymocytes. The thymocyte population is recovered within 2 wecks and a cortical and medullary region can be distinguished. CsA treatment in combination with irradiation results in a strongly inhibited recovery of the medulla during CsA treatment, whereas the cortex recovers to normal size and morphology. The presence of the medullary dendritic cells and epithelial cells is reduced proportionally to the small size of the medulla. However, the distribution of these stromal cells is normal. During the CsA administration, the thymuses from irradiated and CsA-treated rats are very similar to thymuses from CsA-treated rats. In conclusion, no changes specific for irradiation plus CsA treatment have been observed. Regarding the distribution and size of medullary stromal cells and residing thymocytes, thymuses from irradiated and CsA-treated rats hardly differ from the thymuses from rats treated only with CsA. Therefore, irradiation seems essential in the generation of CsA-Al by eliminating suppressor cell circuits in the periphery. 


\section{Introduction}

The fungal metabolite Cyclosporin-A (CsA) is a very potent immunosuppressive drug that predominantly acts on T cell-dependent responses (1). It is effectively used in preventing graft rejection and graft-versus-host disease (GVH) secondary to allogeneic bone marrow transplantation (BMT). Although CsA is also very useful in inhibiting the progression of several autoimmune diseases, surprisingly, autoimmune phenomena may rise upon withdrawal of CsA treatment under certain conditions. Rats treated with CsA after lethal irradiation and consecutive syngeneic BMT develop GVH-like lesions after CsA administration is stopped (2); in humans too, similar lesions have been reported after autologous BMT (3). The crucial role of the thymus in the induction of this CsA-induced autoimmunity (CsA-AI) has unequivocally been established $(4,5)$.

Immunosuppression with CsA not only effectively blocks the proliferation of mature peripheral $T$ cells, but also blocks thymocyte maturation (reviewed byRitter and Boyd, 1993) (6). Maturation of cortical CD4CD8 double-positive (DP) thymocytes into medullary CD4 and CD8 single-positive (SP) thymocytes is strongly inhibited (7-9). Immunohistochemical analysis of CsA-treated thymuses from rodents shows a relatively small medulla, in which the loss of medullary thymocytes is accompanied by a loss of medullary stromal cells (10-12) and formation of large area's denuded of MHC class II positive epithelial cells (13). The medullary stromal cells, consisting of epithelial cells, macrophages (M $\emptyset$ ) and dendritic cells (DC), play an important role in negative selection of autoreactive cells. The absence or functional alteration of medullary stromal cells has been suggested to lead to the escape of possible autoreactive cells to the periphery and the development of autoimmunity $(11,14,15)$.

Although upon CsA administration in the rat autoreactive T cells are generated (16) and in the mouse the peripheral occurrence of T cells bearing self-reactive T-cell receptors (TCR) as determined by the use of mAb's recognising specific "forbidden TCR $\beta$-chain variable region (BV)", has been demonstrated (8), only the combination of CsA and irradiation evokes CsA$\mathrm{AI}$ in the rat. Lethal irradiation, in terms of complete bone marrow depletion, has numerous effects on the immune system, but syngeneic BMT normally leads to an almost complete recovery of the thymus (17-19). Irradiation wipes out almost the whole thymocyte population, whereas the thymic stromal cells are relatively radio-resistant. Shielding of the thymus during irradiation prevents disease both in rat (20) and in mouse (21). It has been suggested that both whole-body irradiation including the thymus and CsA treatment have effects on the thymus essential for the induction of CsA-AI. Alternatively, post-CsA prevention of thymic recovery by thymectomy in unirradiated rats consistently evokes CsA-AI (22). This implies that the effect of irradiation can be replaced by thymectomy after the CsA treatment, suggesting that a normal thymic microenvironment after CsA is neccessary to reestablish self-tolerance through autoregulatory cells. 
In our rat model, the combination of CsA and irradiation evokes CsA-AI. So this study was designed to determine the differential effects of CsA and irradiation on the thymus, as compared to the combinatory effects. The attention was focused on (1) the presence and immunohistochemical properties of the thymic stroma with special reference to the medullary DC and epithelial cells and (2) the number and phenotype of thymocytes during and after CsA treatment. Furthermore, the disease-inducing effects of the separate treatments in combination with thymectomies were determined.

\section{Materials and methods}

Animals Fomale inbred LEW rats $\left(\mathrm{RT}^{\mathrm{l}}\right)$ were obtained from the Central Animal Facility of the University of Limburg, the Netherlands. The animals were maintained under specific pathogen free conditions until use and had free access to food and water. Rats were 6 weeks of age at the start of the experiment.

Protocol for the Induction of CsA-AI Rats were given $8.5 \mathrm{~Gy} \mathrm{X}$-irradiation at $0.5 \mathrm{~Gy} / \mathrm{min}$,, using a Röntgen irradiation machine (Philips MUI5GF/225 kV, Hamburg, Germany) one day prior to syngeneic BMT. Recipient rats were given $6 \times 10^{7}$ viable nucleated syngeneic bone marrow cells intravenously into a tail vein as previously described (23). Starting from the day of BMT the rats received subcutaneously $7.5 \mathrm{mg} \mathrm{CsA} / \mathrm{kg}$ per day for 28 days. CsA, a kind gift from Sandoz Pharma Ltd., Basel, Switzerland, was dissolved in olive oil at a concentration of $7.5 \mathrm{mg} / \mathrm{ml}$. In the experiments, where indicated, the X-irradiated syngeneic BM reconstituted, CsA-treated (X-BM CsA-) rats, were compared to X-BM OO-rats (X-irradiated, syngeneic $\mathrm{BM}$ reconstituted and olive oil treated), CsA-rats (only CsA-treated rats) and OO-rats (olive oil only-treated rats).

Thymectomies Rats were thymectomized on different time points as indicated. Rats were intubated and maintained on artificial respiration while under ketamine (Nimatek $50 \mathrm{mg} / \mathrm{kg}$, i.m.) and xylazine (Sedamun $6 \mathrm{mg} / \mathrm{kg}$, s.c.) anesthesia. The thorax was opened and all prepericardial soft tissue inclusive of the thymus was removed; the thorax and skin were closed with 4-0 suture. Sham thymectomized rats were operated in a similar fashion, except that the thymus was not removed.

Experimental Design In the first experiment, the immunohistochemistry of the thymus was studied. Rats that were $\mathrm{X}$-irradiated and given syngenic bone marrow (X-BM) and CsA-treated according to the previously mentioned protocol (X-BM CsA), were compared to three different control groups; rats irradiated and syngeneic bone marrow reconstituted and treated with olive oil only (X-BM OO), rats only treated with CsA (CsA) and rats administered olive oil only (OO). Two rats from each group were sacrificed at $48 \mathrm{hr}$ after irradiation and consecutive BMT and thereafter weekly starting from day 7 for up to 8 weeks. 
In a second experiment, the thymocyte population was studied by flowcytometry. Rats were treated similarly. The thymuses were collected at the same time points and prepared for flowcytometry.

The third experiment was designed to evaluate the disease-inducing effects of the separate treatments in combination with thymectomies. Thymectomies were performed on three different time points (days 7, 10 and 14) after irradiation and consecutive BMT (X-BM OOrats) or directly after the cessation of a four weeks course of CsA administration (CsA-rats).

Monoclonal Antibodies The mouse anti-rat monoclonal antibodies (mAb) used for immunohistochemistry are specified in table I. 1A29 was kindly provided by Prof. M. Miyasaki (Tokyo, Japan). The ED-series were kindly provided by dr. C.D. Dijkstra (Amsterdam, the Netherlands). The set of HIS mAb's were kindly provided by dr. J. Kampinga (Groningen, the Netherlands). W3/25 and the OX mAb's were obtained from European Collection of Animal Cell Cultures (Salisbury, UK). OX62 was kindly provided by dr. M. Brenan (Oxford, UK), and R73 was kindly provided by Prof. Th. Hünig (Würzburg, Germany). RCK102 was obtained from Organon Teknika (the Netherlands).

Immunohistochemistry The thymus was snap frozen in isopentane and used for cryosections. Four to six $\mu \mathrm{m}$-thick thymus cryosections were cut, air dried, and stored at $-20{ }^{\circ} \mathrm{C}$. All thymus-sections were stained using a two step immuno-peroxidase technique after acetone fixation. Sections were incubated for $60 \mathrm{~min}$. with $\mathrm{mAb}$ in the appropriate dilution. After washing in PBS, slides were incubated with a 1:200 dilution of rabbit anti-mouse $\mathrm{Ig}$ peroxidase conjugate (DAKO, Denmark) in PBS with $0.5 \%(w / v)$ bovine serum albumin (BSA, Sigma) and 3\% (v/v) normal rat serum for $30 \mathrm{~min}$. After washing with PBS, the sections were stained for peroxidase activity with 3,3'-diaminobenzidine-tetrahydrochloride (Sigma, St. Louis, MO) $(0.5 \mathrm{mg} / \mathrm{ml}$, in Tris- $\mathrm{HCl}$ buffer $(\mathrm{pH} 7.6)$. containing $0.02 \%(\mathrm{v} / \mathrm{v})$ $\mathrm{H}_{2} \mathrm{O}_{2}$ ). Control sections were incubated in the same way omitting the first-step mAb. Subsequently, the sections were counterstained with hematoxylin, dehydrated, and covered with Entallan (Merck, Germany).

Flowcytometry The thymus was teased apart and passed through a $100 \mu$-mesh nylon gauze and collected in balanced salt solution supplemented with $2 \%$ heat-inactivated new born calf serum. These cells were kept on ice until all samples were collected. The thymocytes were spun down ( $316 \mathrm{~g}, 10 \mathrm{~min} ., 4^{\circ} \mathrm{C}$ ), resuspended in PBS containing $0.5 \% \mathrm{BSA}$, and counted in a Bürker Hemocytumeter while viability was assessed by trypan blue exclusion. For tri-colour flowcytometry. $5 \times 10^{5}$ cells per simple were centrifuged in a 96-well microtiter-plate ( $236 \mathrm{~g}, 3$ min, $4^{\circ} \mathrm{C}$ ) and resuspended in $20 \mu \mathrm{lPBS}$ containing $0.5 \% \mathrm{BSA}, 10 \mathrm{mM} \mathrm{NaN}_{3}$ and the following conjugated mAb's: ER2 (38) conjugated to FITC (a kind gift from dr. B. de Geus, Leiden, the Netherlands) recognising the rat $\mathrm{CD} 4$ antigen, OX8 conjugated to PE (Caltag, Hycult, Uden, the Netherlands) recognising the rat CD8 antigen and R73 conjugated to biotin (a kind gift from Prof. Th. Hünig, Würzburg, Germany) recognising the rat TCR $\alpha \beta$ and that 
Table I

\begin{tabular}{|c|c|c|}
\hline $\mathbf{m A b}$ & Antigen and Expression in the Thymus & Reference \\
\hline $1 / 429$ & ICAM-1, present on DC and epithelium & (24) \\
\hline EDI & Macrosialin,present in $M \emptyset$ and DC & (25) \\
\hline ED2. & Cortical Mø & (25) \\
\hline ED8 & Complement receptor type 3, present on DC, MØ and granulocytes & (26) \\
\hline ED19 & CTES III' & \\
\hline $\mathrm{ED} 20$ & CTES II & \\
\hline HIS37 & CTES I & (27) \\
\hline HIS 38 & CTES III & (27) \\
\hline HIS39 & CTES II & $(27)$ \\
\hline HIS45 & medullary thymocyles & (28) \\
\hline OX6 & MHC class II (RTIB), present on DC, epithelium and $M \varnothing$ & (29) \\
\hline $0 \times 7$ & Thyl.1 present on thymocytes & (30) \\
\hline $0 \times 8$ & CD8, present on all cortical and a subset of the medullary thymocytes & (31) \\
\hline OX18 & $\begin{array}{l}\text { MHC class I (RTIA) present on all cells with high expression on } \\
\text { epithelium, M } \emptyset \text { and DC }\end{array}$ & $(32)$ \\
\hline OX19 & CD5, pan $T$ cell marker present on all thymocytes & (33) \\
\hline OX39 & Interleukin 2 receptor, present on $\mathrm{T}$ blasts and $\mathrm{DC}$ & (34) \\
\hline OX62 & Integrin like structure, present on DC & (35) \\
\hline $\mathrm{R} 73$ & T cell receptor $\alpha \beta$ & (36) \\
\hline RCKI02 & all types of keratin, not species specific & \\
\hline W3/35 & $\begin{array}{l}\mathrm{CD} 4 \text {, present on all cortical thymocytes, a subset of medullary } \\
\text { thymocytes and } \mathrm{M} \emptyset\end{array}$ & (37) \\
\hline
\end{tabular}

is detected in a second step labelling by the streptavidin conjugated fluorochrome Cy-Chrome (Pharmingen, USA). By using these three labelled mAb's together with the appropriate controls and by using optimal settings and compensation, the expression of CD4, CD8, and TCR $\alpha \beta$ was determined on a FACSort (Becton Dickinson).

\section{Results}

Thymus Morphology and Thymocyte Number The thymus was morphologically assessed for the relative size of the medulla and for thymocyte density within the cortex and medulla withhematoxylin and eosin sections. The thymocyte number was determined by counting single- cell suspensions in a Bürker hemocytometer.

\footnotetext{
1 CTES : cluster of thymic epithelial staining

CTES I pan epithelial cells

CTES II subcapsular/perivascular and the majority of medullary epithelial cells

CTES III cortical epithelial cells including thymic nurse cells (TNC)

CTES IV Hassall's corpuscles and all medullary epithelial cells

CTES V Hassall's corpuscles and, sometimes, a surrounding halo of medullary

epithelial cells
} 
Total body irradiation with 8.5 Gy caused a collapse of the thymic architecture and a strong reduction of thymocytes within $48 \mathrm{hr}$. Whereas the medulla seemed only slightly affected, the cortical thymocytes had completely disappeared. One week after irradiation, there was hardly any cortex or medulla detectable, but as soon as 2 weeks after irradiation, a new cortex was formed together with a smal. medulla.

Two days after irradiation, the total number and viability of thymocytes were very low. During the 2 weeks following irradiation, thymocyte cell number increased from $1.2 \times 10^{7}$ at week one to $\pm 40 \times 10^{7}$ at weck 2. Thereafter, the cell number increased much slower (Fig. 1). This thymocyte recovery was in harmony with morphological restoration of the thymus. There was a little difference in total thymocyte number between X-BM CsA or X-BM OO-rats, but the differences in cortex/medulla ratio were drastic. Two weeks after irradiation the medulla in the X-BM CsA-thymus was very small compared to X-BM OO and OO-thymuses but resembled the C.A-thymus. As soon as one week after the daily administration of $7.5 \mathrm{mg}$ $\mathrm{CsA} / \mathrm{kg}$ a reduction of thymic medullary area was noticed in CsA-thymuses. Two weeks after the initial administration, the reduction was maximal and remained the same at least until one week after the 4-week course of CsA-administration had been terminated, both in X-BM CsA and CsA-thymuses. The cortical area recovered within 2 weeks after irradiation and seemed to be unaffected by $\mathrm{CsA}$ in X-BM CsA-thymuses.

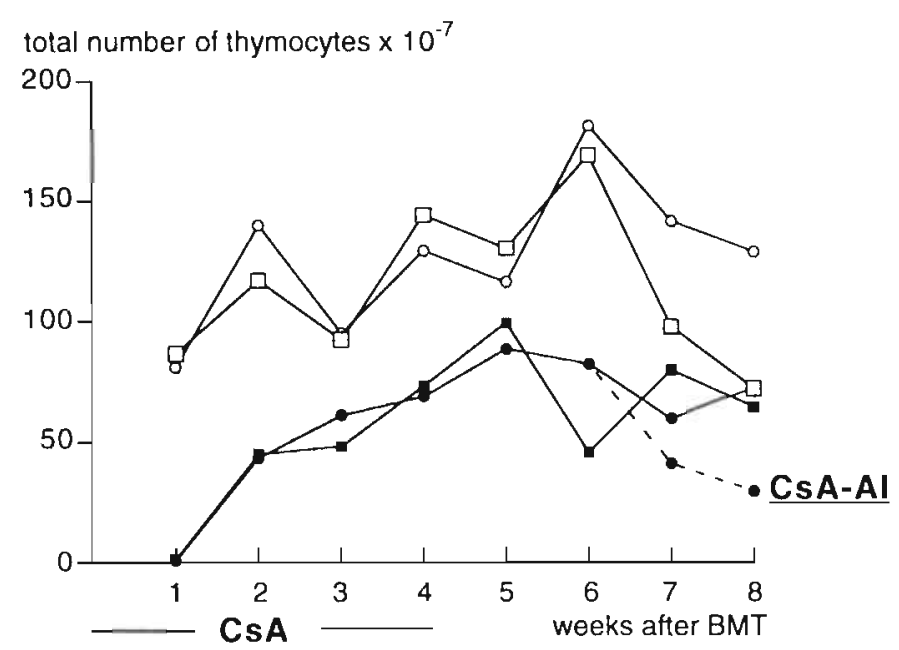

Figure 1: Average of total number of viable thymocytes isolated from two thymuses per group (OO-thymuses; open squares, CsA-thymuses; open circles, X-BM OO-thymuses; closed squares, X-BM CsA-thymuses; closed circles) at the time indicated. Cell numbers were assessed using a Burker Hemocytometer. From week 6 and later when CsA-AI becomes manifets 2 rats, free of macroscopical signs (X-BM CsA) and 2 rats with clear signs of denmatitis (X-BM CSA-AI : dotted line) were assessed 
Dendritic Cells We used a set of mAb's reactive with DC in the thymic medulla. Most of these $\mathrm{mAb}$ 's, however, are not specific for DC but additionally react in the thymus with epithelial cells (OX6, OX 18, IA29), MØ (ED1, ED8, 1A29, OX6, OX18), or thymocytes (OX18). The diffuse staining patterns of the mAb's recognizing epithelial cells or $\mathrm{M} \emptyset$ besides DC in the thymic medulla made it difficult to distinguish between the different cell types. Especially the mAb's OX39 and OX62, which in the thymic medulla recognize specifically DC, appeared to be very useful for the identification of this cell type.

As mentioned before, in X-BM CsA-rats the thymic architecture was perturbed by irradiation and the medulla recovery was strongly inhibited by the CsA treatment. As in X-BM OO-thymuses, the effects of irradiation were very drastic; one week after irradiation a clearly detectable medulla was absent. Although the DC antigens were present, it was impossible to determine whether it concerned cell debris or viable cells. Morphologically, normal cells expressing OX6, OX18, OX39, or OX62 were not detectable in the medulla. However, in XBM CsA-rats, a small medulla could be detected as soon as 2 weeks after irradiation (Fig. 2). The medulla of X-BM CsA-thymuses was of comparable size as in CsA-thymuses. OX62 and OX39-positive cells were present in a normal distribution in the medulla, as was the expression of MHC class I and II, ICAM-1, ED1 and ED8. Therefore, the expression of these markers is very indicative for the presence of DC in X-BM CsA-thymuses, as well as CsA-thymuses from 2 weeks after irradiation onwards. In X-BM OO-thymuses as soon as 2 weeks after irradiation normal distribution and expression of medullary DC antigens was seen (Fig. 2).

A partial recovery of the medullary size in X-BM CsA and CsA-thymuses was observed at 2 weeks after cessation of the CsA treatment together with a recovery of medullary stromal cells expressing ED1, ED8, OX6, OX18, OX39, and OX62.

Thymic Epithelial Cells A panel of mAb's recognizing thymic epithelium was used to examine different subsets of epithelial cells. The mAb's HIS37 and RCK 102, both pan epithelial cell markers in the thymus, visualized 3 different area's with regard to the presence and morphology of epithelium: (1) the medulla with epithelial cells most abundantly present in the cortico-medullary region, (2) the cortex with the fine reticular epithelium, and (3) the epithelial free area's closely located to the capsule surrounding the thymus and the protruding scptae. Furthermore, the mAb's HIS.38 and ED19 recognize cortical epithelial cells, whereas HIS39 and ED20 are specific for medullary epithelium. The epithelial cells are also detected by the earlier mentioned mAb's OX6, OX18 and 1 A29.

In X-BM CsA-rats, the cortical restoration seemed normal. HIS38 as well as ED 19 clearly showed the cortical arei, which was very extensive after two wecks. However, a combination of changes in thymic architecture was observed (see table II). The epithelial free area's clusi: to 

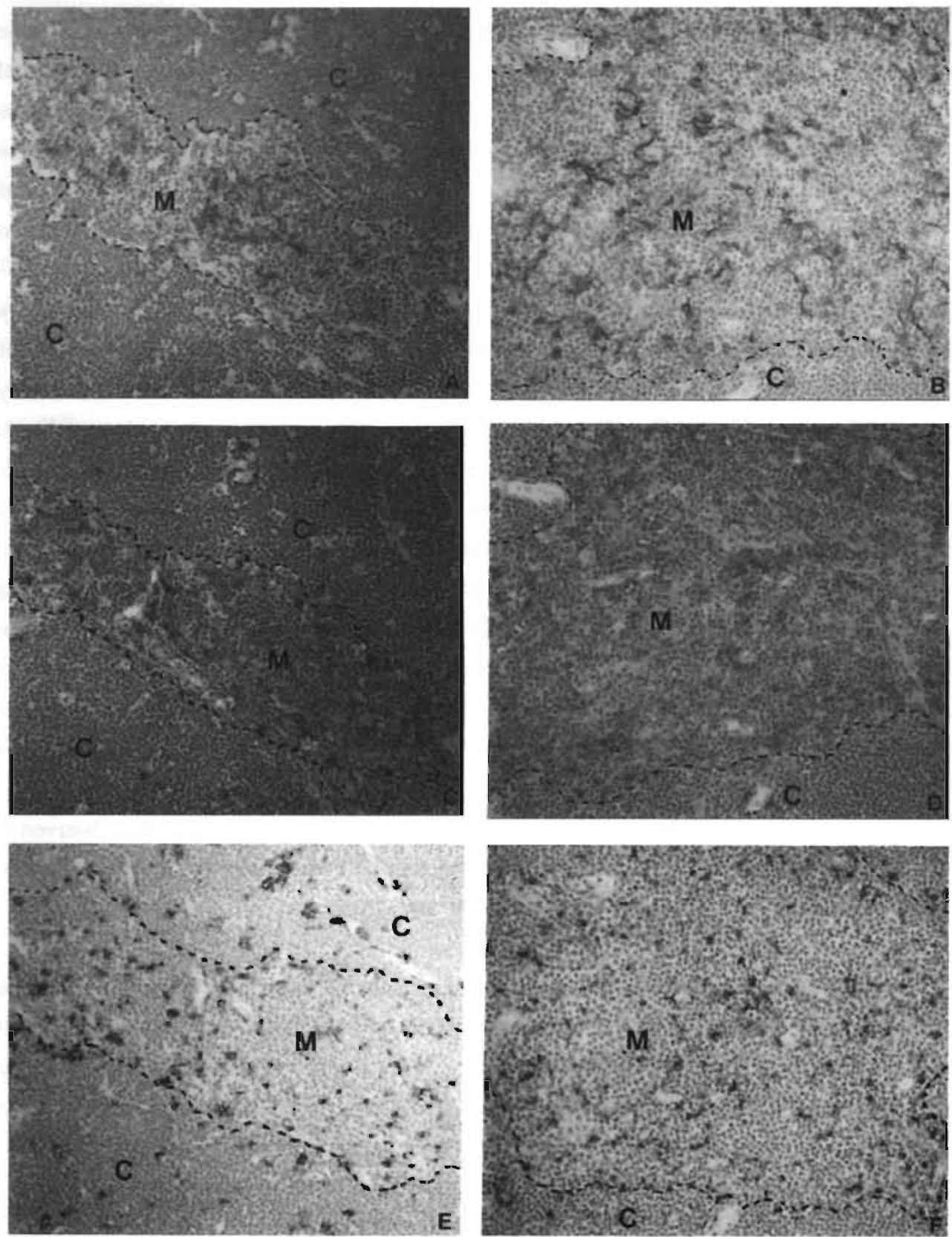

Figure 2: Thymuses from $X-B M C s A(A, C$ and $E)$ and $X-B M O O(B, D$ and $F)$ rats isolated at 2 weeks after irradiation and BMT. Cortex-medulla border is indicated by dotted line; $M$ : medulla, $C$ : cortex. $A$ and $B ; D C$ as recognised by mAb OX62, C and $D$; $\mathbb{L} 2$ receptor present in the medulla on $D C$ as recognised by $m A b O X 39, E$ and $\mathrm{F}$; Macrosialin, present in $\mathrm{M \emptyset}$ and $\mathrm{DC}$ as recognised by mAb EDI. 
Table II

\begin{tabular}{|c|c|c|c|c|}
\hline \multirow{3}{*}{ OO-treated } & \multirow{3}{*}{$\begin{array}{l}\text { thymocyte numbers } \\
\text { (fig. 1) } \\
\text { nomnal; steady }\end{array}$} & \multirow{3}{*}{$\begin{array}{c}\text { relative amount of } \\
\text { TCR } \alpha \beta^{\text {high }} \text { cells (fig. } 4 \text { ) }\end{array}$} & \multicolumn{2}{|c|}{ epithelial free area's related to } \\
\hline & & & the septea & the medulla \\
\hline & & & normal & absent \\
\hline CsA-treated & normal; steady & $\begin{array}{c}\text { decrease untill week } 3 \text {, } \\
\text { slow recovery }\end{array}$ & numnal & presint \\
\hline X-BM OO-treated & $\begin{array}{l}\text { decteased, slow and } \\
\text { incomplete recovery }\end{array}$ & normal from week 2 & flat & absent \\
\hline X-BM CsA-trcated & $\begin{array}{l}\text { decreased, slow and } \\
\text { incomplete recovery }\end{array}$ & $\begin{array}{c}\text { decrease till week } 3 \text {, slow } \\
\text { recovery }\end{array}$ & flat & present \\
\hline
\end{tabular}

the septae and capsule became very flat. Furthermore, after 2 weeks, vast area's void of epithelium developed surrounding the medulla. The medulla remained relatively small as determined by the medullary epithelium markers HIS39 and ED20. Thymuses from X-BM CsA-rats showed no difference in the epithelium cell pattern compared to CsA-thymuses at 2 weeks after irradiation, except for the absence of the flat epithelial free area's close to the septae and capsule in the CsA-thymuses. Overall, these changes were especially clearly visualised by the mAb OX6, recognising MHC class II present on epithelial cells, MØ, and DC (Fig. 3). In $\mathrm{X}$-BM OO-rats, irradiation damage seemed restored within two weeks. Typically, the epithelial free ares's close to the septae and capsule were very flat as in X-BM CsA-thymuses, but the epithelial free area's around the medulla were not observed.

Macrophages The presence of M $\varnothing$ was examined with the MAb's EDl (nonocytes, M $\emptyset$, and $\mathrm{DC}$ ) and ED2 (cortical MØ). In X-BM CsA and X-BM OO-thymuses, $48 \mathrm{hr}$ after irradiation, in the cortex the relatively radio-resistant $M \emptyset$ were packed very densely against each other due to the disappearance of cortical thymocytes. As soon as 2 weeks after irradiation, EDI and ED2-positive $\mathrm{M} \emptyset$ were normally distributed throughout the cortex, both in X-BM CsA and XBM OO-thymuses. In CsA-thymuses, ED2 distribution in the cortex was not disturbed by CsA. ED2-positive cells never were observed in the medulla, as identified by the localization of the morphological difference between cortical and medullary thymocytes, in any of the thymus sections of all four groups we studied. In the epithelial free area's surrounding the medulla, EDI and ED2-positive cells were present in a normal distribution, comparable to the EDI and ED2 distribution in the cortex. The distribution of ED1-positive M $\emptyset$ in the medulla was normal 2 weeks after irradiation and seemed unaffected by the C'sA treatment. 

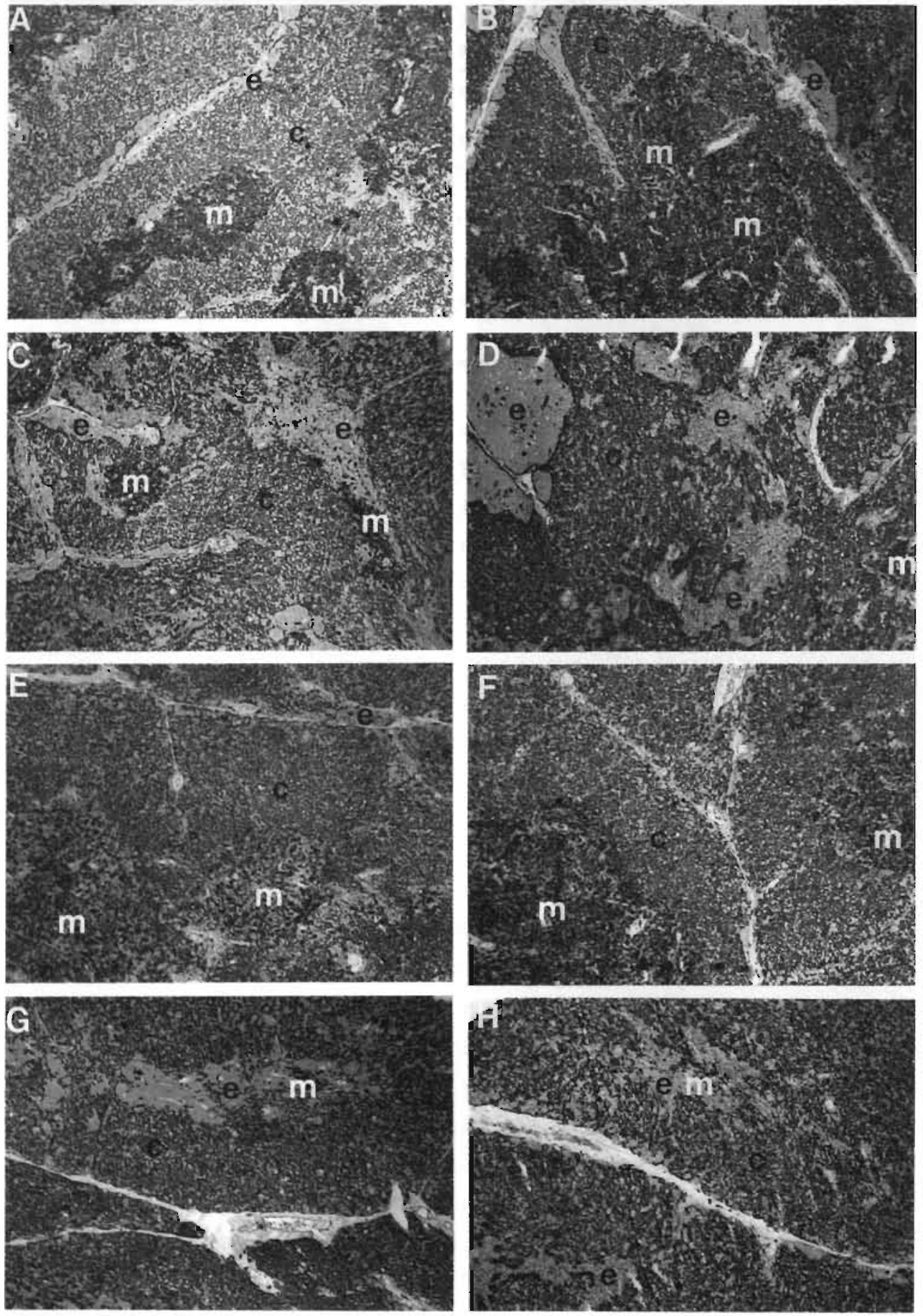
Figure 3: Thymuses from $O O(A, B), C s A(C, D), X-B M O O(E, F)$ and $X-B M C s A(G, H)$ rats at 2 and 4 weeks after initiation of the experiment. Sections were stained with mAb OX6 recognising MHC class II (RTIB) present on epithelial cells and DC. A, C, E and F; week 2; B, D, F and G; week4. (e: epithelial free area's void of MHC class II, $c$ : cortex with fine reticular epithelium, and $\mathrm{m}$ : medulla with DC and epithelium) In $\mathrm{C}$ and D $(\mathrm{Cs} A)$ and $\mathrm{G}$ and $\mathrm{H}(\mathrm{X}-\mathrm{BM} \mathrm{CsA})$ arrows are indicating the small medulary remnants.

Thymocytes The thymocytes have been studied with OX19, R73 (both expressed low in the cortex and high in the medulla), HIS45 (specific for medullary thymocytes). OX8, and W3/25 (in the cortex all thymocytes are positive, whereas in the medulla, approximately two-third is W3/25-positive and one-third is OX8-positive). The antigen expression recognised by these mAb's was not changed in any of the observed thymic sections at any time. The only difference was observed in the distribution. In X-BM CsA-thymuses 2 weeks after irradiation, a normal cortex and a small medulla could be detected like in CsA-thymuses. In the epithelial free area's in the vicinity of the medulla, as formed by the CsA treatment, and in the epithelial free area's close to the septae and capsule, the thymocytes had a cortical phenotype. In X-BM $\mathrm{OO}$ and OO-thymuses the distribution was normal. Overall, the distribution described was according to the stromal cell distribution defining cortex and medulla. After cessation of the

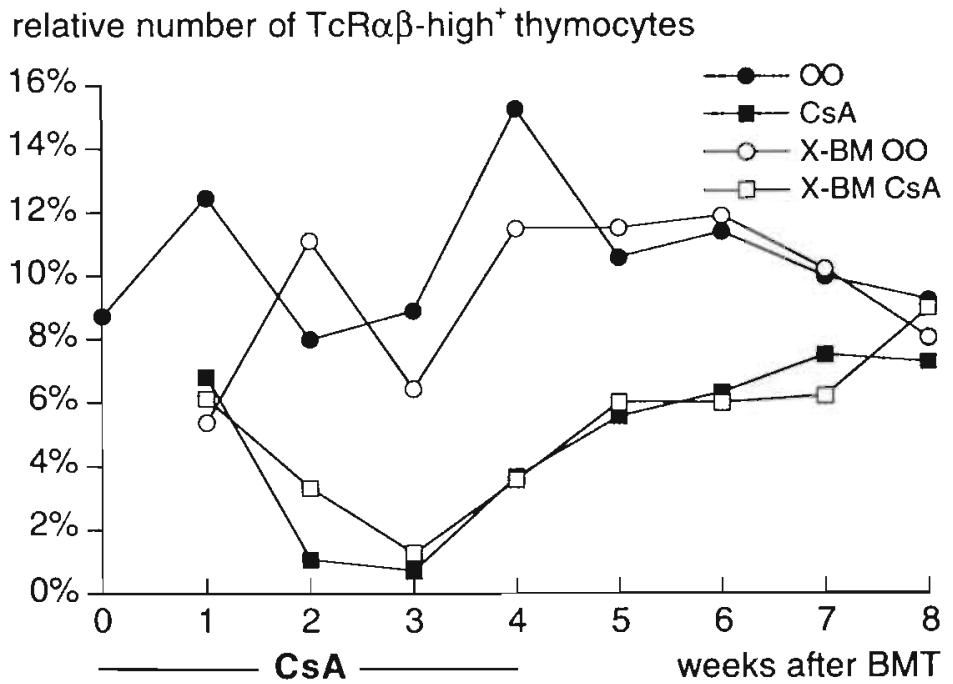

Figure 4: Relative number of TCR $\alpha \beta^{\text {high }}$ thymocytes. Every week thymocytes were assessed for their expression of CD4, CD8 and TCR $\alpha \beta$ using tri-colour flow-cytometry. Rats were treated with CsA from week 0 up to week 4. Using a life gate 10,000 cells per sample were analysed. Per group two thymuses were analysed and the average relative amount of TCR $\alpha \beta^{\text {high }}$ thymocytes is shown. OO-thymuses were assessed from week 0 , thymuses of CsA, X-BM OO and X-BM CsA-rats were tested from week I until week 8. 
CsA treatment both X-BM CsA and CsA-thymuses gradually recovered as stated above, and the distribution of cortical and medullary thymocytes resembled the normal situation. At the onset of disease, a disturbance in thymic morphology was observed affecting cortex and medulla (as described by Beschorner et al. (16)). This was associated with a reduction of thymocyte number (Fig. 1) and a decrease of thymic size.
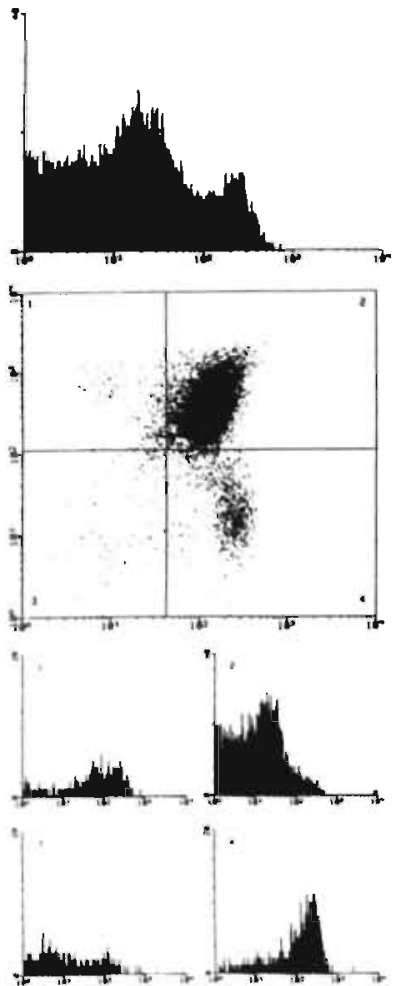

$\infty$
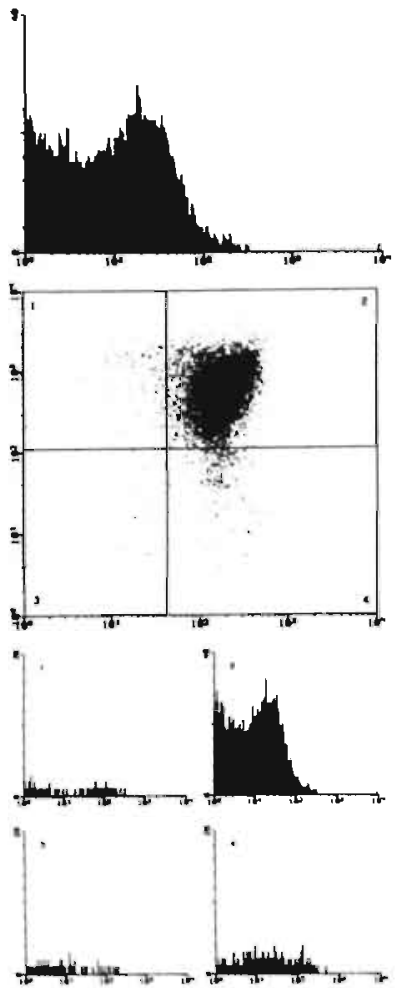

CsA
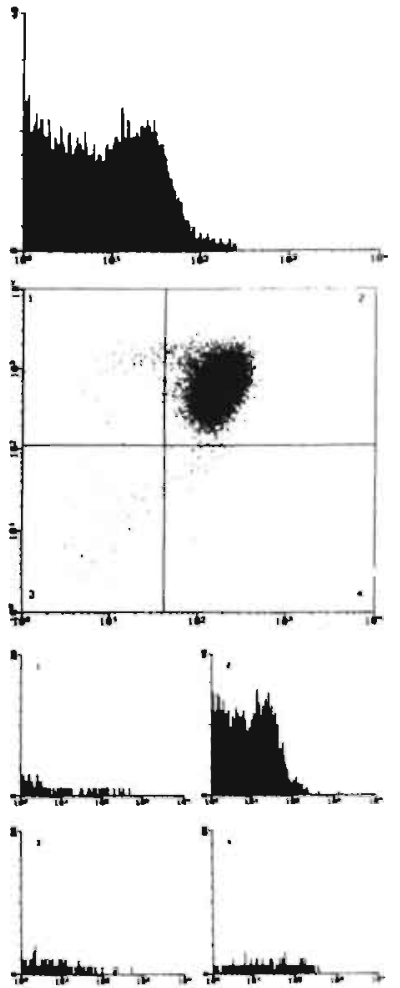

$\mathrm{X}-\mathrm{BM} \operatorname{Cs} \mathrm{A}$

Figure 5: By tri-colour floweylometry the CD4, CD8 and TCR $\alpha \beta$ expression of thymocytes, isolated from thymuses at week 4, was assessed. Using a life gate 10,000 cells per sample were analysed. The first column shows the analysis of a control thymus (OO), in the second column a CsA treated thymus (CsA) is analysed. and in the third column a thymus from an irradiated and CSA treated rat (X-BM CsA) is analysed. In the upper panels the total expression of TCR $\alpha \beta$ is shown. The middle panels show the dot plot analysis for CD4 (FITC) and CD8 (PE) for the same thymocyte populations. Per quadrant the TCR $\alpha \beta$ expression is depicted in the lower

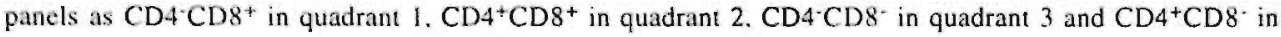
quadrant 4. Notice the presence of TCR . $^{\text {high }}$ cells in quadrant $I$ and 4 of the OO-thymus and the absence in the CsA and X-BM CsA-thymuses due to the strong decrease of CD4 and CD8 SP thymocytes, rather then not expressing TCR $\alpha \beta$ by these cells. 
By tri-colour flowcytometry, we studied the thymocyte populations with respect to the antigens $\mathrm{CD} 4, \mathrm{CD} 8$, and TCR $\alpha \beta$. In X-BM CsA-thymuses the number of TCR $\alpha \beta^{\text {high }}$ thymocytes remained very low during CsA administration (Fig. 4), whereas in X-BM OOthymuses the strong depletion of the thymocytes was overcome as soon as 2 weeks after irradiation (Fig. 4). In CsA-thymuses the TCR $\alpha \beta^{\text {high }}$ thymocytes also deminished upon CsA administration (Fig. 4). Tri-colour analysis showed that in X-BM CsA and CsA-thymuses the medullary CD4 and CD8 SP TCR $\alpha \beta^{\text {high }}$ thymocytes disappeared, whereas the cortical CD4CD8 DP TCR $\alpha$ Bintermediate thymocytes were unaffected (Fig. 5). After the CsA treatment was stopped, the number of CD4 and CD8 SP TCR $\alpha \beta^{\text {high }}$ cells started to normalize in X-BM CsA and CsA-thymuses. As CsA-AI developed, the total number of thymocytes was reduced, but the relative number of CD4 and CD8 SP TCR $\alpha \beta^{\text {high }}$ cells remained the same. All these changes in thymocyte population were in accordance with the changes observed by immunohistochemistry.

The Effects of Thymectomies Performed after Irradiation or CsA treatment To evaluate the effects of an abrogated recovery after irradiation or CsA treatment only, thymectomies were performed. Because the presence of the stromal microenvironment recovers in the second week after irradiation, the possible generation of autoreactive $\mathrm{T}$-cells during this period was evaluated by thymectomies, preventing subsequently the generation of regulatory $\mathrm{T}$-cells in the thymus. At days 7, 10, and 14 after irradiation and consecutive BMT each time, $3 \mathrm{X}$-BM OOrats were thymectomized and daily observed for the development of CsA-AI. None of these animals developed macroscopical signs of CsA-AI within a period of 3 months after thymectomy.

In order to test the alternative hypothesis that the effect of irridiation can be replaced by thymectomy after the CsA treatment, two groups of 12 CsA-rats were thymectomised at day 28 directly after a continuous course of CsA administration. Again, no macroscopical signs of CsA-AI developed within a period of 3 months after thymectomy.

\section{Discussion}

The induction of CSA-AI requires the combination of lethal irradiation and syngeneic bone marrow reconstitution and the treatment with CsA for a given period. Early after irradiation, the thymus morphology is very much perturbed. Because the thymocyte population has almost completely disappeared, stromal cells are densely packed. Therefore, the presence and distribution of specific stromal cell types are difficult to determine immunohistochemically. Two weeks after irradiation the thymus is repopulated with thymocyles and a morphologically 
distinguishable cortex and medulla are formed. Whereas the cortex morphology and size are normal, the restoration of the medulla is strongly inhibited by the CsA treatment. The presence of the medullary DC and epithelial cells is reduced proportionally to the small size of the medulla; however, the distribution of these stromal cells in the shrunken medulla is normal.

The effects of CsA on the thymus are still obscure. CsA causes a strong involution of the thymic medulla and a reduction of DC in a dose-dependent manner (39). There is increasing evidenci that C $\mathrm{A}$ interferes with the early steps in $\mathrm{T}$ cell activation by inhibiting the transcription of genes involved in cytokine production (1). Similar events occur in the maturation steps from cortical double-positive thymocytes into single-positive medullary thymocytes. A cascade of activation events is supposed to be essential in which several cytokines are produced (reviewed by Ritter and Boyd, 1993 (6). It has been shown that the medullary stroma is highly dependent upon the presence of TCR $\alpha \beta^{\text {high }}$ thymocytes $(40,41)$. A cytokine-driven network of factors produced by stromal cells and thymocytes might be very important for the maintenance of the medulla. The development of medullary DC probably is dependent on the production of cytokines, such as GM-CSF and LL2. Therefore, an effect on thymocyte maturation probably also involves an influence on DC maturation and turnover. On the other hand, the thymocytes are highly dependent on the stromal cells for their selection. It has been suggested that the absence of stromal cells in CsA-treated thymuses is responsible for the leakage of autoreactive cells to the periphery. In this study, we showed that the antigenic density and distribution of these stromal cells are not disturbed. Thus, the role of CsA in inhibiting negative selection is not explained by this activity of CsA. It has been described that CsA also inhibits apoptosis (42-44). Therefore, it seems likely that thymocytes that are no longer allowed to become activated due to the presence of CsA escape apoptosis and leave the thymus unselected. Although CsA treatment causes the formation of "forbidden TCR BV" possible autoreactive T-cells $(8,45), \mathrm{CsA}$ treatment alone is not sufficient to cause disease (22).

After irradiation and BMT, the presence of the thymus is essential during the first two weeks of CsA administration for the development of CsA-AI (4, 5). During this period the effects of irradiation must be overcome, and a strong influx of thymocytes is observed. The presence of medullary DC is hard to determine and it is tempting to suggest that a lack of negative selection might occur during this period due to the absence of DC. However, DC are relatively radio resistant (19) and thymectomies of X-BM OO-rats at 7, 10, or 14 days after irradiation and BMT did not induce autoimmune phenomena. Hence, the T-cells that mature early after irradiation in X-BM OO-rats do not form an autoreactive population capable of inducing autoimmunity as they do in X-BM CsA-rats. 
Our data show morphological changes in thymic architecture, especially in the distribution of cortex and medulla. However, it seems that there are no essential differences found in thymuses from X-BM CsA-rats compared to CsA-rats, regarding the presence of thymic stromal cells. Cells essential for thymic selection are present, and the phenotype of the stromal cells and thymocytes is normal. At the onset of disease, the thymus seems to be one of the organs affected in CsA-AI. Thymus morphology shows that this effect probably is not mediated by corticosteroids as induced by a stress-response, but that the thymus is one of the target organs of CsA-AI (16). Although we know that the thymus is allowed to recover after irradiation, albeit in an altered fashion due to CsA administration, very often no thymic remnants are found in the late acute phase of disease. In X-BM CsA-rats, thymectomies performed directly after the cessation of CsA administration do not influence the course of disease, indicating the essential role for the thymus early after irradiation during CsA treatment, but not in the period thereafter. Inability to recover after CsA cessation, however, is not an explanation for development of discase as stated by others (22), because in our study thymectomies performed directly after the cessation of CsA treatment in CsA-rats does not cause CsA-AI. Because irradiation is essential to evoke CsA-AI, it is likely that there is an additional effect on the peripheral immune system that normally suppresses effectively autoreactive $T$-cells leaking from the thymus during CsA treatment. The role and characteristics $0:$ this peripheral counterpart in the induction of CsA-AI are described in chapter 5 .

\section{Acknowledgements}

The authors wish to thank Prof. Th. Hünig (Würzburg, Germany), Prof. M. Miyasaki (Tokyo, Japan), Dr. C.D. Dijkstra (Amsterdam, the Netherlands), Dr. J. Kampinga (Groningen, the Nitherlands), Dr. M. Brenan (Oxford, UK) and Dr. B. de Geus (Leiden, the Netherlands) for the generous gift of monoclonal antibodies. Additionally we wish to thank Prof. Dr. A. Kruisheek and Dr. L. Jones (Netherlands Cancer Institute. Amsterdam, the Netherlands) for their help in developing the rat tri-colour flowcytometry, and Prof. Dr. J. Raus and J. Lambrechts (Dr. L. Willems Institute, Diepenbeek, Belgium) for providing their facilitics to analyse our flowcytometry samples. Furthermore we would like to express our gratitude towards Mrs. M-J. van de Gaar and M. Vaessen for their excellent technical assistance. 


\section{References}

1 Schreiber, S. L. and Crabtree, G. R. (1992) The mechanism of action of cyclosporin A and FK506. Immunol. Today. 13:136-141

2 Glazier, A., Tutschka, P. J., Farmer, E. R. and Santos, G. W. (1983) Graft-versus-host disease in cyclosporin A-treated rats after syngeneic and autologous bone marrow reconstitution. J. Exp. Med. 158: $1-8$

3 Jones, R. S., Hess, A. D., Mann, R. B., Piantadosi, S., Vogelsang, G. B., Farmer, E. R., Geller, R. B. and Sintus, G. W. (1989) Induction of graft-versus-host disease after autologous bone marrow transplantation. Lancet. 1:754-747

4 Surokin. R., Kimura, H., Schroder, K., Wilson, D. H. and Wilson, D. B. (1986) Cyclosporin-induced autsimmunity: Conditions for expressing disease, requirement for intact thymus, and potency estimates of autoimmune lymphocytes in drug-treated rats. J. Exp. Med. 164:1615-1625

5 Beijleveld, L. J. J., Damoiseaux, J. G. M. C., Wodzig. K. W. H. and van Breda Vriesman, P. J. C. (1995) $\mathrm{X}$-irradiation of the thymus is not required for the induction of Cyclosporin-A induced autoimmunity. Transplantation. 59:1601-1605

6 Ritter, M. A. and Boyd, R. L. (1993) Development in the thymus: it takes two to tango. Immunol. Today. 14:462-469

7 Gao, E. K., Lo, D., Cheney, R., Kanagawa, O and Sprent, J. (1988) Abnormal differentiation of thymocytes in mice treated with Cyclosporin A. Nature. 336: 176-179

8 Jenkins, M. K., Schwartz, R. H. and Pardoll, D. M. (1988) Effects of Cyclosporin A on $T$ cell development and clonal deletion. Sicieme. 241:1655-1658

9 Kanariou, M., Huby, R., Ladyman, H., Colic, M., Sivolapenko, G. and Lampert, 1. (1989) Immunosuppression with cyclosporin $\mathrm{A}$ alters the thymic microenvironment. Clin. Exp. Immunol. 78:263-270

10 Tanaka, M., Shihonara. K., Fukumoto, T., Tanaka, H. and Kaneko, T. (1988) Effect of cyclosporin A on rat thymus: time course analysis by immunoperoxidase technique and flow cytometry. Clin. Exp. Immunol. 72:216-221

11 Schuurman, H.-J., Loveren, v. H., Rozing, J., van Dijk, A., Loeber, J. G. and Vos, J. G. (1990) Cyclosporin and the rat thymus. An immunohistochemical study. Thymus. 16:235-254

12 Ritter, M. A and Ladyman, H. M. (1991) The effects of cyclosporin on the thymic microenvironment and T cell development. In Thymus Update. M.D. Kendall and M.A. Ritter, \$ditors. Harwood Acad Press, Chur. 157-177.

13 Bruijntjes, J. P., Kuper, F., Robinson, J. E. and Schuurman, H.-J. (1993) Epithelium free area in the thymic cortex of rats. Dev. Immunol. 3:113-122

14 Beschorner, W. E. and Armas, O. A. (1991) Loss of medullary dendritic cells in the thymus after cyclosporine and irradiation. Cell. Immunol. 132:505-514

15 de Waal, E. J.. Rademakers, L. H. P. M. Schuurman, H. J. and van Loveren, H. (1992) Interdigitating cells in the rat thymus during Cyclosporin A treatment: ultrastructural observations. Thymus. 20:163170

16 Beschomer, W. E. Hess, A. D., Shinn, C. A. and Santos, G. W. (1988) Transfer of Cyclosporineassociated syngeneic graft-versus-host disease by thymocytes. Transplantation. 45:209-215 
17 Mulder, A. H., Visser, J. W. M., Zoetelief, J. and van Bekkum, D. W. (1988) The entry of the prothymocyte into the thymus after lethal irradiation and bone marrow transplantation. II. Time of entry. Thymus. 11:29-41

18 Mulder, A. H. and Visser, J. W. M. (1988) The entry of the prothymocyte into the thymus after lethal irradiation and bone marrow transplantation. 1. Seeding of bone marrow cells into the thymus. Thymus. 11:15-27

19 Murawska, M. B., Duijvestijn, A. M., Klatter, F. A., Ammerlaan, W., Meedendorp, B. and Nieuwenhuis, P. (1991) Differential kinetics of various subsets of thymic bone marrow-derived stromal cells in rat chimeras. Scand. J. Immunol. 33:473-484

20 Beschorner. W. E., Di Gennaro, K. A., Hess, A. D. and Santos, G. W. (1987) Cyclosporine and the thymus: Influence of iradiation and age on thymic immunopathology and recovery. Cell. Immunol. 110:350-364

21 Cheney, R. T. and Sprent, J. (1985) Capacity of cyclosporine to induce uuto-graft-versus-host disease and impair intrathymic T cell differentiation. Transpl. Proc. 17:528-530

22 Beschorner, W. E., Ren, H., Phillips, J., Pulido, H. B. J., Hruban, R. H. and Hess, A. D. (1991) Prevention of syngeneic graft-versus-host disease by recovery of thymic microenvironment after cyclosporine. Transplantation. 52:668-674

23 Bos, G. M. J., Majoor, G. D., Willighagen, R. G. J. and van Breda Vriesman, P. J. C. (1989) Chronic cycluspurinc-induced autnimmune discase in the rat: a new experimental model for scleroderma. $J$. Invest. Dermatol. 93:610-615

24 Timatani, T. and Miyasaka, M. (1990) Identification of monoclonal antibodies reactive with the rat homolog of ICAM-1, and evidence for a differential involvement of ICAM-1 in the adherence of resting versus activated lymphocytes to high endothelial cells. Int. Inmunol. 2:165-171

25 Dijkstra, C. D., Döpp, E. A., Joling, P. and Kraal, G. (1985) The heterogeneity of mononuclear phagocytes in lymphoid organs: distinct macrophage subpopulations in the rat recognized by monoclonal antibodies ED1, ED2 and ED3. Immunology. 54:589-599

26 Damoiseaux, J. G. M. C., Döpp, E. A., Neefjes, J. J., Beelen, R. H. J. and Dijkstra, C. D. (1989) Heterogeneity of macrophages in the rat evidenced by variability in determinants: two new anti-rat macrophage antibodies against a heterodimer of 160 and $95 \mathrm{kd}$ (CD11/CD18). J. Leukocyte Biol. 46:556-564

27 Kampinga, J., Kroese, F. G. M., Duijvestijn, A. M., Murawska, M. B., Pol, G. H. and Nieuwenhuis, P. (1987) The rat thymus microenvironment: Subsets of thymic epithelial cells defined by monoclonal antibodies. Transpl. Proc. 19:3171-3174

28 Aspinall, R. and Kampinga, J. (1989) A novel lymphocyle surface antigen recognized by the monoclonal antibody HIS45. Thymus. 13:245-52

29 McMaster, W. R. and Williams, A. F. (1979) Identification of la glycoproteins in rat thymus and purification from rat spleen. Eur. J. Immunol. 9:426-433

30 Mason, D. W. and Williams, A. F. (1980) The kinetics of antibody binding to membrane antigens in solution and at the cell surface. Biochem. J. 187:1-20

31 Brideau, R. J., Carter, P. B., McMaster, W. R., Mason, D. W. and Williams, A. F. (1980) Two subsets of rat $T$ lymphocytes defined with monoclonal antibodies, Eur. J. Immunol. 10:609-615 
32 Fukumoto, T., McMaster, W. R. and Williams, A. F. (1982) Mouse monoclonal antibodies against rat major histocompatibility antigens. Two Ia antigens and expression of $\mathrm{Ia}$ and class $\mathrm{I}$ antigens in rat thymus. Eur. J. Immunol. 12:237-243

33 Dallman, M. J., Thomas, M. L. and Green, J. R. (1984) MRC OX-19: a monoclonal antibody that labels rat T lymphocytes and augments in vitro proliferative responses. Eur. J. Immunol. 14:260-267

34 Paterson, D. J., Jefferies, W. A., Green, J. R., Brandon, M. R., Corthesy, P., Puklavec, M. and Williams, A. F. (1987) Antigens of activated rat T lymphocytes including a molecule of 50,000 Mr detected only on CD4 positive 'T blasis. Mol. Immunol. 24:1281-1290

35 Brenan, M. and Puklavec, M. (1992) The MRC OX-62 antigen: a useful marker in the purification of rat veiled cells with the biochemical properties of an integrin. J. Exp. Med. 175:1457-1465

36 Hünig, T., Wallny, H.-J., Hartley, J. K., Lawetzky, A. and Tiefenthaler, G. (1989) A monoclonal antibody to a constant determinant of the ralt $\Upsilon$ cell antigen receptor that induces T cell activation. J. Exp. Med. $169: 73-86$

37 Williams, A. F., Galfre, G. and Milstein, C. (1977) Analysis of cell surfaces by xenogeneic myelomahybrid antibodies: differentiation antigens of rat lymphocytes. Cell. 12:663-673

38 Joling. P., Tielen, F. J., Vaessen, L. M. B., Huijbregts, J. M. A. and Rozing, J. (1985) New markers on T cell subpupulations defined by monoclonal antibodies. Transplant. Proc. 17:1857-1860

39 Damoiseaux, J. G. M. C., Beijleveld, L. J. J, and van Breda Vriesman, P. J. C. (1994) The effects of in vivo cyclosporin A administration on rat thymic dendritic cells. Clin. Exp. Immunol. 96:513-520

40 Shores, E. W., Ewijk, W. v. and Singer, A. (1991) Disorganization and restoration of thymic medullary epithelial cells in T-cell receptor-negative SCID mice: evidence that receptor-bearing lymphucytes: influence maturation of the thymic microenvironment. Eur. J. Immunol. 21:1657-1661

41 Thomson, A. W. (1992) The spectrum of action of new immunosuppressive drugs. Clin. Exp. Immunol. 89:170-173

42 MacPherson, G. G. (1989) Properties of lymph-borne (veiled) dendritic cells in culture: I. Modulation of phenotype, survival and function: partial dependence on GM-CSF. Immunology. 68:102-107

43 McCarthy, S. A., Cacchione, R. N., Mainwaring, M. S. and Cairns, J. C. (1992) The effects of immunosuppressive drugs on the regulation of attivation-induced apoptutic cell death in thymocytes. Transplantation. 54:543-547

44 Yasutomi, D., Odaka, C., Saito, S., Niizeki, H., Kizaki, H. and Tadakuma, T. (1992) Inhibition of programmed cell death by Cyclosporin $\mathrm{A}$; preferential blocking of cell death induced by signals via TCR/CD3 complex and its mode of action. Immunology 77:68-74

45 Bryson, J. S., Caywood, B. E. and Kaplan, A. M. (1991) Relationship of cyclosporin A-mediated inhibition of clonal deletion and development of syngeneic graft-versus-host disease. J. Immunol. $147: 391 \cdot 397$ 


\section{CHAPTER 4 The effects of in vivo Cyclosporin-A administration on rat thymic dendritic cells}

Jan G.M.C. Damoiseaux, Leo J.J. Beijleveld and Peter J.C. van Breda Vriesman.

The Department of Immunology, Faculty of Medicine, University of Limburg, Maastricht, the Netherlands.

Published in: Clinical and Experimental Imunology, Volume 96, pages 513-520, 1994

\section{Summary}

Cyclosporin A (CsA) induces a graft-versus-host-like disease (GVHD) in lethally irradiated Lewis rats reconstituted with syngeneic bone marrow. The role of the thymus in the generation of disease has been unequivocally established. It has been suggested that the CsA induced disappearance of thymic dendritic cells (DC) is responsible for the generation of the autoaggressive cells. In this study we quantify the loss of DC upon in vivo CsA administration in normal and bone marrow-reconstituted rats using an isolation technique. The phenotype of the $\mathrm{DC}$ is determined using monoclonal antibodies $(\mathrm{mAb})$ recognizing antigens which are expressed on thymic medullary DC. Furthermore, the functional aspects are assessed by determining the antigen presentation capacity. Short-term CsA exposure clearly affects the number of DC isolated from the thymus in a concentration dependent manner. However, in all instances a substantial number of DC can be isolated from CsA treated animals. These isolated DC exhibit an identical phenotype and function as DC isolated from control animals. Therefore the partial deficiency of DC can not be held as essential for loss of tolerance. 


\section{Introduction}

Cyclosporin A (CsA) is a fungal metabolite with potent immunosuppressive properties. Paradoxically. under certain circumstances CsA may also induce autoimmune disease $(1,2)$. Lethally irradiated Lewis rats reconstituted with syngeneic bone matrow and given CsA for 4 weeks develop, after withdrawal of CsA, thymus dependent autoimmune disease (CsA-AI) (1). The symptoms of discase, as well as the histologic lesions, are similar to those seen in acute graft-verus-host disease (GVHD) after allogeneic bone marrow transplantation (1-3).

Several studies have demonstrated an essential role for the thymus in the induction of CsAAI $(1,4,5)$. Daily administration of the immunosuppressive drug CsA causes strong involution of thymic medulla due to a maturation arrest of double positive thymocytes in the cortex (6). In the mouse CsA treatment alone has been shown to result in the generation of autoreactive $T$ cells (7). However, the defective clonal deletion in the thymus is not sufficient for triggering CsA-AI. The presence of regulatory $\mathrm{T}$ cells in the periphery prevents the development of CsA-AI. Therefore, total body irradiation is essential for induction of disease by destroying this suppressor circuit. Besides the effect of CsA on the thymocytes, the Major Histocompatibility Complex (MHC) class II-positive cells as well as the EDI-positive cells are almost completcly absent in the rat thymic medulla after CsA administration $(8,9)$. The absence of these antigens has been assuciated with the disappearance of the medullary dendritic cells (DC). Thymic DC are considered to have a major role in thymocyte maturation as well as in tolerance induction by clonal deletion (10). Therefore the observed reduction in medullary DC has been thought responsible for the generation of autoreactive $\mathrm{T}$-cells during CsA administration.

In our model of CsA-AI we use comparatively low concentrations of CsA in order to affect $T$ cell development in the thymus and do not observe the complete disappearance of DC in the thymic medulla using immunohistochemical methods (11). Since in situ DC are difficult to detect whereas in vitro DC are more easily identified by their morphological features, we have quantitated the CsA-induced changes in DC number using an isolation technique. Therefore rats were treated for up to two weeks with various concentrations of CsA in combination with or without previous irradiation and bone marrow transplantation (BMT). DC were purified after collagenase digestion of the thymus using density gradient centrifugation. Low density cells were identified as DC based on morphological characteristics (irregular-shaped, eccentric nucleus, and extensive cell processes) and strong expression of MHC class I and II antigens. In addition the DC were phenotypically and functionally characterized. 


\section{Materials and Methods}

Animals Female inbred LEW rats (RT1 ${ }^{\text {l) }}$ were obtained from the Central Animal Facility of the University of Limburg, the Netherlands. The animals were maintained under specific pathogen free conditions until use and had free access to food and water. Rats were 6 weeks of age at the start of the experiment.

Cyclosporin A CsA, a gift from Sandoz Pharma. Ltd., Basel, Switzerland, was dissolved in olive oil $(\mathrm{OO})$ at a concentration of $7.5,15$, and $30 \mathrm{mg} / \mathrm{ml}$. Rats were weighed daily and received $7.5,15$, or $30 \mathrm{mg} \mathrm{CsA} / \mathrm{kg}(=1 \mathrm{ml} / \mathrm{kg}$ ) subcutaneously for the time indicated (CsArats). Control animals daily received $1 \mathrm{ml} \mathrm{OO} / \mathrm{kg}$ (OO-rats). Three to 4 animals were examined for each time point and CsA-concentration.

Irradiation and bone marrow transplantation (BMT) Rats were given a lethal dose of 8.5 Gy at $0.5 \mathrm{~Gy} / \mathrm{min}$ using a Röntgen irradiation machine (Philips MU15F/225 kV, Hamburg, Germany). The next day rats received $6 \times 10^{7}$ viable syngeneic bone marrow cells, collected from tibias and femurs, intravenously into a tail vein. Starting from the day of BMT rats daily received olive oil only (X-BM OO) or $7.5 \mathrm{mg} \mathrm{CsA} / \mathrm{kg}$ (X-BM CsA) for 14 days.

Monoclonal antibodies The reactivity with and function of the antigens recognized by the $\mathrm{mAb}$ used for immunocytochemistry are listed in table I. OX-6 (MHC class II antigens) (12), OX-18 (MHC class I antigens) (13), and OX-39 (CD25, LL-2 receptor) (14) were obtained from the ECACC (Salisbury, England); OX-62 (recognizing an integrin-like antigen specific for DC) (15) was kindly provided by Dr. M. Brenan (Oxford, England); EDl (CD68, macrosialin) (16) and ED8 (Complement Receptor type 3, CD1 lb/CD18) (17) were kindly provided by Dr. C.D. Dijkstra (Amsterdam, The Netherlands); and i A29 (CD54, ICAM-1) (18) was kindly provided by Dr. M. Miyasaka (Tokyo, Japan).

Dendritic cell isolation DC were isolated from thymus using a modification of the method described previously (17). The thymus was cut into small pieces and incubated for $90 \mathrm{~min}$ with $5 \mathrm{mg}$ collagenase (Collagenase CLS III, $116 \mathrm{U} / \mathrm{mg}$, Worthington, New Jersey, U.K.) and 0.1 mg DNase (Deoxyribonuclease DP, $1729 \mathrm{U} / \mathrm{mg}$, Worthington) in $10 \mathrm{ml}$ RPMI-1640 supplemented with penicillin/streptomycin and glutamine at $370 \mathrm{C}$. The suspension was gently pressed through nylon gauze and cultured overnight in RPMI- 1640 supplemented with $2 \mathrm{mM}$ glutamine, $100 \mathrm{U} / \mathrm{ml}$ penicillin, $100 \mu \mathrm{g} / \mathrm{ml}$ streptomycin, and $10 \% \mathrm{FCS}$, henceforth designated as culture medium. Then the non-adherent cell fractions were put onto $14.5 \%(\mathrm{w} / \mathrm{v}) \mathrm{Nycodenz}$ gradients (Nycomed A.S., Oslo, Norway) in RPMI-1640 with $3 \%$ serum and $5 \mathrm{mM}$ EDTA to prevent cell clustering. These gradients were centrifuged at $600 \mathrm{~g}$ at $200 \mathrm{C}$ for $20 \mathrm{~min}$, and the low density cells were collected from the interphases. These cells were cultured again for 2 hrs to remove the remaining macrophage contamination and the non-adherent cells were lurther enriched for DC on a second Nycodenz gradient as described above.

$T$ cell isolation $T$ cells were prepared from rat lymph node cell suspensions by passage over nylon wool columns to deplete B cells and adherent cells, as described before (19). An indirect 
Table I. List of mAb reactive with Dendritic Cells

\begin{tabular}{lllc}
\hline \hline $\mathrm{mAb}$ & Antigen & Function & Reference \\
\hline OX-6 & MHC Class II & Antigen Presentation & $(12)$ \\
OX-18 & MHC Class I & Antigen Presentation & $(13)$ \\
OX-39 & CD25 (IL-2R) & Binding IL-2 & $(14)$ \\
OX-62 & Integrin & Adhesion? & $(15)$ \\
ED1 & CD68 (Macrosialin) & Antigen processing ? & $(16)$ \\
ED8 & CR3 (CDIIb/CD18) & Adhesion & $(17)$ \\
1A29 & CD54 (ICAM-1) & Adhesion & $(18)$ \\
\hline \hline
\end{tabular}

method with Sheep anti mouse IgG coated magnetic beads (Dynal, Oslo, Norway) in combination with the mAb OX6 (MHC class II) and OX12 ( $\mathrm{K}$-light chain) was used to remove the contaminating non-T-cells. T-cells were used as responder cells in the proliferation assays.

Immunocytochemistry Cytocentrifuge preparations made from freshly isolated cells were airdried and fixed in a mixture of acetone and formaldehyde (40:1) for $10 \mathrm{sec}$. Slides were washed in PBS and incubated for 60 min with ascites or culture supernatants, diluted in PBS with $0.5 \%$ BSA. After washing in PBS, slides were covered with a 1:200 dilution of Rabbit anti mouse Ig peroxidase (Dakopatts, Copenhagen, Denmark) in PBS with $0.5 \%$ BSA and $3 \%$ normal rat serum for $30 \mathrm{~min}$. After washing with PBS, the slides were stained for peroxidase activity with 3,3'-diaminobenzidine-tetrahydrochloride (Sigma, St. Louis, $\mathrm{MO})(0.5 \mathrm{mg} / \mathrm{ml}$ in Tris- $\mathrm{HCl}$ buffer ( $\mathrm{pH} 7.6$ ), containing $0.01 \% \mathrm{H}_{2} \mathrm{O}_{2}$ ). Control slides were incubated in the same way, omitting the first step or using an isotype-matched irrelevant control mouse antibody. At least 200 cells were counted on eikh preparation.

Flowcytometry Single-cell suspensions were directly incubated for 30 min on ice with mAb diluted in PBS containing 0.5\% BSA and $10 \mathrm{mM}$ sodium azide (PBSAA). All incubations were performed in the presence of $5 \mathrm{mM}$ EDTA to prevent cell clustering. After washing in PBSAA cells were incubated for $30 \mathrm{~min}$ on ice in a 1:100 dilution in PBSAA of FITCconjugated Goat anti mouse Fab2 fragments (Cappel, Organon Teknika, Boxtel, The Netherlands). After washing with PBSAA cells were examined for fluorescence with a FACSort (Becton Dickinson) and analyzed with Lysys II software. Gating for the DC population was performed on the basis of the combination of forward versus sideward scatter profile, high expression of MHC class II antigens, and low autofluorescence.

Accessory Assay The response of purified LEW T-cells to PHA was measured by culturing $1 \times 10^{5}$ T-cells in $0.2 \mathrm{ml}$ culture medium with PHA ( $1 \mathrm{mg} /$ well; Difco, Detroit, USA) and various numbers of 2000 rad-irradiated LEW thymic DC in flat-bottom microtiter plates. After 48 hours, cells were pulsed with $0.25 \mathrm{mCi}\left[{ }^{3} \mathrm{H}\right] \mathrm{TdR}$ (Amersham International, Amersham, UK), were harvested 24 hours later and analyzed in a liquid scintillation counter. 
Mixed leukocyte reaction (MLR) The allogeneic MLR was performed by culturing purified BN T-cells $\left(1 \times 10^{5}\right.$ or $\left.2 \times 10^{5}\right)$ in $0.2 \mathrm{ml}$ culture medium with various numbers of 2000 radirradiated LEW thymic DC in round-bottom microtiter plates. After 48 hours, cells were pulsed with $0.25 \mathrm{mCi}\left[{ }^{3} \mathrm{H}\right] \mathrm{TdR}$, harvested 24 hours later and analyzed in a liquid scintillation counter.

\section{Results}

DC were enriched from an enzymatically digested thymus cell suspension by density gradient centrifugation. After overnight culturing large clusters of DC with thymocytes could be observed floating in the culture flasks. During the separation on Nycudenz gradients clustering of thymocytes with DC was prevented by the presence of $5 \mathrm{mM}$ EDTA. Macrophages and epithelial cells were removed by two adhesion steps. The remaining DC population had a purity varying between $70-90 \%$ as determined initially by morphological characteristies (irregularshaped, eccentric nucleus, and extensive cell processes) (Fig. 1). Immunocytochemical staining revealed that these cells also strongly expressed MHC class I and class II molecules. The contaminating population as determined on cytocentrifuge preparations was essentially composed of thymocytes; only few macrophages $(<5 \%)$ were encountered. The average yield per thymus was about $6 \times 105 \mathrm{DC}$. The average yield and purity of the DC population did not vary significantly between control animals of 6 to 8 weeks of age.
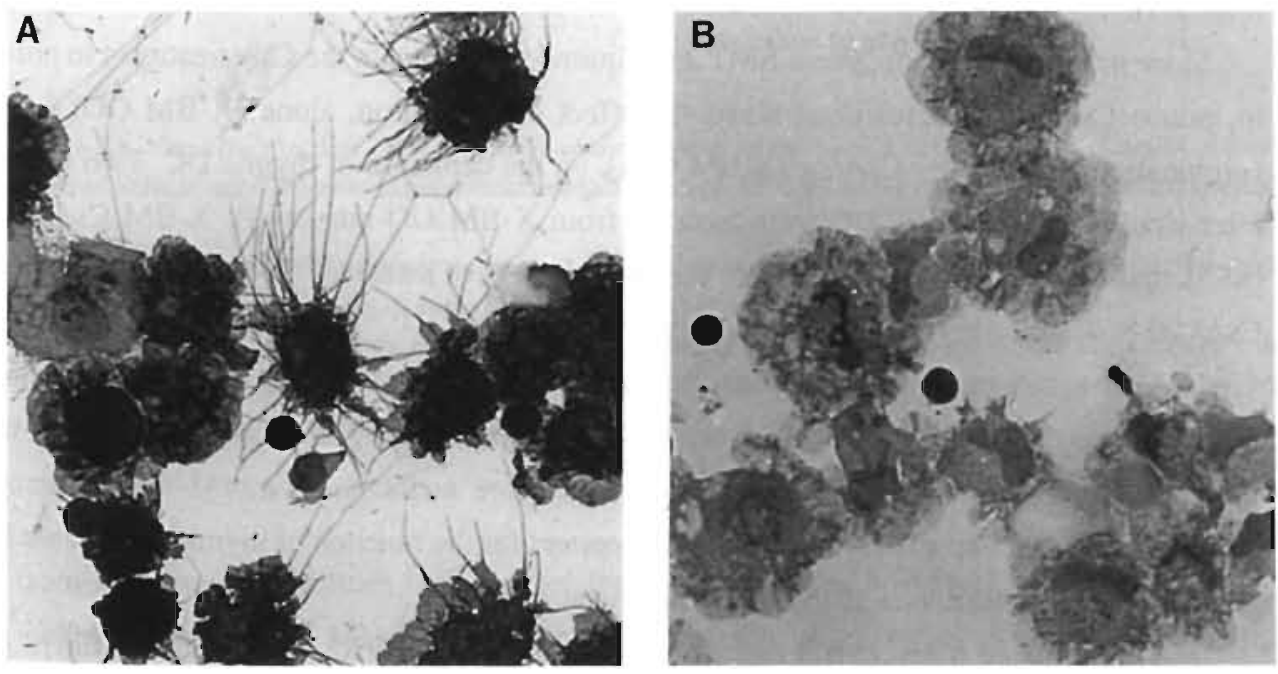

Figure 1. Cytocentrifuge preparations of isolated thymic DC immunocytochemically stained for the expression of MHC class II (A) or OX-62 (B). Thymic DC strongly express MHC class II antigens on their surface through which the extensive processes are clearly visible. The OX-62 staining is rather weak on the major subset of the thymic DC. 
DC isolated from CsA treated animals showed no morphological differences. Furthermore, no change in density of the DC, which might have influenced the yield by using gradient centrifugation, was observed by examining whether the high density cells were contaminated with cells showing dendritic morphology. Moreover, thymic DC lend to cluster strongly with thymocytes in suspension. Hardly any of such clusters were ohserved in the high density population. In cases that low numbers of DC were isolated the macrophage contamination was increased to $\pm 10 \%$. However, these macrophages had a swollen appearance and could easily be distinguished from DC.

In vive CsA administration of $7.5 \mathrm{mg} / \mathrm{kg}$ during a period of 14 days clearly affected the number of DC isolated from the thymus in two independent experiments. In the first week of treatment there was a slight decrease of $20-30 \%$. From day 10 onwards the effect was the strongest with a decrease of about 50-60\% (Fig. 2A). In one of the two experiments a slight but significant $(p<0.01)$ recovery was observed from day 10 to day 14 . Furthermore, the effect of CsA concentration on the number of isolated DC was determined at two different time points: 10 days and 14 days. The lowest CsA concentration $(7.5 \mathrm{mg} / \mathrm{kg}$ ) revealed that, compared to controls, only $40-50 \%$ of DC were isolated at day 10 and 14 . The two highest CsA concentrations ( 15 and $30 \mathrm{mg} / \mathrm{kg}$ ) resulted at both time points in the isolation of only 20 $30 \%$ of control DC numbers. This dosis-effect relation revealed a concentration dependent effect on the decrease in DC number. The maximal effect was obtained with $15 \mathrm{mg} \mathrm{CsA} / \mathrm{kg}$ (Fig. 2B).

Since irradiation and syngeneic BMT are required in addition to the CsA treatment in order to induce CsA-AI, we also determined the effect of irradiation, alone (X-BM OO) or in combination with $7.5 \mathrm{mg} \mathrm{CsA} / \mathrm{kg}$ (X-BM CsA), on the depletion of thymic DC. Two weeks after irradiation and BMT DC were isolated from X-BM OO-rats ( $n=3), X$-BM CsA-rats $(n=5)$, and OO-rats $(n=2)$. Compared to the controls in both instances (X-BM OO and X-BM CsA) $70-80 \%$ of the thymic DC were depleted (not shown).

In order to determine possible functional deficits of the thymic DC by CSA administration we determined the phenotype of the isolated cell population using immunocytochemistry on cytocentrifuge preparations and FACS analysis. Therefore we focussed on mAb that recognize antigens which are expected or known to he important for the function of thymic DC (Table I). All these $\mathrm{mAb}$ are reactive with the $\mathrm{DC}$ in the thymic medullat.

The DC isolated from control animals strongly expressed MHC class I and II antigens as determined by reactivity with respectively $\mathrm{mAb} O X-18$ and $\mathrm{OX}-6$. The expression of these antigens was used besides morphological criteria (irregular-shaped, eccentric nucleus, and extensive cell processes) for the identification of DC. Therefore, more or less by definition. all the DC were positive for OX-6 (Fig. IA) and OX-18. The same stands for the DC isolated 

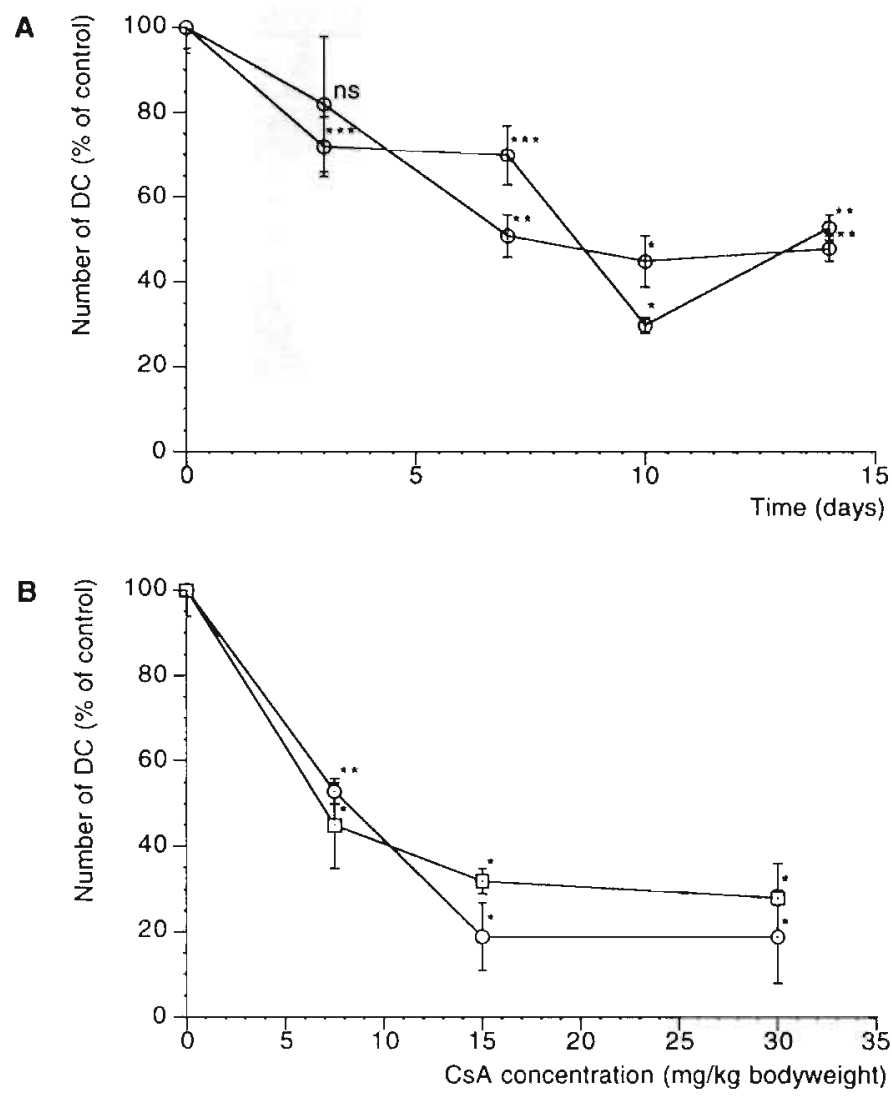

Figure 2A. The effect in time of in vivo CsA administration on the number of thymic DC. Control animals rcceived vehicle only, whereas experimental animals received $7.5 \mathrm{mg} \mathrm{CsA} / \mathrm{kg}$ daily. Two separate experiments are shown.

Figure 2B. The effect of CsA concentration on the number of thymic DC. Animals were treated with 0 (vehicle only), $7.5,15$, or $30 \mathrm{mg} \mathrm{CsA} / \mathrm{kg}$ daily for 10 days (squares) or 14 days (circles).

The number of DC obtained in the experimental groups $(n=3$ or $n=4)$ is presented as the percentage $( \pm S D)$ of the mean of the cuntrol group ( $n=3$ ). Statistical differences (Student's $t$ test) between the respective control and experimental groups are indicated $\left({ }^{*} p<0.001 ;{ }^{* *} p<0.01 ;{ }^{* *} p<0.05\right.$; or not significant (ns)).

from CsA treated animals. In none of these suspensions, however, cells with dendritic morphology lacking MHC class I or II expression, were observed on cytocentrifuge preparations. Most of the cells with dendritic morphology stained immunocytochemically with the mAb OX-39 (CD25, IL-2R), OX-62 (integrin), ED1 (CD68, macrosialin), and 1 A29 (CD54, ICAM-1). Although the mAb EDl is known as a pan-macrophage marker it also reacts with DC in a very specific way: staining of DC is restricted to a small spot near the nucleus in 
Table II. Effect of In vivo CsA. Administration on the Phenotype of Thymic Dendritic Cells

\begin{tabular}{lcccc}
\hline \hline $\mathrm{mAb}$ & $0 \mathrm{mg} / \mathrm{kg} \mathrm{CsA}$ & $7.5 \mathrm{mg} / \mathrm{kg} \mathrm{CsA}$ & $15 \mathrm{mg} / \mathrm{kg} \mathrm{CsA}$ & $30 \mathrm{mg} / \mathrm{kg} \mathrm{CsA}$ \\
\hline OX-6* & $82 \pm 3 \%$ & $70 \pm 3 \%$ & $65 \pm 3 \%$ & $75 \pm 2 \%$ \\
$\mathrm{OX}^{*} 18^{*}$ & $76 \pm 4 \%$ & $70 \pm 3 \%$ & $66 \pm 2 \%$ & $71 \pm 3 \%$ \\
$\mathrm{OX}^{*} 39^{* *}$ & $57 \pm 2 \%$ & $64 \pm 6 \%$ & $59 \pm 5 \%$ & $59 \pm 5 \%$ \\
$\mathrm{OX}^{* * *}$ & $81 \pm 4 \%$ & $78 \pm 1 \%$ & $77 \pm 6 \%$ & $\mathrm{ND}$ \\
ED $^{* *}$ & $87 \pm 4 \%$ & $91 \pm 3 \%$ & $83 \pm 2 \%$ & $\mathrm{ND}$ \\
ED8 $^{* *}$ & $16 \pm 4 \%$ & $15 \pm 2 \%$ & $17 \pm 5 \%$ & $\mathrm{ND}$ \\
$1 \mathrm{~A} 29^{* *}$ & $96 \pm 2 \%$ & $93 \pm 1 \%$ & $96 \pm 1 \%$ & $\mathrm{ND}$ \\
\hline \hline
\end{tabular}

Phenotype of thymic dendritic cells as determined by immuno-cytochemistry on cytocentrifuge preparations. Dendritic cells were isolated from animals that had been treated with different concentrations of CsA for 14 days. Dendritic cells were identified on the basis of morphological characteristics (irregular-shaped, eccentric nucleus, and extensive cell processes). "Since MHC class I and II are expressed by all dendritic cells, results for these markers are presented as percentages of the total cell population ( \pm SD). " Results obtained with the other markers are presented as percentages of the dendritic cell population $( \pm S D)$. ND, not determined.

contrast to the overall cytoplasm staining in macrophages. Only a minor subpopulation stained with the mAb ED8 (CR3, CD11b/CD18). In vivo CsA administration did not influence the phenotype as determined on cytocentrifuge preparations of the isolated DC: nor at different time points (not shown), neither with different CsA concentrations (Table II).

FACS-analysis was performed to determine eventual differences in the level of antigen expression. In the FACS-analysis the morphological criteria for identification of DC were lacking. However, most contaminating thymocytes could be excluded by gating for DC on the basis of the forward versus sideward scatter profile, whereas impurity caused by macrophages was eliminated by excluding autofluorescent cells from the DC gate. These gating procedures resulted in an increase in MHC class II expression from $\pm 75 \%$ to more than $95 \%$, whereas about $60 \%$ of the original cell number was recovered within the DC gate.

Phenotypic characterization of thymic DC by FACS analysis revealed strong expression of MHC class I and class II antigens, as well as CD54 (ICAM-1) on nearly all DC. Intermediate antigen levels were detected by the mAb OX-39 (CD25, IL-2R) and OX-62, staining the majority of DC, and ED8 (CR3, CD11b/CD18), staining a minor subpopulation. ED1 (CD68, macrosialin) expression was not observed by FACS-analysis. In vivo CsA administration did not influence the DC phenotype with respect to number of positive cells or staining intensity (Fig.3).

In order to examine possible functional effects of in vivo CsA administration the efficiency of thymic DC in the induction of T-cell proliferation was determined in an accessory assay and an MLR. In the absence of thymic DC as accessory cells, LEW $T$-cells failed to respond to 


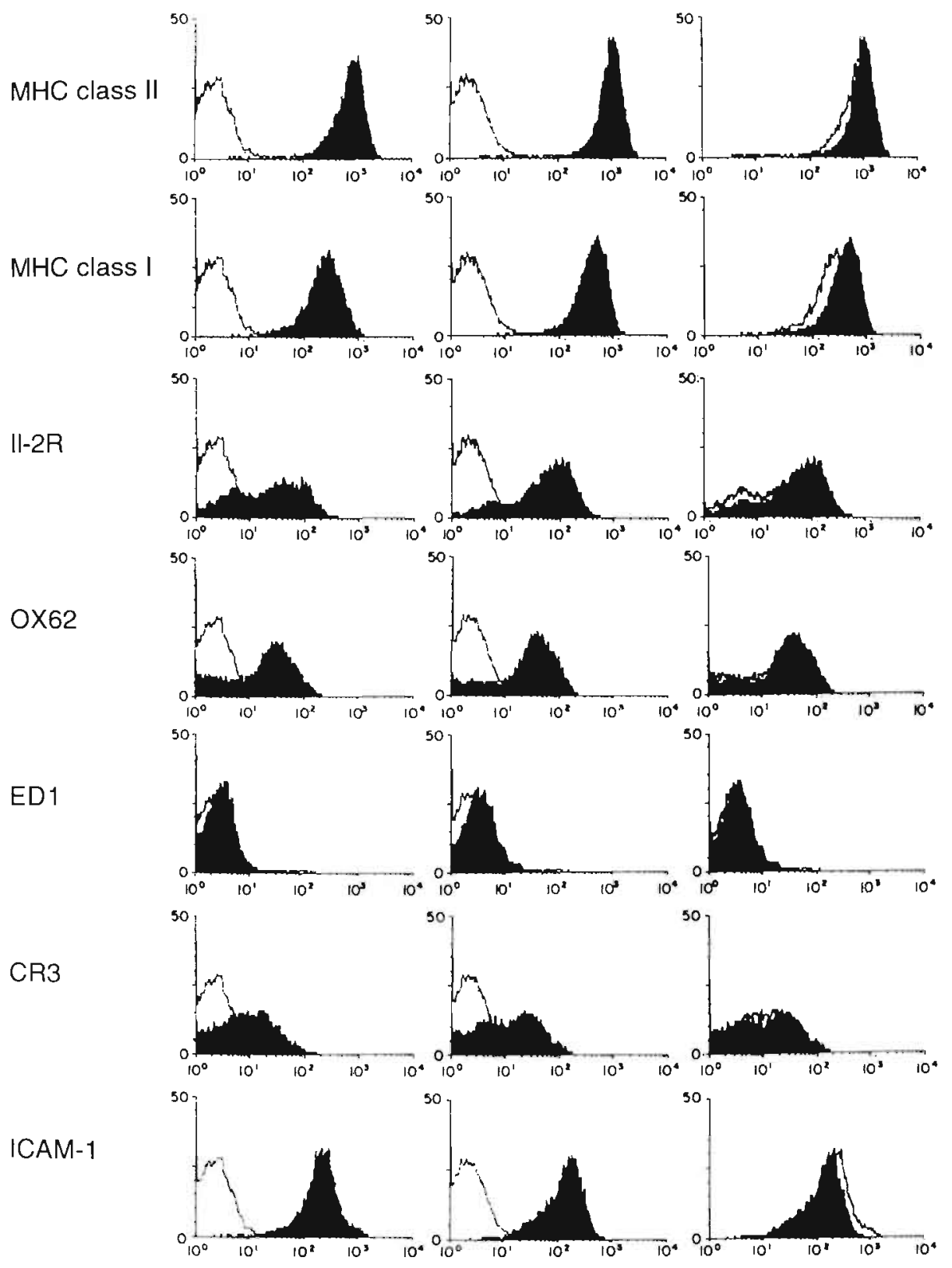

Figure 3. Effect of in vivo CsA administration on the cell surface phenotype of rat thymic DC. In the left column the shaded protiles show the expression of the indicated marker by thymic DC of control animals receiving velicle only, whereas in the middle column the shaded profiles show the expression of the indicated marker by thymic DC of experimental animals that had received $7.5 \mathrm{mg} \mathrm{CsA} / \mathrm{kg}$ daily for 10 days. The black line in both left and middle column indicates the control staining of rat thymic DC. In the right column the expression of the indicated marker by thymic DC of control (black line) and experimental animals (shaded profile) are compared. 

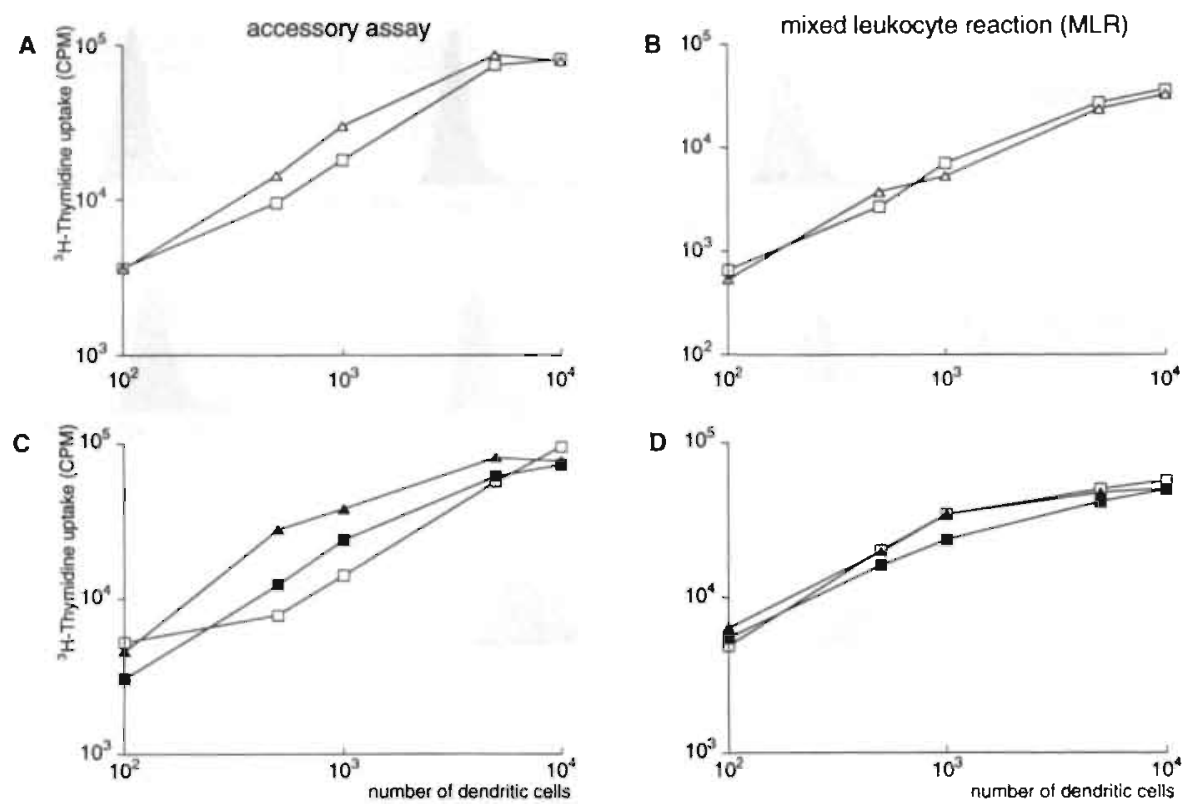

Figure 4. Functional characterization of thymic DC upon in vivo CsA administration. The accessory activity was examined by determining the PHA-induced T-cell proliferation. Various numbers of LEW DC were cultured with $10^{5} \mathrm{LEW}$ T-cells and $1 \mathrm{mg} /$ well PHA (upper and lower left diagrams). In order to determine the capacity of the DC 10 induce an allogeneic MLR various numbers of LEW DC were cultured with $1 \times 10^{5}$ or $2 \times 10^{5} \mathrm{BN}$ Tcells (upper and lower right diagrams respectively). In the first experiment (upper diagrams) thymic DC of control animals (open squares) were functionally compared with thymic DC obtaincd from animals that had been treated daily with $7.5^{\circ} \mathrm{mg} / \mathrm{kg}$ for 14 days (open triangles). In the second experiment (lower diagrams) thymic DC of control animals (open squares) were functionally compared with thymic DC obtained from animals two weeks after BMT only (closed squares) or in combination with daily $7.5 \mathrm{mg} / \mathrm{kg} \mathrm{CsA}$ administration (closed triangles). Means of triplicate values are given.

PHA $(<300 \mathrm{cpm})$. Irradiated thymic DC (104) alone or in the presence of PHA also failed to incorporate $\left[{ }^{3} \mathrm{H}\right] \mathrm{TdR}(<400 \mathrm{cpm})$. The presence of thymic $\mathrm{DC}$ was also required for the incorporation of $\left[{ }^{3} \mathrm{H}\right] \mathrm{TdR}$ in $\mathrm{BN}$ T-cells $(<300 \mathrm{cpm})$. In the first experiment thymic DC of control animals were functionally compared with thymic DC obtained from animals that had been treated daily with $7.5 \mathrm{mg} / \mathrm{kg}$ for 14 days. In the second experiment thymic DC of control animals were functionally compared with thymic DC obtained from X-BM OO-rats and X-BM CsA rats two weeks after BMT (X-BM OO) and $7.5 \mathrm{mg} / \mathrm{kg}$ CsA administration (X-BM CsA). Both experiments revealed that the proliferative response in the accessory assay as well as in the MLR was dependent on the thymic DC number. DC isolated from control or experimental animals resulted in comparable $\mathrm{T}$-cell responses (Fig. 4). In the accessory assay the $\left[{ }^{3} \mathrm{H}\right] \mathrm{TdR}$ incorporation in both experiments was about $4000 \mathrm{cpm}$ with as few as $10^{2} \mathrm{DC}$ and up to $80,000 \mathrm{cpm}$ with $10^{4} \mathrm{DC}$. In the MLR of the first experiment ( $\left.1 \times 10^{5} \mathrm{BN} \mathrm{T}-\mathrm{cells}\right)$ the $\left[{ }^{3} \mathrm{H}\right] \mathrm{TdR}$ 
incorporation was about $600 \mathrm{cpm}$ up to $35,000 \mathrm{cpm}$ for respectively $10^{2} \mathrm{DC}$ and $10^{4} \mathrm{DC}$. In the second MLR experiment ( $2 \times 105$ BN-Tcells) the $[3 \mathrm{H}] \mathrm{TdR}$ incorporation was about 5000 cpm up to $50,000 \mathrm{cpm}$ for respectively $10^{2} \mathrm{DC}$ and $10^{4} \mathrm{DC}$.

\section{Discussion}

Rat thymic DC have been isolated by separation of the low density fraction following an isolation protocol slightly modified from the one described previously (17). The yield, purity and phenotype are mainly in agreement with the results obtained by others in the rat $(20,21)$ and mouse $(22,23)$. In accordance with these studies rat thymic DC express high levels of MHC class I and class II molecules. CD25 (IL-2R) expression on thymic DC is still controversial $(21,23,24)$. It is suggested that CD25 expression on thymic DC is upregulated upon culture as has been reported for rat veiled cells (25). However, it should be noted that in the rat mAb OX-39 labels a subpopulation of medul]ary DC in situ (14) and therefore the CD25 positive DC we isolated may very well represent this subpopulation. The rat macrophage and DC marker EDI (CD68, macrosialin) stains DC only intracytoplasmic. Consequently reactivity could only be observed in cytocentrifuge preparations. Since macrophages show EDI reactivity throughout the cytoplasm, whereas DC isolated from lymphoid tissues show only light granular spots restricted to a distinct area in the cytocenter, ED1 is a very suitable marker for the identification of DC in vitro (26). In addition we used the mAb OX-62, reacting with the majority of the isolated thymic DC. Although this marker is not restricted to this cell type the labeling correlates with DC forming a diffuse network in the thymic medulla (15). Furthermore, the isolated DC are very efficient accessory cells and induce strong T-cell proliferative responses in an allogeneic MLR comparable to DC isolated from the thoracic duct lymph (27).

Upon in vito CsA administration our results show a concentration dependent decrease in DC number, but it never results in a complete disappearance of DC. These results seem to contradict earlier findings that CsA causes an almost complete loss of DC in the thymic medulla as determined in situ by MHC class II or EDl expression $(8,9)$. Although thymic DC express the MHC class II surfacc antigen and the EDI cytoplasmic antigen (17), respectively epithelial cells and macrophages can have these same characteristics. Identification in situ of DC therefore may be very difficult in the diffuse labelling of the medulla. Since the decrease in DC number in our experiments never exceeds $70-80 \%$, it can be argued that the remaining 20-30\% concernes precursor cells. These precursor cells are probably not observed as such in situ, but are able to malure during overnight culturing as applied in our isolation procedure. Rather comparabe to the DC data presented here, Milicevic et al. recently demonstrated that especially 
the mature medullary epithelial cells are lost upon CsA treatment, while the less mature survive (28). However, using among others the mAb OX-39 and OX-62 in situ we were stil able to identify substantial numbers of DC in the thymic medulla of irradiated and CsA treated animals (11). These findings indicate that in vivo CsA administration not fully removes the mature thymic medullary DC.

Although we do see a strong decrease in DC number, we also find a slight recovery during CsA administration within 2 weeks. Ultrastructural observations by De Waal et al. revealed that this recovery concems new DC immigrants with an immature character, i.e. absence of Birbeck granules, and the lack of coated vesicles with amorphous or membranous contents (29). The identity of this precursor is still obscure. Predominantly immature macrophages are present along the blood vessels in the corticomedullary region of the thymus. It has been suggested that these corticomedullary macrophages represent precursors for the cortical macrophage as well as for the medullary DC (30). Recently it appeared that thymic DC and T-cells develop simultaneously in the thymus from a common precursor population (31).

In order to determine possible functional deficits we first determined the phenotype of the isolated thymic DC. In vivo CsA administration appeared not to influence the phenotype. Especially the expression of adhesion molecules like CD54 (ICAM-1), CR3 (CDI lb/CD18), and possibly the integrin-like OX-62 antigen may be important in the interaction between DC and thymocytes. The significance of the CD25 (IL-2R) expression on thymic DC is still obscure. CD25 is suggested to be involved in T-cell activation, but may also trigger DC maturation (25). The suggestion, based on the phenotypic analysis, that the function of thymic $\mathrm{DC}$ is not influenced upon in vivo CsA administration is confirmed by additional functional studies. Neither accessory activity nor the capacity to induce an allogeneic MLR are affected.

From our results we like to conclude that the observed disturbance of T-cell maturation by CsA is not caused by a complete disappearance or phenotypic and functional change of the thymic medullary DC. It is more likely that the CsA induced absence of mature T-cells in the thymic medulla interferes with the maintenance and maturation of the medullary DC, as has been shown to be the case for growth of medullary epithelial cells (32). CsA inhibits expression of early $\mathrm{T}$ cell activation genes among which besides IL-2 also GM-CSF is affected (33). Lack of these cytokines may cause the disturbed DC number within the thymic medulla. Nevertheless, DC numbers may increase within 2 weeks while CsA treatment is still going on. The notion that DC recover in the thymus during CsA treatment is consistent with reports indicating that the thymus is essential for the induction of CSA-AI during the first 2 weeks of CsA therapy, but not thereafter (4).

Altogether the DC are far from completely depleted upon CsA administration and the antigen expression and function remain the same. Thus, in the model of CsA-AI the altered 
negative selection is not caused by CsA-induced depletion of DC. It remains obscure whether the observed reduction in the first 2 weeks of CsA administration can be held responsible for the generation of autoreactive T cell inducing CsA-AI. Since CsA also blocks apoptosis (34, $35)$, it is more likely that autoreactive thymocytes escape apoptosis and finally are able to leave the thymus.

\section{Acknowledgements}

The authors wish to thank the excellent technical assistance of Marie-Jose van de Gaar. Additionally generous gift of monoclonal antibodies by Dr. M. Brennan (Oxford. England), Dr. C.D. Dijkstra (Amsterdam, The Netherlands). and Prof. M. Miyasaka (Tokyo, Japan), are gratefully acknowledged.

\section{References}

I Glazier, A., Tutschka, P. J., Farmer, E. R. and Santos, G. W. (1983) Graft-versus-host disease in cyclosporin A-treated rats after syngeneic and autologous bone marrow reconstitution. J. Exp. Med. 158: $1-8$

2 Bos, G. M. J., Majoor, G. D. and van Breda Vriesman, P. J. C. (1990) Graft-versus-host disease: the need for a new terminology. Immunol. Today. 11:433-436

3 Beschorner, W. E., Shinn, C. A., Fischer, A. C., Santos, G. W. and Hess, A. D. (1988) Cyclesporineinduced pseudo-graft-versus-host disease in the early post-cyclosporine period. Transplantation. 46, Suppl.: 112S-117S

4 Sorokin, R., Kimura, H., Schroder, K., Wilson. D. H. and Wilson, D. B. (1986) Cyclosporin-induced autoimmunity: Conditions for expressing disease, requirement for intact thymus, and potency estimates of autoimmune lymphocytes in drug-treated rats. J. Exp. Med. 164: 1615-1625

5 Wodzig, K.W.H., Majoor, G.D. and van Breda Vriesman, P.J.C. (1993) Kinetics of inducer/effector cell generation in the thymus in Cyclosporine-induced autoimmunity. Transplani. Proc. 25:2819-2821

6 Kosugi, A., Sharrow, S. O. and Shearer, G. M. (1989) Effect of cyclosporin A on lymphopoiesis. I. Absence of mature $\mathrm{T}$ cells in thymus and periphery of bone marrow transplanted mice treated with cyclosporin A. J. Immunol. 142:3026-3032

7 Jenkins, M. K., Schwartz, R. H. and Pardoll, D. M. (1988) Effects of Cyclosporin A on T cell development and clonal deletion. Science. 241:1655-1658

8 Beschorner, W. E. and Armas, O. A. (1991) Loss of medullary dendritic ceils in the thymus after cyclosporine and irradiation. Cell. Immunol. 132:505-514

9 Schuurman, H.-J., Loveren, v. H., Rozing, J., van Dijk, A., Loeber, J. G. and Vos, J. G. (1990) Cyclosporin and the rat thymus. An immunohistochemical study. Thymus. 16:235-254

10 Fairchild, P. J. and Austyn, J. M. (1990) Thymic dendritic cells: phenotype and function. Int. Rev. Immunol. 6:187-196 
11 Beijleveld, L. J. J., Damoiseaux, J. G. M. C. and van Breda Vriesman, P. J. C. (1995) The differential effects of $\mathrm{X}$-irradiation and Cyclosporin- $\mathrm{A}$ administration on the thymus with respect to the generation of Cyclosporin-A induced Autoimmunity. Dev. Immunol. 4:127-138

12 McMaster, W. R. and Williams, A. F. (1979) Identification of Ia glycoproteins in rat thymus and purification from rat spleen. Eur. J. Immunol. 9:426-433

13 Fukumoto, T., McMaster, W. R. and Williams, A. F. (1982) Mouse monoclonal antibodies against rat major histocompatibility antigens. Two Ia antigens and expression of la and class I antigens in rat thymus. Eur. J. Immunol. 12:237-243

14 Paterson, D. J., Jefferies, W. A., Green, J. R., Brandon, M. R., Corthesy, P., Puklavec, M. and Williams, A. F. (1987) Antigens of activated rat T lymphocytes including a molecule of 50,000 Mr detected only on CD4 positive T blasts. Mol. Immunol. 24:1281-1290

15 Brenan, M. and Puklavec, M. (1992) The MRC OX-62 antigen: a useful marker in the purification of rat veiled cells with the biochemical properties of an integrin. J. Exp. Med. 175:1457-1465

16 Dijkstra, C. D., Döpp, E. A., Joling, P. and Kraal, G. (1985) The heterogeneity of mononuclear phagocytes in lymphoid organs: distinct macrophage subpopulations in the rat recognized by monoclonal antibodies ED1, ED2 and ED3. Immumology. 54:589-599

17 Damoiseaux, J. G. M. C., Döpp, E. A., Neefjes, J. J., Beelen, R. H. J. and Dijkstra, C. D. (1989) Heterogeneity of macrophages in the rat evidenced by variability in determinants: two new anti-rat macrophage antibodies against a heterodimer of 160 and $95 \mathrm{kd}$ (C'DI1/CD18). J. Lellkocyte Biol. 46:556-564

18 Tamatani, T. and Miyasaka, M. (1990) Identification of monuclonal antibudics reactive with the rat homolog of ICAM-1, and evidence for a differential involvement of ICAM-1 in the adherence of resting versus activated lymphocytes to high endothelial cells. Int. Immunol. 2:165-171

19 Julius, M. H., Simpson, E. and Herzenberg, L. A. (1973) A rapid method for the isolation of functional thymus-derived lymphocytes. Eur. J. Immunol 3:645-652

20 Wong, T. W., Klinkert, W. E. F. and Bowers, W. E. (1982) Immunological properties of thymus cell subpopulations: rat thymic dendritic cells are potent accessory cells and stimulators in a mixed leukocyte culture. Immunobiol. 160:413-423

21 Banuls, M. P., Alvarez, A., Ferrero, L, Zapata, A. and Ardavin, C. (1993) Cell-surface marker analysis of rat thymic dendritic cells. Immunology. 79:298-304

22 Crowly, M., Inaba, K., Witmer-Pack, M. and Steinman, R. M. (1989) The cell surface of mouse dendritic cells: FACS analyses of dendritic cells from different tissues including thymus. Cell. Immunol. 118: $108-125$

23 Ardavin, C. and Shortman, K. (1992) Cell surface marker analysis of mouse thymic dentritic cells. Eur. J. Immunol. 22:859-862

24 Vremec, D., Zorbas, M., Scollay, R., Saunders, D. J., Ardavin, C. F., Wu, L. and Shortman, K. (1992) The surface phenotype of dendritic cells purified from mouse thymus and spleen: investigation of the CD8 expression by a subpopulation of dendritic cells. J. Exp. Med. 176:47-58

25 MacPherson, G. G., Fossum, S. and Harrison, B. (1989) Properties of lymph-borne (veiled) dendritic cells in culture: II. Expression of the IL-2 receptor: role of GM-CSF. Immunology. 68:108-113

26 Damoiseaux, J. G. M. C., Döpp, E. A., Calame, W., Chao, D., MacPherson, G. G. and Dijkstra, C. D. (1994) Rat macrophage lysosomal membrane antigen recognized by monoclonal antibody EDl. Immunology. 83:140-147 
27 Nagelkerken, L., Henfling, M. and van Breda Vriesman, P. J. C. (1985) Accessory cell function of thoracic duct nonlymphoid cells, dendritic cells, and splenic adherent cells in the Brown-Norway rat. Cell. Inmunol. 93:520-531

28 Milicevic, Z., Zivanovic, V., Todorovic, J., Colic, M., Kamperdijk, E. W. A., Hoefsmit, E. C. M. and Milicevic, N. (1992) Differential effect of Cyclosporin application on epithelial cells of the rat thymus. Immunohistochemical study. J. Comp. Path. 106:25-35

29 de Waal, E. J., Rademakers, L. H. P. M., Schuurman, H. J. and van Loveren, H. (1992) Interdigitating cells in the rat thymus during Cyclosporin A treatment: ultrastructural observations. Thymus. 20:163170

30 Duijvestijn, A. M., Sminia. T., Köhler, Y. G., Janse, E. M. and Hoefsmit, E. C. M. (1984) Ontogeny of the rat thymus micro-environment: development of the interdigitating cell and macrophage populations. Dev. Comp. Immunol. 8:451-460

31 Ardavin, C., Wu, L., Li, C. L. and Shortman. K. (1993) Thymic dendritic cells and T cells develop simultaneously in the thymus from a common precursor population. Nature. 362:761-763

32 Surh, C. D., Ernst, B. and Sprent, J. (1992) Growth of epithelial cells in the thymic medulla is under the control of mature T eells. J. Exp. Med. 176:611-616

33 Emmel, E. A., Verweij, C. L., Durand, D. B., Higgins, K. M., Lacy, E. and Crabtree, G. R. (1989) Cyclosporin A specifically inhibits function of nuclear proteins involved in T cell activation. Science. 246:1617-1620

34 McCarthy, S. A., Cacchione, R. N., Mainwaring, M. S. and Cairns, J. C. (1992) The effects of immunosuppressive drugs on the regulation of activation-induced apoptotic cell death in thymocytes. Transplantation. 54:543-547

35 Yasutomi, D., Odaka, C., Saito, S., Niizeki, H., Kizaki, H. and Tadakuma, T. (1992) Inhibition of programmed cell death by Cyclosporin A; preferential blocking of cell death induced by signals via TCR/CD3 complex and its mode of action. Immunology. 77:68-74 

CHAPTER 5 Susceptibility for clinically manifest Cyclosporine-A induced autoimmune disease is associated with Interferon $\gamma$ producing CD45RC+RT6- Thelper cells

Leo J.J. Beijleveld', Herman Groen², Chris P.M. Broeren3, Flip A. Klatter2, Jaap Kampinga2, Jan G.M.C. Damoiseaux 1 and Peter J.C. van Breda Vriesman ${ }^{1}$

I The Department of Immunology, Faculty of Medicine, University of Limburg, Maastricht; 2 the Department of Histology and Cell Biology, Faculty of Medicine, University of Groningen. Groningen; and ${ }^{3}$ the Institute of Infectious Diseases and Immunology, Faculty of Veterinary Medicine, University of Utrecht, Utrecht. the Netherlands

Accepted by Clinical and Experimental Immunology

\section{Summary}

Lethally irradiated Lewis rats reconstituted with syngeneic bone marrow and given Cyclosporin-A (CsA) for a 4 week period, develop, upon withdrawal of CsA, a graft-versushost like disease, so called CsA induced Autoimmunity (CsA-AI). This T cell mediated autoimmune disease is thymus dependent; it is generally held that this disease is a consequence of aberrant $\mathrm{T}$ cell recovery brought about by Cyclosporin- $\mathrm{A}$.

In this study we determined mononuclear cell subsets phenotypically by tri-colour flowcytometry. A strong decrease in recent thymic emigrants (RTE: Thy 1.1+. TCR $\alpha \beta^{+}$) was observed as a consequence of CSA treatment eventually resulting in decreased absolute peripheral $T$ cell numbers. In these rats no altered CD4 : CD8 $\mathrm{T}$ cell ratio was observed prior to onset of C.A-AI: CD4+ and CD8+ non T cells consisted predominantly of monocytes (CD4dim $\left.{ }^{+}, \mathrm{TCR} \alpha \beta^{-}\right)$and natural killer cells $\left(\mathrm{CD}^{+}, \mathrm{TCR} \alpha \beta\right)$ respectively.

Lewis rats, $\mathrm{X}$-irradiated, syngeneic bone marrow reconstituted and treated with $\mathrm{Cs} A$, showed a marked and persistent, relative expansion of mature CD45RC+. RT6- Th cells. In contrast, Brown Norway rats treated in a similar fashion, or Lewis rats subjected to either CsA treatment or X-irradiation did not show a comparable expansion of mature CD45RC+, RT6- Th cells, nor did these animals develop CsA-A1. The CD45RC+ ${ }^{+}, \mathrm{RT}^{-}$- Th cells produced IL 2 and moreover constituted the only Th subset producing IFlV $y$ upon stimulation and therefore were considered as Thl like effector cells. These results are consistent with the view that a persistent preponderance of Thl cells and not the mere presence of autoreactive cells determines whether or not clinically manifest CsA-AI will occur. 


\section{Introduction}

The development of the so called autoimmune Graft versus Host disease in Lewis rats, lethally irradiated and reconstituted with syngeneic bone marrow, and next given a 4 week treatment with Cyclosporin-A (CsA), is T cell mediated (1-3). Although the effect of lethal irradiation on the hematopoietic cells is corrected by syngeneic bone marrow transplantation (BMT), $T$ cell recovery is impaired and far from complete under concomittant CsA administration. The development of autoimmune disease after use of the immuno-suppressive drug CsA is supposed to be due to the inhibition of intra-thymic negative selection of self reactive thymocytes during CsA administration $(4,5)$. If this were the case increased numbers of recent thymic emigrants (RTE) in the periphery, as observed by others after CsA administration (6-8) might preceed the development of disease. The autoreactive $T$ cells which induce this graft versus host like disease are demonstrable by adoptive transfer experiments and disease can be succesfully transferred by $\mathrm{CD} 4^{+}$cells $(9), \mathrm{CD} 8^{+}$cells (10) or by combinations of $\mathrm{CD} 4^{+}$and CD8 ${ }^{+}$cells (11), provided an autoregulatory $\mathrm{T}$ cell circuit in the recipient is first eliminated by $\mathrm{X}$-irradiation (12). In addition, in animals developing CsA-AI an increase in peripheral blood $\mathrm{CD}^{+}$cells precedes the onset of clinical diseilse (13). It has been shown, however, that in the rat both CD4 and CD8 are not $\mathrm{T}$ cell specific and are also expressed on monocytes and NK cells respectively $(14,15)$. Finally not all strains of rats (16) or mice (17-19) which are subjected to X-irradiation, BMT and CsA-therapy develop disease although CsA impairs thymocyte maturation $(20,21)$ and selection (22-24) regardless of strain.

Based on studies involving function and development of peripheral $T$ cells in the rat Kampinga et al. have constructed a concept for rat Th cell development in which several maturational stages can be discriminated based on the expression of Thy 1.1, CD45RC and RT6 (25). Thy 1.1 is a marker for RTE which is lost within two weeks after they enter the periphery $(26,27)$. RTE first start to express RT6, an allotypic T cell marker (28), and after losing Thy 1.1 reactivity, the expression of $\mathrm{CD} 45 \mathrm{RC}$, a high molecular weight isoform of CD45 is induced together with the RT6 expression (26). Upon activation CD45RC and RT6 expressions are lost $(29,30)$. Thereafter Th cells differentiate into CD45RC+RT6- or CD45RC-RT6+ memory cells, with proposed Th1 like and Th2 like activity respectively. $\mathrm{CD} 45 \mathrm{RC}+$ Th cells have been shown to produce predominantly IL2 and IFN $\gamma$, whereas the lymphokine production of the CD45RC-subpopulation consists mainly of IL4 and IL10 (31). In previous studies balances between $\mathrm{CD} 45 \mathrm{RC}^{+}$and $\mathrm{CD} 45 \mathrm{RC}$ - Th cells or $\mathrm{RT}^{+}$and $\mathrm{RT}^{-} \mathrm{Th}$ cells were demonstrated to regulate susceptibility and development of autoimmune disease (11, 31-35). Th cells capable of inducing $\mathrm{T}$ cell mediated autoimmune disease are found within the $\mathrm{CD}^{-} 5 \mathrm{RC}^{+}$or RT6- subset whereas suppressor activity is found among the CD45RC- $\mathrm{R}^{-} \mathrm{RT}^{+}$ Th cells $(11,26,33,36-38)$. Altogether, in the rat the combinatory expression profiles of RT6 
and CD45RC enable the identification of four mature (Thy 1.1-) Th cell subsets with

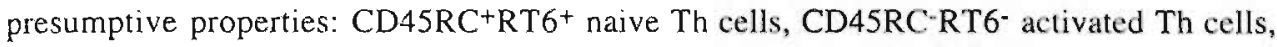
CD45RC+RT6- Th1 like memory cells and CD45RC-RT6+ Th2 like memory cells.

Thus, given identical impairment of negative thymic selection by $\mathrm{CsA}$, the differences between Lewis rats, which are susceptible to induction of disease, and BN rats which are resistant (16) might reside in different ratio's of Th cell populations upon induction of ( $\mathrm{sA}$ A AI. Therefore, in this study we addressed the following four questions. Are increased numbers of RTE demonstrable in rats in the induction phase of CsA-AI, that is prior to cessation of CsA medication? Is the disease associated with altered CD4 : CD8 ratio's in peripheral blood? Is development of disease associated with a skewing towards CD45RC+, RT6- Th cells and do these cells produce Thl associated cytokines?

\section{Materials and Methods}

Animals Female inbred Lewis $\left(\mathrm{RT}^{\mathrm{I}}\right)$ and Brown Norway (BN, RT1 ${ }^{\mathrm{n}}$ ) rats were obtained from the Central Animal Facility of the University of Limburg, the Netherlands. The animals were maintained under specific pathogen free conditions until use and had free access to food and water. Rats were 6 weeks of age at the start of the experiment.

Protocol for the Induction of CsA-AI Rats were given $8.5 \mathrm{~Gy} \mathrm{X}$-irradiation at $0.5 \mathrm{~Gy} / \mathrm{min}$., using a Röntgen irradiation machine (Philips MU15GF/225 kV, Hamburg, Germany) one day prior to syngeneic BMT. Recipient rats were given $6 \times 10^{7}$ viable nucleated syngeneic bone marrow cells intravenously into a tail vein as previously described (2). Starting from the day of BMT the rats received subcutaneously $7.5 \mathrm{mg}$ CsA/kg per day for 28 days. CsA, a kind gift from Sandoz Pharma Ltd., Basel, Switzerland, was dissolved in olive oil (OO) at a concentration of $7.5 \mathrm{mg} / \mathrm{ml}$. In the experiments, where indicated, the $X$-irradiated syngeneic $\mathrm{BM}$ reconstituted, CsA-treated (X-BM CsA-) rats, were compared to X-BM OO-rats (Xirradiated, syngeneic BM reconstituted and olive oil treated), CsA-rats (only CsA-treated rats) and $\mathrm{OO}$-rats (olive oil only treated rats).

Monoclonal Antibodies The biotinylated mAb R73 (TCR $\alpha \beta$ ) (39) and supernatants of the mAb's V65 (TCR $\gamma \delta)$ (40), 341 (CD8 $\alpha \beta$, specific for Tcyt/suppr. cells) (15) and NK (equivalent to mAb 3.2.3. (41); Dr. E. Krause and Prof. Th. Hünig. personal communication) were kindly provided by Prof. Th. Hünig (University of Würzburg, Germany). The biotinylated mAb ER2 (CD4, expressed by Th cells and macrophages) (42) was kindly provided by Dr. B. de Geus (TNO, Leiden, The Netherlands). The biotinylated mAb ED8 (CR3, present on macrophages and granulocytes) (43) was kindly provided by Prof. C.D. Dijkstra (Free University of Amsterdam, the Netherlands). The hybridoma cell-line producing 3G2 (RT6.1; RT6 alloantigen expressed in Lewis) (44) was kindly donated by Prof. K. Wonigeit (Medische Hochschule, Hannover, Germany). The hybridoma cell-line producing 
GY1/12 (RT6.2; RT6 alloantigen expressed in BN) (45) was kindly donated by Dr. G. Butcher (Department of Animal Physiology, Babraham, UK). HIS25 (CD45RC; LCA-isotype present on all Tcyt/suppr., part of Thelper- and all B-cells) (46) and HIS51 (Thy 1.1, within the TCR $\alpha \beta+$ cell population specific for RTE) (47) were produced by the Department of Histology, University of Groningen, the Netherlands. W3/25 (CD4) (48), OX6 (RT1B; MHC class II) (49), OX22 (CD45RC) (50) and OX35 (CD4) (14) were obtained from the European Collection of Animal Cell Culture (Salisbury, UK). PE conjugated OX8 (CD $8 \alpha \alpha$, Tcyt/suppr.-cells and natural killer cells) (5I) was obtained from Pharmingen (San Diego, CA, USA). Biotinylation or conjugation with FITC or APC of the mAb's were performed using standard protocols.

Preparation of cell suspensions Rats were exsanguinated under ether anaesthesia via the aorta or by heart puncture with a syringe containing $100 \mu \mathrm{l}$ heparin $(10,000 \mathrm{U} / \mathrm{ml}$, Leo Pharmaceutical Products, Weesp, the Netherlands) or blood was repeatedly collected via the retro-orbital vein plexus. The peripheral blood leukocyte (PBL) cell number was detennined in Türk solution with a Bürker Haemocytometer or with a Coulter Counter (Coulter Electronics). The erythrocytes in the buffy coats were lysed with NH4Cl-buffer $(0.155 \mathrm{M} \mathrm{NH} 4 \mathrm{Cl}, 0.01 \mathrm{M}$ $\mathrm{KHCO} 3,0.1 \mathrm{mM}$ EDTA, pH7.4) after which the cells were spun down at $316 \mathrm{~g}$ for 10 minutes at $4{ }^{\circ} \mathrm{C}$ and resuspended in PBS containing $0.5 \% \mathrm{~W} / \mathrm{V}$ bovine serum albumin (PBSBSA) (BSA, Sigma, St.Louis, MO, USA).

Cervical and mesenteric lymph nodes were pooled, teased apart and passed through a 100 mesh nylon gauze and collected in PBS-BSA. The lymph node cells (LNC) were spun down ( $316 \mathrm{~g}, 10 \mathrm{~min}, 4^{\circ} \mathrm{C}$ ) and resuspended in PBS-BSA. All cell suspensions were counted in a Bürker Haemocytometer while viability was assessed by Trypan Blue exclusion.

Flowcytometry Five $\times 10^{5}$ cells per sample were centrifuged in a 96 well microtiter-plate (236 $\mathrm{g}, 3 \mathrm{~min}, 4^{\circ} \mathrm{C}$ ) and resuspended in PBS-BSA containing $10 \mathrm{mM} \mathrm{NaN} 3$ and conjugated $\mathrm{mAb}$. The combined expression of CD4 (FITC), CD8 or Thy I.I (PE) and TCR $\alpha \beta$ (biotinconjugated, stained in a second step with streptavidin-Cy Chrome, Pharmingen, San Diego, CA, USA) on PBL and/or LNC was determined on a FACSort (Becton Dickinson, Etten Leur, the Netherlands). The cells were run using the LYSYS II software package (Becton Dickinson), and 10,000 events were acquired in list mode with gating on viable mononuclear cells using the forward light scitter (FSC) and side light scatter (SSC) parameters. Analysis was performed using the same software.

When unlabeled primary antibodies were used in combination with CD4 and CD8 expression, PBL were incubated consecutively with: 1. the unlabeled mAb, 2. FITC conjugated Goat anti Mouse Fab2 (Cappel, Organon Teknika Corp., West Chester, PA, USA) 3. excess irrelevant mouse mAb in order to block free binding sites of the Goat anti Mouse Fab2, 4. PE conjugated OX8 and biotinilated ER2, and 5. streptavidin Cy-Chrome. After each incubation excess reagents were removed by extensive washing.

When a Coulter ELITE flowcytometer (Coulter Epics, Hyaleah, USA) was used cells were stained with mAb conjugated to FITC, APC, PE or biotin and stained in a second step incubation with either streptavidin-PE (SBA, Birmingham, AL, USA) or streptavidin-APC 
(Gibco BRL., Gaithersburg, MD, USA). Cell samples were labelled with combinations of directly conjugated $\mathrm{mAb}$ reactive with $\mathrm{CD} 4, \mathrm{CD} 8, \mathrm{TCR} \alpha \beta$, Thy 1.1, CD45RC and RT6. To determine the Th subsets, as acquired by CD4, Thy 1.1, RT6, and CD45RC expression, 2 tricolour stainings are required (CD4-Thy 1.1-RT6 and CD4-CD45RC-RT6) since coexpression of Thy 1.1 and $\mathrm{CD} 45 \mathrm{RC}$ has been reported to be negligible (26). CD4 T cells were distinguished from CD4+ monocytes based on a lower forward light scatter profile and higher CD4 expression by Th cells. To determine the relative sizes of the different CD4 T cell subsets 30,000 to 50,000 cells were recorded. The analysis was done using the ELITE analysis software.

Immuno-histochemistry A transversal section of spleen and cervical lymph nodes mounted in a piece of liver was snap frozen in isopentane and used for cryosections. Six $\mu \mathrm{m}$ thick cryosections were cut, air dried and stored at $-20^{\circ} \mathrm{C}$. Al] sections were fixed in aceton and subsequently stained using a two step immuno-peroxidase technique as described previously (21); next the sections were counterstained with hematoxilin, dehydrated and covered with Entallan (Merck, Germany).

Isolation of CD4 $T$ cell subsets To study the different CD4 subsets for cytokine expression, mesenteric and cervical LNC were isolated from normal 8 week old Lewis rats. The lymph nodes were first teased apart in Dulbecco's balanced salt solution (DBSS) with $10 \%$ iFCS and penicillin $(100 \mathrm{U} / \mathrm{ml})$ and streptomycin $(100 \mu \mathrm{g} / \mathrm{ml})$ and flushed through a 100 mesh nylon gauze. Cells were fractionated over a nylon wool column (Fenwall Laboratories, Deerfield, IL) to enrich for $\mathrm{T}$ cells as previously described (52). Finally non-T cells and CD8+ cells were depleted by negative selection using mAb OX8 (CD8 $\alpha \alpha), 341(\mathrm{CD} 8 \alpha \beta)$ and OX6 (RT1B) and subsequently Sheep anti Mouse IgG-coated magnetic beads (Dynal, Oslo, Norway). The depletion was checked by flowcytometry. More than $97 \%$ of the cells were CD8-, CD4+ and TCR $\alpha \beta^{+}$. Next, the cells were stained with mAb OX22 (CD45RC) and 3G2 (RT6.1). These cells were sorted on a FACStar (Becton Dickinson). Two x $10^{5}$ cells with the CD45RC+RT6.1+, CD45RC-RT6.1+, CD45RC+RT6.1- or CD45RC-RT6.1- phenotype were collected.

Cytokine PCR The cytokine mRNA production of the sorted $\mathrm{CD} 4^{+}$Th cell subsets was determined by RT-PCR after in vitro activation of the respective subsets. Cells were stimulated by cross-linking of the TCR by the MAb R73 in the presence of spleen dendritic cells. Tissue culture plates (96 well flatbottom, Costar) were coated with Rabbit anti Mouse Ig (DAKO) and next incubated with mAb R73 (TCR $\alpha \beta$ ) or UDI5 (irrelevant isotype matched control mAb). Spleen dendritic cells were isolated as described before (43) and were used as accessory cells ( $5 \times 10^{3}$ dendritic cells/well). The respective $T$ cell subsets $\left(5 \times 10^{4}\right.$ cells/well) were added and subsequentially analyzed for cytokine mRNA production or proliferation. To determine proliferation, cells were cultured for 72 hours and pulsed with $\left[{ }^{3} \mathrm{H}\right]$-thymidine for another 18 hours. Cells were harvested on fibreglass filters and $\left[{ }^{3} \mathrm{H}\right]$-thymidine incorporation was measured. 
Total RNA was isolated after 16 hours culture by extraction with RNAzol (Cinna Biotex, USA) and next transcribed into cDNA using reverse transcriptase (Gibco Brl.). Aliquots of cDNA were made up to a final volume of $20 \mu \mathrm{l}$ containing $0.2 \mathrm{mM}$ of dATP, dCTP, dGTP and dTTP each, $50 \mathrm{mM} \mathrm{KCl}, 10 \mathrm{mM}$ Tris- $\mathrm{HCl}$ (pH 9.0 at $25^{\circ} \mathrm{C}$ ), $1.5 \mathrm{mM} \mathrm{MgCl}_{2}, 0.01 \%$ gelatin, $0.1 \%$ Triton $\mathrm{X}-100,40 \mathrm{ng}$ of primers and $0.5 \mathrm{U}$ AmpliTaq DNA polymerase I (Perkin Elmer, Cetus) and subjected to 24,27 or 30 cycles (in case of G3PDH) or 27,30 or 33 cycles (in case of rat cytokines) of 15 seconds at $94^{\circ} \mathrm{C}, 30$ seconds at $60^{\circ} \mathrm{C}$ and 1 minute at $72^{\circ} \mathrm{C}$ followed by one cycle of 7 minutes at $72^{\circ} \mathrm{C}$ using the PE9600 PCR apparatus (Perkin Elmer). The number of cyles we used was within the range of exponential DNA amplification. G3PDH and rat cytokine primers were based on published DNA sequences and are as follows:

\begin{tabular}{|c|c|c|}
\hline \multirow[t]{2}{*}{ G3PDH (53): } & sense : & 5'-ACCACAGTCCATGCCATCAC-3' \\
\hline & anti-sense & 5'-TCCACCACCCTGTTGCTGTA-3' \\
\hline \multirow[t]{2}{*}{ IL2 (54): } & sense & 5'-AGCAAAAGCTTTCACTTGGAAGAC-3' \\
\hline & anti-sense & 5'-TGAGATGATGCITTGACAGATGGC-3' \\
\hline \multirow[t]{2}{*}{ IL4 (55): } & sense & 5'-GGGCTTCCAGGGTGCTTCGCAAAT-3', \\
\hline & anti-sense & 5'-TTCAGTGTTGTGAGCGTGGACTCA-3' \\
\hline \multirow[t]{2}{*}{ ILIO (56): } & sense & 5'-TGCCAAGCCTTGTCAGAAATGATCAAG-3' \\
\hline & anti-sense & 5'-GTATCCAGAGGGTCTTCAGCTTCTCTC-3' \\
\hline & sense & 5'-ATCTGGACGAACTGGCAAAAGGACG-3' \\
\hline & anti-sense & 5'-CCTTAGGCTAGATTCTGGTGACAGC-3'. \\
\hline
\end{tabular}

In all expreriments controls without template were included for the detection of false positive PCR reations. Resultant PCR products were visualized on an ethidium bromide stained $2 \%$ agarose gel under UV light.

\section{Results}

Absolute numbers of recent thymic emigrants are decreased in CsA treated Lewis rats Since CsA is known to interfere with $\mathrm{T}$ cell development in the thymus, we asked the question whether CsA causes an altered thymic output into the periphery. In the rat it has been shown that peripheral TCR $\alpha \beta^{+} T$ cells are Thyl.1 negative and only T cells that have left the thymus recently, i.e. within 7 days, do express Thy $1.1(26,27)$. Therefore peripheral blood was repeatedly collected on the indicated time and Thy 1.1 expression was determined in combination with TCR $\alpha \beta$.

In CsA-(treated) rats thymic output is progressively suppressed resulting in an almost tenfold decrease in TCR $\alpha \beta^{+}$, Thy 1.1+RTE $\left(0.04 \times 10^{6}\right.$ cells $\left./ \mathrm{ml}\right)$ compared to OO-(treated) rats $\left(0.36 \times 10^{6} \mathrm{cells} / \mathrm{ml}\right)$ (Table IA). This decrease in thymic output resulted in a prolonged lower $\mathrm{T}$ cell number in CsA-rats compared to OO-rats (Table IB). Total body X-irradiation yielded very low leukocyte numbers during the first 2 weeks after syngenic BMT. Therefore the X-BM rats were analyzed starting from week 2. In X-BM CsA-rats at week 2 the number of RTE was $0.02 \times 10^{6}$ cells $/ \mathrm{ml}$, comprising about $30 \%$ of the peripheral blood T cells 
whereas in X-BM OO-rats the number of RTE was $0.09 \times 10^{6}$ cells/ml, colnprising about $36 \%$ of all peripheral T cells (Table IA \& B). Four weeks after $\mathrm{X}$-irradiation and syngencic BMT in both X-BM CsA- and X-BM OO-rats over $10 \%$ of the peripheral T cells were Thyl.1+: in absolute numbers however the X-BM CsA-rats had about 6 times less RTE and TCR $\alpha \beta+T$ cells compared to X-BM OO-rats, and this persisted until development of disease. Eventually the decreased output of RTE in X-BM CsA-treated rats resulted in a decreased recovery of the peripheral $\mathrm{T}$ cells.

These results show that CsA treatment alone results in suppression of thymic output and in combination with X-irradiation and syngeneic BMT in inhibition of restoration of the peripheral $\mathrm{T}$ cell population.

Table IA: Absolute number of RTE / ml peripheral blood $\times 10^{-6}$

\begin{tabular}{lccccc}
\hline \hline day after syngeneic BMT & 3 & 7 & 14 & 28 & 42 \\
\hline $\mathrm{OO}$ & $0.48 \pm 0.07$ & $0.60 \pm 0.05$ & $0.42 \pm 0.06$ & $0.36 \pm 0.08$ & $0.33 \pm 0.10$ \\
CsA & $0.76 \pm 0.23$ & $0.17 \pm 0.04$ & $0.02 \pm 0.01$ & $0.04 \pm 0.04$ & $0.25 \pm 0.06$ \\
X-BM OO & N.D. & N.D. & $0.09 \pm 0.04$ & $0.23 \pm 0.07$ & $0.22 \pm 0.03$ \\
X-BM CsA & N.D. & N.D. & $0.02 \pm 0.00$ & $0.04 \pm 0.00$ & $0.05 \pm 0.10$ \\
\hline \hline
\end{tabular}

Table IB: Absolute number of T cells / $\mathrm{ml}$ peripheral blood x 10-6

\begin{tabular}{lccccc}
\hline \hline day after syngeneic BMT & 3 & 7 & 14 & 28 & 42 \\
\hline OO & $3.15 \pm 0.26$ & $4.65 \pm 0.48$ & $4.25 \pm 0.29$ & $4.02 \pm 1.01$ & $5.22 \pm 0.81$ \\
CsA & $4.62 \pm 1.37$ & $3.39 \pm 0.42$ & $1.82 \pm 0.40$ & $1.67 \pm 0.47$ & $2.75 \pm 0.75$ \\
X-BM OO & N.D. & N.D. & $0.31 \pm 0.14$ & $2.09 \pm 0.60$ & $3.32 \pm 0.16$ \\
X-BM CsA & N.D. & N.D. & $0.07 \pm 0.01$ & $0.31 \pm 0.08$ & $0.76 \pm 0.18$ \\
\hline \hline
\end{tabular}

Abbreviations; OO, olive oil treated for up to 28 days; CsA, Cyclosporin A-treated for up 1028 days; X-BM OO, X-irradiated, syngeneic bone marrow reconstituted and treated with olive oil for up to 28 days, X-BM CsA, $X$-irradiated, syngeneic bone marrow reconstituted and treated with Cyclosporin A for 28 days; N.D., not determined.

Peripheral T cell recovery as determined by CD4 and CD8 expression In order to investigate the CD4 and CD8 expression on peripheral T cells in Lewis rats subjected to the protocol for induction of CsA-AI, tri-colour flowcytometry was performed using mAb reactive with CD4, CD $8 \alpha \alpha$ and TCR $\alpha \beta$. Rats were sacrificed and peripheral blood and mesenteric and cervical lymph nodes were collected as described. Two weeks after $\mathrm{X}$-irradiation and syngeneic BMT the relative amount of TCR $\alpha \beta+$ cells in peripheral blood of X-BM OO- and X-BM CsA-treated 
rats was still less than $10 \%$ of the mononuclear leukocytes. In X-BM OO-treated rats the TCR $\alpha \beta+$ cells rapidly expanded thereafter and normalized to approximately $70 \%$ of the mononuclear cells within 6 weeks. The recovery of $T$ cells in X-BM CsA-treated rats was strongly suppressed, and even at 8 weeks after BMT, eg. 4 weeks after cessation of CsAtherapy, the T cell population was less than $40 \%$ of the mononuclear cells (Fig. 1A). In the unirradiated CsA-rats a progressive decrease of the number of $\mathrm{T}$ cells to $50 \%$ of the mononuclear cells was observed, which remained until 2 weeks after cessation of CsA administration. Thereafter the $\mathrm{T}$ cell population recovered and was within normal limits at week combinatory effects in X-BM CsA-rats resulted in an incomplete recovery of the $\mathrm{T}$ cell population (Fig. 1B).
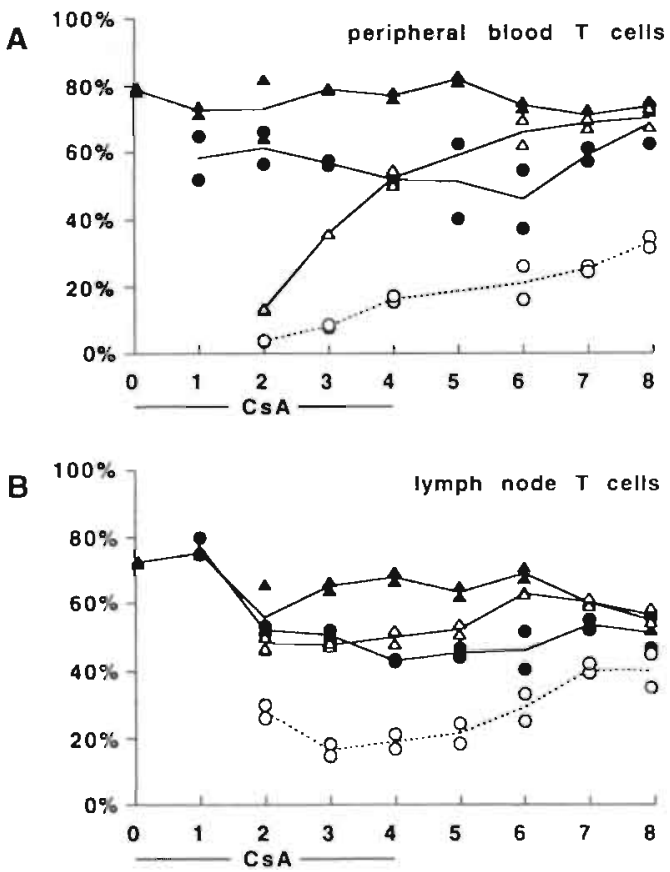

Figure $1 \mathrm{~A}$ and $\mathrm{B}$ : Phenotypic analysis of peripheral blood and lymph node $\mathrm{T}$ cells.

Weekly, starting from 2 weeks after X-irradiation and syngeneic BMT (X-BM), expression of TCR $\alpha \beta$ within the mononuclear cells was analyzed by FACS on peripheral bloud (figure $A$ ) and lymph node cells (figure $B$ ) of two rats from each group. i.e. X-BM CsA- (open circles). X-BM OO- (open triangles), CsA- (closed circles) or OOrats (closed triangles). OO- and CsA-rats were assessed from the beginning of the experiment. The amount of $T$ cells per rat tested, is expressed as the percentage of total mononuclear cells. The average per control group is represented as a solid line: the average of the X-BM CsA group is depicted by the dotted line. 
Both in PBL and LNC the ratio of single positive (SP) CD4+ : CD8+ TCRo $3+\mathrm{T}$ cells wats about $4: 1$ in OO-rats. Only at 2 weeks after syngeneic BMT in X-BM OO- and X-BM C $\mathrm{AA-}$ rats the ratio was elevated to $6: 1$ and $7.5: 1$ respectively (Fig. $2 \mathrm{~A} \& \mathrm{~B}$ ). Later on, the X-BM OO- and X-BM CsA-rats showed a ratio of $4: 1$.

Besides the CD4 : CD8 cell ratio within the TCR $\alpha \beta+$ PBL and $L N C$ the relative amount of CD4CD8 double positive (DP) and CD4CD8 double negative (DN) T cells was deternined. In $\mathrm{X}$-BM CsA-rats there was an increase in CD4CD8 DP T cells during CsA administration but they never exceeded $10 \%$ of the total $T$ cell population. On the other hand, there was a relative increase up to $30 \%$ in DN $\mathrm{T}$ cells during CsA administration which was normalized to less than $10 \%$, however, upon onset of disease (data not shown).
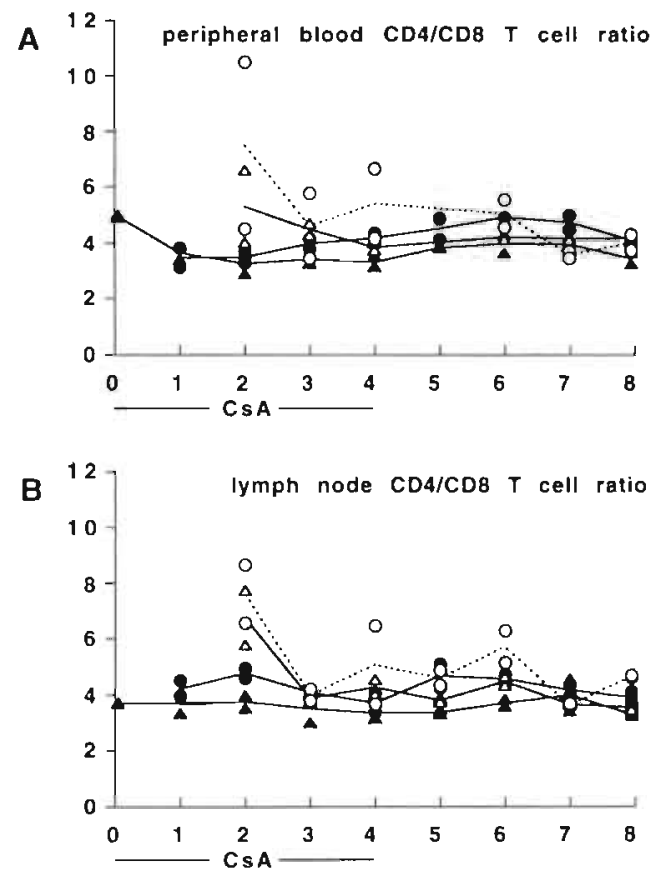

Figure $2 \mathrm{~A}$ and $\mathrm{B}$ : Phenotypic analysis of peripheral blond and lymph node $\mathrm{CD} 4 / \mathrm{CD} 8 \mathrm{~T}$ cell ratio.

Weekly, starting from 2 weeks after X-irradiation and syngeneic BMT (X-BM), the ratio of CD4 ${ }^{+}$TCR $\alpha \beta^{+}$cells over CD8 ${ }^{+}$TCR $\alpha \beta^{+}$cells was determined by FACS in peripheral blood (figure $A$ ) and lymph node cells (figure $\mathrm{B}$ ) of two rats from each group, i.e. X-BM CsA- (open circles), X-BM OO- (open triangles), CsA- (closed circles) or OO-rats (closed triangles). OO- and CsA-rats were assessed from the beginning of the experiment. The average per control group is represented as a solid line; the average of the X-BM CsA group is depicted by the dotted line. 
Because the analysis revealed high numbers of $\mathrm{CD} 4+$ and $\mathrm{CD} 8+\mathrm{TCR} \alpha \beta$ - cells in $\mathrm{X}-\mathrm{BM}$ CsA-rats we further characterized these cells. PBL, isolated 4 weeks after BMT and CsA therapy, were analyzed for CD4 and CD8 expression combined with the expression of TCR $\alpha \beta$, TCR $\gamma \delta, C R 3, N K$ antigen and $\mathrm{CD} 8 \alpha \beta$ heterodimer (Fig. 3). About $88 \%$ of the CD8 SP cells expressed an NK cell specific antigen, whereas only $12 \%$ were $T$ cells expressing TCR $\alpha \beta$ or $\mathrm{CD} 8 \alpha \beta$. TCR $\gamma \delta$ cells were hardly identified within the CD8 SP subset. CD4CD8 DN cells were predominantly negative for the markers used. The CD4CD8 DP cells nearly all expressed the monocyte marker CR3. Expression of TCR $\alpha \beta$ and $C D 8 \alpha \beta$ was less then $10 \%$. Apparently the monocytes expressed both CD4 and CD8 $\alpha \alpha$ and T cells were almost absent in the CD4CD8 DP subset. Also the CD4 SP population consisted mainly out of CR3+ monocytes. Only $18 \%$ expressed TCR $\alpha \beta ; \gamma \delta$ T cells were not detected.
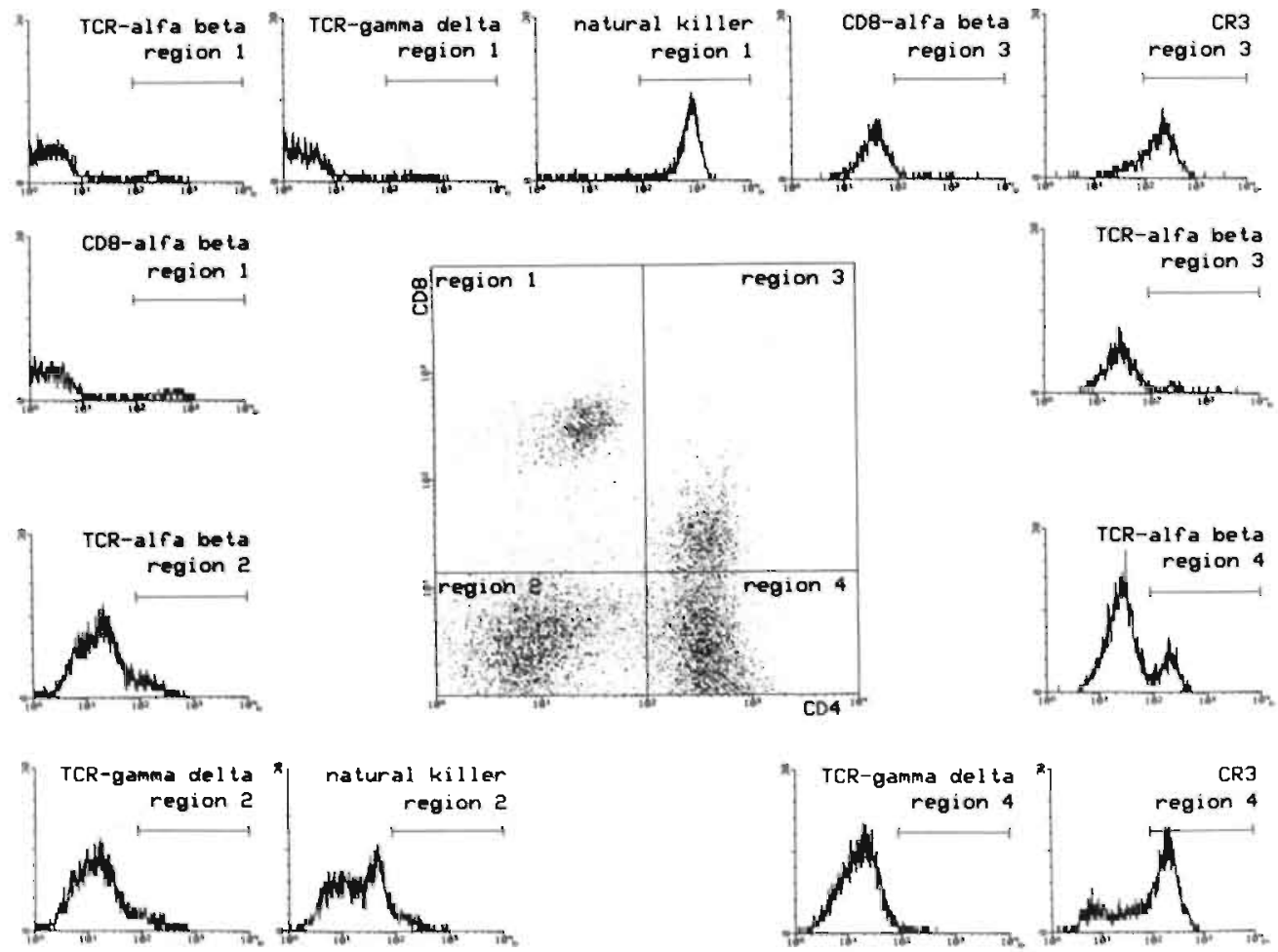

Figure 3: Analysis of peripheral blood mononuclear cells in X-BM CsA-rats by tri-colour flowcytometry. Expression of TCR $\alpha \beta$. TCR $\gamma \delta, C D 8 \alpha \beta, N K$, and CR3 on CD4 SP, CD8 SP. CD4CD8 DN and CD4CD8 DP peripheral blood mononuclear cells. 
In addition, $\mathrm{T}$ cell recovery after $\mathrm{X}$-irradiation and syngeneic BMT was assessed by immunohistology. In spleen and lymph nodes from X-BM OO- and X-BM CsA-rats, 2 weeks after BMT, few TCR $\alpha \beta^{+}$cells were present. Four weeks after BMT the T cell area's in the XBM OO-rats had completely recovered, whereas the T cell area's in X-BM CsA-rats remained very small and recovered only slightly in the 4 weeks after cessation of CsA treatment. The compartimentalization of the lymphoid organs was normal. In unirradiated CsA-rat tissues, T cell area's were decreased in size during and 2 weeks after CsA administrution compared to OO-rats. In T cell area's of spleen and lymph node sections, obtained from X-BM CsA-rats, hardly any Thy $1.1+$ lymphocytes were seen. Overall the findings of histological analysis of spleen and cervical lymph nodes corresponded with those of flowcytometry analysis.

In summary, CsA treatment caused a strong reduction of T cell recovery in X-BM CsArats. This recovery was obscured by the large amount of TCR $\alpha \beta$-cells expressing CD 4 or CD8, which were further characterized as monocytes and NK cells respectively. Furthermore, monocytes appeared to express both CD4 and CD8. No changes in CD4: CD8 T cell ratio's were observed, but during CSA administration the relative amount of DP and DN TCR $\alpha \beta^{+}$ cells was increased in X-BM CsA-rats. However, absolute numbers of DP and DN T cells were low and at the onset of disease the relative amount of these cells had declined to normal.

Induction of CSA-AI results in a relative increase of CD4SRC+RT6. Th cells in the CSA-AI susceptible Lewis rat To assess the development of the CD4 Th subsets in the course of induction of CsA-AI, flowcytometry was performed with the tri-colour combinations CD4/CD45RC/RT6 and CD4/Thyl.1/RT6.

As described above, CsA partially abrogates thymic output resulting in decreased numbers of RTE. Furthermore, the analysis of peripheral Th cell phenotypes in X-BM CsA-rats showed a decrease of the percentage of CD45RC, RT6 DP Th cells in favour of CD45RC, RT6 DN Th cells. This was most prominent at the onset of disease. Control groups always had a preponderance of CD45RC, RT6 DP over DN Th cells (Table II).

With respect to the presumed $T h \mathrm{~L}$ like and Th2 like memory cells, recognized as CD45RC+RT6- and CD45RC- $\mathrm{RT}^{-} 6^{+}$respectively, in X-BM OO-rats, a strong relative increase in CD45RC+RT6- Th cells was observed 4 weeks after the start of the experiment, whereas the CD45RC-RT6+ Th cells remained unaffected. The increase in CD45RC+RT6- Th cells was even more pronounced in X-BM CsA-rats. The striking difference between the X-BM OO- and $X$-BM CsA-rats became most evident 2 weeks after cessation of the CsA therapy. Especially when evaluating the $\mathrm{CD}_{45 \mathrm{RC}} \mathrm{RT}^{-}$: CD45RC-RT6 ${ }^{+}$Th cell ratio it appeared that this ratio reversed in favour of the CD45RC+RT6- Th cells in X-BM CsA-rats (Th1: Th2 $=2.83$, Table II), whereas the ratio was almost restored to normal in X-BM OO-rats (Th1: Th2 $=0.68$ ). The experiment has been repeated twice revealing the same results. Given the low absolute numbers 
Table II: CD4 T cell subsets in LEW and BN rats

\begin{tabular}{lcccccc}
\hline \hline & LEW rats & \multicolumn{5}{c}{ BN rats } \\
\hline Week 4 & $\mathrm{OO}$ & $\mathrm{CsA}$ & $\mathrm{X}$-BM OO & $\mathrm{X}$-BM CsA & $\mathrm{OO}$ & $\mathrm{X}$-BM CsA \\
& $\mathrm{n}=2$ & $\mathrm{n}=2$ & $\mathrm{n}=2$ & $\mathrm{n}=3$ & $\mathrm{n}=3$ & $\mathrm{n}=2$ \\
\hline RTE $^{2}$ & $17.4 \%$ & $3.3 \%$ & $24.4 \%$ & $10.5 \%$ & $13.0 \%$ & $4.8 \%$ \\
Naive & $58.4 \%$ & $77.8 \%$ & $32.7 \%$ & $22.1 \%$ & $36.5 \%$ & $18.8 \%$ \\
Activated & $8.5 \%$ & $6.7 \%$ & $16.2 \%$ & $33.2 \%$ & $31.1 \%$ & $68.6 \%$ \\
Th1 & $4.8 \%$ & $4.1 \%$ & $17.1 \%$ & $25.4 \%$ & $3.0 \%$ & $1.9 \%$ \\
Th2 & $11.0 \%$ & $8.3 \%$ & $9.7 \%$ & $8.9 \%$ & $16.4 \%$ & $5.9 \%$ \\
Th1 / Th2 & 0.44 & 0.49 & 1.76 & 2.85 & 0.18 & 0.32 \\
& & & & & & \\
\hline Week 6 & $\mathrm{n}=2$ & $\mathrm{n}=2$ & $\mathrm{n}=2$ & $\mathrm{n}=3$ & $\mathrm{n}=1$ & $\mathrm{n}=5$ \\
\hline RTE & $19.0 \%$ & $8.5 \%$ & $16.3 \%$ & $8.1 \%$ & $12.8 \%$ & $15.2 \%$ \\
Naive & $49.0 \%$ & $67.5 \%$ & $39.1 \%$ & $14.0 \%$ & $39.1 \%$ & $19.7 \%$ \\
Activated & $12.5 \%$ & $12.7 \%$ & $19.2 \%$ & $50.6 \%$ & $10.7 \%$ & $25.4 \%$ \\
Th1 & $4.1 \%$ & $2.5 \%$ & $10.4 \%$ & $20.1 \%$ & $2.8 \%$ & $1.5 \%$ \\
Th2 & $15.5 \%$ & $8.9 \%$ & $15.2 \%$ & $7.1 \%$ & $31.0 \%$ & $29.3 \%$ \\
Th1 / Th2 & 0.26 & 0.28 & 0.68 & 2.83 & 0.09 & 0.05 \\
\hline \hline
\end{tabular}

Flowcytometry analysis of peripheral blood Th cells in LEW and BN rats during CSA therapy (Week 4) and thereafter (Week 6).

1 OO (olive oil treated), CsA (Cyclosporin-A treated), X-BM OO (X-irradiated, syngeneic BM reconstituted and olive oil treated) and X-BM CsA (X-irradiated, syngeneic BM reconstituted and CsA treated).

${ }^{2}$ Phenotypic descrimination of $\mathrm{CD} 4^{+}$TCR $\alpha \beta^{+}$Th cell subsets according to Kampinga et al [25]: RTE (Thy $1.1^{+}$), Naive (Thyl.1\%, CD45RC+, RT6 ), Activated (Thy 1.1', CD45RC, RT6), Thl (Thyl.1', CD45RC+, RT6) and Th2 (Thy 1.1, CD45RC, RT6 $6^{+}$).

of T cells in X-BM CsA-rats, all Th subsets were decreased in terms of absolute numbers. Nevertheless, these results show that only the combination of CsA plus X-irradiation resulted in a persistent reversal of the CD45RC+RT6 ${ }^{*}$ : CD45RC-RT6+ (Th1 : Th2) ratio.

CsA-AI resistant Brown Norway rats show no increase in CD45RC+RT6- Th cells after $X$ irradiation, syngeneic BMT and CsA treatment In order to determine peripheral blood T cell development in CsA-AI resistant BN rats, we performed flowcytometry analysis on PBL of unirradiated $\mathrm{OO}$ - and $\mathrm{X}-\mathrm{BM} \mathrm{Cs} \mathrm{A}-\mathrm{BN}$ rats. Like in Lewis rats, $\mathrm{X}-\mathrm{BM} \mathrm{CsA}-\mathrm{BN}$ rats showed a reduction of $\mathrm{CD} 4+\mathrm{RTE}$. Furthermore, as compared to OO-BN rats, the X-BM CsA-BN rats revealed a strong increase in CD45RC, RT6 DN Th cells up to $70 \% 4$ weeks after BMT. However, 2 weeks after cessation of CsA administration the number of CD45RC, RT6 DN Th cells was reduced (Table II). 
The CD45RC+RT6- : CD45RC-RT6+ ratio in OO-BN was in favour of CD45RC-RT6+ Th cells $(0.18: 1$ to $0.09: 1)$. In X-BM CsA-BN a relative strong decrease in CD45RC-RT6+ was observed at week 4 while the CD45RC+RT6- Th cells were only slightly decreased. However, the CD45RC+RT6' : CD45RC-RT6+ ratio in the X-BM CsA-BN did not reverse (Th1 : Th2 = 0.32, Table II) and was restored to normal values 2 weeks after cessation of CsA administration by a strong increase in CD45RC-RT6+ Th cells (Th1: Th2 $=0.05$ ). In conclusion these experiments revealed that in the resistant BN rats, subjected to the protocol for induction of CsA-AI, no skewing towards CD45RC+RT6- Th cells occurred.

\section{CD45RC ${ }^{+}$RT6- Th cells produce a high amount of Interferon $\gamma m R N A$ upon in vitro activation} To characterize cytokine mRNA production by the mature Thy 1.1- Th subsets described above, the different subsets were isolated. Since X-BM CsA-rats with clinical manifest CsA-AI have only very few $T$ cells and isolation of sufficient Th cells of each subset from CsA-AI diseased rats appeared to be extremely difficult, $C D 4+T C R \alpha \beta+$ cells were isolated from normal Lewis rats. The cells were sorted based on their expression of CD45RC and RT6 in four different populations proposed to represent Thl like (CD45RC+RT6-), Th2 like (CD45RC-RT6+), naive Th (CD45RC+RT6+) and activated Th cells (CD45RC-RT6-). In order to establish the production of IL2, IL4, IL10 and IFN $\gamma$ mRNA by these Th subsets the cells were harvested 16 hours after activation, and mRNA production was determined by RT-PCR. As a control for activation of the Th cells, proliferation was assessed in parallel cultures.

Activation by cross-linking of the TCR in the presence of spleen dendritic cells resulted in all subsets in the formation of blast like cells and in extensive proliferation after a culture period of 72 hours (Fig. 4A). CD45RC ${ }^{+}$RT6 $^{-}$cells cultured in the presence of dendritic cellls but without cross-linking of the TCR also formed blast like cells and incorporated $\left[{ }^{3} \mathrm{H}\right]$-thymidine:

To establish mRNA levels of G3PDH and rat cytokines, RT-PCR was performed as described. The amount of G3PDH mRNA was comparable in all samples (Fig. 4B). All 4 Th cell populations produced IL2 mRNA after 16 hours of stimulation with TCR cross-linking mAb (Fig. 4C). No IL2 mRNA was detectable in the CD45RC+RT6- subset cultured for 16 hours in the presence of control $\mathrm{mAb}$, in spite of the activated state indicated by proliferation and blast like morphology after 72 hours of culture. The CD45RC-RT6*' subset produced relatively little IL2 mRNA. A striking difference, however, was observed for the production of IFN $\gamma$. Only CD45RC+RT6- Th cells, activated by TCR cross linking, produced a detectable amount of IFN $\gamma$ mRNA (Fig. 4D). The amount of IL4 mRNA and IL 10 mRNA was equally low in all samples as assessed under UV light. There was no clear difference between the 4 different subsets, either activated or cultured on mock antibody. Additional phosphor imaging analysis of southern blots of the PCR products, hybridized with specific [32P]-labelled probes, 
did not reveal upregulation of IL4 or IL10 mRNA in any of the R73 activated Th subsets compared to control Th cell subsets (data not shown). Dendritic cells produced no detectable amounts of cytokine mRNA. Altogether the CD45RC+RT6- Th subset, i.e. the Th subset which is relatively expanded in CsA-AI diseased Lewis rats, was distinct from the other populations by the high expression of IFN $\gamma$ mRNA upon stimulation by cross-linking of the TCR in the presence of spleen dendritic cells.

Figure 4: CD4 T cells were isolated from lymph nodes from one control LEW rat, sorted based on the expression of CD45RC and RT6 and cultured in the presence of splecn dendritic cells and TCR cross-linking mAb (R73) or mock mAb. The proliferative response of Th cell subsets was determined by $\left[{ }^{3} \mathrm{H}\right]$-thymidine incorporation in the final 18 hours of 90 hour culture (Fig. A). Stimulation Index (S. .) was calculated as the [3H]-thymidine incorporation of each Th cell subset, cultured in the presence of mAb R73 (hatched bars). devided by the $\left[{ }^{3} \mathrm{H}\right]$-thymidine incorporation after culture in the presence of mock $\mathrm{mAb}$ (open hars).

The production of cytokine mRNA was determined by RT-PCR of sorted Th cells cultured for $16 \mathrm{~h}$ as described above. Resultant PCR products were seperated on an ethidium-bromide stained $2 \%$ Agarose gel and visualized under UV light. The gels show the result of 27 PCR cycles in case of G3PDH (Fig. B) or 33 PCR cycles in case of IL2 (Fig. C) and IFN (Fig. D). Lanes: M: length marker, -: negative control (only shown for IFN $\gamma$, D), 1: CD45RC ${ }^{+}, \mathrm{RT}^{-}$Th (Thl cells according to the model of Kampinga et al. [25]) cells cultured with mock

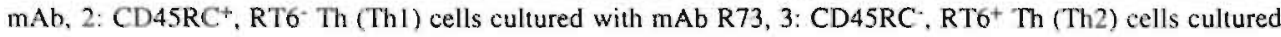
with mock mAb, 4: CD45RC; RT6 $6^{+}$Th (Th2) cells cultured with mAb R73, 5: CD45RC . RT6 $^{+}$(naive) Th cells cultured with mock mAb, 6: CD45RC ${ }^{+}$. RT6* (naive) Th cells cultured with mAb R73, 7: CD45RC; RT6- (activated) Th cells cultured with mock mAb. 8: CD45RC : RT6- (activated) Th cells cultured with mAb R73. 
A

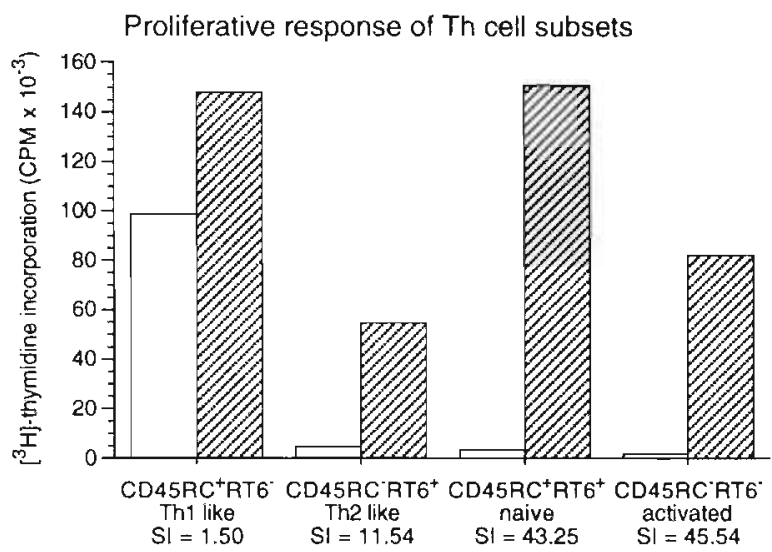

B

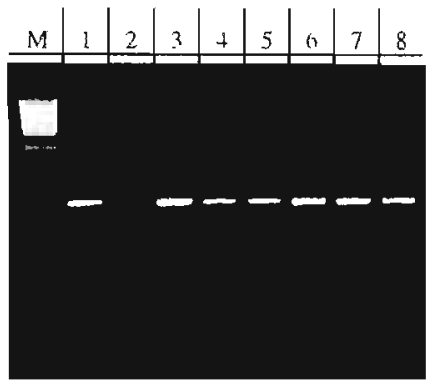

C

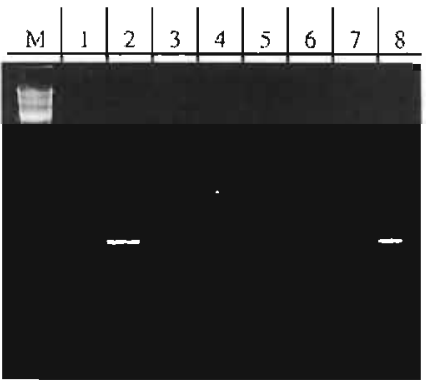

D

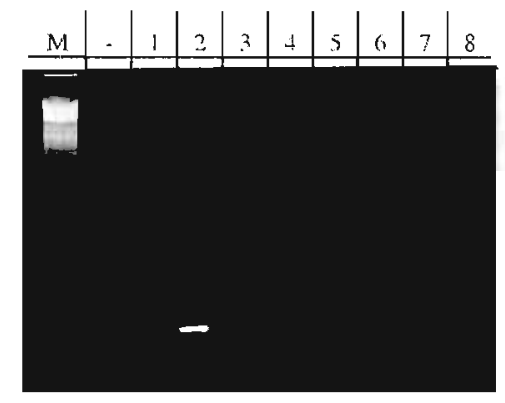




\section{Discussion}

The main findings of this study are fourfold. First, a strong decrease in recent thymic emigrants (RTE) is demonstrabie in the periphery of Lewis rats treated with CsA. Next, CsA$\mathrm{AI}$ in Lewis rats is not associated with increases in $\mathrm{CD}^{+} \Upsilon$ cells but is associated with a persistent reversal of the $\mathrm{CD} 45 \mathrm{RC}^{+} \mathrm{RT}^{-} 6^{-}$: $\mathrm{CD} 45 \mathrm{RC} \mathrm{C}^{-} \mathrm{RT} 6^{+}$ratio as a result of a relative increase of the CD45RC+RT6- Th subset. In BN rats such a reversal is absent which supports the notion that the ratio of CD45RC+RT6 : CD45RC-RT6 $6^{+}$, i.e. the ratio of Th1: Th2 cells, determines susceptibility to disease in Lewis and resistance in $\mathrm{BN}$ rats. Finally, the CD45RC $+R^{-T} 6$ - Th cells are the only Th cells able to produce substantial amounts of message for IFN $\gamma$. Therefore these cells are considered Thl cells.

Our results contradict 2 previous observations: the leakage of cortical thymocytes into the periphery $(7,8)$ and the delayed recovery of $\mathrm{CD} 4$ cells in experimental rats suggesting the importance of Th cells (13). Tri-colour flowcytometry for examination of CD4 and CD8 expression in combination with TCR $\alpha \beta$ enabled us to determine CD4+ and CD8+ T cells. In this way the majority of CD4CD8 DP cells was identified as CR3+ monocytes instead of cortical thymocytes. Furthermore, our analysis of Thy 1.1 expression, a marker for RTE (2527), on peripheral $T$ cells demonstrated that CsA decreases thymic output. Yet, autoreactive cells are generated as shown in Lewis rats in CsA-AI, in spite of the fact that there is a decreased thymic output. With respect to the suggested selective elfect of CsA on $\mathrm{CD} 4^{+}$cells our results demonstrate that the majority of $\mathrm{CD}^{+}$cells are NK cells, whereas most $\mathrm{CD} 4^{+}$cells are monocytes. Altogether, CD4 and CD8 $\mathrm{T}$ cells are equally affected resulting in an unaltered CD4 : CD8 T cell ratio. A slight relative increase in CD4CD8 DP T cells is observed, but absolute numbers are not elevated when compared to the controls. The absolute numbers of CD4CD8 DN T cells on the other hand is elevated compared to the controls. However, the DN $\mathrm{T}$ cells play no role in development of $\mathrm{CSA}-\mathrm{AI}$, as has been demonstrated by adoptive transfer of DN T cells from diseased CsA-AI rats into thymectomized X-irradiated recipient rats (Chapter 6). Overall it seems that at the onset of disease the relative distribution of $\mathrm{T}$ cell subsets as defined by CD4, CD 8 and TCR $\alpha \beta$ expression is comparable to the normal situation except for the low number of $\mathrm{T}$ cells.

Many reports have shown that the $\mathrm{CD4} 4^{+} \mathrm{T}$ cell subset can be subdivided by the expression of CD45RC and RT6. These populations have counter-regulatory properties with respect to autoimmunity, including $\mathrm{CsA}-\mathrm{AI}(11,31-33,36,38,58,59)$. In vivo manipulation of the balance between these subsets by depleting antibodies reactive with CD45RC or RT6 as well as adoptive transfer of the respective $T$ cell subpopulations in Diabetic Prone/BioBreeding (DP/BB) rats has shown that within the $\mathrm{RT}^{+}$population a protective population resides. whereas $\mathrm{CD}_{45 \mathrm{RC}^{+}}$cells aggravate the course of disease $(33,38)$. Adoptive transfer studies in 
the model of CsA-AI have shown that adding normal splenocytes or lymph node cells to effector cells derived from diseased rats prevents development of disease (12). The responsible autoregulatory cells were CD45RC- $\mathrm{T}$ cells (11). Phenotypical analysis of peripheral $\mathrm{T}$ cell maturation (25), established from vascular thymus transplantation studies within R'T7 congenic rat strains, revealed the presence of 5 different $C D 4 T$ cell subsets, including Th cells coexpressing CD45RC and RT6. Therefore the expression of CD45RC or RT6 can not, by itself, represent a homogenous Th cell population. Kampinga et al postulated a model in which CD45RC+RT6 ${ }^{+}$DP represent naive Th cells, while CD45RC+RT6- and CD45RC-RT6 ${ }^{+}$form Th1 and Th2 like cells respectively (25). In this study we demonstrate prior to CAA-AI the stable reversal of the CD45RC+RT6- $\mathrm{CD}^{+} 5 \mathrm{RC} \mathrm{R}^{-\mathrm{RT}} 6^{+}$ratio (i.e. Th1: Th2 ratio) in favour of $\mathrm{CD}^{2} 5 \mathrm{RC}^{+} \mathrm{RT}^{-}$in the susceptible Lewis. This reversal is caused by a relative expansion of the $\mathrm{CD} 45 \mathrm{RC}+\mathrm{RT} 6$ - Th cell subset. BN rats subjected to the same protocol for induction of CsA-AI did not show an expansion of $\mathrm{CD}^{2} 5 \mathrm{RC}^{+} \mathrm{RT}^{-}$nor a reversal in the $\mathrm{CD}^{-} 5 \mathrm{RC} \mathrm{C}^{+} \mathrm{RT} 6^{-}: \mathrm{CD}^{-} 5 \mathrm{RC}^{-}$ $\mathrm{RT}^{+}$ratio.

Upon in vitro stimulation by cross-linking of the TCR, CD45RC+RT6- Th cells produce mRNA coding for the cytokines IL2 and IFN $\gamma$. IFN $\gamma$ is a key cytokine in macrophage activation and induction of MHC clas II upregulation on epithelial cells, two aspects observed in the target organs of CsA-AI (60). Moreover, the production of IL2 in combination with IFNy is a confirmation of the model of Kampinga with respect to the identification of Thl cells by the CD45RC+RT6- phenotype.

We were unable to detect an upregulation of ILA or IL 10 mRNA upon stimulation in any of the 4 Th cell subpopulations although all 4 subsets reacted to TCR cross-linking in the presence of dendritic cells with formation of a blast like morphology and production of IL2 mRNA. The freshly isolated CD45RC-RT6- DN Th cells apparently do not represent currently activated Th cells since, in the absence of cross-linking of the TCR, they produced no cylokines nor developed a blast like morphology. This might be because activated Th cells in the rat are known to express MHC class II as well as CD8 and therefore may be eliminated by the negative selection procedures used. In conclusion our results define only the CD45RC+RT6Th cells as Thl cells.

While $\mathrm{BN}$ rats are resistant to induction of $\mathrm{T}$ cell mediated diseases such as experimental allergic encephalomyelitis, rheumatoid arthritis, and CsA-AI, they are very susceptible for the antibody mediated Mercury-Chloride induced autoimmunity (61). Here an inversed situation exists: the effector cells are found within the CD45RC- $T$ cells, whereas protection is obtained with normal $C D 45 R C+T$ cells (59). It has been shown that there are large differences in the CD45RC+RT6 : CD45RC-RT6+ ratio between different rat strains, but not between age and sex matched individuals within a specific inbred rat strain (35). These results of 
CD45RC+RT6- : CD45RC-RT6+ ratios correlate well with susceptibility for cell or antibody mediated experimental autoimmune models in the respective rat strains (35).

The question remains what mechanism results in the development of CsA-AI. Several models have revealed that under physiological circumstances potentially autoreactive $\mathrm{T}$ cells are present. Repeated low dose (i.e. not lethal) total body X-irradiation results in the development of thyroiditis (62) and diabetes (38) in thymectomized rats and a scala of organ specific autoimmune phenomena in mice (63). Furthermore, depletion of RT6+ cells in Diabetes Resistant (DR) BB rats leads to the development of diabetes (33). Moreover, in the mouse CsA has been shown to result in "lorbidden V-beta" bearing $T$ cells in the thymus and periphery by interference with negative selection $(22,23)$. But the mere presence of autoreactive $T$ cells, as caused by CsA therapy. does not result in autoimmunity (64). As mentioned above special circumstances are required (repeated low dose X-irradiation or depletion of RT6+ cells), which also result in a relative increase of autoreactive $\mathrm{T}$ cells. CSA-AI has in common with irradiation induced autoimmunity and diabetes in the DP BB rat that the animals are rendered relatively lymphopenic (32). Our results show that high dose X-irradiation induced lymphopenia in Lewis rats results in a transient increase of Thl cells. As stated by Perez et al. (65) it is tempting to see $\mathrm{Th} \mathrm{L}$ as principal effector cells and Th2 as regulatory cells that control Th1 mediated inflammation. Furthermore, they predict that Th1 cells arise early during $T$ cell differentiation, and may be induced to convert into regulatory Th2 cells. The resistance or susceptibility of certain strains to induction of autoimmune disease may therefore reside in the potency of the periphery to enhance the shift from Thl to Th2 activity. This is illustrated by our results in CsA-AI; a disease in Lewis rats mediated by $\mathrm{CD} 4+\mathrm{Th} 1$ effector cells.

\section{Acknowledgements}

The authors wish to thank Prof. Th. Hünig (Würzburg, Germany), Prof. K.Wonigeit (Hannover. Germany), Dr. G. Butcher (Babraham, UK), Prof. C.D. Dijkstra (Amsterdam, the Netherlands) and Dr. B. de Geus (Leiden, the Netherlands) for the generous gift of monoclonal antibodies. Furthermore we would like to express our gratitude towards Geert Mesander (Shared Flowcytometry Facilities, University of Groningen) and Nomdo Westendaal (Flowcytometry Facilities, University Hospital of Utrecht) for flowcytometry assistance and Jennie Pater, Marie-José van de Gaar, Mia Vaessen and Harry van der Heijden for their excellent technical assistance. 


\section{References}

I Glazier, A., Tutschka, P. J., Farmer, E. R. and Santos, G. W. (1983) Graft-versus-host disease in cyclosporin A-treated rats after syngeneic and autologous bone marrow reconstitution. J. Exp. Med. 158:1-8

2 Bos, G. M. J., Majoor, G. D., Willighagen, R. G. J. and van Breda Vriesman, P. J. C. (1989) Chronic cyclosporine-induced autoimmune disease in the rat: a new experimental model for scleroderma. $J$. Invest. Dermatol. 93:610-615

3 Majoor, G. D., Wodzig. K. W. H. and van Breda Vriesman, P. J. C. (199I) Cyclosporin-induced autoimmunity. In Thymus Update. M.D. Kendall and M.A. Ritter. Editors. Harwood Acad Press, Chur, Switzerland. 179-200

4 Yasutomi, D., Odaka, C., Saito, S., Niizeki, H., Kizaki, H. and Tadakuma, T. (1992) Inhibition of programmed cell death by Cyclosporin A; preticrential blocking of cell death induced hy signals via TCR/CD3 complex and its mode of action. Immunology: 77:68-74

5 Urdahl, K. B., Pardoll, D. M. and Jenkins, M. K. (1994) Cyclosporin A inhibits positive selection and delays negative selection in $\alpha \beta$ TCR transgenic mice. J. Immunol. 152:2853-2859

6 Hess, A. D., Vugelsang, G. B., Heyd, J. and Beschorner, W. E. (1987) Cyclosporine-induced syngeneic graft-versus-host disease: Assesment of T-cell differentiation. Transplant. Proc. 19:2683-2686

7 Chen-Woan, M. and Goldschneider, I. (1991) Evidence that cyclosporine treatment causes the appearance in rat lymph node of $\mathrm{T}$ cells having the antigenic phenotypes of cortical thymocytes. Transplantation. 51:661-668

8 Hosseinzadeh, H. and Goldschneider, I. (1993) Demonstration of large-scale migration of cortical thymocytes to peripheral lymphoid tissues in cyclosporin A-treated rats. J. Exp. Med. 178:285-293

9 Sorokin, R., Kimura, H., Schroder, K., Wilson, D. H. and Wilson, D. B. (1986) Cyclosporin-induced autoimmunity: Conditions for expressing disease, requirement for intact thymus, and potency estimates of autoimmune lymphocytes in drug-treated rats. J. Exp. Med. 164:1615-1625

10 Hess, A. D., Fischer, A. C. and Beschorner, W. E. (1990) Effector mechanisms in cyclosporine A-induced syngeneic graft-versus-host disease. Role of $\mathrm{CD} 4+$ and $\mathrm{CD} 8+\mathrm{T}$ lymphocyte subsets. J. Immunol. $145: 526-533$

11 Fischer, A. C., Laulis, M. K., Horwitz, L., Beschorner, W. E. and Hess, A. D. (1989) Host resistance to cyclosporine induced syngeneic graft-versus-host disease: Requirements for two distinct lymphocyte subsets. J. Immunol. 143:827-832

12 Hess, A. D., Fischer, A. C., Horwitz, L., Bright, E. C. and Laulis, M. K. (1994) Characterization of peripheral autoregulatory mechanisms that prevent development of Cyclosporin-induced syngeneic graft-versus-host disease. J. Immunol. 153:400-41 I

13 Bos, G. M. J., Majoor, G. D. and van Breda Vriesman, P. J. C. (198s) Cyclosporin-A induces a selective, reversible suppression of $T$-helper lymphocyte regencration after syngeneic bone marrow transplantation: association with syngeneic graft-versus-host disidic. Clin. Exp. Immunol. 74:443-448

14 Jefferies, W. A., Green, J. R. and Williams, A. F. (1985) Authentic T helper CD4 (W3/25) antigen on rat peritoneal macrophages. J. Exp. Med. 162:121-127

15 Torres-Nagel, N., Kraus, E., Brown, M. H., Tiefenthaler, G., Mitnacht, R., Williams, A. F. and Hünig, T. (1992) Differential thymus dependence of rat CD8 isoform expression. Eur. J. Immunol. 22:28412848 
16 Wodzig, K. W. H., Majoor, G. D. and van Breda Vriesman, P. J. C. (1993) Susceptibility and resistance to Cyclosporin A-induced autoimmunity in rats. Autoimmunity. 16:29-37

17 Bryson, J. S., Jennings, C. D., Caywood, B. E. and Kaplan, A. M. (1989) Induction of a syngeneic graftversus-host disease-like syndrome in DBA/2 mice. Transplantation. 48:1042-1047

18 Bryson, J. S., Caywood, B. E. and Kaplan, A. M. (1991) Relationship of cyclosporin A-mediated inhibition of clonal deletion and development of syngeneic graft-versus-host disease. J. Immunot. 147:391-397

19 Bucy, R. P., Xu, X. Y., Li, J. and Huang, G. Q. (1993) Cyclosporin A-induced autoimmune disease in mice. J. Immunol. 151:1039-1050

20 Tanaka, M., Shihonara, K., Fukumoto, T., Tanaka, H. and Kaneko, T. (1988) Effect of cyclusporin A on rat thymus: time course analysis by immunoperoxidase technique and flow cytometry. Clin. Exp. Immunol. 72:216-221

21 Beijleveld, L. J. J., Damoiseaux, J. G. M. C. and van Breda Vriesman, P. J. C. (1995) The differential effects of $\mathrm{X}$-irradiation and Cyclosporin-A administration on the thymus with respect to the generation of Cyclosporin-A induced Autoimmunity. Dev. Immunol. 4:127-138

22 Gao, E. K., I.v, D., Cheney, R., Kanagawa, O. and Sprent, J. (1988) Abnormal differentiation of thymocytes in mice treated with Cyclosporin A. Nature. 336: 176-179

23 Jenkins, M. K., Schwartz, R. H. and Pardoll, D. M. (1988) Effects of Cyclosporin A on T cell development and clonal deletion. Science. 241:1655-1658

24 Fischer, A. C, Ruvolo, P. P., Burt, R., Horwitz, L. R., Bright, E. C., Hess, J. M., Beschorner, W. E. and Hess, A. D. (1995) Characterization of the autoreactive T cell repertoire in Cyclosporin-induced syngeneic Graft-versus-Host disease. A highly conserved repentoire mediates autoaggression. $J$. Immunol. 154:3713-3725

25 Kampinga, J., Groen, H., Klatter, F., Meedendorp, B., Aspinall, R., Roser, R. and Nieuwenhuis, P. (1992) Post-thymic T cell development in rats: an update. Biochem. Soc. Trans. 20: 191-197

26 Yang, C. and Bell, E. B. (1992) Functional maturation of recent thymic emigrants in the periphery: development of alloreactivity correlates with the cyclic expression of CD45RC isoforms. Eur. $J$. Immunol. 22:2261-2269

27 Hosseinzadeh, H. and Goldschneider. I. (1993) Recent thymic emigrants in the rat express a unique antigenic phenotype and undergo post-thymic maturation in peripheral lymphoid tissues. J. Immunol. 150:1670-1679

28 Lubaroff, D. M., Butcher, G., DeWitt, C., Gill III, T, Günther, E., Howard, J. and Wonigeit, K. (. m (1983) Standardized nomenclature for rat T-cell alloantigens: Report of the committee. Transpl. Proc. $15: 1683$

29 Hunt, H. D. and Lubaroff, D. M. (1987) Changes in membrane antigen phenotype of $T$ cells during lectin activation. Tranpl. Proc. 19:3179

30 Powrie, F. and Mason, D. (1990) Subsets of rat CD4+ T cells defined by their differential expression of variants of the CD45 antigen: developmental relationships and in vitro and in vivo functions. Carr Top. Microbiol. Immunol. 159:79

31 Fowell, D., McKnight, A. J., Powrie, F., Dyke, R. and Mason, D. (1991) Subsets of CD4+ T cells and their roles in the induction and prevention of autoimrnunity. Immunol. Rev. 123:37-64

32 Greiner, D. L., Handler, E. S., Nakano, K., Mordes, J. P. and Rossini, A. A. (1986) Absence of the RT-6 T cell subset in diabetes-prone BB/W rats. J. Immunol. 136:148-151 
33 Greiner, D. L., Mordes, J. P., Handler, E. S., Angelillo, M., Nakamura, N. and Rossini, A. A. (1987) Depletion of RT6.I+ T lymphocytes induces diabetes in resistant biobreeding/worcester (BB/W) rats. $I$. Exp. Med. 166:461-475

34 Sarawar, S. R., Sparshott, S. M., Sutton, P., Yang. C. P., Hutchinson, I. V. and Bell, E. B. (1993) Rupid re-expression of $\mathrm{CD} 45 \mathrm{RC}$ on rat $\mathrm{CD} 4 \mathrm{~T}$ cells in vitro correlates with a change in function. Eur. $J$. Immunol. 23: 103-107

35 Groen, H., Klatter, F. A., van Petersen, A. S., Pater, J. M., Nieuwenhuis, P. and Kampinga. J. (1993) Composition of rat CD4+ resting memory $\mathrm{T}$-cell pool is influenced by major histocompatibility complex. Transplant. Proc. 25:2782-2783

36 Powrie, F. and Mason, D. (1990) OX-22 high CD4+ T Cells induce wasting disease with multiple organ pathology: Prevention by the OX-22 low subset. J. Exp. Med. 172:1701-1708

37 Hunt, H. D. and Lubaroff, D. M. (1992) Identification of functional T cell subsets and surface antigen changes during activation as they relate to RT6. Cell. Immunol. 143:194-211

38 Fowell, D. and Mason, D. (1993) Evidence that the $T$ cell repertoire of normal rats contains cells with the potential to cause diabetes. Characterization of the $\mathrm{CD} 4+\mathrm{T}$ cell subset that inhibits this autoimmune potential. J. Exp. Med. 177:627-636

39 Hünig, T., Wallny, H.-J., Hartley, J. K., Lawetzky, A and Tiefenthaler, G. (1989) A monoclonal antibody to a constant determinant of the rat $\mathrm{T}$ cell antigen receptor that induces $\mathrm{T}$ cell activation. J. Exp. Med. 169:73-86

40 Kühnlein, P., Park, H.-J., Hermann, T., Elbe, A. and Hünig, T. (1994) Identification and characterization of $y / \delta$ T-lymphocytes in peripheral lymphoid organs, small intestine, and skin with a monoclonal antibody to a constant determinant of the $\gamma / \delta$ T-cell receptor. J. Immunol. 153:979-986

41 Chambers, W. H., Vujanovic, N. L., DeLeo, A. B., Olszowy, M. W., Herberman, R. B. and Hiserodt, J. C. (1989) Monoclonal antibody to a triggering structure expressed on rat natural killer cells and adherent lymphokine-activated killer cells. J. Exp. Med. 169:1373-1389

42 Joling, P., Tielen, F. J., Vaessen, L. M. B., Huijbregis, J. M. A. and Rozing, J. (1985) New markers on T cell subpopulations defined by monoclonal antibodies. Transplant. Proc. 17:1857-1860

43 Damoiseaux, J. G. M. C., Döpp, E. A., Neefjes, J. J., Beelen, R. H. J. and Dijkstra, C. D. (1989) Heterogeneity of macrophages in the rat evidenced by variability in determinants: two new anti-rat macrophage antibodies against a heterodimer of 160 and $95 \mathrm{kd}$ (CDII/CDI8). J. Leukocye Biol. 46:556-564

44 Fangman, J., Schwinzer, R., Winkler, M. and Wonigeit, K. (1990) Expression of RT6 alloantigens and the T cell reccptor on intestinal intraepithelial lymphocytes of the rat. Transpl. Proc. 22:2545

Butcher. G. W. (1987) A list of monoclonal antibodies specific for alloantigens of the rat. $J$. Immunogenetics 14:162-176

46 Kroese, F. G. M., Opstelten, D., Wubbena, A. S., Deenen, G. J., Aten, J., Schwander, E. H., Leij, L. d. and Nieuwenhuis, P. (1985) Monoclonal antibodies to rat B lymphocyle (sub-)populations. Adv. Exp. Med. Biol. 237:81-89

47 Hermans, M. H. A and Opstelten, D. (1991) In situ vizualization of hemopoietic cell subsets and stromal elements in rat and mouse bone marrow by immunostaining of frozen sections. J. Histochem. Cyrochem. 29:1627

48 Williams, A. F., Galfre, G. and Milstein, C. (1977) Analysis of cell surfaces by xenogeneic myelomahybrid antibodies: differentiation antigens of rat lymphocytes. Cell. 12:663-673 
49 McMaster. W. R. and Williams, A. F. (1979) Identification of Ia glycoproteins in rat thymus and purification from rat spleen. Eur. J. Immunol. 9:426-433

50 Spickett, G. P., Brandon, M. R., Mason, D. W., Williams, A. F. and Woollett, G. R. (1983) MRC OX22, a monoclonal antibody that labels a new subset of T lymphocytes and reacts with the high molecular weight form of the leukocyte-common antigen. J. Exp. Med. 158:795-810

51 Brideau, R. J., Carter, P. B., MeMaster, W. R., Mason, D. W. and Williams, A. F. (1980) Two subsets of rat T lymphocytes defined with monoclonal antibodies. Eur. J. Immunol. 10:609-615

52 Julius, M. H., Simpson, E. and Herzenberg, L. A. (1973) A rapid method for the isolation of functional thymus-derived lymphocytes. Eur. J. Immunol. 3:645-652

53 Fort, P., Marty, L., Piechaczyk, M., el Sabrouty, S., Dani, C., Jeanteur, P. and Blanchard, J. M. (1985) Various rat adult tissues express only one major mRNA species from the glyceraldehyde-3-phosphatedehydrogenase multigenic family. Nucleic Acids Res. 13: [43]

54 McKnight, A. J., Mason, D. W. and Barclay, A. N. (1989) Sequence of rat interleukin 2 and anomalous binding of a mouse interleukin 2 cDNA prohe to rat MHC class II-associated invariant chain mRNA. Immunogenetics. 30:145

55 McKnight, A. J., Barclay, A. N. and Mason, D. W. (1991) Molecular cloning of ratt interleukin 4 cDNA and analysis of the cytokine repertoire of subsets of CD4+ T cells. Eur. J. Immunol. 21:1187-1194

56 Goodman, R. E., Oblak, J. and Bell, R. G. (1992) Synthesis and characterization of rat interleukin-10 (IL10) cDNA clones from the RNA of cultured OX8- OX22- thoracic duct T cells. Biochem. Biophys. Res. Commun. 189:1

57 Dijkema, R., van der Meide, P. H., Pouwels, P. H., Caspers, M., Dubbeld, M. and Schellekens, H. (1985) Cloning and expression of the chromosomal immune interferon gene of the rat. EMBO J. 4:76I

58 Groen, H., Klatter, F. A., Brons, N. H. C., Wubbena, A. S., Nieuwenhuis, P. and Kampinga, J. (1995) High-frequency, but reduced absolute numbers of recent thymic migrants anong peripheral blood $T$ lymphocytes in Diabetes-prone BB rats. Cell Immunol. 163:113-119

59 Mathieson, P. W., Thiru, S. and Oliveira. D. B. G. (1993) Regulatory role of OX22high T-cells in mercury-induced autoimmunity in the Brown Norway rat. J. Exp. Med. 177:1309-1316

60 Damoseaux, J. G. M. C., Beijleveld, L. J. J. and van Breda Vriesman, P. J. C. (1995) Cutaneous immunopatholugy of Cyclosporin-A induced autoimmunity in the rat. Clin. Immunol. Immunopathol. 77:315-323

6I Mathicson, P. W. (1992) Mercuric chloride-induced autoimmunity. Autoimmunity. 13:243-247

62 Penhale, W. J., Farmer, A., McKenna, R. P. and Irvine, W. J. (1973) Spontaneous thyroiditis in thymectontized and irradiated Wistar rats. Clin. Exp. Immunol. 15:226-236

b3 Sakaguchi, N., Miyai, K. and Sakaguchi, S. (1994) Ionizing radiation and autoimmunity. Induction of autoimune disease in mice by high dose fractionated total lymphoid irradiation and its prevention by inckulating normal T cells. J. Immunol. 152:2586-2595

64 Beijleveld, L. J. J., Damoiseaux. J. G. M. C. Wodrig. K. W. H. and van Breda Vriesman, P. J. C. (1995) $\mathrm{X}$-irradiation of the thymus is not required for the induction of Cyclosporin-A induced autoimmunity. Transplantation. 59:1601-1605

65 Perez, V. L., Lederer, J. A., Lichtman, A. H. and Abbas. A. K. (1995) Stability of Thi and Th2 populations. International Immunol. 7:869-875 
Leo J.J. Beijleveld', Jan G.M.C. Damoiseaux ', Mihovil Roglic², Argyrios N. Theofilopoulos ${ }^{2}$ and Peter J.C. van Breda Vriesman ${ }^{1}$

1 The Department of Immunology. Faculty of Medicine, University of Limburg, P.O.B. 616, 6200 MD Maastricht, The Netherlands and; 2 The Department of Immunology. The Scripps Research Institute, 10666 North Torrey Pines Road/IMM3, La Jolla, California 92037

Accepted by Transplantation

\section{Summary}

Lethally-irradiated Lewis rats reconstituted with syngeneic bone marrow and given Cyclosporin-A for 4 wecks develop a $\mathrm{GvH}$-like disease upon withdrawal of CsA. Autoreactive $\mathrm{T}$ cells inducing this thymus-dependent autoimmune disease, termed $\mathrm{CsA}-\mathrm{AI}$, are demonstrable by adoptive transfer, provided regulatory cells in recipient rats are eliminated. Earlier studies have not unequivocally defined the effector $\mathrm{T}$ cells responsible for development of CsA-AI. Some of these studies suggest that both CD4 and CD8 T cells are required, while other studies indicate disease transfer by CD4 or CD8 T cells only.

To further clarify this issue, it was necessary to study putative effector T cells in a welldefined setting. Hence. adoptive transfer studies were designed wherein the effect of the $T$ cells of interest could be studied without being influenced by $T$ cells of unwanted origin. Accordingly, recipient rats were thymectomized prior to irradiation, lymph node cells (LNC) from diseased donor rats were depleted of CD4 or CD8 cells before adoptive transfer, and recipients were treated in vivo with $\mathrm{CD} 4$ - or CD8-depleting $\mathrm{mAb}$.

The results showed that CsA-AI developed after adoptive transfer with LNC, depleted of either CD4 or CD8 cells. Analysis of PBL and histologic specimens confirmed the absence of the depleted subset. In both instances, the typical MHC class II expression on keratinocytes, and the presence of EDl+ macrophages, were identical to the lesions in the primary donors, where both CD4 and CD8 T cells were present. Analysis of the T cell Receptor $\beta$-chain variable region (BV) repertoires revealed that their expression patterns in LNC of diseased donors or recipients was comparable to that in normal thymus or LNC; hence, there was no restricted BV repertoire. Taken in toto, our observations indicate that $\mathrm{CsA}$ - AI involves both CD4 and CD8 T cells, and that either of these subsets per se can generate identical macroscopic and microscopic signs of disease. 


\section{Introduction}

Cyclosporin-A (CsA), a fungal metabolite, is widely used for its immunosuppressive activity in the treatment of allograft rejection and graft-versus-host disease (GvHD) after allogeneic bone marrow transplantation (BMT). In contrast with immunosuppression, CsA can also induce autoreactivity, as shown in Lewis rats wherein transient treatment with CsA after total body irradiation and syngeneic BMT results in a systemic autoimmune disease $(1,2)$. This CsA-induced autoimmunity (CsA-AI) is T-cell-mediated and requires an intact thymus during the first two weeks of CsA administration $(3,4)$. It is evident that autoreactive $T$ cells are produced in the thymus and migrate into the periphery during CsA administration (4). Total body irradiation is essential for CsA-AI development, perhaps acting by eliminating the regulatory $\mathrm{T}$ cell circuit in the periphery.

To characterize the immunopathologic mechanism of CsA-AI, the disease-inducing capacity of $T$ cells and of their subsets has been studied using a variety of approaches. First, phenotypic analysis of peripheral blood lymphocytes (PBL) revealed suppression of the CD4 cell population during CsA treatment, and reappearance of CD4 cells coincided with development of clinical CsA-AI symptoms, suggesting that the cells responsible for disease induction reside in the CD4 population (2). However, this is refuted by the observation that CD8 T cells are also affected by $\mathrm{CsA}$ in a manner similar to CD4 cells (Chapter 5). Second, immunohistochemical studies of the skin, a major target organ, have shown that the epidermis is predominantly infiltrated by CD4 cells $(5,6)$ during the acute phase of CsA-AI, whereas another study indicated equal numbers of CD4 and CD8 T cells (7). Adoptive transfer experiments are a third method to identify $\mathrm{T}$ effector cells, but the results have been conflicling. Sorokin et al. transferred disease with as few as $3 \times 10^{5} \mathrm{CD} 4 \mathrm{LNC}$ from animals with acute CsA-AI (3), while Fischer et al. demonstrated a requirement for both CD4 and CD8 T cells (8), and Hess et al. showed that transfer of large numbers $\left(\times 3 \times 10^{7}\right)$ of splenic CD 8 cells was sufficient to induce CsA-AI in the secondary recipients, whereas CD4 cells were ineffective (9). However, in co-transfer of small numbers of CD4 cells. lower numbers of CD8 cells were required for disease transfer (9). The fourth method is in vivo depletion of CD4 or CD8 cells with monoclonal antibodies $(\mathrm{mAb})$ after adoptive transfer of $\mathrm{CsA}$-AI with T cells. In this approach, CD8 depletion completely abrogated disease, while CD4 depletion strongly delayed the onset, and decreased disease severity (10). Taken together, the specific role of CD4 and CD8 T cells in the effector mechanism of CsA-AI remains a topic of debate.

In this study, we reevaluated this question by performing adoptive transfer studies under rigorous cell separation regimens. The T cell subsets used were obtained by negative selection in vitro and clearly defined by tri-colour flow cytometry. Furthermure, adoptive transfer of such cells was performed in thymectomized recipients that received anti-CD4 or anti-CD8 
treatment to prevent new thymic output and eliminate minor contaminants remaining after in vitro selection. Recipients were monitored for disease onset and $\mathrm{T}$ cells in peripheral blood and skin biopsies were analyzed for phenotypic composition as well as T cell Receptor (TCR) $\beta$ chain variable region (BV) expression profiles. The results indicate that either $T$ cell subset is sufficient for CsA-AI transfer, and that these autoreactive cells exhibit no discernable restriction in the BV they display.

\section{Materials \& Methods}

Animals Female inbred Lewis rats (RT1') were obtained from the Central Animal Facility of the University of Limburg, the Netherlands. The animals were maintained under specific pathogen free conditions until use and had free access to food and water. Rats were 6 weeks of age at the start of the experiment.

Protocol for the Induction of CSA-AI Rats were given $8.5 \mathrm{~Gy} X$-irradiation at $0.5 \mathrm{~Gy} / \mathrm{min}$., using a Röntgen irradiation machine (Philips MU15GF/225 kV, Hamburg, Germany) one day prior to syngeneic BMT. Recipient rats were given $6 \times 10^{7}$ viable nucleated syngeneic bone marrow cells intravenously into a tail vein as previously described (11). Starting from the day of BMT the rats received subcutaneously $7.5 \mathrm{mg} \mathrm{CsA} / \mathrm{kg}$ per day for 28 days. CsA, a kind gift from Sandoz Pharma Ltd., Basel, Switzerland, was dissolved in olive oil at a concentration of $7.5 \mathrm{mg} / \mathrm{ml}$. In the experiments, where indicated, the X-irradiated syngeneic BM reconstituted, CsA-treated (X-BM CsA-) rats, were compared to X-BM OO-rats (X-irradiated, syngeneic $\mathrm{BM}$ reconstituted and olive oil treated), CsA-rats (only CsA-treated rats) and OO-rats (olive oil only-treated rats).

Adoptive Transfer of CSA-AI LNC were harvested from animals 2 to 3 weeks after withdrawal of CSA when macroscopic signs of CSA-AI, i.e., dermatitis and severe weight loss, were evident. Putative effector cells were infused together with syngeneic bone marrow cells $\left(6 \times 10^{7}\right)$ into irradiated secondary recipients. Where indicated, thymectomies were performed in the secondary recipients the week prior to adoptive transfer. While under ketamine (Nimatek $50 \mathrm{mg} / \mathrm{kg}$, intramuscularly) and xylazine (Sedamun $6 \mathrm{mg} / \mathrm{kg}$, subcutaneously) anesthesia, rats were intubated and maintained on artificial respiration. The thorax was opened and all prepericardial soft tissue consistent with thymus was removed; the thorax and skin were closed using 4-0 suture. Since in vitro depletion of $T$ cell subsets never resulted in complete elimination of the respective subset, the T cells were further depleted in viro by intravenous injection on days $0,2,4,6$ and 8 with $0.5 \mathrm{mg} \mathrm{mAb} \mathrm{OX-38} \mathrm{(anti-CD4)} \mathrm{or}$ $0.3 \mathrm{mg} \mathrm{OX}-8$ (anti-CD8) per rat.

Scoring for CsA-Induced and Adoptively-Transferred Autoimmunity All animals appeared healthy during the course of CsA treatment. After CsA withdrawal or adoptive transfer, development of C.A-AI was daily assessed by examination for symptoms of disease, including erythroderma (hyperemia of the skin of the ears, feet and tail), dermatitis, alopecia and weight 
loss. At regular intervals, ear biopsies were taken for microscopic evaluation of disease, with the presence of $\mathrm{T}$ cell infiltrates in the epidermis and hair follicles, infiltration and activation of macrophages, and induction of MHC class II antigens on the keratinocytes considered as positive signs of ongoing disease (7).

Monoclonal Antibodies For immunohistochemistry, the mAb R73 (TCR $\alpha \beta$ ) (12), R78 (TCR BV8S2), B73 (TCR BV8S5), G101 (TCR BV 10) (13) and 341 (CD8 $\alpha \beta$ heterodimers) (14) were kindly provided by Prof. Th. Hünig (Würzburg. Germany), HIS42 (TCR BV 16) (15) was kindly donated by Dr. J. Kampinga (University of Groningen, The Netherlands), the mAb ED1 (inflammatory macrophages; CD68) and ED2 (resident tissue macrophages) (16) were kindly provided by Prof. C.D. Dijkstra (Free University Amsterdam, The Netherlands) and the hybridomas producing the mAb W3/25 (CD4) (17) and OX6 (MHC class II; RT-1B) (18) were obtained from the European Collection of Animal Cell Cultures (ECACC, Salisbury, England). For FACS analysis, the mAb OX35 (CD4) (19) conjugated to FITC, the mAb OX8 (CD8 $\alpha \alpha$ ) (20) and HIS51 (Thy 1.1) (21) conjugated to PE, and the MAb R73 (TCR $\alpha \beta$ ) conjugated to biotin were purchased from Pharmingen (San Diego, California, USA). For in vitro depletion, the mAb ER2 (CD4) (22), kindly provided by Dr. B. de Geus (TNO Leiden, The Netherlands), OX8 (ECACC), 341 and OX6 were used. For in vivo depletion of $\mathrm{T}$ cell subsets, the mAb OX-38 (CD4, ECACC) (19) and OX8 were employed.

Lymph Node Cell Suspensions for Adoptive Transfer Lymph nodes (cervical, mesenterial and axillary) of animals with clear macroscopic pathology of CsA-AI, or control age-matched rats, were pooled and teased apart in Dulbecco's balanced salt solution. The tissue was either first enzymatically digested with collagenase CLS III $(0.5 \mathrm{mg} / \mathrm{ml}$; Worthington, New Jersey, UK) and DNase $\left(0.1 \mathrm{mg} / \mathrm{ml}\right.$; Worthington) for $30 \mathrm{~min}$ at $37^{\circ} \mathrm{C}$ and flushed through a 100 -mesh nylon gauze, or was directly passed through 100 -mesh nylon gauze. To remove dead cells, a discontinuous Percoll gradient of $30 \%$ and $80 \%$ (Pharmacia, Uppsala, Sweden) was used and interface cells were collected. Cells were fractionated over nylon wool (Fenwall Laboratories, Deerfield, IL) to enrich for T cells, as previously described (23). Finally, cell populations were negatively selected using mAb and, subsequently, sheep-anti-mouse IgG-coated magnetic beads (Dynal, Oslo, Norway). As a positive control, $5 \times 10^{7}$ viable unselected LNC were adoptively transferred to secondary recipients. The percentage of CD4 and CD8 cells was determined in both the initial LNC population and in the LNC populations obtained after depletion. The absolute number of injected CD4 or CD8 cells was equal to the absolute injected number of the same $T$ cell subset in the initial LNC population used as a positive control.

Flowcytometry and Immunohistochemistry Flow cytometry and immunohisto-chemistry were performed as described previously (24). Expression of CD4, CD8 or HIS51 and TCR $\alpha \beta$ on PBL (obtained via the retro-orbital plexus) and LNC (obtained as described above) was determined using LYSYS II software (Becton Dickinson); 10,000 events were acquired in list mode with gating on viable lymphoid cells using the forward light scatter (FSC) and side light scatter (SSC) parameters, or with gating on viable TCR $\alpha \beta^{+}$lymphoid cells using the FSC and 
FL3 parameters. Immunohistochemistry substrate for the peroxidase conjugate was 3-amino-9ethyl carbazole (Sigma) followed by counterstaining with hematoxilin.

RNase protection assay Total RNA was isolated from normal rat thymus and lymph nodes and the ear of diseased CSA-AI donor and recipient rats in Guanidinium Thiocyanate buffer (Stratagene, La Jolla, CA) as described (25). Rat-specific probes were prepared using oligonucleotide primers derived from sequences of 20 Lewis rat BV genes (26). The probes, ranging in size from 95 to 285 base pairs, were pooled into 2 probe sets (27). Using the T7 promotor, the mixed probes were used as templates to synthesize antisense RNA with T7 RNA polymerase (Promega) in the presence of $\left[{ }^{32} \mathrm{P}\right]$-UTP, as described (28). TCR $\beta$-chain constant region $(\mathrm{BC})$ probe was separately transcribed to anti-sense RNA and served as an internal standard. The probe set and $\mathrm{BC}$ were labelled to $\approx 5,000$ and $250 \mathrm{cpm} /$ uridine residue, respectively. This mix was hybridized for $16 \mathrm{hrs}$ at $56^{\circ} \mathrm{C}$ with 2 to $6 \mu \mathrm{g}$ total RNA isolated as described (28).

In the ear biopsy RNA samples, the amount of specific TCR mRNA was too low for detection, thus cDNA was synthesized from total RNA using M-MuLV reverse transcriptase (Gibco BRL, Grand Island, New York) and an oligo (dT) 12-18 primer. The resultant cDNA was G-tailed by terminal deoxytransferase (TdT, Boehringer, Mannheim) in $0.75 \mu \mathrm{M} \mathrm{CoCl}_{2}$ and $0.5 \mu \mathrm{M}$ dGTP. One third of the purified product was subjected to PCR amplification by Taq polymerase (Promega, Madison, Wisconsin).

After three initial cycles $\left(94^{\circ} \mathrm{C} / 20 \mathrm{sec}, 55^{\circ} \mathrm{C} / 30 \mathrm{sec}\right.$. and $\left.72^{\circ} \mathrm{C} / 90 \mathrm{sec}\right)$ using $\mathrm{T} 7 \mathrm{poly}(\mathrm{dC})$ (5'-GCCAGTGAATTGTATACGACTCACTATAGGAGATCCCCCCCCCCCCCC-3') and BC external primers (5'-AGGCCTCCGCACTGATGTTCTGTGT-3'), T7 anchor primer (5'CAGGTTTGGGTGAGTCCTCTGACCAGT-3') was added and the reaction continued for an additional 25 cycles $\left(94^{\circ} \mathrm{C} / 20 \mathrm{sec} ., 60^{\circ} \mathrm{C} / 35 \mathrm{sec}\right.$. and $72^{\circ} \mathrm{C} / 90 \mathrm{sec}$.). The resultant $\mathrm{PCR}$ product was extracted and subjected to a second PCR amplification using T7 anchor and BC internal (5'CAGGTTTGGGTGAGTCCTCTGACCAGT-3') primers for 15 cycles $\left(94^{\circ} \mathrm{C} / 20 \mathrm{sec}\right.$, $60^{\circ} \mathrm{C} / 35 \mathrm{sec}$. and $72^{\circ} \mathrm{C} / 90 \mathrm{sec}$.). The final PCR product was treated with proteinase $\mathrm{K}$, phenol/chloroformextracted and ethanol-precipitated to obtain RNase-free conditions. Aliquots of the amplified samples were used as templates for synthesizing sense RNA using T7 RNA polymerase in the presence of $\left[{ }^{35}\right.$ S]UTP for quantitation of the final product. All specimens were amplified in duplicate for verification of results. The RNA samples obtained via amplification were mixed with the labelled probe sets, as discribed above.

After RNase A $(5 \mu \mathrm{g} / \mathrm{ml})$ and RNase Tl $(10 \mathrm{U} / \mathrm{ml})$ treatment, "protected" double-stranded probe:target mRNA hybrids were phenol/chloroform-extracted, ethanol-precipitated, and electrophoresed after denaturation on a standard 6\% polyacrylamide sequencing gel. Dried gels were autoradiographed on Kodak XAR film with intensifying screens at $-70^{\circ} \mathrm{C}$ for $16-24 \mathrm{hrs}$ and quantified as described (27). 


\section{Results}

Adoptive Transfer of CsA-AI is T-Cell-Dependent To establish the T-cell dependency of CsAAI, adoptive transfer of purified $T$ cells from CsA-AI animals was performed. Cervical and mesenteric lymph nodes were collected from 11 donors with evident weight loss, dermatitis, and confirmed histologic epidermal $T$ cell infiltration. $T$ cells were adoptively transferred to secondary recipients in four different concentrations: $1.5 \times 10^{7}(\mathrm{n}=3), 6 \times 10^{6}(\mathrm{n}=3), 2 \times 10^{6}$ $(n=3)$, and $6 \times 10^{5}(n=3)$. Disease developed in a dose-dependent fashion, as exemplified by the relative weight loss (Fig. 1a). Recipients of $1.5 \times 10^{7}$ and $6 \times 10^{6} \mathrm{~T}$ cells displayed erythroderma and severe dermatitis, whereas recipients of $2 \times 10^{6} \mathrm{~T}$ cells developed erythroderma and mild dermatitis. Two of 3 recipients of $6 \times 10^{5} \mathrm{~T}$ cells developed erythroderma, and one also had signs of very mild dermatitis. In addition to the qualitative differences, there was also a clear delay in disease onset when lower numbers of $\mathrm{T}$ cells were transferred to secondary recipients (Fig. Ib).
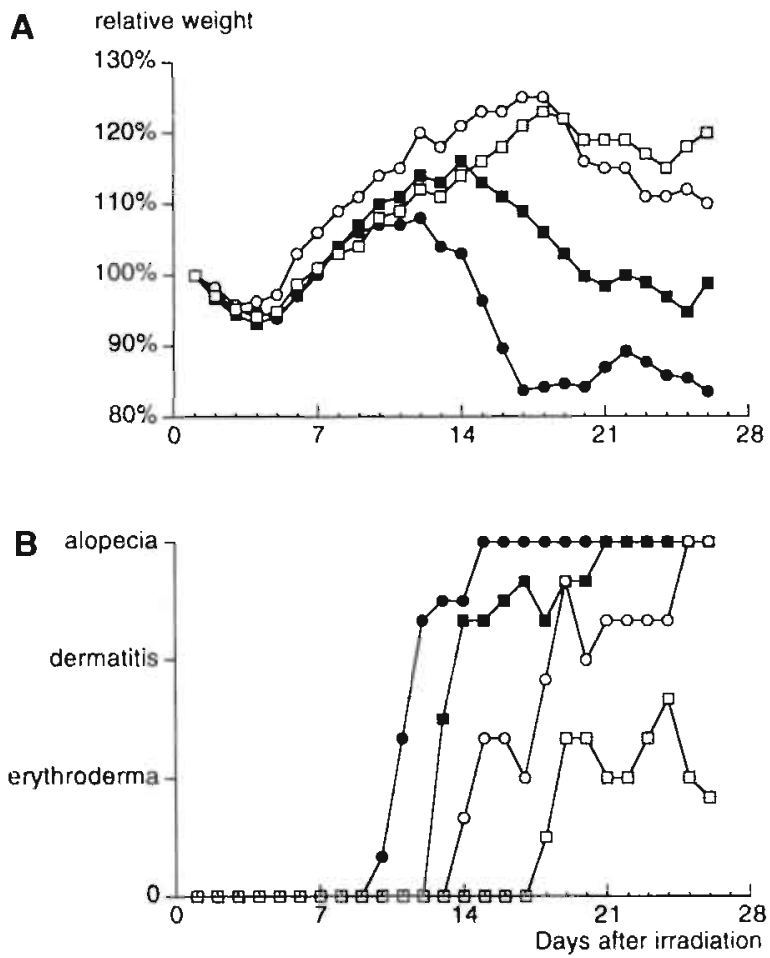

Figure 1; Development of CsA-AI upon adoptive transfer of enriched $\mathrm{T}$ cells. Lymph node $\mathrm{T}$ cells were purified using a Percoll gradient, nylon wool column, and negative depletion using the mAb OX-6 in combination with magnetic beads. The obtained T cell population was $>95 \%$ pure as determined by expression of TCR $\alpha \beta$. (A) Average relative weight changes after $X$-irradiation, syngeneic BMT together with adoptive transfer of CsA-AI derived T cells (closed circles $1.5 \times 10^{7}$ cells, $n=3$, closed squares $6 \times 10^{6}$ cells, $n=3$, open circles $2 \times 10^{6}$ cells, $n=3$. open squares $6 \times 10^{5}$ cells, $n=3$ ). (B) Average development of Cs A-Al associated macroscopical symptoms. 
Adoptive Transfer of CsA-AI by CD4 or CD8 T Cells Results in Temporary Absence of the Reciprocal Subset Since non-T cells, cotransferred with the putative effector T cells, did not alter the disease outcome (data not shown), a pilot experiment was performed to establish the role of $\mathrm{T}$ cell subsets. Viable LNC were obtained by discontinuous Percoll gradient centrifugation, CD4 or CD8 T cells were incubated with ER2 (CD4) or 341 (CD8 $\alpha \beta)$ and OX8 $(C D 8 \alpha \alpha)$ and depleted with magnetic beads. Adoptive transfer of LNC enriched for the CD4 or CD8 subset resulted in macroscopic and histologic development of CsA-AI. Regardless of the enriched $\mathrm{T}$ cell population transferred, the $\mathrm{T}$ cell infiltration in the epidermis of experimental rats consisted of CD4 and CD8 cells, and did not differ from that observed in control rats receiving whole LNC suspensions. Furthermore, flow cytometric analysis of $\mathrm{T}$ cells in peripheral blood revealed that the CD4/CD8 ratio was restored to normal in recipients of either subset 16 days after adoptive transfer. This finding might be explained by selective expansion of the minor contamination of the subsets by the opposite type of cells, or by new thymic

A relative weight
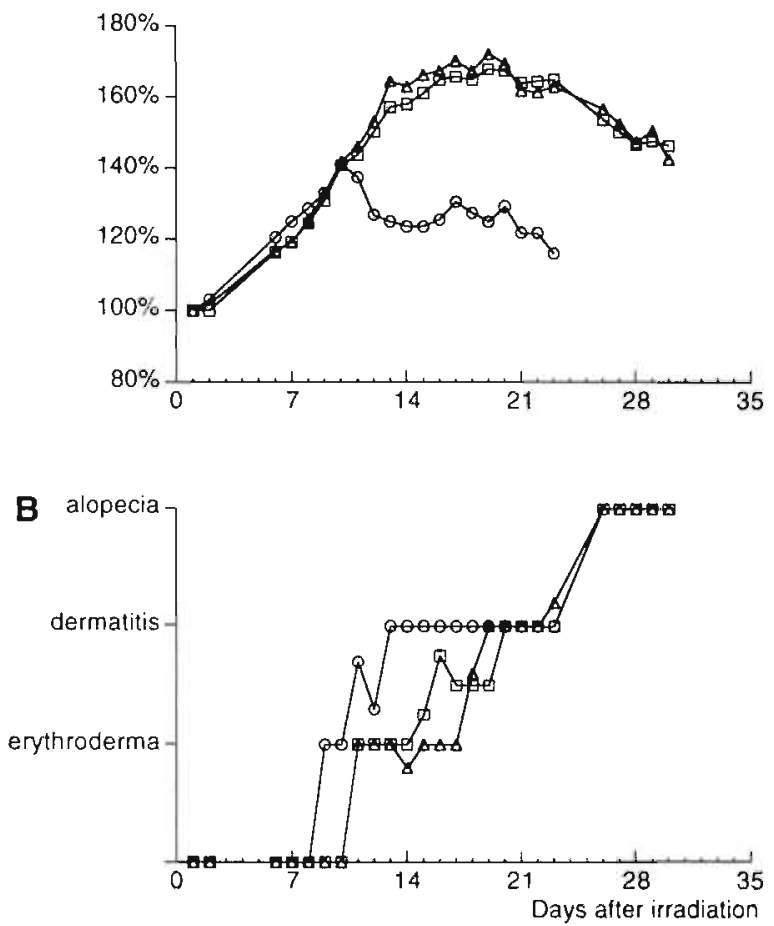

Figure 2; Development of CsA-AI upon adoptive transfer of CD4 or CD8 depleted LNC into thymectomized rats. LNC suspensions were prepared by using enzymatic digestion of the lymphoid tissue. Next $\mathrm{CD}^{+}$or $\mathrm{CD} 8^{+}$ $T$ cells were depleted with magnetic beads after incubation with ER2 (CD4) or 341 (CD8 $\alpha \beta$ ) and OX8 $(\mathrm{CD} 8 \alpha \alpha)$. The LNC populations were adoptively transferred into thymectomized recipients. (A) Average relative weight changes after $\mathrm{X}$-irradiation, syngeneic BMT together with adoptive transfer of CsA-AI derived CD4 or CD8 depleted LNC (circles $5 \times 10^{7}$ total LNC, $n=3$, squares $14.3 \times 10^{6}$ CD8 depleted $T$ cells, $n=4$, triangles $5.5 \times 10^{6} \mathrm{CD} 4$ depleted $\mathrm{T}$ cells, $\mathrm{n}=5$ ). (B) Average development of $\mathrm{CsA}-\mathrm{Al}$ associated macrosciopical symptoms. 
output. Since nearly $20 \%$ of the peripheral blood CD4 cells at day 16 post transfer expressed Thy 1.1 (not shown), a marker for recent thymic emigrants in the rat $(29,30)$, the observed recovery was caused, in part, by such emigrants. To circumvent interference by these cells, adoptive experiments with CD4- or CD8-enriched LNC were performed in thymectomized rats. Again, control and experimental rats developed equally severe CsA-AI-associated pathology (Fig. 2), and the epidermis of CD4- and CD8-depleted LNC recipients was heavily infiltrated by both CD4 and CD 8 cells 4 weeks after adoptive transfer. In fact, there was a preponderance of CD8 cells in recipients of CD8-depleted LNC. Phenotypic analysis of peripheral blood T cells 12 days after adoptive transfer, when the first clinical CsA-AI manifestations were observed, revealed recovery of the CD4/CD8 ratio (Table 1) with a relatively high incidence of CD4/CD8 double-negative (DN) TCR $\alpha \beta^{+}$cells. Thymectomy apparently did not prevent recovery of the depleted subset, probably due to the continuing contamination of the transferted LNC suspension by the inefficiently depleted subset.

Table I: CD4/CD8 T cell ratio in adoptive transfer to thymectomized secondary recipients

\begin{tabular}{|c|c|c|c|c|c|c|}
\hline & \multicolumn{3}{|c|}{$\begin{array}{l}\text { LNC populations used for Adoptive } \\
\text { Transfer }{ }^{\text {a }}\end{array}$} & \multicolumn{3}{|c|}{$\begin{array}{c}\text { peripheral blood } \mathrm{T} \text { cell population } 12 \text { days after } \\
\text { Adoptive Transfer }{ }^{b}\end{array}$} \\
\hline & whole LNC & CD4 depleted & CD8 depleted & $\begin{array}{l}\text { whole } \mathrm{LNC} \\
\text { recipients }(\mathrm{n}=3)\end{array}$ & $\begin{array}{l}\text { CD4 depleted } \\
\text { recipients }(n=5)\end{array}$ & $\begin{array}{l}\text { CD8 depleted } \\
\text { recipients }(n=4)\end{array}$ \\
\hline$\omega_{s}$ of T cells ${ }^{*}$ & 37.1 & 40.5 & 53.4 & 5.9 & 5.3 & 5.2 \\
\hline$\%$ of $\mathrm{CD} 4+\mathrm{T}$ cells & 67.9 & 2.0 & 96.0 & 59.9 & 16.2 & 41.3 \\
\hline$\%$ of CD $8+T$ cells & 23.1 & 89.4 & 0.2 & 30.5 & 41.1 & 10.1 \\
\hline$\%$ of DP T cells $\mathrm{d}$ & 3.3 & 0.7 & 0.9 & 3.8 & 0.9 & 3.4 \\
\hline$\%$ of DN T cells ${ }^{d}$ & 5.7 & 7.9 & 2.9 & 5.8 & 41.8 & 45.2 \\
\hline CD4/CD8 T cell ratio & 2.8 & $<0.1$ & $>100$ & 2.0 & 0.4 & 4. 1 \\
\hline
\end{tabular}

a Lymph node cells from clinical manifest CsA-AI donors were isolated, devided in three aliquots, and depleted either for CD4 cells. CD8 cells or used undepleted as positive control. LNC suspensions were prepared by enzymatic digestion of the lymphoid tissue. Next CD4 or CD8 cells were depleted with magnetic beads after incubation with ER2 (CD4) or 341 (CDS $\alpha \beta)$ and $\mathrm{OX} 8(\mathrm{CD} 8 \alpha \alpha)$ respectively. Purity of obtained LNC suspensions was determined by tri-colour flowcytometry.

b When disease was clinical manifest in all three groups (day 12 after adoptive transfer) peripheral blood was isolated and assessed by tri-colour flowcytometry for T cell distribution.

$c \%$ of $\mathrm{T}$ eells is defined as the percentage of cells expressing TCR $\alpha \beta$.

d\% of CD4 SP, CD8 SP. CD4/CD8 DP or CD4/CD8 DN cells within the TCR $\alpha \beta^{+}$cell population

Both CD4 and CD8 cells separately induce CSA-AI upon adoptive transfer The data above showed that the presence of the thymus and small contaminations by either CD4 or CDs cells in the transferred LNC resulted in a $\mathrm{T}$ cell infiltrate in the skin consisting of both subsets. Thereafter, after adoptive transfer of depleted LNC into thymectomized recipients, mAb were 
administered intravenously to further deplete any emerging CD4 or CD8 cells. Control and experimental animals developed severe CsA-AI-associated pathology (Fig. 3), and disease commenced at the same time in both groups. In CD4 or CD8 cell recipients, there was a slight delay before full disease development (Fig. 3). Recipients of CD8 cells developed dermatitis earlier than the CD4 counterparts. Phenotypic analysis of T cells in peripheral blood 10 days after adoptive transfer, when the first clinical manifestations of $\mathrm{CsA}-\mathrm{AI}$ were observed, and at 18 days post-transfer, showed that the CD4/CD8 ratio was not restored to normal (Table II). Again, a relatively large number of CD4/CD8 DN T cells was detectable. The epidermis of both CD4- and CD8-depleted LNC recipients was heavily infiltrated by TCR $\alpha \beta^{+}$cells at 11 and 18 days after adoptive transfer. Staining of serial sections with CD4 and CD8 $\alpha \beta$-reactive mAb revealed that the $\mathrm{T}$ cell infiltrate was devoid of the depleted $\mathrm{T}$ cell subset (Fig. 4).
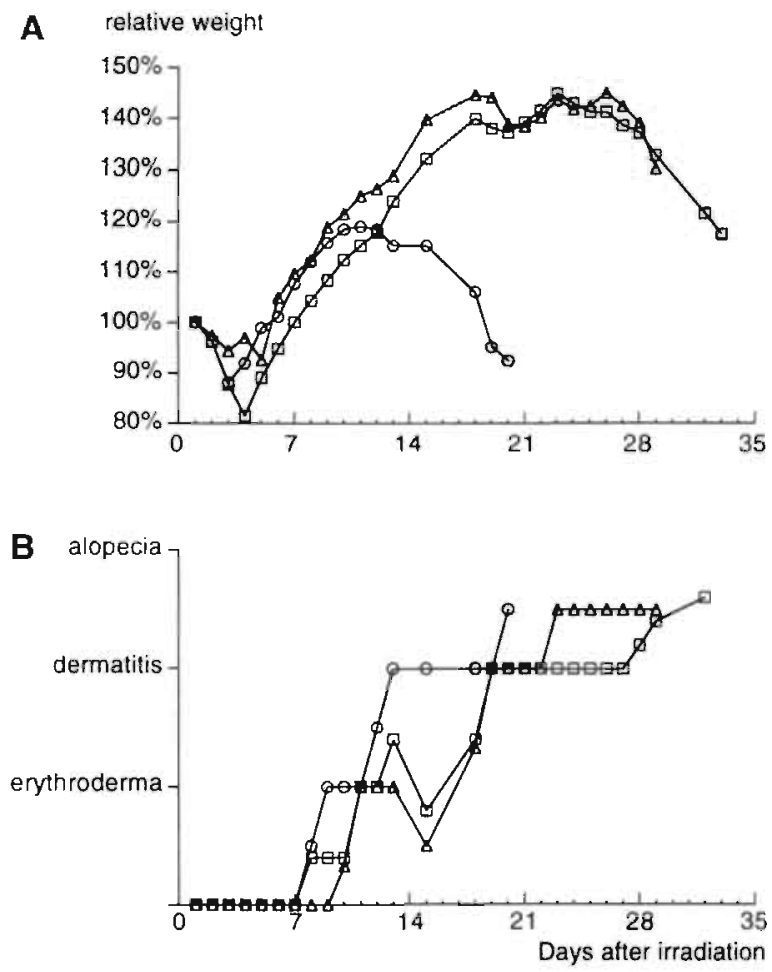

Figure 3: Development of CsA-AI upon adoptive transfer of CD4 or CD8 depleted LNC. LNC suspensions were prepared by using enzymatic digestion of the lymphoid tissue. Next $\mathrm{CD} 4^{+}$or $\mathrm{CD}^{+} \mathrm{T}$ cells were depleted with magnetic beads after incubation with ER2 (CD4) or 34 I (CD8 $\alpha \beta)$ and OX8 (CD $8 \alpha \alpha)$. The LNC populations were adoptively transferred into thymectomized recipient rats and next given in vivo depleting mAb. (A) Average relative weight changes after $\mathrm{X}$-imadiation, syngeneic BMT together with adoptive transfer of CsA-AI derived CD4 or CD8 depleted LNC (circles $5 \times 10^{7}$ total LNC, $n=2$, squares $14.2 \times 10^{6}$ CD8 depleted T cells, $n=5$, triangles $5.5 \times 10^{6} \mathrm{CD} 4$ depleted $\mathrm{T}$ cells, $\mathrm{n}=3$ ). (B) Average development of $\mathrm{Cs} A-\mathrm{AI}$ associated macroscopical symptoms. 
Table II: CD4/CD8 T cell ratio in adoptive transfer to thymectomized secondary recipients receiving in vivo depleting $\mathrm{mAb}$ post transfer

\begin{tabular}{|c|c|c|c|c|c|c|}
\hline & \multicolumn{3}{|c|}{$\begin{array}{l}\text { LNC populations used for Adoptive } \\
\text { Transfer }{ }^{a}\end{array}$} & \multicolumn{3}{|c|}{$\begin{array}{c}\text { peripheral blood } \mathrm{T} \text { cell population } 12 \text { days after } \\
\text { Adoptive Transfer }{ }^{\mathrm{b}}\end{array}$} \\
\hline & whole LNC & CD4 depleted & CD8 depleted & $\begin{array}{l}\text { whole } \mathrm{LNC} \\
\text { recipients }(\mathrm{n}=3)\end{array}$ & $\begin{array}{l}\text { CD4 depleted } \\
\text { recipients }(n=5)\end{array}$ & $\begin{array}{l}\mathrm{CD} 8 \text { depleted } \\
\text { recipients }(\mathrm{n}=4)\end{array}$ \\
\hline$\%$ of $\mathrm{T}$ cells ${ }^{\mathrm{C}}$ & 36.7 & 37.4 & 76.2 & 6.2 & 5.7 & 1.1 \\
\hline$\%$ of $\mathrm{CD}_{4}{ }^{+} \mathrm{T}$ cells $\mathrm{d}$ & 77.4 & 6.1 & 98.3 & 45.8 & 2.4 & 67.6 \\
\hline$\%$ of $\mathrm{CD}^{+}{ }^{+} \mathrm{T}$ cells ${ }^{\mathrm{d}}$ & 16.7 & 84.3 & 0.2 & 43.9 & 50.1 & 1.7 \\
\hline$\%$ of DP T cells ${ }^{d}$ & 2.9 & 4.2 & 0.5 & 2.0 & 0.5 & 1.9 \\
\hline$\%$ of DN T cells ${ }^{d}$ & 3.0 & 5.4 & 1.0 & 8.3 & 47.0 & 28.8 \\
\hline CD4/CD8 $\mathrm{T}$ cell ratio & 4.7 & $<0.1$ & $>100$ & 1.0 & $<0.1$ & 39.8 \\
\hline
\end{tabular}

${ }^{a}$ Lymph node cells from clinical manifest CsA-AI donors were isolated, devided in three aliquots, and depleted either for CD4 cells, CD8 cells or used undepleted as positive control. LNC suspensions were prepared by enzymatic digestion of the lymphoid tissue. Next CD4 or CD8 cells were depleted with magnetic beads after incubation with ER2 (CD4) or $341(C D 8 \alpha \beta)$ and OX8 $(C D 8 \alpha \alpha)$ respectively. Purity of obtained LNC suspensions was determined by tri-colour flowcytometry.

bhen disease was clinical manifest in all three groups (day 12 after adoptive transfer) peripheral blood was isolated and assessed by tri-colour floweytometry for $\mathrm{T}$ cell subset distribution.

c $\%$ of $\mathrm{T}$ cells is defined as the percentage of cells expressing TCR $\alpha \beta$.

$₫ \%$ of CD4 SP, CD8 SP, CD4/CD8 DP or CD4/CD8 DN cells within the TCR $\alpha \beta^{+}$cell population

Figure 4: Infiltrating CD4 or CD8 $\mathrm{T}$ cells in the epidermis from X-irradiated, thymectomized rats given CD8depleted LNC (Fig. 4 A to C) or CD4-depleted LNC (D to F). After adoptive transfer the rats were treated with CD8 or CD4 depleting mAb respectively. At 18 days after adoptive transfer when disease was clinical manifest ear biopsies were taken. Section A and D, stained with mAb anti TCR $\alpha \beta$ (R73), shows T cells in the epidermis. Section B and E, stained with $\mathrm{mAb}$ anti CD4 (W3/25), shows large macrophages in the dermis and CD4 $\mathrm{T}$ cells in the epidermis, present in section B (CD4 recipieni) and almost absent in section $\mathrm{E}$ (CD8 recipient). Section $C$ and $F$, stained with mAb anti $C D 8 \alpha \beta$ (341), shows CD8 $T$ cells in the epidermis of section $\mathrm{F}$ (CD8 recipient) which are absent in section $\mathrm{C}(\mathrm{CD} 4$ recipient). Abbreviations: e, central cartillage layer; d, demis: e, epidermis. 

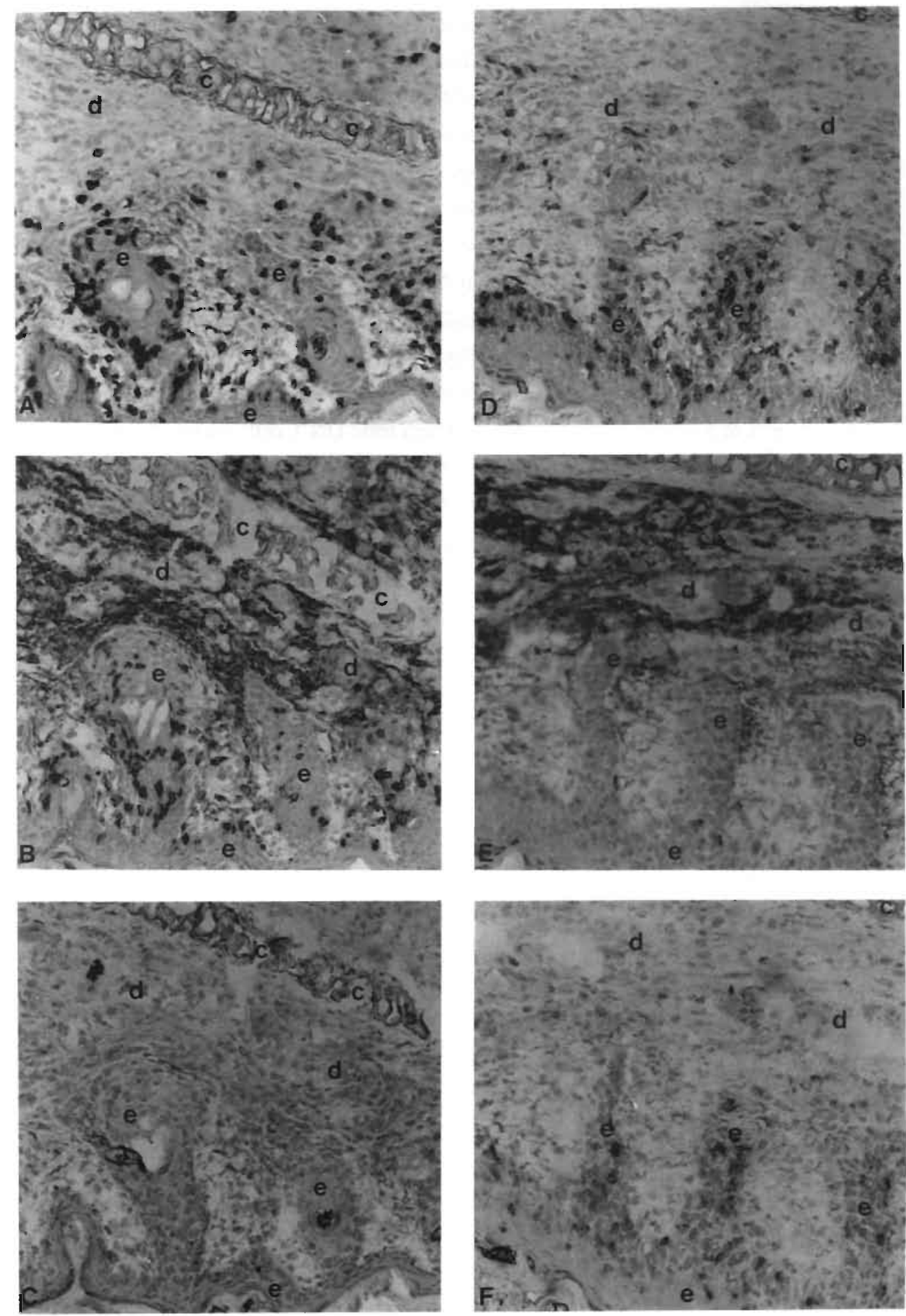
Double-negative T cells are not involved in the induction of CSA-AI As described above, analysis of PBL of thymectomized and irradiated rats receiving CD4- or CD8-depleted LNC revealed a relative increase of DN TCR $\alpha \beta^{+}$cells (see Tables 1 and 2). To establish the possible role of these DN T cells, LNC of rats with clear macroscopic signs of CsA-AI were harvested, depleted of CD4 and CD8 cells, and the suspension subjected to FACS analysis. Thereafter, $6.2 \times 10^{5} \mathrm{DN} \mathrm{T}$ cells, equal to the absolute number in the initial LNC suspension, was adoptively transferred into thymectomized recipients. CD4 and CD8 depletion was not complete, and $12.2 \%$ of the initial CD4 and $3.6 \%$ of the initial CD8 T cell population was cotransferred. To ensure deletion of these single-positive cells, rats were given depleting $\mathrm{mAb}$ to both CD4 (OX38) and CD8 (OX8) on days $0,2,4,6,8$ and 10 after adoptive transfer. FACS analysis of the recipients 22 days after adoptive transfer showed an average of $3.8 \%$ TCR $\alpha \beta^{+}$cells in peripheral blood, $\approx 86 \%$ of which were DN T cells, and $\approx 14 \%$ were singlepositive (CD4 or CD8). At 45 days after adoptive transfer, TCR $\alpha \beta^{+}$cells increased to $5.2 \%$, $80 \%$ being DN T cells, $13 \%$ CD4, and 7\% CD8 T cells. Absolute numbers of CD4 and CD8 cells were low, but those of DN T cells $\left( \pm 1.42 \times 10^{5}\right.$ cells $\left./ \mathrm{ml}\right)$ were only slightly elevated compared to those of normal, irradiated and thymectomized rats or rats receiving total LNC from donors with signs of CsA-AI (unpublished data). Three of 5 rats developed very mild dermatitis 42 days after adoptive transfer. Ear biopsies revealed the presence of TCR $\alpha \beta^{+}$and $\mathrm{CD}_{4}+$ lymphocytes in the dermis and epidermis. As demonstrated by the $\mathrm{T}$ cell dose-response curve in this study, the development of mild dermatitis after 42 days in 3 recipients can be explained by contaminating CD4 cells. Therefore, DN, TCR $\alpha \beta^{+}$cells are not responsible for CsA-AI.

CD4 or CD8 cells from CsA-treated rats or from X-irradiated treated rats do not adoptive'ly transfer disease CSA-AI is induced by a combination of total body irradiation and C.sA treatment. We tested whether separate treatments with either component caused development of autoreactive $\mathrm{T}$ cells that could induce $\mathrm{CsA}-\mathrm{AI}$ upon adoptive transfer after in vitro depletion of either CD4 or CD8 cells. Rats given CsA only or irradiation plus the solvent only do not develop disease, but they were sacrificed as soon as disease developed in rats that in parallel had received both irradiation and CsA. CD4- and CD8-depleted LNC were injected into thymectomized recipients in amounts equal to the initial LNC suspensions from irradiated or CsA-treated donors. None of these rats developed signs of discuse within 6 weeks after adoptive transfer, and microscopic analysis of the skin showed no infiltrates of T cells or MHC class II expression on keratinocytes (not shown). 
Infiltrating $T$ cells are accompanied by inflammatory macrophages and MHC class II expression by keratinocytes Rats were biopsied after adoptive transfer in all the above experiments. Even during erythroderma, the early phase of acute CsA-AI, TCR $\alpha \beta^{+}$cell infiltrates were detectable in the epidermis. When whole LNC suspensions were transferred, serial sections showed that these epidermal infiltrates were $\mathrm{CD}^{+}$and $\mathrm{CD} 8^{+}$cells. Infiltrating $\mathrm{EDI}^{+}$macrophages, which also express $\mathrm{CD} 4$, were observed in the dermis, and in the outer rim of the hair follicles. The CD4-expressing cells in the epidermis, however, were clearly $T$ cells, since $\mathrm{EDI}^{+}$macrophages were never detected in the epidermis. CD8 expression in the epidermis consisted of cytotoxic/MHC class I-restricted $\mathrm{T}$ cells, since they were detected with the mAb 341, reactive with $C D 8 \alpha \beta$ heterodimer, present only on cytotoxic/MHC class Irestricted T cells (Fig. 4). Expression of MHC class II on keratinocytes in the epidermis and macrophages in the dermis was observed only if infiltrating $T$ cells were present locally. The resident $\mathrm{ED}_{2}{ }^{+}$macrophages in the dermis appeared swollen, but their numbers were not increased and they did not infiltrate the epidermis. These phenomena were observed in all diseased animals whether they were given subset-depleted LNC or whole LNC suspensions. In the case of adoptive transfer or CD4- or CD8-depleted LNC to thymectomized and posttransfer in vivo mAb-treated recipients, the only difference observed was the absence of the depleted $\mathrm{T}$ cell subset in the epidermis.

Characterization of the $T$ cell Receptor $B V$ repertoire in lymph node-and skin-infiltrating $T$ cells We determined the TCR BV repertoire to establish whether CsA-AI-mediating T cells have a restricted composition. RNA was extracted from normal thymus $(n=2)$ as a baseline for the naive, unselected, repertoire and compared with that of normal LNC $(n=2), L N C$ of CsAAI-diseased rats $(\mathrm{n}=2)$, and $\mathrm{LNC}$ of CD4 $(\mathrm{n}=2)$ or $\mathrm{CD} 8$ recipients $(\mathrm{n}=2)$.

In the RNase protection assay, all BV families were present at comparable ratios in normal thymocytes and normal LNC as well as LNC from diseased donors and recipients (Fig. 5). In diseased CsA-AI donors and diseased CD4 or CD8 recipients, no family was exclusively or consistently overexpressed in peripheral lymphoid organs, indicating that the BV repertoire in diseased animals is unbiased. The BV repertoire could not be measured in the infiltrated ear of diseased rats by the classical RNase protection assay due to the low amount of TCR-specific mRNA. However, such an assessment was possible if BV-specific anchor PCR amplification preceded the classical assay. Analysis of 3 biopsy specimens ( 2 from CsA-AI donors and one from a CD4 recipient) revealed the presence of most BV families. BV 14 was increased in one CSA-AI donor and BV13 and BV15 were increased in a CD4 recipient. Moreover, analysis of ear biopsies from CsA-AI rats (donors and recipients of CD4 and CD8 celis) with a few 


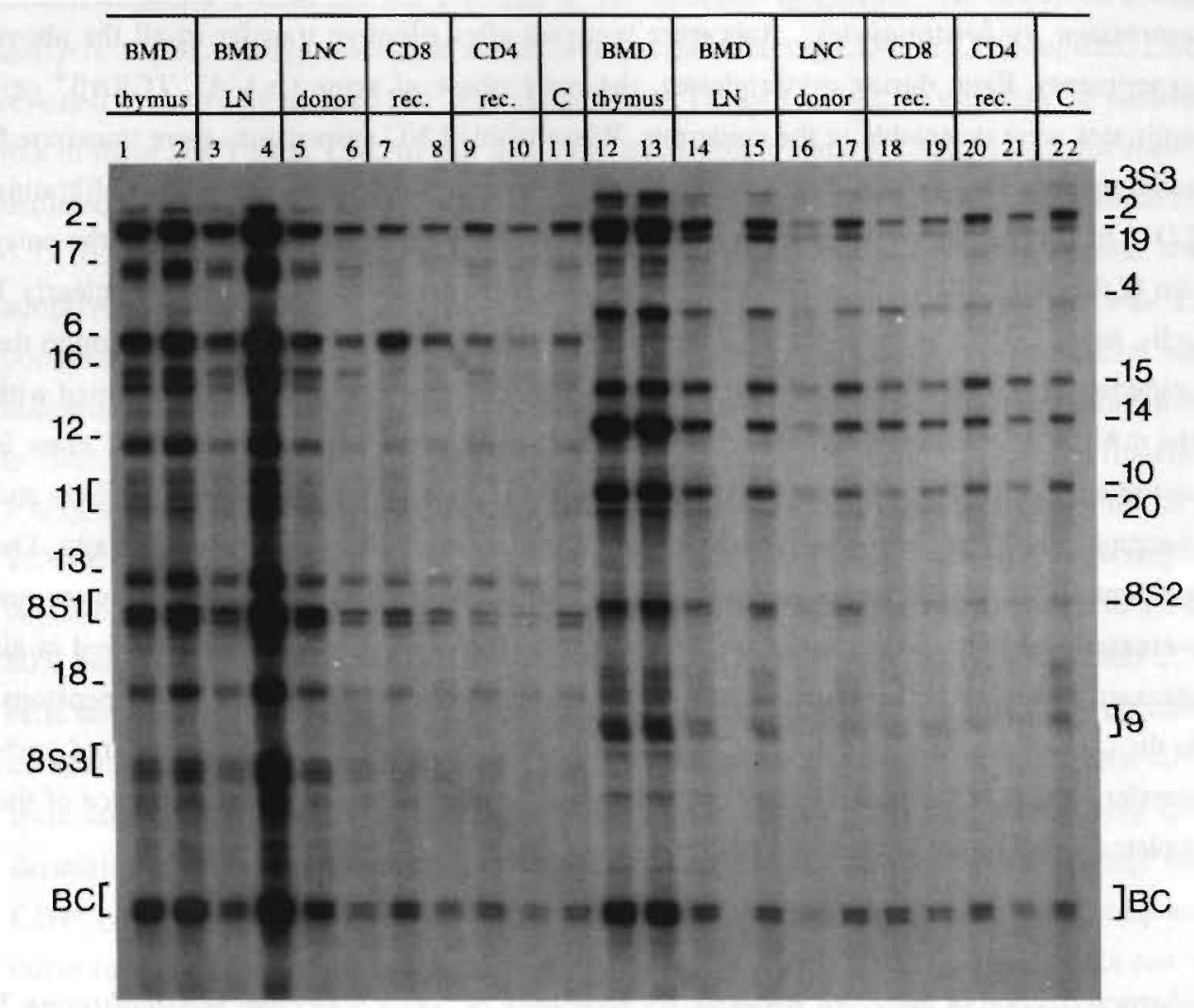

B 257 relative TCR BV family mRNA expression (\%)

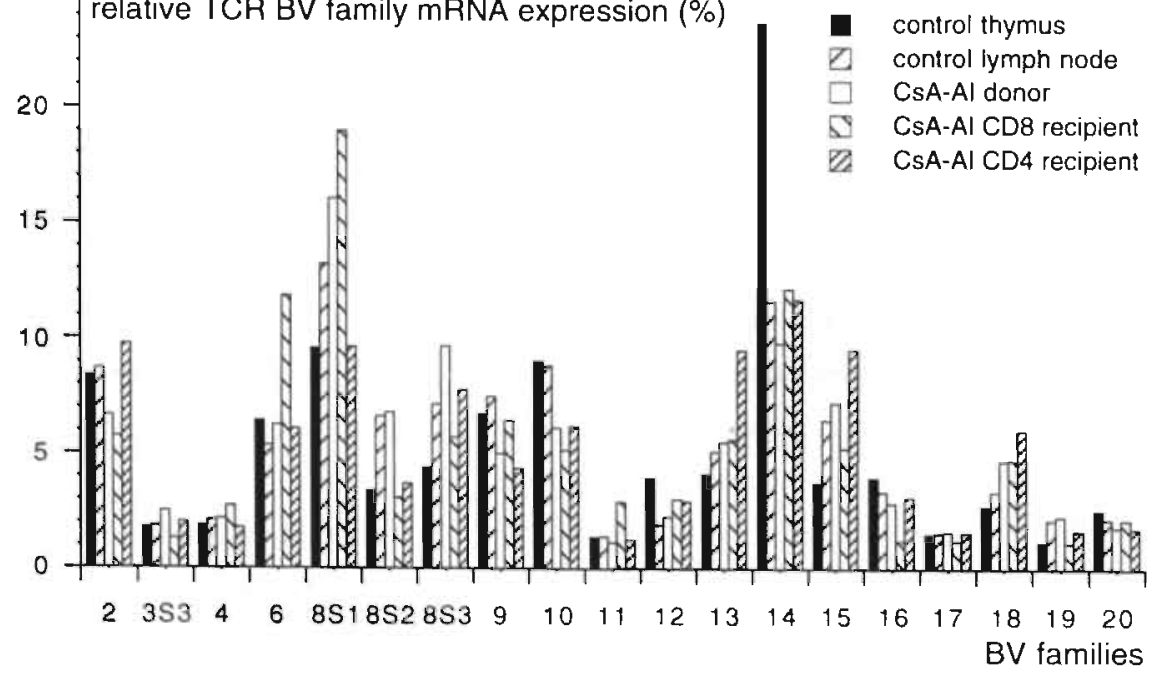


avalable TCR BV $\mathrm{mAb}$ (BV8S2, BV8S5, BV10 and BV16) revealed that the respective BV were represented at frequencies similar to those of normal rat peripheral $T$ cells (data not shown).

\section{Discussion}

The main findings of this study on the characterization of effector T cells in CsA-AI are twofold: first, CsA-AI can be successfully transferred by both CD4 and CD8 TCR $\alpha \beta^{+}$cells, as confirmed by the absence of the reciprocal subset in peripheral blood and skin biopsies of the affected secondary recipients. Although both $\mathrm{T}$ cell subsets cause identical lesions, about 3 times as many CD4 than CD8 cells were required for similar kinetics and disease severity, indicating that the CD8 population was more effective. Second, the CD4 and CD8 populations from recipient rats with clinically evident CsA-AI have complete BV repertoires comparable to those of the CsA-AI donors and of normal lymph node $T$ cells and thymocytes, thereby making it unlikely that any particular BV speciticity is more important for disease induction.

This study attributes an effector role to CD4 and CD8 $\mathrm{T}$ cells provided they are isolated from clinically-manifest CsA-AI donors and administered to thymectomized, irradiated lecipients. Whether these T cells are depleted for non-T cells, or depleted for CD4 or CD8 cells does not affect the outcome since all recipients developed CsA-AI. In the donor rats, CD4 and CD8 $\mathrm{T}$ cells were equally endowed with autoimmune potential, and both subsets were demonstrable in the skin lesions (7). Thus, both $\mathrm{T}$ cell subsets appear to be involved in the induction phase of $\mathrm{CsA}-\mathrm{AI}$ in the primary donors. In several autoimmune models, i.e. spontaneous diabetes in mice (31) and rats (32), and in radiation-induced autoimmune diabetes and thyroiditis (33), it has been demonstrated that both CD4 and CD8 cells are required for disease development, although CD8 cells isolated from prediseased syngeneic donors do permit diabetes development.

Figure 5: (A) Autoradiogram of a rat TCR BV-RNase protection assay. TCR BV distribution in normal thymus (lanes $1.2 \& 12,13$ ) and lymph nodes (lanes $3,4 \& 14,15$ ), obtained from rat used as BM donor, CsA-AI diseased donor rat lymph nodes (lanes $5,6 \& 16,17$ ), and lymph nodes isolated from thymectomized rats receiving CD4 depleted LNC, i.e. CD8 recipient (hanes 7,8 \& 18, 19), or CD8 depleted LNC, i.e. CD4 recipient (lanes $9,10 \& 20,21$ ) and next given in vivo depleting anti CD4 or CD8 depleting mAb respectively. CSA-AI donor and recipient lymph nodes were isolated when disease was clinical manifest. Spleen from a normal Lewis rat from a different breeding stock was taken as an external control (C: lanes $11 \& 22$ ). Rat mRNA from the indicated tissues is hybridized to anti-sense [32 P]-labeled RNA strands in iwo different sets each containing BV2 and $\beta$-chain contant region (BC). Lanes 1 to 11 contain BV2, 6, 8S1, 8S3, 11, 12, 13, 16, 18 and BC. Lanes 12 to 22 contain BV2, 3S3, 4, 8S2, 9, 10, 14, 15, 19, 20 and BC.

(B) Histogram of the average percentage of TCR BV families. TCR BV family mRNA expression, shown in autoradiogram Fig. 5A, was quantitated and expressed as the percentage of total TCR BV repertoire. The histogram shows TCR BV disiribution in normal thymus $(n=2)$, normal lymph node $(n=2)$, CsA-AI donor lymph node $(n=2)$, CD4 T cell recipient lymph node $(n=2)$ and CD8 T cell recipient lymph node $(n=2)$. 
Once CsA-AI is established, mesenterial, cervical and axillary lymph nodes are enriched with autoreactive CD4 and CD8 T cells with the ability to migrate into the epithelium of the skin. The lesions caused by CD4 or CD 8 cells are indistinguishable and may thus be caused by similar mechanisms. IFN $\gamma$ is a key cytokine in enhancing MHC class II expression and macrophage activation, both hallmarks of CsA-AI, and there is ample evidence that CD4 Th cells are not the only cells producing high amounts of cytokines. CD8 cells have been demonstrated to produce cytokines equal to, or better than, CD4 cells in man (34) and rat (35). A dichotomy of the CD4 cells. known as Th1 and Th2 cells, has also been described for CD8 cells (36). The consequence of this duality is that both CD4 and CD8 T cells can be driven in their response to exhibit typical Thl or Th2 characteristics. In CsA-AI-diseased rats, there is a relative expansion of Th cells, phenotypically distinguished by expression of CD45RC and absence of RT6, which functionally exhibit Th1 characteristics, i.e. expression of IL2 and IFN $\gamma$ mRNA, and expansion of these Thl cells appears to determine the presence or absence of disease (submitted). The role of Thl cells, described in CsA-AI and other autoimmune models (37), may, therefore, reside in skewing the CD4 and CD8 T cells towards a cell-mediated immune response. Once effector cells are generated in sufficient quantity within these subsets, they can persist in their autoaggressive behaviour and generate new lesions upon adoptive transfer, provided regulatory mechanisms of the normal recipients are eliminated prior to transfer $(3,8,38,39)$. The fact that CD8 cells are better IFN $\gamma$ producers than CD4 T cells (35) may explain why about three times more CD4 than CD8 cells are required to cause similar disease.

Many autoimmune models, such as experimental allergic encephalomyelitis (40) and collagen induced arthritis (41), show restricted TCR BV usage in the autoreactive effector cells. However, unlike many autoimmune models, CsA-AI is not induced by immunization, but is based on aberrant $T$ cell recovery after total ablation by high-dose irradiation. We could not detect aberrations in the BV repertoires of lymph node- or skin-infiltrating $T$ cells, using the RNase protection assay and immunohistochemistry in diseased donors or recipients of CD4and CD8-depleted LNC. This contrasts with the report by Fischer and colleagues (42), who identified the exclusive presence of BV8S5 and BV12 in the peripheral blood of secondary recipients by RT-PCR using BV-specific primers and attributed an effector role to the BV8S5expressing $T$ cells based on disease ablation following depletion of these cells. In agreement with our findings, humans subjected to an anti-cancer treatment protocol that induces CsA-AI also do not display consistent BV distortions (43).

Development of CsA-AI depends on the genetic background of the rat strain as well as the absence of regulatory $\mathrm{T}$ cells $(3,4,8,38,44)$. After irradiation, peripheral $\mathrm{T}$ cell recovery may be impaired by CsA in two ways: 1) CsA may inhibit thymocyte maturation, resulting in slow 
peripheral recovery, and 2) CsA may inhibit negative thymic selection, resulting in an increased frequency of potentially autoreactive $T$ cells $(45-47)$. The disturbed peripheral $T$ cell repertoire transiently exhibit increases in T cells of the ThI type, which persist upon CsA treatment (submitted). A lack of regulatory cells combined with an increased frequency of autoreactive $\mathrm{T}$ cells in the CD4 and CD8 subsets enhances CsA-AI development and further perpetuates the Th1 response. The TCR BV repertoire in these effector populations is, however, not biased.

\section{Acknowledgements}

The authors wish to thank Prof. Th. Hünig (Würzburg, Germany), Dr. J Kampinga (Groningen, the Netherlands), Prof. C.D. Dijkstra (Amsterdam, the Netherlands) and Dr. B. de Geus (Leiden, the Netherlands) for the generous gift of monoclonal antibodies. Furthermore we would like to express our gratitude towards Marie-José van de Gaar and Hary van der Heijden for their excellent technical assistance.

\section{References}

1 Glazier, A., Tutschka, P. J., Farmer, E. R. and Santos, G. W. (1983) Graft-versus-host disease in cyclosporin A-treated rats after syngeneic and autologous bone marrow reconstitution. J. Exp. Med. 158: $1-8$

2 Bos, G. M. J., Majoor, G. D. and van Breda Vriesman, P. J. C. (1988) Cyclosporin-A induces a selective, reversible suppression of $T$-helper lymphocyte regeneration after syngeneic bone marrow transplantation: association with syngeneic graft-versus-host disease. Clin. Exp. Immunol. 74:443-448

3 Sorokin, R., Kimura, H., Schroder, K., Wilson. D. H. and Wilson, D. B. (1986) Cyclosporin-induced autoimmunity: Conditions for expressing disease, requirement for intact thymus, and potency estimates of autoimmune lymphocytes in drug-treated rats. J. Exp. Med. 164:1615-1625

4 Beijleveld, L. J. J., Damoiseaux, J. G. M. C., Wodzig. K. W. H. and van Breda Vriesman, P. J. C. (1995) $\mathrm{X}$-irradiation of the thymus is not required for the induction of Cyclosporin-A induced autoimmunity. Transplantation. 59:1601-1605

5 Beschorner, W. E., Hess, A. D., Shinn, C. A. and Santos, G. W. (1988) Transfer of Cyclosporineassociated syngeneic graft-versus-host disease by thymocytes. Transplantation. 45:209-215

6 Beschorner, W. E., Shinn, C. A., Fischer, A. C., Santos, G. W. and Hess, A. D. (1988) Cyclosporineinduced pseudo-graft-versus-host disease in the early post-cyclosporine period. Transplantation. 46, Suppl.: 112S-117S

7 Damoiseaux, J. G. M. C., Beijleveld, L. J. J. and van Breda Vriesinan, P. J. C. (1995) Cutaneous immunopathology of Cyclosporin-A induced autoimmunity in the rat. Clin. Immunol. Immanopathol. 77:315-323

8 Fischer, A. C.. Laulis, M. K., Horwitz, L., Beschorner, W. E. and Hess, A. D. (1989) Host resistance to cyclosporine induced syngeneic graft-versus-host disease: Requirements for two distinct lymphocyte subsets. J. Immunol. 143:827-832 
9 Hess, A. D., Fischer, A. C. and Beschorner, W. E. (1990) Effector mechanisms in cyclosporine A-induced syngeneic graft-versus-host disease. Role of CD4+ and CD8+ T lymphocyte subsets. J. Immunol. $145: 526-533$

10 Hess, A. D., Horwitz, L. R., Laulis, M. K. and Fuchs, E. (1993) Cyclosporine-induced syngeneic graft-vshost disease: prevention of autoaggression by treatment with monoclonal antibodies to $\mathrm{T}$ lymphocyte cell surface determinants and to MHC class II antigens. Clin. Immunol. Immunopathol. 69:341-350

11 Bos, G. M. J., Majoor, G. D., Willighagen, R. G. J. and van Breda Vriesman, P. J. C. (1989) Chronic cyclosporine-induced autoimmune disease in the rat: a new experimental model for scleroderma. $J$. Invest. Dermatol. 93:610-615

12 Hünig, T., Wallny, H.-J., Hartley, J. K., Lawetzky, A. and Tiefenthaler, G. (1989) A monoclonal antibody to a constant determinant of the rat $\mathrm{T}$ cell antigen receptor that induces $\mathrm{T}$ cell activation. J. Exp. Med. $169: 73-86$

13 Torres-Nagel, N. E., Gold, D. P. and Hünig, T. (1993) Identification of rat Terb-V8.2, 8.5, and 10 gene products by monoclonal antibodies. Immunogenet. 37:305-308

14 Torres-Nagel, N., Kraus, E., Brown, M. H., Tiefenthaler, G., Mitnacht, R., Williams, A. F. and Hünig, T. (1992) Differential thymus dependence of rat CD8 isoform expression. Eur. J. Immunol, 22:28412848

15 Kampinga, J., Kroese, F. G., Pol, G. H., Nieuwenhuis, P., Haag, F., Singh, P. B., Roser, B. and Aspinall, R. (1989) A monoclonal antibody to a determinant of the rat $T$ cell antigen receptor expressed by a minor subset of T cells. Int. Immunol. 1:289-95

16 Dijkstra, C. D., Döpp, E. A., Joling, P. and Kraal, G. (1985) The heterogeneity of mononuclear phagocytes in lymphoid organs: distinct macrophage subpopulations in the rat recognized by monoclonal antibodies EDI, ED2 and ED3. Immunology. 54:589-599

17 Williams, A. F. Galfre, G. and Milstein, C. (1977) Analysis of cell surfaces by xenogeneic myelomahybrid antibodies: differentiation antigens of rat lymphocytes. Cell. 12:663-673

18 McMaster, W. R. and Williams, A. F. (1979) Identification of la glycoproteins in rat thymus and purification from rat spleen. Eur. J. Immunol. 9:426-433

19 Jefferies, W. A., Green, J. R. and Williams, A. F. (1985) Authentic T helper CD4 (W3/25) antigen on rat peritoneal macrophages. J. Exp. Med. 162:121-127

20 Brideau, R. J., Carter, P. B., McMaster, W. R., Mason, D. W. and Williams, A. F. (1980) Two subsets of rat T lymphocytes defined with monoclonal antibodies. Eur. J. Immunol. 10:609-615

21 Hermans, M. H. A. and Opstelten, D. (1991) In situ vizualization of hemopoietic cell subsets and stromal elements in rat and mouse bone marrow by immunostaining of frozen sections. J. Histochem. Cytochem. 29:1627

22 Joling, P., Tielen, F. J., Vaessen, L. M. B., Huijbregts, J. M. A. and Rozing, J. (1985) New markers on T cell subpopulations defined by monoclonal antibodies. Transplant. Proc. 17:1857-1860

23 Julius, M. H., Simpson, E. and Herzenberg. L. A. (1973) A rapid method for the isolation of functional thymus-derived lymphocytes. Eur. J. Immunol. 3:645-652

24 Beijleveld, L. J. J., Damoiseaux, J. G. M. C. and van Breda Vriesman, P. J. C. (1995) The differential effects of $\mathrm{X}$-irradiation and Cyclosporin-A administration on the thymus with respect to the generation of Cyclosporin-A induced Autoimmunity. Dev. Immunol. 4:127-138

25 Chomczynski, P. and Sacchi, N. (1987) Single-step method of RNA isolation by acid Guanidinium Thiocyanate-Phenol-Chloroform extraction. Anal. Biochem. 162:156-159 
26 Smith, L. R., Kono, D. H. and Theofilopoulos, A. N. (1991) Complexity and sequence identification of 24 rat $V_{\beta}$ genes. Journal of Immunology. 147:375-379

27 Smith, L. R., Kono, D. H., Kammuller, M. E., Balderas, R. S. and Theofilopoulos, A. N. (1992) $V_{\beta}$ repertoire in rats and implications for endogenous superantigens. European Journal of Immunology. 22:641-645

28 Singer, P. A., Balderas, R. S. and Theofilopoulos, A. N. (1990) Thymic selection defines multiple T cell receptor $\mathrm{V}$ beta 'repertoire phenotypes' at the CD4/CD8 subset level. EMBO J. 9:3641-3641

29 Yang. C. and Bell, E. B. (1992) Functional maturation of recent thymic emigrants in the periphery: development of alloreactivity correlates with the cyclic expression of CD45RC isoforms. Eur. J. Immunol. 22:2261-2269

30 Hosseinzadeh, H. and Goldschneider, I. (1993) Recent thymic emigrants in the rat express a unique antigenic phenotype and undergo post-thymic maturation in peripheral lymphoid tissues. J. Immunol. 150:1670-1679

31 Thivolet, C., Bendelac, A., Bedossa, P., Bach, J.-F. and Carnaud, C. (1991) CD8+ T cell homing to the pancreas in the nonobese diabetic mouse is CD4+ T cell-dependent. J. Immunol. 146:85-88

32 Whalen, B. J., Greiner, D. L., Mordes, J. P. and Rossini, A. A. (1994) Adoptive transfer of autoimmune diabetes mellitus to athymic rats: syngergy of $\mathrm{CD} 4+$ and $\mathrm{CD} 8+\mathrm{T}$ cells and prevention by RT6 $+\mathrm{T}$ cells. J Autoimmunity. 7:819-831

33 Fowell, D. and Mason, D. (1993) Evidence that the T cell repertoire of normal rats contains cells with the potential to cause diabetes. Characterization of the $\mathrm{CD} 4+\mathrm{T}$ cell subset that inhibits this autoimmune potential. J. Exp. Med. 177:627-636

34 Conlon, K., Osborne, J., Morimoto, C., Ortaldo, J. R. and Young, H. A. (1995) Comparison of lymphokine secretion and mRNA expression in the CD45RA+ and CD45RO+ subsets of human peripheral blood CD4+ and CD8+ lymphocytes. Eur J lmmunol. 25:644-648

35 Noble, A., Macary, P. A. and Kemeny, D. M. (1995) IFN- $\gamma$ and IL-4 regulate the growth and differentiation of $\mathrm{CD}^{+} \mathrm{T}$ cells into subpopulations with distinct cytokine profiles. J. Immunol. 155:2928-2937

36 Kemeny, D. M. Noble, A., Holmes, B. J. and Diaz-Sanchez, D. (1994) Imune regulation: a new role for the $\mathrm{CDB}^{+} \mathrm{T}$ cell. Immunol. Today. 15:107-110

37 KaL. J. D., Benoist, C. and Mathis, D. (1995) T helper cell subsets in insulin-dependent diabetes. Science. 268:1185-1188

38 Fischer, A. C., Beschorner, W. E. and Hess, A. D. (1989) Requirements for the induction and adoptive transfer of cyclosporine-induced syngeneic graft-verus-host-disease. J. Exp. Med. 169:1031-1041

39 Hess, A. D. Fischer, A. C.. Horwitz, L.. Bright, E. C. and Laulis, M. K. (1994) Characterization of peripheral autoregulatory mechanisms that prevent development of Cyclosporin-induced syngeneic graft-versus-host disease. J. Immunol. 153:400-411

40 Burns, F. R., Li, X., Shen, N., Offner, H., Chou, Y., Vandenbark, A. A. and Heber-Katz, E. (1989) Both rat and mouse $T$ cell receptors specific for the encephalitogenic determinant of myelin basic protein use similar $V \alpha$ and $V \beta$ chain genes even though the major histocompatibility complex and encephalitogenic determinants being recognized are different. J. Exp. Med. 169:27-39

41 Erlandsson, H., Müssener, A., Klareskog, L. and Gold, D. P. (1994) Restricted T cell receptor usage in DA rats during early collagen-induced arthritis. Eur J Immunol. 24:1929-1932 
42 Fischer, A. C., Ruvolo, P. P., Burt, R., Horwitz, L. R., Bright, E. C., Hess, J. M., Beschorner, W. E. and Hess, A. D. (1995) Characterization of the autoreactive T cell repertoire in Cyclosporin-induced syngeneic Graft-versus-Host disease. A highly conserved repertoire mediates autoaggression. J. Immunol. 154:3713-3725

43 Ruvolo, P. P., Fischer, A. C., Vogelsang, G. B., Jones, R. J. and Hess, A. D. (1995) Analysis of the Tcell receptor repertoire in autologous Graft-versus-Host disease. $\ln \mathrm{T}$ cell receptor use in human autoimmune disease. M.M. Davis and J. Buxbaum, Editors. New York. 432-434

44 Wodzig, K. W. H., Majoor, G. D. and van Breda Vriesman, P. J. C. (1993) Susceptibility and resistance to Cyclosporin A-induced autoimmunity in rats. Autoimmumity; 16:29-37

45 Gao, E. K., Lo, D., Cheney, R., Kanagawa, O. and Sprent, J. (1988) Abnormal differentiation of thymocytes in mice treated with Cyclnsporin A. Nature. 336: 176-179

46 Jenkins. M. K., Schwartz, R. H. and Pardoll, D. M. (1988) Eftects of Cyclosporin A on T cell development and clonal deletion. Science. 241:1655-1658

47 Kanariou, M., Huby, R., Ladyman, H., Colic. M., Sivolapenko, G. and Lampert, I. (1989) Immunosuppression with cyclosporin A alters the thymic microenvironment. Clin. Exp. Immunol. 78:26.3-270 


\section{Summary}

Cyclosporin-A induced autoimmunity is an experimental model of disease that can be readily induced in young Lewis rats. This model is discussed in Chapter 1 , in the context of intrathymic $T$ cell development, including positive and negative selection, and peripheral tolerance versus autoimmunity. The most conspicuous target organ in this model is the skin; its acute and subacute pathology includes, in chronological order, erythroderma (reddening of the skin), dermatitis (inflammation of the skin seen as a brownish discolouring), and alopecia (severe hair loss). This pathology has striking similarity with Graft-versus-Host disease (GvH), a disease observed after transplantation of allogeneic bone marrow into immuno-compromised recipients. The development of GvH-like pathology in this experimental model is remarkable because the disease is induced by procedures which are used to prevent $\mathrm{GvH}$ in man after bone marrow transplantation (BMT). Those procedures in man are firstly the use of allogeneic but fully matched major histocompatibility complex (MHC) marrow, and secondly, Cyclosporin-A therapy. Cyclosporin-A (CsA) is an immunosuppressive drug used clinically to prevent allograft rejection, to suppress ongoing autoimmune diseases and to prevent $\mathrm{GvH}$ after allogeneic BMT.

Although the GvH-like disease in Lewis rats resembles clinically GvH seen in man after BMT, the animal disease is not caused by mismatches for major or minor histocompatibility complex antigens. In the rat model, disease is brought about by total body irradiation of $8.5 \mathrm{~Gy}$ followed by a syngeneic (MHC identical) BMT; next CsA is given for a 4 to 6 week period. After stopping CsA, disease develops in the susceptible Lewis strain. In the rat model, syngeneic BMT is not necessary since disease also develops when a hindleg of the rat is shielded during $\mathrm{X}$-irradiation, and thereby allows rescue by autologous bone marrow reconstitution. This observation led to two conclusions. First, the GvH-like disease in the rat could not be due to $\mathrm{MHC}$ mismatches and was therefore of an autoimmune nature; hence the disease is called CsA autoimmune disease (CSA-AI). This description is not quite correct either, because CsA given for a 6 week period does not cause disease when the rat is not conditioned by prior $\mathrm{X}$-irradiation. The second, and as we will show 'erroneous', conclusion 
was that the thymus had to be in the field of $\mathrm{X}$-irradiation. This conclusion was supported by the fact that CsA-AI is thymus dependent: thymectomy prior to X-irradiation and CsA-therapy prevents disease and autoreactive, thymus derived $\mathrm{T}$ cells are the effector cells as shown by adoptive transfer studies. These adoptive transfers are only successful, however, when the auto-regulatory $(\mathrm{T})$ cells in the recipient are first eliminated by $\mathrm{X}$-irradiation or Cyclophosphamide administration. It is clear then, that for disease to develop one needs not only the generation of autoreactive thymic derived $\mathrm{T}$ cells, but also suppression or modulation of a peripheral regulatory $T$ cell circuit. In this thesis we have examined both the events in the thymus and in the periphery.

In Chapter 2, we first asked the question at which point in time the autoreactive $T$ cells leave the thymus. In order to address this question serial thymectomies were performed in rats. subjected to total body $X$-irradiation $(8.5 \mathrm{~Gy})$, with a rescue with $6 \times 10^{7}$ syngeneic bone marrow cells, and next given CsA $(7.5 \mathrm{mg} / \mathrm{kg} / \mathrm{day})$ for up to 6 weeks. When not thymectomized, these rats develop, 2 to 3 weeks after cessation of CsA, CsA-AI. Thymectomies performed within 8 days of X-irradiation prevented CsA-AI. Thymectomics performed on day 12 or thereafter allowed development of disease. However, incidence and severity increased between day 12 and 21 thymectomies. From day 21 on, no further increase in severity and incidence was observed. Thus within 2 weeks after X-irradiation, the thymus is repopulated and autoreactive cells have moved into the periphery under CsA-therapy, and indeed continuation of CsA treatment for up to 6 weeks after thymectomy did not influence disease. We next asked the question whether or not the thymus had to be in the field of Xirradiation. For this purpose, Lewis rats were first thymectomized; they were next $\mathrm{X}$-irradiated (8.5 Gy), given syngeneic bone marrow cells, two syngeneic neonatal thymus lobes transplanted under the renal capsule, and CsA. These rats develop CsA-AI after cessation of CsA medication given for 4 or 6 weeks, showing that the thymus is necessary -without transplantation of thymic lobes no disease develops- but $\mathrm{X}$-irradiation of the thymus is not required.

Given that $\mathrm{X}$-irradiation of the thymus is not required to bring about disease we next asked the question in Chapter 3 how CsA brings about thymus derived autoreactive $T$ cells into the periphery. CsA has been shown to interfere with intrathymic selection. This -the literature holds- is due to a disappearance of the MHC class II antigens in the thymic dendritic cells, or alternatively, due to a decrease of these dendritic cells altogether; either way resulting in defective negative selection. This, at any rate, was assumed to explain the appearance of "forbidden" $T$ cells (in terms of $T$ cell receptor (TCR) $\beta$-chain variable region (BV) usage) into 
the periphery of mice treated with CsA. In order to address this question, Lewis rats were. treated with CsA and/or X-irradiation. The effect of treatment on thymic stromal cells (including dendritic cells), and thymocyte population was examined in terms of histology, immunohistochemistry and thymocyte phenotype by means of tricolour staining of the thymocytes followed by flowcytometric analysis. Using fluorescent labeled monoclonal antibodies (mAb) to $\mathrm{CD} 4, \mathrm{CD} 8$ and $\mathrm{TCR} \alpha \beta$, the thymocyte population can be divided into cortical (relatively immature) CD4CD8 double positive (DP) TCR $\alpha \beta^{\text {intermediate expressing }}$ cells, and medullary (more mature) CD4 or CD8 single positive (SP) cells which are TCR $\alpha \beta^{\text {high }}$. X-irradiation followed by syngeneic BMT resulted in a severe depletion of thymocytes, but the thymus had returned to nomal in terms of all parameters mentioned above in a 2 -week period. A different picture emerged when CsA $(7.5 \mathrm{mg} / \mathrm{kg} /$ day $)$ was added to this regimen. First, CsA by itself, or given after prior X-irradiation and syngeneic BMT, caused a remarkable decrease in size of the medulla of the thymus (involution), including a decreased number of medullary dendritic cells without, however, influencing their expression of MHC class II antigens; and although the medulla has decreased remarkably in size, the antigen distribution and density of the remnant epithelial cells and dendritic cells did not differ from normal.

CsA treatment led also to a sharp decrease in CD4 and CD8 SP thymocytes, brought about by a maturation arrest of the cortical CD4CD8 DP thymocytes. The combination of $X$ irradiation and CsA allowed a recovery of cortical thymocytes but not of the medullary ones. These observations were inconsistent with the notion that the appearance of peripheral autoreactive and thymic derived $\mathrm{T}$ cells in $\mathrm{CsA}-\mathrm{AI}$ was due to an altered thymic medullary microenvironment.

We therefore asked the question in Chapter 4 whether or not CsA influenced the function of the thymic dendritic cells. For this purpose C.s. in doses of $7.51030 \mathrm{mgr} / \mathrm{kg} / \mathrm{daty}$, was given to Lewis rats for a 2 week period; next the number and function of the thymic dendritic cells was measured in vitro in terms of accessory function and capacity to induce allogencic lymphocyte proliferation. CsA decreased the number of dendritic cells: but these cells were entirely normal in terms of membrane antigens, accessory cell activity and capacity to induce allogeneic $\Upsilon$ cell-proliferation. These results are incompatible with the view that CsA sclectively interferes with thymic dendritic cells. They support rather the view that the medullary involution is secondary to a maturation arrest of the cortical thymocytes. Since the integrity of the medulla requires the presence of mature thymocytes, in the absence of an inflow of SP thymocytes into the medulla, involution of the medulla occurs. 
Although autoreactive T cells apparently are thymus derived, CsA alone does not induce disease. Peripheral mechanisms for tolerance induction are additionally involved in CsA-AI. This indicates that CsA-AI is principally due to a failure of peripheral $\mathrm{T}$ cell regulation and suppressor circuits. Therefore we turned from the thymus to the periphery.

Peripheral Thelper (Th) cell-dependent immune responses develop into Th1 or Th2 responses. The difference between these two is made on the basis of secreted cytokines. The Th 1 response includes the delayed type hypersensitivity reaction and is characterized by the secretion of interleukin 2 and interferon $\gamma$, whereas the Th2 response uses other cytokines, e.g. IL4 and IL10, and provides B cell help. It has now become clear that preponderance of Th2 cells may suppress ThI responses, and the reverse, and that this effect is brought about by cytokines. In addition, it is postulated that in Th cell mediated autoimmune models, a skewing of peripheral $\mathrm{T}$ cells in favour of Th2 may prevent disease, and the reverse facilitates it. In the model of CsA-AI the peripheral skin lesions appear histologically to be Thl (delayed type hypersensitivity) mediated.

In Chapter 5 we determined the thymus dependent, peripheral $\mathrm{T}$ cell maturation in relation to development of CsA-AI. Thymic output can be assessed by determining the number of Thy $1.1^{+}$(a marker for young, i.e. less then 14 days old, rat T cells) TCR $\alpha \beta^{+}$recent thymic emigrants (RTE). X-irradiation induced a peripheral T cell depletion completely reversed in a 6 week period. CsA caused a decrease in RTE which was also observed in rats subjected to Xirradiation with syngeneic bone marrow rescue and CsA therapy; the latter showed decreased numbers of T cells until CsA-AI; CD4 and CD8 T cells were equally decreased. In CsA-AI rats, however, TCR $\alpha \beta$ - cells were observed expressing CD4, CD 8 or both. The majority of the CD8+ TCR $\alpha \beta$ - cells were identified to be NK cells. The CD4+ and CD4CD8 DP TCR $\alpha \beta^{-}$ cclls were demonstrated to be mostly monocytes as defined by the expression of CR3.

In order 10 be informed about Th1 and Th2 subset distribution, the CD45RC and RT6 antigens were used; in rats Th 1-like cells are postulated to carry the marker CD45RC but lack RT6, whereas Th2-like cells show the reverse. Lewis rats developing Cs.A-AI, showed a marked and persistent relative expansion of mature Thl-like cells (CD45RC ${ }^{+}$, RT6 ${ }^{-}$) resulting in a reversal of the Th1:Th2 ratio in favour of the CD45RC+, RT6 ${ }^{-}$Th1-like cell subscl: in Brown Norwaty rats. which are resistant to induction of CsA-AI, the ratio of Th1:Th2 cells did not reverse. Lewis rats suhjected to either X-irradiation or C $S A$ therapy did not show increases of Thl comparahle to CsA-AI. We demonstrated that the CD45RC+, RT6- Th cells isolated from normal Lewis rats produced IL2 mRNA, and moreover, constituted the only Th subset producing interferon $y$ mRA on stimulation, indicating their ThI nature. Altogether, this 
suggests that susceptibility or resistance to $\mathrm{CsA}-\mathrm{AI}$ requires, apart from thymic derived autoreactive $\mathrm{T}$ cells, a skewing of the Thl:Th2 balance in favour of Th1.

In Chapter 6 we have addressed the issue of the autoreactive T effector cells, and their TCR BV-repertoire, in adoptive transfer studies. The literature on this issue is conflicting since by means of adoptive transfer studies the disease has been transferred with CD 4 cells by some, by CD8 cells by others, whereas again others claimed the requirement of both CD4 and CD8 cells. There is consensus that the recipient needs to be conditioned by $\mathrm{X}$-irradiation or Cyclophosphamide treatment; adoptive transfers with $\mathrm{T}$ cells, derived from Lewis rats with acute CsA-AI, into normal Lewis rats does not yield disease. The autoregulatory $\mathrm{T}$ cell circuit of the recipient has to be first deleted.

To determine the efficacy of autoreactive CD4 and CD8 $\mathrm{T}$ cells, the adoptive transfer studies were carried out in a well defined experimental protocol. For this purpose the recipient rats were first thymectomized, next $\mathrm{X}$-irradiated and given syngeneic marrow; by this manoeuvre the adoptively transferred cells could not be contaminated by new thymic output of the thymus of the recipient. Next, lymph nodes of animals with CSA-AI were harvested, prepared into single cell suspensions, depleted of either CD4 or CD8 cells, and were next infused intravenously into the recipient; when CD4 $\Upsilon$ cells were adoptively transferred the recipient received also in vivo depleting mAb to the CD8 subset, and when CD8 $T$ cells were transferred $\mathrm{mAb}$ to $\mathrm{CD} 4$ was given. After adoptive transfer, when the rats developed discase, the transferred cells were monitored by flowcytometry of peripheral blood and skin biopsies were taken for immunohistologic analysis. CsA-AI developed after adoptive transfer of either CD4 or CD8 T cells in the absence of the depleted subset. Both CD4 and CD8 transfers caused similar lesions with similar kinetics. The enhanced MHC class II expression on keratinocytes, and the presence of ED1+ macrophages was identical to the lesions observed in the primary donors. The difference was that in the primary donor the skin lesions contain both CD4 and CD8 $\mathrm{T}$ cells, whereas in the lesions from adoptive transfers either CD4+ TCR $\alpha \beta^{+}$cells or $\mathrm{CD} 8^{+} \mathrm{TCR} \alpha \beta^{+}$cells were present. These results show that phenotypically completely different $T$ cell subsets cause identical lesions: in other words, dissociation of presumed phenotype-related function and in vivo biological effect. How this is brought about is entirely speculative.

We analysed in addition the TCR repertoire in terms of the BV-usage. This revealed the patterns of TCR BV expression in the lymph node cells from rats with CsA-AI and recipients of adoptive transfer (developing disease in the absence of either CD4 or CD8 T cells) to be comparable to that of normal Lewis thymocytes or lymph node cells. Also the epidermal T cell infiltrates in recipients of adoptively transferred cells showed no preferential use of TCR BV 
families. These results do not support the view that CsA-AI results from a peripheral expansion of T cell populations in terms of TCR BV usige.

The work presented in these chapters may be shortly summarised as follows.

CsA-AI is the result of aberrant $T$ cell development after $X$-irradiation and CsA therapy. CsA has a clearcut effect on thymic architecture and thymocyte maturation; a decrease in the number of mature thymocytes and, secondary to this effect, involution of the medulla. Although all stromal cells are still present and seem to be able to provide the micro-environment that is important for negative selection, upon CsA therapy autoreactive thymocytes are generated. CsA acts directly on the thymocytes, by interfering with the intra-cellular signal upon activation via the TCR, and thereby altering the fate of the thymocytes during maturation. Because of impaired selection, among the thymocytes that have survived both positive and negative selection, the frequency of autoreactive thymocytes is increased.

$\mathrm{X}$-irradiation is obligatory to condition the periphery. Provided the periphery is void of regulatory cells, CsA-AI can develop. Already during CsA therapy, thymus derived autoreactive $T$ cells enter the periphery, and after CsA therapy is stopped, CsA-AI will develop. Autoreactive $T$ cells are demonstrable in lymph nodes, spleen and in the lesions. Expansion of CD45RC+, RT6-,Th1-like cells is critical for CsA-AI to develop. Whether or not this will occur is genetically controlled. Activation of the Thl-like cells results in IL2 and IFN $\gamma$ production, which in addition may lead to further skewing of other $\mathrm{T}$ cells. including CD8 $\mathrm{T}$ cells, to respond in a similar fashion. When disease is clinically manifest, effector $T$ cells are demonstrable within the CD4 and CD8 T cell population by adoptive transfer. There is no evidence for restricted usage of any TCR BV family. The antigen in CsA-AI is unknown, but hoth CD4 and CD8 $\mathrm{T}$ cells populations contain effector $\mathrm{T}$ cells. Since virtually all Lewis rats, subjected to X-irradiation and CsA therapy develop similar disease it is suggested that the autoantigen(s) are related to epithelial cell antigen(s) expressed in the thymus and in the skin. 


\section{Samenvatting}

Cyclosporine A-geinduceerde autoimmuniteit is een model voor autoimmuunziekte in mens en proefdier en het kan op eenvoudige wijze gegenereerd worden in de Lewis rat. Dit model wordt beschreven in Hoofdstuk 1, in de context van de intrathymale $\mathrm{T}$ cel ontwikkeling, welke positieve en negatieve selectie omvat, en perifere tolerantie versus autoimmuniteit. Het meest in het oog springende doelwit-orgaan in dit model is de huid; de acute en subacute huidpathologie omvat in chronologische volgorde erythroderma (intense roodverkleuring van de huid), dermatitis (ontsteking van de huid, gekenmerkt door een bruinverkleuring) en alopecia (kaalheid door haarverlies); en wanneer de ziekte chronisch wordt is deze niet te onderscheiden van cutane humane scleroderma in histologische zin. Deze pathologie toont grote overeenkomst met de Graft-versus-Host reactie (GvH), een fenomeen dat wordt waargenomen bij immuundeficiënte ontvangers na allogene beenmergtransplantatie. De ontwikkeling van de $\mathrm{GvH}$-achtige pathologie in dit experimentele model is op het eerste gezicht zeer opmerkelijk. Immers dit model wordt geïnduceerd onder condities die bij de mens normaliter worden gebruikt om GvH na beenmergtransplantatie te voorkomen. De eerste voorwaarde die wordt toegepast is het gebruik van volledig compatibel beenmerg (bij inteelt proefdierstammen aangeduid als syngeen of genetisch identiek beenmerg). De tweede voorwaarde is het gebruik van Cyclosporine A, een immunosuppressief geneesmiddel dat gebruikt wordt om orgaan-afstoting na transplantatie tegen te gaan, om verschillende autoimmuunzickten te onderdrukken en om een GvH-rcactic na allogene beenmergtransplantatie te voorkomen.

Alhoewel de GvH-achtige ziekte in de Lewis rat overetnkomsten vertoont met klinische GvH bij de mens na beenmergtransplantatie, is de ziekte bij het proefdier niet het gevolg van incompatibiliteit in de transplantatie-antigenen, bepaald door de Major Histocompatibility Complex (MHC) en nonMHC antigenen. Er wordt immers gebruik gemaakt van syngene beenmergdonoren. In het rattemodel wordt de ziekte geïnduceerd door middel van een letale lichaamsbestraling van 8,5 Gy, een dag later gevolgd door syngene beenmergtransplantatie. Hierna worden de ratten behandeld met CsA gedurende 4 tot 6 weken. Ongeveer 2 weken nadat de CsA behandeling is gestaakt ontwikkelt zich de ziekte in de hiervoor gevoelige Lewis rattestam. In het rattemodel kan syngene beenmergtransplantatie ook vervangen worden door 
het afschermen van een van de achterpoten tijdens de bestraling. Hierdoor kan het beenmerg zich via het beschermde autologe beenmerg weer herstellen. Ook dan kan de ziekte weer ontstaan. Deze observaties hebben geleid tot twee conclusies. Ten eerste, de GvH-achtige ziekte in de rat is niet het gevolg van MHC of nonMHC antigen incompatibiliteit en heeft derhalve een autoimmuun karakter. Daarom is gekozen voor de naam Cyclosporine A (CsA) geïnduceerde autoimmuniteit, kortweg CsA-AI. Deze naamgeving is echter ook niet geheel correct; CsA alleen, gegeven gedurende zes weken, induceert geen ziekte. Het is noodzakelijk dat de ratten vooraf worden geconditioneerd door letale bestraling. De tweede conclusie, en zoals wij zullen aantonen 'foute' conclusie, die werd getrokken was dat de thymus binnen het veld van bestraling moet liggen. Deze conclusie werd gestaafd door het feit dat CsA-AI afhankelijk is van de aanwezigheid van de thymus. Thymectomie, uitgevoerd voor bestraling en CsA behandeling, zal het ontstaan van CsA-AI verhinderen. Voorts is aangetoond door middel van transfer studies dat de effector cellen autoreactieve $T$ cellen zijn, afkomstig uit de thymus. T cel transfer experimenten leveren alleen ziekte in de ontvanger als de ontvangers vooraf gedepleteerd worden van perifere, rijpe T cellen, hetzij door letale bestraling, hetzij door behandeling met Cyclophosphamide. Het is duidelijk dat voor de ontwikkeling van CsA-AI niet alleen autoreactieve, uit de thymus afkomstige $T$ cellen nodig zijn, maar ook een modulatie (onderdrukking of verwijdering) van de regulerende perifere $\mathrm{T}$ cel populaties. In dit proefschrift worden de effecten beschreven die plaats vinden in de thymus en in de periferie in relatie tot het ontstaan van C.SA-AI.

In Hoofdstuk 2 vragen wij ons af op welk moment de autoreactieve $\mathrm{T}$ cellen de thymus verlaten. Om deze vraag te kunnen beantwoorden zijn gedurende de CsA behandeling thymectomien uitgevoerd in Lewis ratten die vooraf bestraald zijn met een dosis van 8,5 Gy, syngeen beenmerg hebben gekregen en vervolgens behandeld werden met CsA gedurende maximaal 6 weken. De ratten die niet gethymectomeerd werden, ontwikkelden ongeveer 2 à 3 weken na de beëindiging van de CsA behandeling CsA-AI. Wanneer echter een thymectomie werd uitgevoerd binnen 8 dagen na de bestraling ontstond er geen ziekte. Thymectomiën uitgevoerd op dag 12 of later leidden wel tot het ontstaan van CsA-AI. Voorts bleek dat de incidentie en de mate van ernst van CsA-AI namen toe wanneer thymectomiën later werden uitgevoerd, met een maximale incidentie en emst van vanaf 21 dagen. Dit betekent dat binnen 3 weken na bestraling de thymus alweer thymocyten bevat en dat autoreactieve $T$ cellen gedurende de CsA behandeling de thymus verlaten en naar de periferie gaan. Vervolgens is de vraag gesteld of het bestralen van de thymus daadwerkelijk noodzakelijk is voor het induceren van CsA-AI. Hiervoor zijn Lewis ratten gethymectomeerd, vervolgens bestraald en voorzien van syngeen beenmerg. Gelijktijdig met de beenmergtransplantatie zijn onbehandelde thymus lobjes, afkomstig van neonatale syngene ratten, onder het nierkapsel geplaatst. Wanneer deze 
ratten vervolgens met $\mathrm{CsA}$ behandeld werden gedurende 4 tot 6 weken ontstond CsA-AI. Dit experiment toont aan dat de thymus nodig is, maar dat bestraling van de thymus zelf niet noodzakelijk is voor het ontstaan van ziekte.

Met het gegeven dat bestraling van de thymus niet nodig is om CsA-AI te induceren zijn we vervolgens in Hoofdstuk 3 gaan kijken hoe CsA het ontstaan van autoreactieve, uit de thymus afkomstige $\mathrm{T}$ cellen induceert. Het is beschreven dat CsA interfereert met intrathymale selectie processen. In de literatuur is dit toegeschreven aan de afname van MHC klasse II antigenen op de dendritische cellen in de thymus, of aan de afname van de dendritische cellen zelf. Beide mechanismen zouden leiden tot het ontstaan van een aberrante negatieve selectie. Dit zou de verklaring kunnen zijn voor het ontstaan van perifere "verboden" T cellen ("verboden" in de $z$ in van expressie van bepaalde variabele $\beta$-keten families (BV) van de T cel receptor (TCR)) zoals waargenomen in muizen behandeld met CsA. Om deze vraag te beantwoorden zijn Lewis ratten behandeld met CsA en/of 8,5 Gy bestraling. Het effect van de behandeling op het thymus stroma, inclusief de dendritische cellen, en het eftect op de thymocyt populatie werd bepaald door middel van histologie, immunohistochemie en flowcytometrie. De thymocyt populatie kan worden onderverdeeld in corticale, relatief onrijpe CD4CD8 dubbel positieve (DP) TCR $\alpha \beta$ zwak positieve cellen (TCR $\alpha \beta$ intermediate), en medullaire, meer rijpe CD4 of CD8 enkel positieve (SP) cellen die TCR $\alpha \beta$ hoog positief (TCR $\alpha \beta$ high) zijn. 8,5 Gy bestraling in combinatic met syngene beenmergtransplantatie leidt in eerste instantie tot een depletie van thymocyten, echter de thymus is, in de zin van de bovengenoemde parameters, 2 weken na bestraling weer normaal. Een totaal ander beeld wordt echter waargenomen wanneer CsA behandeling $(7,5 \mathrm{mg} / \mathrm{kg}$ per dag) wordt toegepast. CsA behandeling op zichzelf of in combinatie met bestraling en beenmergtransplantatie leidt tot een duidelijke afname van de grootte van de medulla in de thymus (involutie) en tot een afname van het aantal medullaire dendritische cellen. De expressie van MHC klasse II op de stromale cellen wordt echter niet beïnvloed; hoewel de medulla aanzienlijk afneemt in grootte blijft de verdeling en dichtheid van de antigeen expressie op het overblijvende medullaire epitheel en de dendritische cellen hetzelfde.

CsA behandeling leidt tevens tot een dramatische afname van de CD4 en CD8 SP thymocyten, wat wijst op een maturatie arrest van de onrijpere CD4CD8 DP thymocyten. De combinatie van bestraling met CsA behandeling verhindert niet het herstel van de corticale thymocyten in de thymus maar remt wel in sterke mate het herstel van de medullaire CD4 en CD8 SP TCR $\alpha$ Bhigh thymocyten. Deze observaties zijn in tegenspraak met de gedachte dat het bestaan van perifere autoreactieve, uit de thymus afkomstige $T$ cellen het gevolg is van een veranderd micromilieu in de thymus medulla. 
De vraag die hieruit volgt is of CsA de functie van de thymus dendritische cellen beïnvloedt. Die wordt behandeld in Hoofdstuk 4. Om deze vraag te kunnen beantwoorden zijn Lewis ratten behandeld met toenemende doses CsA $(7,5 ; 15$ en $30 \mathrm{mg} / \mathrm{kg}$ per dag) gedurende 2 weken. Vervolgens is het aantal dendritische cellen per thymus bepaald door de cellen te isoleren en is in vitro bepaald of deze cellen nog in staat zijn te functioneren als "accessory" cel of om allogene $\mathrm{T}$ cellen tot proliferatie aan te zetten. CsA behandeling leidt tot een dosis afhankelijke afname van het aantal geïsoleerde dendritische cellen. Deze geïsoleerde dendritische cellen wijken echter niet af van controle dendritische cellen voor wat betreft de expressie van membraan antigenen, de mate van "accessory" activiteit of het induceren van allogene T cel proliferatie in een zogenaamde "mixed leukocyt reaction'. Deze resultaten zijn niet verenigbaar met het idee dat CsA selectief interfereert met thymus dendritische cellen. De resultaten ondersteunen daarentegen eerder de gedachte dat de medullaire involutie, inclusief de afname van de dendritische cellen, secundair het gevolg is van de sterke maturatie arrest van de corticale CD4CD8 DP thymocyten. Aangezien beschreven is dat de integriteit van de medulla afhangt van de aanwezigheid van rijpe thymocyten, is bij een afname van instroom van nieuwe, rijpe SP thymocyten in de medulla involutie van de medulla het gevolg.

Autoreactieve T cellen zijn klaarblijkelijk afkomstig van de thymus. Echter de behandeling met $\mathrm{CsA}$ op zich leidt niet tot het ontstaan van ziekte. Regulatoire perifere mechanismen spelen dan ook een belangrijke rol in het al dan niet ontstaan van CsA-AI, wat aangeeft dat CsA-AI in principe het gevolg is van een niet adequaat functionerend regulatoir perifeer $T$ cel circuit. Om dit aspect nader te onderzoeken zijn we van de thymus naar de periferie gegaan.

Perifere T helper (Th) cel-afhankelijke immuun responsen ontwikkelen zich in een Thl of Th2 respons. Beide responsen worden functioneel onderscheiden op basis van de geproduceerde cytokines. De Thl respons omvat de vertraagd type overgevoeligheidsreactie en wordt gekenmerkt door de productic van onder andere Interleukine (IL) 2 en Interferon (IFN) $\gamma$, terwijl de Th2 respons onder andere gebruik maakt van de cytokines IL4 en IL10 en betrokken is bij B cel hulp. Het is duidelijk geworden dat een overheersende Th2 respons in staat is om een Thl respons te onderdrukken; het omgekeerde is eveneens het geval. Deze onderlinge remming wordt gestuurd door de geproduceerde cytokines. Verder is het idee geopperd dat in Th cel afhankelijke autoimmuun modellen een verschuiving van de perifere $\mathrm{T}$ cellen in het voordeel van Th2 cellen ziekte kan voorkomen, terwijl het tegenovergestelde juist autoimmuniteit kan veroorzaken of verergeren. In het $\mathrm{CsA}$-AI model vertonen de huidlaesies histologisch karakteristieken van een vertraagd type overgevoeligheidsreactie en duiden op een Thl respons. 
In Hoofdstuk 5 bestuderen we de thymus afhankelijke, perifere T cel rijping in relatie tot de ontwikkeling van CSA-AI. De hoeveelheid recente thymus emigranten (RTE) in de periferie, c.q. de mate van thymale productie, kan worden gemeten door het aantal Thy $1.1+$ TCR $\alpha$. $\beta$ high cellen te bepalen (Thyl.1-expressie is in de rat een kenmerk voor jonge $T$ cellen die de thymus korter dan 14 dagen verlaten hebben). Bestraling leidt tot een volledig verdwijnen van perifere $T$ cellen, hetgeen weer hersteld is 6 weken na de beenmergtransplantatie. CsA behandeling alleen resulteert uiteindelijk in een afname van het aantal RTE. Hetzelfde wordt ook waargenomen bij de combinatie van bestraling, beenmergtransplantatie en CsA behandeling. Deze combinatie leidt echter tot een ernstige remming van het herstel van de perifere $T$ cel populatie tot aan het ontstaan van CsA-AI. Het aantal CD4 en CD8 T cellen is in gelijke mate afgenomen. In CsA-AI ratten worden cellen wargenomen die geen TCR $\alpha \beta$ tot expressie brengen maar wel CD4, CD8 of beide. De meerderheid van deze CD8+ TCR $\alpha \beta^{-}$cellen bleken NK cellen te zijn, terwijl de CD4 en CD4CD8 DP TCR $\alpha \beta$ - cellen gekarakteriseerd zijn als monocyten.

Om meer te weten te komen over de verdeling van Th1 en Th2 cellen is gebruik gemaakt van de membraan markers CD45RC en RT6. Men veronderstelt dat in de rat Th1 . achtige cellen CD45RC+ zijn maar geen RT6 tot expressie brengen, terwijl Th2-achtige cellen juist geen CD45RC op het oppervlak hebben maar wel RT6. Lewis ratten die CsA-AI ontwikkelen, laten een duidelijke en blijvende toename, relatief ten opzichte van andere Th cellen, van rijpe Th1-achtige (CD45RC+ ${ }^{+}, \mathrm{RT}^{-}$) cellen zien hetgeen leidt tot een omkering van de Th1:Th2 ratio in het voordeel van de Th1-achtige cellen. Wanneer gekeken wordt in Brown Norway ratten, die ongevoelig zijn voor de inductie van CsA-AI, dan valt op dat ten gevolge van bestraling en CsA behandeling de Thl:Th2 ratio niet omkeert in het voordeel van de Th1achtige cellen. Deze omkering wordt ook niet waargenomen in Lewis ratten die alleen hestralald zijn of alleen met CsA behandeld zijn. Verder laten we in dit hoofustuk zien dat normale Lewis CD45RC+, RT6- Th cellen in staat zijn om IL2 en, typisch voor alleen deze Th cellen, IFNy mRNA te produceren nat in vitro stimulatic. Dit is een cytokine patroon katakteristiek voor Th1 cellen. Daarmee is voor deze phenotypisch gekarakteriseerde Th cellen aangetoond dat deze Thl cellen zijn. Samenvattend wijzen deze bevindingen erop dat gevoeligheid, of juist ongevoeligheid, voor CSA-AI niet alleen afhangt van uit de thymus afkomstige autoreacticve $\mathrm{T}$ cellen, maar ook afhangt van een perifere verschuiving van de Th1:Th2 ratio in het voordeel van Thl.

In Hoofdstuk 6 wordt gekeken naar de autoreactieve T cellen en het gebruik van het TCR BV repertoire door middel van adoptieve transfer studies. In de literatuur zijn tegenstrijdige resultaten beschreven, in die zin dat in adoptieve transfer studies CsA-AI kon worden overgebracht met alleen CD4 cellen, terwijl anderen juist rapporteerden dat CD8 cellen nodig 
zijn, terwijl weer anderen meldden dat zowel CD4 als CD8 cellen nodig zijn voor een succesvolle overdracht van ziekte. Er is in ieder geval concensus dat de ontvanger geconditioneerd dient te worden met bestraling of Cyclophosphamide behandeling; adoptieve transfers met $T$ cellen, geïsoleerd uit Lewis ratten met acute CsA-AI, naar normale Lewis ratten leidt nooit tot het ontstaan van ziekte. Het autoregulatoire T cel circuit van de ontvanger dient vooraf verwijderd te worden.

Om de efficiëntie te kunnen bepalen waarmee CD4 en CD8 T cellen ziekte kunnen overbrengen zijn adoptieve transfer studies uitgevoerd met een goed gedefinieerd protocol. Ontvanger ratten zijn vooraf eerst gethymectomeerd, vervolgens bestraald en voorzien van syngeen beenmerg. Door deze behandeling wordt voorkomen dat na transfer de ingespoten $T$ cellen gecontamineerd worden met nieuwe $T$ cellen afkomstig van de thymus. Van Lewis ratten, met duidelijke klinische verschijnselen van acute CsA-AI, werden de mesenteriale, cervicale en axillaire lymfe knopen verzameld en verwerkt tot cel suspensies. Deze suspensies werden vervolgens in vitro gedepleteerd van CD4 of CD8 positieve cellen en daarna ingespoten in de geconditioneerde ontvanger ratten. De ontvangers van CD4 T cellen werden daarna behandeld met monoclonale antilichamen (mAb) die in vivo CD $8^{+}$cellen depleteren; CD8 $\mathrm{T}$ cel ontvangers kregen CD4 depleterende mAb toegediend. Na de transfer, op het moment van ziek worden, werden de doorgespoten T cellen bestudeerd; het perifere bloed met behulp van flowcytometrie en de huid biopsiën door middel van immunohistochemie. Zowel na de transfer van alleen CD4 als alleen CD8 $\mathrm{T}$ cellen ontwikkelde zich CsA-AI in de ontvanger ratten in de afwezigheid van de vooraf gedepleteerde $T$ cel subset. De laesies die ontstaan na transfer van CD4 of CD8 T cellen zijn niet van elkaar te onderscheiden; niet in kinetiek noch in microscopische of macroscopische parameters die getoetst zijn. De geïnduceerde MHC klasse II expressic op keratinocyten en de aanwezigheid van ED1+ macrofagen in CD4 en CD8 ontvangers was identiek aan die in de laesies zoals die waargenomen werden in donoren. Het enige waarneembare verschil was de aanwezigheid van CD4 én CD8 positieve TCR $\alpha \beta^{+}$cellen in de donoren, terwijl in de ontvangers alleen $\mathrm{CD} 4^{+} \mathrm{TCR} \alpha \beta^{+}$of alleen $\mathrm{CD} 8^{+} \mathrm{TCR} \alpha \beta^{+}$ aanwezig waren. Deze resultaten laten zien dat phenotypisch geheel verschillende $T$ cel subsets vergelijkbare laesies kunnen veroorzaken: met andere woorden, er is een discrepantie tussen de veronderstelde phenotypisch gerelateerde functie en het werkelijke in vivo biologische effect. Hoe dit ontstaat is vooralsnog speculatief.

Verder is het TCR repertoire bepaald aan de hand van het TCR BV gebruik. Dit laat zien dat het TCR BV repertoire in de lymfe knopen van ratten met acute CsA-AI en de ontvangers in adoptieve transfer studies (die ziekte ontwikkelden in afwezigheid van hetzij CD4 hetzij CD8 T cellen) vergelijkbaar was met die van normale Lewis thymocyten of lymfe knoop cellen. Ook de epidermale $T$ cel infiltraten in de ontvangers van de adoptief overgebrachte $T$ cellen vertoonden geen preferentieel gebruik van TCR BV families. Deze resultaten ondersteunen niet 
de gedachte dat CsA-Al het resultaa is van perifere expansie van $\mathrm{T}$ cellen in de zin van TCR BV gehrik.

Het werk zoals dat gepresenteerd is in deze hoofdswkken kan als volgt kort worden samengevat.

CsA-AI is het gevolg van een afwijkende $T$ cel ontwikkeling na bestraling en CsA behandeling. CsA heeft een duidelijk effect op de thymus architectuur en thymocyt rijping: een afname van het aantal rijpe thymocyten en secundair hieraan cen involutie van de medulla. Alhowel alle stromale cellen aanwezig zijn en het aannemelijk is dat deze nog in staat zijn hei micromilieu te vormen dat nodig is voor negatieve selectie, worden ten gevolge van de CsA behandeling autoreactieve T cellen gevormd. CsA heeft een direct effect op de thymocyten doordat CsA interfereert met het intra-cellulaire signaal dat volgt op activatie via de TCR en daardoor grijpt CsA in op het resultaat van de selectie van de thymocyten gedurende de rijping. Tengevolge van de verstoorde selectie zal uiteindelijk binnen de thymocyten die zowel de positieve als de negatieve selectie hebben overleefd de frequentie van autoreactieve thymocyten zijn toegenomen.

Bestraling is nodig voor het conditioneren van de periferie. Alleen wanneer de perifere regulatoire $\mathrm{T}$ cellen verwijderd zijn, kan CsA-AI ontwikkelen. Al tijdens de CsA behandeling zullen thymocyten uit de thymus naar de periferie migreren en nadat de CsA behandeling is gestaakt, zullen de autoreactieve T cellen CsA-AI veroorzaken. Autoreactieve T cellen zijn dan aantoonbaar in de lymfe knopen, de milt en in de laesies. Expansie van CD45RC ${ }^{+}$, RT6- Thlachtige cellen is kritisch voor de ontwikkeling van CsA-AI. De activatie van de Thl-achtige: cellen leidt tot productie van IL2 en IFN $\gamma$, wat op zichzelf weer kan leiden tot een verdere verschuiving van andere $\mathrm{T}$ cellen, inclusief de CD8 $\mathrm{T}$ cellen, om op een gelijke wijze te reageren bij activatie. Op het moment dat de ziekte klinisch manifest is, zijn effector $T$ cellen aantoonbaar binnen zowel de CD4 als de CD8 T cel subsets door middel van transfer studies. Er zijn geen aanwijzingen voor een beperkt TCR BV familie gebruik. Het antigeen in CsA-AI is onbekend maar zowel de CD4 als de CD8 T cellen zijn betrokken als effector T cel. Aangezien feitelijk alle Lewis ratten, na te zijn behandeld met bestraling en CsA, dezelfde ziekte ontwikkelen suggereert dit dat het (de) autoantigen(en) verband houdt met epitheliale antigenen die voorkomen in de thymus en in de huid. 

Publications

Damoiseaux, J.G.M.C., Beijleveld, L.J.J. and van Breda Vriesman. P.J.C. (1993: Quantification and phenotypic characterization of the rat thymic dendritic cell population upon in vivo cyclosporine administration. Transplantation Proceedings. 25:2814-2815

Damoiseaux, J.G.M.C., Beijleveld. L.J.J. and van Breda Vriesman, P.J.C. (199f) The effects of in vivo cyclosporin-A aldministration on rat thymic dendritic crlls. Climical Experimental Immunology . 96: 513-520

Beijleveld, L.J.J., Damoiseaux, J.G.M.C. and van Breda Vriesman, P.J.C. (1995) The differential effects of $X$-irradiation and Cyclosporin- $A$ administration on the thymus with respect to the generation of Cyclosporin-A induced Autoimmunity. Developmental Iminunolog: 4: 127-138

Beijlcveld. L.J.J., Damoiseaux, J.G.M.C., Wodzig. K.W.H. and van Breda Vriesman, P.J.C. (1995) X-irradiation of the thymus is not required for the induction of CyclosporinA induced Autoimmunity. Transplantation. 59:1601-1605

Damuiseaux, J.G.M.C., Beijleveld, L.J.J. and van Breda Vriesman, P.J.C. (1995) Cutaneous immunopathology of Cyclosporin-A induced autoimmunity in the rat. Clinical Immunology and Immanopathology: 77:315-323

Damoiseaux, J.G.M.C., Beijleveld, L.J.J., Schuurman, H.J. and van Breda Vriesman, P.J.C. The effect of in vivo Rapamycin treatment on de novo T cell development in relation to induction of autoimmune-like immunopathology in the rat. Accepted by Transplantation Beijleveld, L.J.J., Groen, H., Broeren, C.M., Klatter, F., Kampinga, J., Damoiseaux, J.G.M.C. and van Breda Vriesman, P.J.C. Susceptibility for clinically manifest Cyclosporine-A induced autoimmune disease is associated with Interferon $\gamma$ producing CD45RC+RT6- Thelper cells. Accepted by Clinical and Experimental Immunology

Beijleveld, L.J.J., Damoiseaux, J.G.M.C., Roglic, M., Theofilopoulos, A.N. and van Breda Vriesman, P.J.C. Effector cells in Cyclosporin-A induced autoimmunity: Both CD4 and CD8 T cells generate autoimmune disease upon adoptive transfer. Accepted by Transplantation 

Dankwoord

Lef hii,

Utt is sjoen yewees.

noe is wt tied

un weijer be goon.

Mith geer wit wt.

geer seet allemoal becoún'l

Be lange maven.

Leo.

137 



\section{Curriculum Vitae}

Leo Beijleveld werd geboren op 5 augustus 1963 in Maastricht. Hij behaulde in 1981 het diploma Atheneum $\beta$ aan het Stedelijk Lyceum en HAVO te Maastricht. Vervolgens begon hij met de studie Biologie aan de Vrije Universiteit van Amsterdam. In 1990 behaalde hij aan de Rijksuniversiteit Groningen het doctorial examen Biologie, afstudeerrichting Dierfysiologie met als hoofdvakken Moleculaire Biologie (Nederlands Kanker Instituut, afdeling Tumorbiologie onder leiding van Dr. R. Michalides en Dr. E. Schuuring) en Celbiologie/Dierfysiologie (Pathologisch Anatomisch Laboratorium van de Rijksuniversiteit Groningen onder leiding van Prof. J.J. Weening en Dr. W. Bakker). Aansluitend was hij tot september 1991 werkzaam als toegevoegd onderzoeker bij laatstgenoemde vakgroep. Van september 1991 tot september 1995 was hij als onderzoeker in opleiding verbonden aan de vakgroep Immunologie van de Rijksuniversiteit Limburg te Maastricht. Onder leiding van Prof. Dr. P. J. C. van Breda Vriesinan en Dr. J.G.M.C. Damoiseaux werd gedurende deze periode het onderzock verricht beschreven in dit proefschrift. Momenteel is Leo Beijleveld als postdoctoraal onderzoeker werkzaam bij het Département Pathologie Rénale \& Vasculaire, INSERM Unité 28, te Toulouse (onder leiding van Prof. Ph. Druet). 


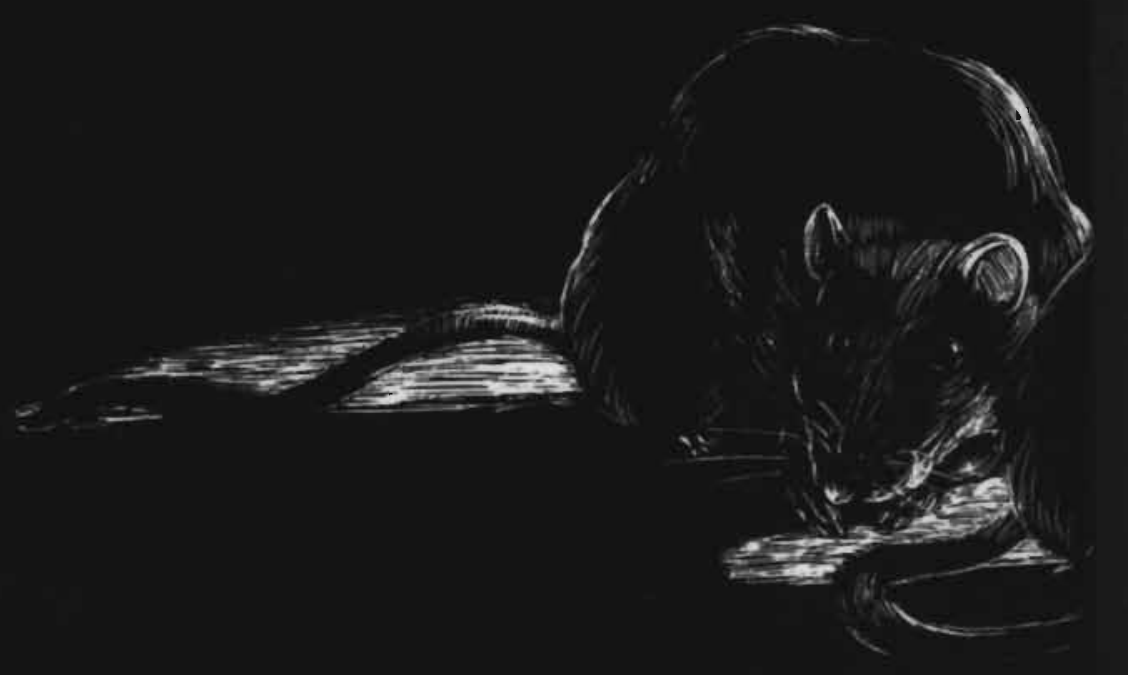

